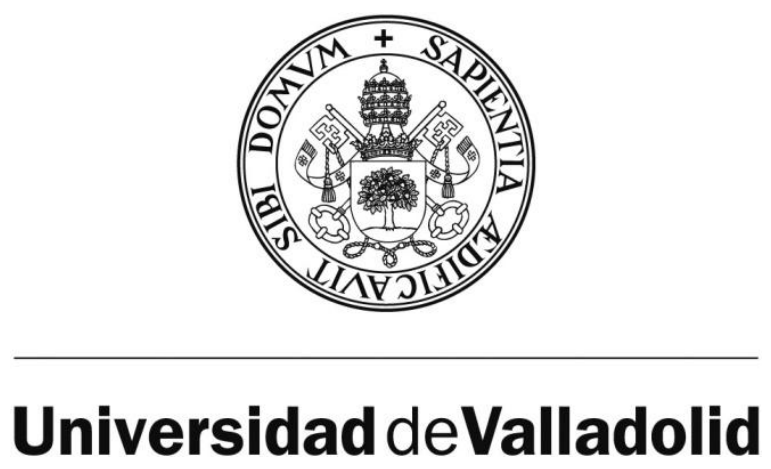

\author{
FACULTAD DE CIENCIAS \\ DEPARTAMENTO DE FÍSICA APLICADA
}

TESIS DOCTORAL:

\title{
REDUCCIÓN DE AZÚCAR EN MOSTOS POR NANOFILTRACIÓN PARA LA OBTENCIÓN DE VINOS CON MENOR GRADO ALCOHÓLICO.
}

Presentada por NOEMI GARCÍA MARTÍN para optar al grado de doctora por la Universidad de Valladolid

Dirigida por:

PEDRO PRÁDANOS DEL PICO

LAURA PALACIO MARTÍNEZ 



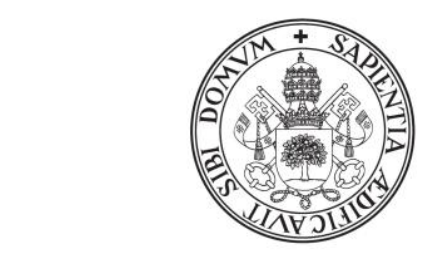

\title{
Universidad deValladolid
}

\author{
Dr. Pedro Prádanos del Pico \\ Catedrático del Departamento de Física Aplicada \\ Universidad de Valladolid \\ y \\ Dr. Laura Palacio Martínez \\ Profesora Titular del Departamento de Física Aplicada \\ Universidad de Valladolid
}

como directores de la Tesis Doctoral titulada "Reducción de azúcar en mostos por nanofiltración para la obtención de vinos con menor grado alcohólico" presentada por D. aN Noemi García Martín, alumna del programa de doctorado en Química Analítica. Contaminación y Medio Ambiente, impartido por la Universidad de Valladolid, autorizan la presentación de la misma, considerando que el trabajo presentado constituye su tesis para optar al grado de Doctor, ya que se trata de un trabajo original y todos los resultados presentados y los análisis realizados son fruto de su investigación.

Valladolid, a de de 2014

Fdo. Pedro Prádanos del Pico

Fdo. Laura Palacio Martínez 



\section{AGRADECIMIENTOS}

Quiero expresar mi gratitud a todas aquellas personas que directa o indirectamente han contribuido para que este trabajo fuese posible.

En primer lugar a mis directores de tesis, al Dr. D. Pedro Prádanos del Pico por ofrecerme sus conocimientos, mostrarme sus consejos ante las dificultades surgidas y apoyarme en mi formación y a la Dra. D. a Laura Palacio Martínez, por su entrega, dedicación y constante disponibilidad ante los requerimientos de este trabajo de investigación. Me he sentido privilegiada de haber realizado con ellos esta tesis doctoral y de mantener un trato personal que se resume en mi gran afecto hacia ellos.

A la Junta de Castilla y León por la financiación de la beca que supuso el inicio de este trabajo a través del proyecto BU-03-C3-2. Así como al Dr. D. Antonio Hernández Giménez, por darme la oportunidad de acceder a dicha beca de investigación, y por la confianza depositada en este proyecto.

Al Dr. D. Javier Carmona del Rio de la Universidad de Extremadura, por su asesoramiento en la caracterización estructural de la membrana.

A los miembros de la Estación Enológica de Castilla y León que han colaborado en este trabajo, D. Carlos González Huerta, Dra. D. a Silvia Pérez Magariño y Dra. D. a Miriam Ortega Heras. Especialmente a Miriam por el interés puesto en esta investigación y las valiosas sugerencias indicadas, además de los datos aportados.

Igualmente, a la Dra. D. a María Luisa González San José de la Universidad de Burgos, por los análisis organolépticos y aromáticos realizados, y sus orientaciones. 
También quiero agradecer a los miembros del Departamento de Física Aplicada por su inmejorable acogida, en especial a Vero, René, Alberto y Sara. Gracias a su amistad, este trabajo se ha desarrollado con más entusiasmo y constancia.

Finalmente quiero dedicar esta Tesis Doctoral a aquellas personas que me han apoyado y animado en este proyecto. En primer lugar a mi marido Diego, por su comprensión, sus incansables ánimos y por mantener en mí la ilusión. A mis padres Diamante y Pili, de los que aprendí que con esfuerzo y trabajo se consiguen todas tus metas y que son mi referente de sacrificio y entrega. A mi hermana Lorena, por la ayuda y el apoyo recibido en todo este tiempo. Y por último a mis abuelos, cuñados, sobrinas y amigos, por darme energía para afrontar este trabajo.

Gracias a todos.

“El mejor vino no es necesariamente el más caro, sino el que se comparte" Georges Brassens 


\section{CONTENIDO}

PLANTEAMIENTO DE LA TESIS …….............................................................. 7 -

CAPÍTULO 1 INTRODUCCIÓN.............................................................................. 9 -

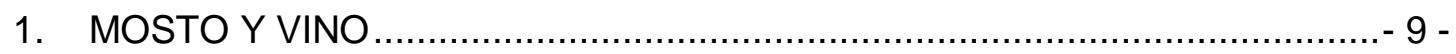

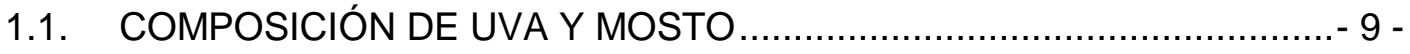

1.2. COMPOSICIÓN DE VINO ..................................................................... 11 -

1.3. MOSTOS UTILIZADOS ..................................................................... 13 -

2. CAUSAS DE LA REDUCCIÓN DE ALCOHOL EN VINOS ...........................- 13 -

2.1. CAMBIO CLIMÁTICO....................................................................... 13 -

2.2. DEMANDA DE VINOS DE BAJA GRADUACIÓN..................................-16 -

2.3. BENEFICIOS PARA LA SALUD ........................................................ 18 -

3. LEGISLACIÓN DE DESALCOHOLIZACIÓN …………..............................- 19 -

4. PROCESOS CONVENCIONALES PARA REDUCIR EL GRADO ALCOHÓLICO -21 -

4.1. TÉCNICAS QUE ACTÚAN SOBRE EL MOSTO …..............................- 22 -

4.2. TÉCNICAS QUE ACTUAN SOBRE EL PRODUCTO FINAL .................. 23 -

4.3. TÉCNICAS QUE ACTUAN EN EL PROCESO DE FERMENTACIÓN ...- 26 -

5. PROCESOS DE MEMBRANA ……......................................................... 28 -

5.1. OTRAS APLICACIONES: ................................................................ 29 -

5.2. REDUCCIÓN DEL GRADO ALCOHÓLICO DEL VINO: ........................ 32 -

6. NUESTRAS MEMBRANAS (NUESTRO PROCESO DE SEPARACIÓN).....- 36 -

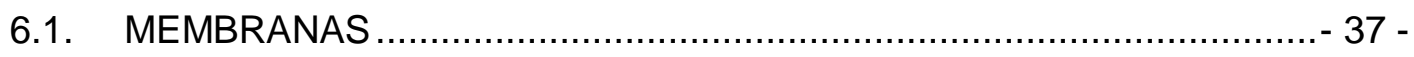

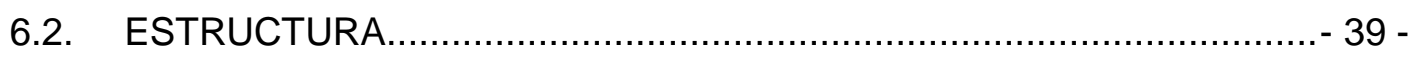

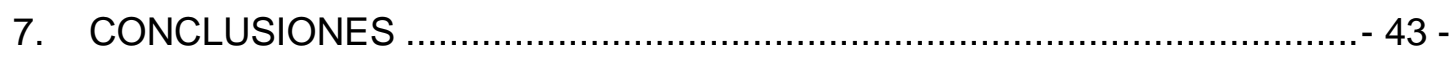

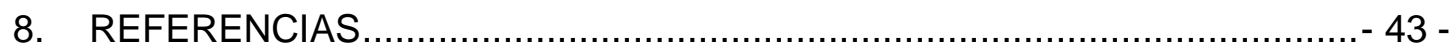

CAPÍTULO 2 CARACTERIZACIÓN DE MEMBRANAS. FILTRACIONES CON DISOLUCIÓN DE AZÚCAR Y MOSTO TINTO COMERCIAL. ...............................- 51 -

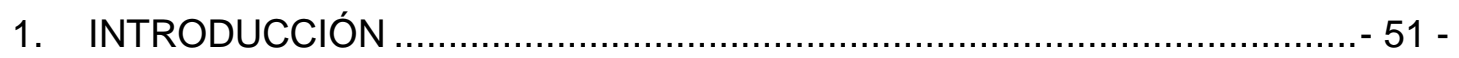

2. CARACTERIZACIÓN FUNCIONAL: TEORÍAS Y MODELOS …...................- 55 -

2.1. PERMEABILIDAD HIDRÁULICA ...................................................... 55 - 
2.2. RETENCIÓN DE SOLUTOS NO CARGADOS .................................... 56 -

2.3. DISTRIBUCIÓN DE TAMAÑO DE PORO ......................................... 62 -

3. MEDIDAS CON MEMBRANAS PLANAS …............................................ 65 -

3.1. MATERIALES USADOS Y DISPOSITIVOS EXPERIMENTALES ......... 65 .

3.1.1) Membranas ............................................................................. 65 -

3.1.2) Solutos ................................................................................. 66

3.1.3) Dispositivo experimental ....................................................... 6 -

3.1.4) Métodos Analíticos .................................................................. 71 -

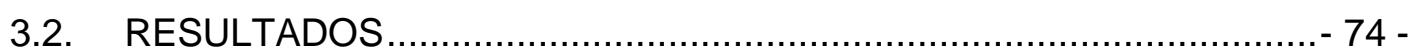

3.2.1) Resultados con los PEG …................................................... 74 -

3.2.2) Resultados con la disolución de azúcar ......................................... 88 -

3.2.3) Resultados con el mosto tinto comercial ....................................... 92 -

4. MEDIDAS CON MÓDULOS ESPIRALES …........................................ 98 -

4.1. MATERIALES USADOS Y DISPOSITIVOS EXPERIMENTALES ......... 98 -

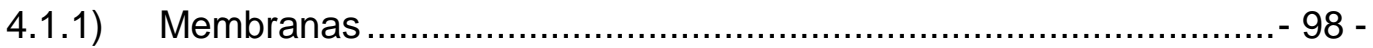

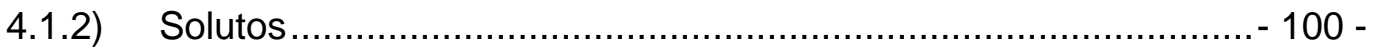

4.1.3) Dispositivo experimental .................................................... 101 -

4.1.4) Métodos Analíticos ................................................................ 103 -

4.2. MATERIALES USADOS Y DISPOSITIVOS EXPERIMENTALES ....... 106 -

4.2.1) Resultados con la disolución de azúcar ..................................... 106 -

4.2.2) Resultados con el mosto tinto comercial .................................... 111 -

5. CONCLUSIONES …............................................................................ 116 -

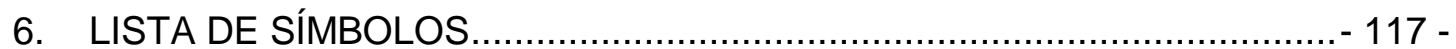

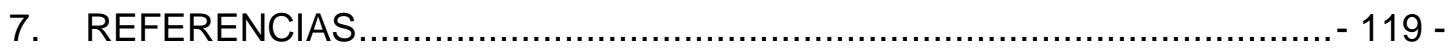

CAPÍTULO 3 DISEÑO DEL PROCESO DE FILTRACIÓN. ................................... 125 -

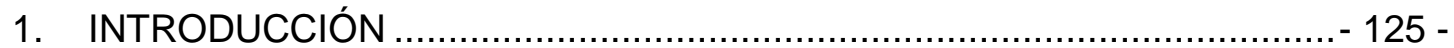

2. MATERIALES USADOS Y DISPOSITIVOS EXPERIMENTALES .............. 125 -

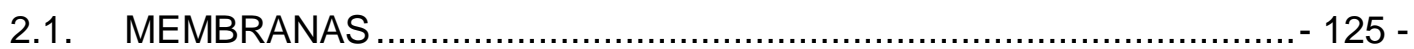

2.2. ELABORACIÓN Y PREPARACIÓN DE MOSTOS ….......................... 125 -

2.3. DISPOSITIVO EXPERIMENTAL ............................................... 126 -

2.4. MÉTODOS ANALÍTICOS ……................................................. 127 -

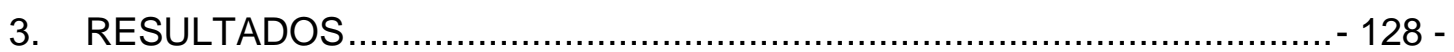

3.1. PERMEABILIDAD HIDRÁULICA ................................................ 128 -

3.2. CURVAS TIEMPO-FLUJO ….................................................... 129 - 
3.3. RETENCIÓN DE AZÚCAR $-133-$

3.3.1) Retención observada $-133-$

3.3.2) Retención verdadera. $-135-$

3.4. RENDIMIENTO DE LA FILTRACIÓN ............................................... 136 -

3.4.1) Concentración de azúcar ..................................................... 137 -

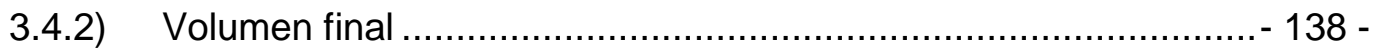

4. ANÁLISIS QUÍMICOS .................................................................. 138 -

4.1. ANÁLISIS DE MOSTOS ......................................................... 139 -

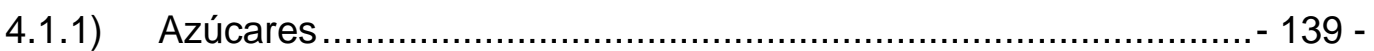

4.1.2) Sustancias de bajo peso molecular ......................................... 141 -

4.1.3) Familias fenólicas y color ....................................................... 142 -

4.2. ELABORACIÓN Y ANÁLISIS DE VINOS …..................................... 145 -

4.2.1) Vino Verdejo ...................................................................... 145 -

4.2.2) Vino Tinta de Toro.............................................................. 148 -

5. ANÁLISIS AROMÁTICO …........................................................... 154 -

6. ANÁLISIS SENSORIAL.................................................................... 157 -

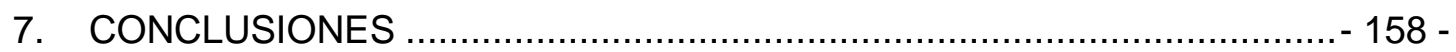

8. REFERENCIAS ................................................................................. 159 -

\section{CAPÍTULO 4 MODIFICACIONES DEL PROCESO DE NANOFILTRACIÓN.} INFLUENCIA DEL TIPO DE MEMBRANA EN LOS VINOS OBTENIDOS ............- 163 -

1. INTRODUCCIÓN …............................................................................ 163 -

2. MATERIALES USADOS Y DISPOSITIVOS EXPERIMENTALES .............. 163 -

2.1. MEMBRANAS ........................................................................ 163 -

2.2. ELABORACIÓN Y PREPARACIÓN DE MOSTOS .............................. 164 -

2.3. DISPOSITIVO EXPERIMENTAL ................................................... 164 -

2.4. MÉTODOS ANALÍTICOS ............................................................... 165 -

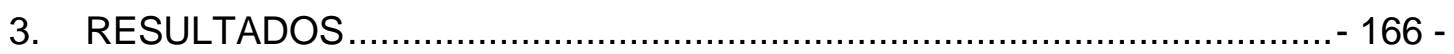

3.1. PERMEABILIDAD HIDRÁULICA ............................................... 166 -

3.2. CURVAS TIEMPO-FLUJO ......................................................... 168 -

3.3. RETENCIÓN DE AZÚCAR ........................................................ 171 -

3.3.1) Mosto Verdejo ...................................................................... 172 -

3.3.2) Mosto Tinta de Toro ................................................................. 173 -

3.4. RENDIMIENTO DE LA FILTRACIÓN............................................... 175 -

3.4.1) Concentración de azúcar ........................................................ 175 - 


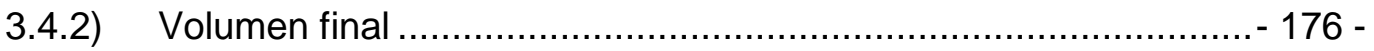

4. ANÁLISIS QUÍMICOS …................................................................. 177 -

4.1. ANÁLISIS DE MOSTOS

4.1.1) Sustancias de bajo peso molecular ......................................... 180 -

4.1.2) Familias fenólicas y color .................................................... 182 -

4.1.3) Aminoácidos ............................................................... 188 -

4.2. ELABORACIÓN Y ANÁLISIS DE VINOS …................................... 193 -

4.2.1) Vino Verdejo ..................................................................... 193 -

4.2.2) Vino Tinta de Toro........................................................... 195 -

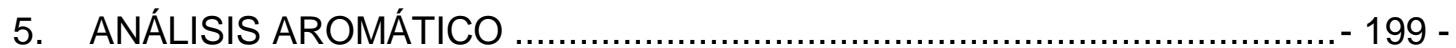

6. ANÁLISIS SENSORIAL................................................................... 201 -

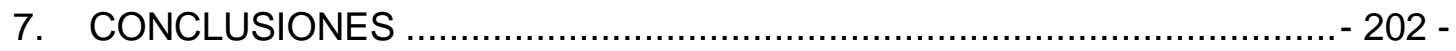

8. REFERENCIAS ............................................................................. 204 -

CAPÍTULO 5 INFLUENCIA DEL DOBLE PROCESO ULTRAFILTRACIÓNNANOFILTRACIÓN EN LOS VINOS DE BAJA GRADUACIÓN............................ 207 -

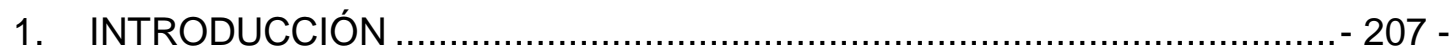

2. MATERIALES USADOS Y DISPOSITIVOS EXPERIMENTALES .............. 208 -

2.1. MEMBRANAS Y MOSTOS …................................................. 208 -

2.2. ELABORACIÓN Y PREPARACIÓN DE MOSTOS ............................. 209 -

2.3. DISPOSITIVO EXPERIMENTAL .................................................. 209 -

2.4. MÉTODOS ANALÍTICOS ............................................................. 210 -

3. RESULTADOS ........................................................................... 211 -

3.1. PERMEABILIDAD HIDRÁULICA ................................................ 211 -

3.2. CURVAS TIEMPO-FLUJO ….................................................. 212 -

3.3. RETENCIÓN DE AZÚCAR ........................................................ 214 -

3.3.1) Mosto Verdejo .................................................................... 215 -

3.3.2) Mosto Tinta de Toro ................................................................ 216 -

3.4. RENDIMIENTO DE LA FILTRACIÓN ............................................ 217 -

3.4.1) Concentración de azúcar ......................................................... 217 -

3.4.2) Volumen final para el mosto Verdejo ........................................ 218 -

4. ANÁLISIS QUÍMICOS ...................................................................... 218 -

4.1. ANÁLISIS DE MOSTOS........................................................ 219 -

4.1.1) Sustancias de bajo peso molecular ....................................... 221 - 
4.1.2) Familias fenólicas y color ................................................... 222 -

4.2. ELABORACIÓN Y ANÁLISIS DE VINOS ….................................. 224 -

4.2.1) Vino Verdejo ....................................................................... 224 -

4.2.2) Vino Tinta de Toro.................................................................. 227 -

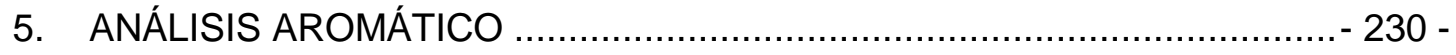

6. ANÁLISIS SENSORIAL............................................................ 233 -

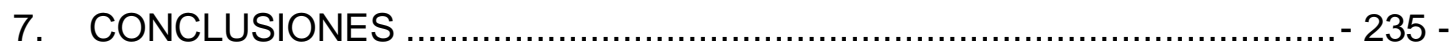

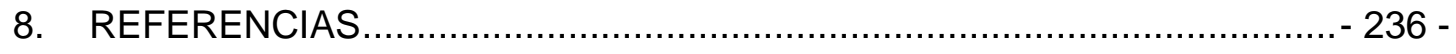

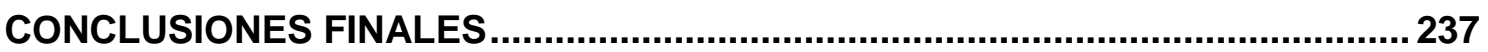





\section{PLANTEAMIENTO DE LA TESIS}

En este trabajo de investigación, se estudia y diseña un proceso de nanofiltración para controlar el contenido alcohólico en vinos con el fin de conseguir una reducción de $2 \%$ en volumen. Para ello, se actuará sobre el contenido en azúcar de los mostos y de esta forma, evitaremos que se modifiquen drásticamente las propiedades organolépticas del vino obtenido.

La tesis está dividida en cinco capítulos, que detallaré a continuación, y finaliza con las conclusiones finales.

En el CAPÍTULO 1 se hace una introducción para establecer el estado del arte del tema. Se describe la composición del mosto y el vino y se explican las causas que justifican la reducción del grado alcohólico en vinos. Valoramos la legislación aplicable a las técnicas de desalcoholización y a los productos obtenidos, además de estudiar las distintas técnicas de reducción de alcohol en vinos. También, se indica cómo funcionan los procesos de separación con membranas de ultra- y nanofiltración que utilizaremos para conseguir el objetivo planteado.

En el CAPÍTULO 2 se explican las teorías y modelos para la caracterización de membranas y se presentan los resultados de caracterización de dichas membranas. Con membranas planas se determina la retención de azúcar utilizando disoluciones de glucosa y fructosa. Además para comprobar la retención de otros componentes importantes de un mosto, se utilizan mostos tintos comerciales. Estos mismos estudios se realizan con módulos de membrana espirales, comprobando el efecto del cambio de escala.

En el CAPÍTULO 3 se aplica el proceso de doble nanofiltración con el módulo de membrana $\mathrm{HL}$ a mostos reales, analizando, durante la nanofiltración, el comportamiento de retención y flujo. Para elaborar los vinos finales se realizan dos mezclas diferentes, el mosto filtrado se mezcla con mosto sin tratar (testigo) o con el retenido obtenido en la primera etapa de nanofiltración. Las proporciones de cada uno serán las necesarias para rebajar el grado alcohólico del vino final aproximadamente $2^{\circ} \mathrm{v} / \mathrm{v}$. Para comprobar la eficacia del proceso, cada uno de estos mostos se fermenta junto con una muestra testigo sin tratar. Todas las mezclas y las fermentaciones, se han realizado por duplicado. Tanto antes como después de la fermentación, se realizan análisis químicos completos para considerar todos los posibles cambios en las características de los vinos. Estos análisis se dividen en azúcares, sustancias de bajo 
peso molecular y familias fenólicas, además de un análisis aromático y sensorial de los vinos finales.

En el CAPÍTULO 4 se optimiza el proceso; en este caso se utilizan todos los módulos de ultra- y nanofiltración de estudio para la filtración de mostos en sólo un paso. En cada proceso de filtración, se estudiará el comportamiento de retención y flujo con el tiempo. Las mezclas realizadas para la elaboración del vino, serán del permeado y el testigo en proporciones adecuadas para conseguir la reducción de graduación indicada. En este caso también se realizan análisis antes y después de la fermentación de todas las pruebas, así como los análisis organolépticos de los vinos correspondientes.

A la vista de lo obtenido hasta este punto, en el CAPÍTULO 5 se establece el proceso definitivo, utilizando la membrana de nanofiltración $\mathrm{HL}$ en solitario o como etapa posterior a la ultrafiltración con la membrana GH. Además, se aumentará la superficie de la membrana de nanofiltración para reducir así el tiempo de filtración, y se controlará la temperatura tanto de alimentación como del permeado a diferencia del resto de capítulos. Se estudiará la capacidad de retención y caída de flujo al utilizar la membrana de ultrafiltración en un paso previo o no. Los mostos obtenidos y los vinos elaborados se analizarán del mismo modo que en capítulos anteriores. Los resultados de estos análisis junto con los análisis aromáticos y sensoriales determinarán la calidad del vino final.

Tras este capítulo, se exponen las conclusiones finales de este trabajo de investigación.

Las figuras y tablas presentadas en este trabajo se referencian con la palabra correspondiente seguida del capítulo en el que aparece y el número que indica su orden de aparición, ambos en números arábigos. Las ecuaciones, aparecen con el número arábigo entre paréntesis, correspondiente a su orden de aparición. En el caso de la marcación decimal se realiza con un punto, que aunque no es lo más apropiado en castellano, nos adaptamos al convenio anglosajón que está más extendido internacionalmente. 


\section{CAPÍTULO 1 INTRODUCCIÓN}

\section{MOSTO Y VINO}

Según el reglamento CE 479/2008 del Consejo Europeo se define:

Mosto de uva como el producto líquido obtenido de uva fresca de manera natural o mediante procedimientos físicos. Se admite un grado alcohólico adquirido que no exceda del $1 \%$ vol.

Vino como el producto obtenido exclusivamente por fermentación alcohólica, total o parcial, de uva fresca, estrujada o no, o de mosto de uva. Las características que debe cumplir serían las siguientes:

- Un grado alcohólico adquirido no inferior al $8.5 \%$ vol, cuando proceda exclusivamente de uva cosechada en las zonas vitícolas $A$ y $B$ a que se refiere el anexo IX, y no inferior al $9 \%$ vol. en las restantes zonas vitícolas, como es nuestro caso. En España las superficies plantadas de vid en las provincias de Valladolid y Zamora entre otras, pertenecen a la zona vitícola CII.

- Un grado alcohólico total no superior al $15 \%$ vol.

Esta bebida alcohólica es una de las más populares en el mundo, principalmente en los países del Mediterráneo, como España, Francia o Italia. Estos países son los productores más importantes de vino, siendo España el país con mayor superficie del cultivo de la vid del mundo [1-2].

\subsection{COMPOSICIÓN DE UVA Y MOSTO}

La composición de la uva, dependerá de las características genéticas de la variedad, de las condiciones de cultivo de la vid, el estado de maduración en el momento de vendimia y de las prácticas de vinificación. De forma general, podemos decir que la uva está compuesta por el hollejo, las pepitas y la pulpa.

En el hollejo, que es la parte exterior del grano de uva, se encuentra la mayor parte de compuestos polifenólicos responsables del color. En el caso de las variedades blancas los responsables del color amarillo serían los flavonoides y en el caso de las variedades tintas los componentes principales del color rojo serían los antocianos. La distribución de los polifenoles en el hollejo y especialmente los taninos, se adopta 
como mecanismo de la vid frente a ataques de enfermedades producidas por hongos sobre el grano de la uva. En las capas de las células del hollejo más cercanas a la pulpa se encuentran los compuestos terpénicos, responsables de los aromas varietales de la uva. Según Togores, la composición media del hollejo en estado fresco puede ser la siguiente: $70.0-80.0 \%$ de agua, $0.5-1.8 \%$ de sustancias tánicas, $1.5-2.0 \%$ de sustancias minerales y $1.0 \%$ de ácidos orgánicos [3].

En cuanto a la composición de las pepitas, contienen de media las siguientes sustancias: $25.0-45.0 \%$ de agua, $34.0-36.0 \%$ de glúcidos, $13.0-20.0 \%$ de aceite, 4.0 $6.0 \%$ de taninos, $4.0-6.5 \%$ de materia nitrogenada, $2.0-4.0 \%$ de materia mineral y $1.0 \%$ de ácidos grasos [3]. En las semillas, los taninos están poco polimerizados, por lo que presentan caracteres sensoriales de acidez y astringencia.

La pulpa representa del $75-85 \%$ del peso del grano de uva y es el tejido de acumulación de sustancias sintetizadas por la vid. El agua es el compuesto mayoritario representando más de un $80 \%$ lo que favorece la disolución del resto de compuestos. Los azúcares serían los siguientes compuestos más abundantes, con concentraciones entre 150-250 g/L, llegando a $300 \mathrm{~g} / \mathrm{L}$ en vendimias sobremaduras. En la uva los azúcares mayoritarios son la glucosa y la fructosa, encontrándose en cantidades prácticamente iguales pero con algo más de fructosa en maduración, ya que la glucosa es más sensible a la respiración celular [4]. El contenido de sacarosa es de 1.0-3.0 g/L, siendo más baja esta concentración para otras pentosas $0.5 \mathrm{~g} / \mathrm{L}$ [3].

Los ácidos orgánicos más importantes en la pulpa son el ácido tartárico, el málico y algo menos el cítrico, en menores concentraciones existen otros ácidos como el ascórbico, el galacturónico, fumárico, oxálico, pirúvico, etc.

De la materia mineral, el potasio es el catión más abundante, representando más del $50 \%$ de las cenizas, le sigue el calcio, magnesio, sodio, hierro y otros elementos minoritarios.

Los compuestos nitrogenados representan en la pulpa el $20-25 \%$ del nitrógeno total del grano de uva, siendo la forma mineral o amoniacal la más fácilmente asimilable por las levaduras que desarrollarán la fermentación alcohólica. En el mosto se encuentran la mayor parte de los aminoácidos, destacando la prolina, arginina, treonina y ácido glutámico que representan cerca del 90\% del conjunto. Los aminoácidos proceden de la hidrólisis de las proteínas por las enzimas pectolíticas naturales que contiene el grano de uva. 
Además de estos compuestos, en la pulpa también se encuentran polifenoles no flavoniodes y pequeñas cantidades de alcoholes, aldehídos y ésteres que participan en el aroma de la uva.

El raspón eliminado en el despalillado antes de vinificar, es pobre en azúcares con menos de $10 \mathrm{~g} / \mathrm{Kg}$ y abundantes en materias minerales, potasio y compuestos fenólicos, pero esta parte no se utiliza para la elaboración de vinos de calidad. La utilización del raspón en ciertas vinificaciones favorece el prensado posterior y disminuye la quiebra oxidásica cuando la uva no está totalmente sana. A parte de estos casos, la fermentación sin el raspón produce una mejora sensorial y aromática del vino final, así como un aumento de color durante la maceración ya que se evita la fijación de la materia colorante en los raspones.

Por todo lo expuesto, podemos deducir que la composición del mosto de uva será muy compleja, incluyendo azúcares, ácidos orgánicos, polisacáridos y polifenoles [5], como se puede ver en la tabla 1.1.

\subsection{COMPOSICIÓN DE VINO}

La composición del vino dependerá de la composición de la uva, pero además de todos los factores que hemos indicado anteriormente y que influyen en la composición del fruto, debemos tener en cuenta que en la elaboración del vino, interviene el metabolismo de las diferentes cepas de levaduras y bacterias que llevarán a cabo la fermentación.

Tradicionalmente se habla del vino como un alimento complejo en cuya composición entran a formar parte más de mil compuestos distintos. Sin embargo, los primeros análisis metabolómicos indican la posibilidad de detectar más de 4000 moléculas distintas, entre las cuales se encuentran algunas cuyos niveles pueden correlacionarse positiva o negativamente con su calidad [6]. Esta cantidad de compuestos puede ser aún mayor si se considera la gran diversidad de tipos de vinos existentes. Una gran parte de estas moléculas tienen su origen en precursores que se hallan en la uva y, por ello, la elaboración de un vino de calidad requiere una uva en óptimos estados sanitario y de maduración. Esta complejidad también depende del proceso de elaboración del vino aplicado a la uva o al mosto y de los sucesivos procesos fermentativos y de crianza de los vinos.

Las técnicas analíticas actuales, han permitido dar a conocer sustancias de concentraciones ínfimas, generalmente volátiles, que participan en el aroma del vino. En la fermentación de los mostos, tiene lugar la desaparición de la glucosa y fructosa, 
y la formación de alcoholes junto con otros productos secundarios como los polioles, el glicerol, diversos ácidos orgánicos y otros compuestos volátiles que constituyen el aroma. El vino contiene más de 800 compuestos orgánicos que contribuyen al aroma del vino [7], esto significa, que cualquier proceso que se realice en el vino, debe optimizar el aroma y el sabor, y reducir la formación de sustancias no deseadas que den lugar a defectos en el vino [8-9].

En la tabla 1.1 se muestran los principales componentes de los mostos y de los vinos clasificados por familias de compuestos, así como sus concentraciones [10].

Tabla 1.1 Principales componentes del mosto y del vino.

\begin{tabular}{|c|c|c|}
\hline & MOSTOS (g/L) & VINOS (g/L) \\
\hline Agua & 700 a 850 & 750 a 900 \\
\hline $\begin{array}{c}\text { Compuestos } \\
\text { polihidroxicarbonílicos }\end{array}$ & 140 a 250 & 0.1 a 2 \\
\hline Polisacáridos & 3 a 5 & 2 a 4 \\
\hline Alcoholes & - & 69 a 121 \\
\hline Polioles & - & 5 a 20 \\
\hline Ácidos orgánicos & 9 a 27 & 3 a 20 \\
\hline Polifenoles & 0.5 & 2 a 6 \\
\hline Compuestos Nitrogenados & 4 a 7 & 3 a 6 \\
\hline Minerales & 0.8 a 2.8 & 0.6 a 2.5 \\
\hline Vitaminas & 0.25 a 0.8 & 0.2 a 0.7 \\
\hline
\end{tabular}

Los polisacáridos constituyen el grupo principal de macromoléculas que se encuentran en un vino, y proceden de las paredes celulares de los microorganismos que llevan a cabo la fermentación alcohólica o de la hidrólisis de las cadenas peptídicas de la uva.

Los compuestos polifenólicos tienen propiedades antioxidantes y son muy importantes en la contribución del color, astringencia y amargor del vino. Estos compuestos pueden ser flavonoides (flavonoles, antocianos y taninos) y no flavonoides (ácidos fenólicos y estilbenos). Los compuestos polifenólicos flavonoides son más abundantes en los vinos tintos, mientras que en los vinos blancos se encuentran tan sólo una pequeña cantidad de taninos.

Los aminoácidos junto con los péptidos y las proteínas constituyen los principales componentes de las sustancias nitrogenadas. Los vinos tintos apenas tienen proteínas libres porque precipitan con los taninos; en el caso de los vinos blancos estas proteínas libres pueden variar de $10-500 \mathrm{mg} / \mathrm{L}$. 
El vino es un medio polidisperso que contiene partículas con tamaños en un rango de 0.1-100 $\mu \mathrm{m}$. Además los distintos componentes pueden formar coloides por si mismos o agregándose con otros compuestos del vino, dependiendo de los parámetros físicoquímicos del vino. En nuestro caso, esto influirá en el ensuciamiento de las membranas durante el proceso de filtración [11].

\subsection{MOSTOS UTILIZADOS}

En este trabajo se utilizan dos variedades de uva, una variedad blanca (Verdejo) y otra tinta (Tinta de Toro). La variedad Verdejo es una de las mejores y más apreciadas variedades de uva blanca españolas; se cultiva principalmente en la Denominación de origen Rueda (Valladolid), en la Comunidad Autónoma de Castilla y León, aunque también puede encontrarse en Portugal. Los vinos Verdejo tienen matices de hierba de monte bajo, con toques afrutados y una excelente acidez. Es un vino blanco con mucho extracto, que se percibe por su volumen y su característico toque amargo, acompañado de una gran expresión frutal [12].

La variedad Tinta de Toro, es una variedad autóctona de esta localidad zamorana. Los vinos elaborados pueden ser consumidos jóvenes ( $\sin$ roble), pero la mayoría pasan diferentes periodos de tiempo en barricas de roble. Los vinos jóvenes de la variedad Tinta de Toro, tienen un intenso color guinda, con toques de azul y morado en la capa fina. Como aromas primarios (propios de la variedad), destacan las frutas rojas y silvestres y en boca, destacan taninos que dan pastosidad en el paladar y largo recorrido. Los vinos de crianza, reserva o gran reserva, tienen color rojo cereza en la capa superior, y en la capa fina se pasa de granates a colores teja a mayor tiempo de envejecimiento. Como aromas, además de los primarios y los secundarios (debidos a la fermentación), son muy importantes los aromas terciarios, propios de la madera de envejecimiento (especias, balsámicos, vainillas, etc.); y en boca, son vinos de gran volumen y largo recorrido [13].

\section{CAUSAS DE LA REDUCCIÓN DE ALCOHOL EN VINOS}

\subsection{CAMBIO CLIMÁTICO}

Como consecuencia del cambio climático, se apuntan diversos impactos en la industria vinícola, tales como alteraciones en el proceso fenológico de los viñedos, en el sabor y en la composición de las uvas y el vino. Estos cambios específicamente regionales afectarán a ciertas variedades de uva, lo que dará lugar a variaciones en los estilos 
vinícolas regionales y cambios espaciales en cuanto a las regiones idóneas para cultivar esta planta.

La comprensión del cambio climático y de los posibles impactos que pueda tener en la viticultura y la producción de vino ha ido en aumento, pues la alteración de los niveles de gases de efecto invernadero y sus variaciones en la superficie terrestre provocan ciertos cambios en la radiación que recibe la Tierra, en la circulación atmosférica y en el ciclo hidrológico. La observación del calentamiento global llevada a cabo durante el último siglo ha demostrado que el mayor calentamiento ocurre en invierno, en primavera y por la noche. Las tendencias de la temperatura indican que éstas están relacionadas con la viabilidad de la producción agrícola, por el grado de dureza del invierno, la posibilidad de heladas y la creciente duración de las estaciones.

Teniendo en cuenta la importancia del clima a la hora de producir vinos de calidad, el impacto del cambio climático no será uniforme en todas las variedades y regiones, sino que éste estará relacionado con el umbral climático, a través del cual todo calentamiento constante impedirá que una región produzca vino de calidad con las variedades existentes. Aunque en muchos casos la gama de variedades que una misma región puede cosechar se expandirá, si una región se dedica a producir vinos que maduran en climas cálidos, la vendimia se convertirá en todo un desafío.

Las observaciones indican que el cambio climático no sólo provocará alteraciones en el medio, sino también en la variedad, por tanto, aunque en algunas regiones la estructura climatológica media mejore, la variabilidad aún será muy evidente y, posiblemente, mucho más restrictiva que hoy en día. Los modelos climáticos de simulación utilizados en investigación [14], indican un desplazamiento y una expansión de las regiones vitícolas hacia el norte de Europa, siendo las zonas del sur de Europa demasiado calurosas para producir vinos de calidad.

En el caso de España, Jones y colaboradores [15], consideran que se ha sufrido un aumento de las temperaturas entre un $0.8^{\circ} \mathrm{C}$ y $1.2^{\circ} \mathrm{C}$ en el caso de la comunidad de Galicia y la provincia de Valladolid. En ambas regiones, dicho calentamiento es más significativo por la noche (las temperaturas mínimas han aumentado entre $1.1{ }^{\circ} \mathrm{C}$ y 2.1 -C) que por el día. Además, el proceso fenológico de la viña en Europa ha demostrado estar íntimamente relacionado con el calentamiento observado, y muestra una tendencia a adelantarse entre 6 y 25 días dependiendo de la variedad y la ubicación de la vid. Los cambios son más significativos en época de envero y cosecha. En esos momentos, se observa un efecto más evidente e integrado del calentamiento de la temporada de crecimiento. La duración de los procesos fenológicos también ha 
disminuido: la floración, el envero y la temporada de crecimiento se han acortado 14, 15 y 17 días, respectivamente. Después de calcular la media teniendo en cuenta todas las ubicaciones y variedades, la fenología de la viña muestra un incremento medio de $1 \stackrel{\circ}{\circ}$ de temperatura durante los últimos 30-50 años.

Además de los impactos relacionados con la temperatura, existen otros problemas significativos que perjudican a la calidad de la uva y al vino, los cuales incluyen una alteración en el crecimiento de la vid provocado por una concentración atmosférica de $\mathrm{CO}_{2}$ mayor, una reducción de la humedad en regiones que carecen de agua y cambios en la presencia o frecuencia de plagas y enfermedades que afectan a las viñas, por la menor dureza del invierno. Este aumento de temperaturas y la disminución de las precipitaciones están afectando al equilibrio entre temperatura y humedad, elementos principales para el cultivo de las uvas de alta calidad. Para adaptarnos a este hecho, se recomienda fomentar la conciencia del consumidor para que incentive el consumo de vinos que provienen de viñas que poseen manejos sostenibles [16], y que se invierta en nuevas variedades de uvas que ofrezcan sabores similares pero con tolerancias climáticas y mejor adaptadas a los cambios futuros del clima [17].

Como hemos indicado, la producción de vinos de calidad está relacionada íntimamente con el clima. El efecto del cambio climático da lugar a un rápido crecimiento de la planta y un desequilibrio de maduración. Una determinada región experimenta un período de maduración que permite que los azúcares se acumulen a un nivel adecuado, que se mantenga la estructura ácida y que se produzca un sabor óptimo para esa variedad, lo que dará lugar a un vino equilibrado. En un entorno más cálido de lo deseado, la vid experimentará los acontecimientos fenológicos más rápidamente, lo cual resultará en una madurez con altos niveles de azúcares y, mientras el productor vinícola esté esperando que la madurez de otros compuestos se desarrollen, la acidez se perderá debido a la respiración de la planta, lo que provocará que el vino no esté en su punto de equilibrio.

Los problemas más significativos de un vino que se ha elaborado con uva en la que se ha alcanzado una temprana acumulación de azúcares, pero que no coincide con el punto óptimo de madurez son los siguientes:

- incremento de los niveles de alcohol.

- baja acidez (mayor pH).

- peor envejecimiento de los vinos por tener menos estabilidad microbiana (a causa de la posible presencia de azúcares residuales). 
- menor calidad de los vinos (sabores herbáceos, menos color, taninos amargos, astringencia, etc.).

De esta forma, el problema más importante al que se enfrentaría el sector vitivinícola en la actualidad, sería el aumento del contenido alcohólico de los vinos. Se ha constatado en la inmensa mayoría de bodegas, una acumulación de azúcares en la uva durante las cosechas de los últimos años [18]. El problema radica en que la calidad de los vinos depende de la madurez fenólica de las uvas lo que está directamente relacionado con el aumento de concentración de azúcar. Una madurez alta de las uvas en la vendimia, da lugar a una menor acidez y un contenido de alcohol probable de un 17\%. Esto dificulta la elaboración del vino (parada de fermentación alcohólica, inestabilidad microbiológica o sensación ardiente en boca) [19]. En consecuencia, surge el dilema de esperar a una maduración adecuada de los componentes fenólicos sin que el contenido en azúcar se dispare y origine vinos con un exceso de alcohol.

\subsection{DEMANDA DE VINOS DE BAJA GRADUACIÓN}

Según el informe de la OIV Statistical report on world vitiviniculture 2013 [1], el consumo del vino en algunos países como España, Francia o Italia ha disminuido en el año 2012, y por el contrario está aumentando rápidamente en Asia (67\% más respecto al año 2000). Actualmente se observa por parte de los consumidores un incremento en la demanda de vinos con bajos niveles de alcohol, debido al papel clave del alcohol en la percepción del vino. Los grados elevados de alcohol generan sensaciones más pesadas y cálidas, si no están adecuadamente contrapuestos con el resto de componentes sensoriales de un vino equilibrado [18].

Al mismo tiempo, el mercado demanda vinos con una riqueza aromática y complejidad, que se consigue si la uva tiene una madurez fenólica elevada aunque como contrapartida el grado alcohólico aumenta [2]. La eliminación del alcohol del vino, reduce el efecto de amargor, calidez y cuerpo del vino, ya que la acidez y la astringencia disminuyen. Los componentes volátiles en los vinos de mayor grado alcohólico disminuyen porque su volatilidad será mayor, lo que no quiere decir que en los vinos desalcoholizados la intensidad aromática sea mayor, ya que parte de los componentes volátiles se pierden en el proceso de desalcoholización [16]. El cambio en las características sensoriales de los vinos desalcoholizados depende claramente de la cantidad de alcohol retirado del producto de partida, ya que el alcohol juega un papel de equilibrio al interaccionar con otros compuestos. 
Además, no debemos olvidar la mayor preocupación de la sociedad por la salud y por un consumo responsable de las bebidas alcohólicas, influida también en parte por las políticas de prevención para favorecer la prudencia (por ejemplo, controles de alcoholemia en la conducción de vehículos) [20]. Por otra parte, el contenido excesivo de etanol conduce a mayores costes en algunos países que imponen impuestos sobre el grado de alcohol [21]. En este contexto, existe una fuerte demanda de vinos con bajos niveles de alcohol.

Hay varios estudios de aceptabilidad de los productos desalcoholizados [22-25], en los que se deduce que la técnica empleada para la desalcoholización es muy importante, ya que:

$\checkmark$ Puede dar lugar a la pérdida de más o menos compuestos aromáticos, compuestos polifenólicos, etc.

$\checkmark$ las valoraciones pueden verse afectadas por las expectativas negativas que se tienen de los vinos desalcoholizados, tales como la pérdida de autenticidad, la preocupación por la conservación y por la calidad final del vino y la sensación de alteración de estos productos.

Por lo general, los consumidores aceptan más los vinos desalcoholizados blancos que los tintos. Esto puede deberse a la complejidad de sustancias presentes en un vino tinto, que hace que puedan retenerse más en el proceso de desalcoholización que en el caso de los vinos blancos.

Desde el Observatorio Español del Mercado del Vino (OEMV), se considera que hay un hueco en el mercado para este tipo de vinos. Desde la Federación Española del Vino (FEV) se considera que se abre una nueva oportunidad de negocio al sector vitivinícola y desde el punto de vista enológico, la opción de desalcoholizar vinos es muy interesante, ya que permite adaptar los vinos al gusto del consumidor, tanto desde la rebaja de un par de grados si tiene mucho grado alcohólico, como para la elaboración de un nuevo producto de baja graduación o sin alcohol [26].

Las investigaciones realizadas en este campo, permitirán a la industria vinícola estar preparada para implantar estrategias de adaptación apropiadas, que permitan ajustar la calidad del vino mediante el desarrollo de nuevas tecnologías. Los estudios realizados intentan controlar el contenido de alcohol del producto final, para que no sea necesario renunciar a la madurez fenólica de la uva, y por lo tanto a la calidad de vino. Con la reducción de alcohol se conseguirá una mayor percepción del sabor, debido a una menor pérdida de volatilidad de compuestos. Además se reducirá el 
fuerte impacto que tiene el grado alcohólico sobre la calidad de vino, alterando la acidez, la astringencia y la volatilidad de los compuestos volátiles, en definitiva las propiedades organolépticas del producto final [27].

\subsection{BENEFICIOS PARA LA SALUD}

Hay varios componentes en el vino tinto que son beneficiosos para la salud: el potasio juega un papel importante en la estabilidad iónica, los ácidos y minerales del vino ayudan a la digestión y los polifenoles tienen efecto antiséptico y antioxidante [11, 28].

Hay muchos estudios que evalúan los beneficios del vino tinto por su alto contenido en antioxidantes, lo que afectará tanto a las características sensoriales como a las nutricionales del vino. Existe una amplia evidencia científica que ha demostrado que el consumo moderado del vino tinto tiene efectos positivos sobre el sistema cardiovascular y que ayuda a contrarrestar el exceso de grasas animales en la dieta. Aparte de estos efectos que provoca la capacidad antioxidante de los polifenoles del vino, éstos también juegan un papel importante en la prevención y disminución de enfermedades crónicas como diabetes, obesidad e hipertensión, así como la actuación frente a la aparición del alzhéimer o frente al cáncer [29-34].

El compuesto polifenólico llamado resveratrol, tiene un alto potencial terapéutico para el tratamiento de enfermedades cardiovasculares, participando en la formación de la lipoproteína de alta densidad (HLDL o colesterol bueno) y regenerando el tejido de miocardio utilizando células madre. Esta propiedad de regular el crecimiento celular, permite el bloqueo de las células cancerosas además de permitir el antienvejecimiento de las células [35]. Debido a todos los beneficios indicados, se están realizando estudios en humanos para comprobar los efectos saludables de este compuesto y reafirmar las evidencias científicas [36-37].

El metabolismo de los sistemas biológicos genera continuamente radicales libres con capacidad para producir daños oxidativos en las proteínas, lípidos y ADN. Esto favorece la aparición de estrés oxidativo y enfermedades crónicas. Aparte del propio metabolismo humano, otros factores externos (tabaquismo, contaminación atmosférica, dieta hipercalórica, radiaciones, etc.), incrementan la concentración de radicales libres. La actividad antioxidante del ser humano, reaccionará frente a estos radicales libres, pero el desequilibrio entre ambos conduce al envejecimiento celular y al desarrollo de las enfermedades crónicas que describimos anteriormente. Los principales antioxidantes de la dieta son vitaminas ( $C, E$ y $A)$, carotenoides y compuestos polifenólicos presentes en alimentos vegetales y bebidas. De ellos, los 
compuestos polifenólicos son los más abundantes, constituyendo el $90 \%$ de la cantidad total de antioxidantes de la dieta, mientras que vitaminas y carotenoides aportarían el 10\% [32].

Sin embargo, las alegaciones presentadas respecto a los beneficios saludables del vino quedan restringidas por el elevado grado alcohólico que está asociado con un daño oxidativo [30]. Aunque los compuestos polifenólicos del vino contrarrestan los aspectos negativos del alcohol, si aplicamos técnicas de reducción de grado alcohólico en el vino, aumentará el interés en el consumo de una bebida con menos grado alcohólico que dará lugar a un producto más saludable (menos calorías), y que mantiene o aumenta los compuestos con capacidad antioxidante protegiendo de los efectos perjudiciales de los radicales libres.

\section{LEGISLACIÓN DE DESALCOHOLIZACIÓN}

De acuerdo con el Reglamento CE 606/2009, la desalcoholización parcial de vinos tiene por objeto la obtención de un vino parcialmente desalcoholizado, mediante la eliminación de una parte del alcohol (etanol) del vino gracias a técnicas físicas separativas. Para realizar la desalcoholización se deben cumplir los siguientes requisitos:

- Los vinos tratados no deben presentar defectos organolépticos y deben ser aptos para el consumo humano directo.

- No se puede proceder a la eliminación del alcohol del vino, si se ha llevado a cabo una de las operaciones de aumento del grado alcohólico en uno de los productos vitivinícolas utilizados en la elaboración del vino considerado.

- La disminución del grado alcohólico volumétrico adquirido, no puede ser superior al $2 \%$ vol y el grado alcohólico volumétrico adquirido del producto final se debe ajustar a la definición de vino indicada anteriormente (no inferior al $8.5 \%$ vol o el $9 \%$ vol, según zonas).

- La aplicación del tratamiento es responsabilidad de un enólogo o un técnico cualificado.

- El tratamiento debe ser registrado.

La Organización Internacional de la Viña y el Vino (OIV) en Junio de 2010, amplió en las resoluciones 373A/2010 y 373B/2010 las técnicas y aplicaciones de membrana a utilizar en mostos y vinos respectivamente. La aprobación de estas resoluciones tienen los siguientes objetivos: 
a) Permitir la elaboración de un vino con características organolépticas más equilibradas.

b) Compensar los efectos de condiciones climáticas adversas, los efectos del cambio climático y remediar algunos defectos organolépticos.

c) Ampliar el número de técnicas disponibles para elaborar productos más adaptados a las expectativas del consumidor.

Para cumplir estos objetivos se autorizan las siguientes técnicas: microfiltración, ultrafiltración, nanofiltración, contactores de membrana, ósmosis inversa y electromembranas, que podrán utilizarse de forma individual o combinada. Los procesos que se llevan a cabo con estas membranas pueden ser tanto en mostos como en vinos: la deshidratación parcial, la reducción de la concentración de algunos ácidos orgánicos y el ajuste de acidez y pH. Para los mostos se pueden aplicar también para la reducción del contenido de azúcar, y en vinos para llevar a cabo la estabilización tartárica, la desalcoholización parcial del vino, o la reducción del nivel de acidez volátil. Estas técnicas siempre deben utilizarse de acuerdo al Código Internacional de las Prácticas Enológicas y al Código Enológico Internacional [38].

En la Asamblea General de 2012 de la Organización Internacional de la Viña y el Vino (OIV) [39], se detallan las nuevas definiciones y procedimientos para reducir el grado alcohólico del vino, considerando los avances de las técnicas utilizadas para este objetivo.

La desalcoholización del vino se define como el procedimiento que consiste en eliminar una parte o prácticamente la totalidad del etanol del vino. Las características que debe cumplir el proceso serían las que hemos comentado anteriormente (Reglamento CE 606/2009), y se pueden utilizar técnicas de separación como la evaporación al vacío, membranas o destilación de forma individual o combinada.

La corrección del contenido en alcohol de un vino se define como el procedimiento que consiste en reducir un contenido excesivo de etanol del vino, con el objetivo de mejorar el equilibrio gustativo del vino. Las condiciones de llevar a cabo esta práctica serán las mismas que las que hemos indicado para la desalcoholización, con la particularidad que el contenido en alcohol puede reducirse como máximo en un $20 \%$ y el grado alcohólico volumétrico mínimo debe ser conforme a la definición de vino que indicamos anteriormente. 
De acuerdo con estas nuevas técnicas enológicas, se define también las nuevas bebidas elaboradas como:

Bebida obtenida por desalcoholización de vino como la bebida obtenida exclusivamente a partir de vino que ha sido exclusivamente objeto de los tratamientos específicos indicados anteriormente, y cuyo grado alcohólico volumétrico es inferior a $0,5 \%$ vol.

Bebida obtenida por desalcoholización parcial del vino como la bebida obtenida exclusivamente a partir de vino que ha sido exclusivamente objeto de tratamientos específicos indicados anteriormente, y cuyo grado alcohólico volumétrico adquirido es igual o superior a $0,5 \%$ vol. e inferior al grado alcohólico volumétrico mínimo aplicable para el vino (que en nuestro caso es de $9 \%$ vol según el reglamento CE 479/2008).

En los dos siguientes apartados, se definen las distintas tecnologías de desalcoholización existentes para reducir el grado alcohólico de los vinos. En el primero de ellos se describirán los procesos que no utilizan membranas y en el segundo nos centraremos en todas las técnicas de membranas que se podrían aplicar para este fin.

\section{PROCESOS CONVENCIONALES PARA REDUCIR EL GRADO ALCOHÓLICO}

La industria enológica implicada ha estado desarrollando y evaluando diferentes estrategias para reducir el contenido de etanol evitando comprometer la calidad del producto final. Numerosos procesos tecnológicos han sido utilizados para eliminar o reducir el alcohol en vino, como por ejemplo: evaporación, destilación, adsorción, extracción, crioconcentración y fermentación parcial.

El objetivo de la desalcoholización es el de conseguir eliminar suficientes moléculas de etanol, conservando a la vez las cualidades originales de los vinos tratados y sin que los costes de producción perjudiquen la competitividad internacional. En términos generales, se considera que los vinos son más bien negativamente sensibles a los tratamientos térmicos y la reducción de la concentración de etanol, puede ir acompañada del riesgo de eliminación de compuestos volátiles que podrían tener un papel importante en el aroma de los vinos así como también en sus cualidades organolépticas generales [40]. 
Las tecnologías de desalcoholización se pueden dividir dependiendo de su forma de actuación. Algunas actúan sobre la materia prima, reduciendo los azúcares fermentables de la uva o del mosto (uso de uvas menos maduras o utilización de enzimas), lo que da lugar a productos de menos graduación. Otras intervienen en el proceso de vinificación, realizando fermentaciones incompletas o utilizando levaduras de bajo rendimiento. Y por último, estarían las técnicas que actúan sobre el producto tras la fermentación alcohólica y/o maloláctica, realizando la eliminación de alcohol del vino por procesos térmicos o con membranas de filtración [41]. A la hora de trabajar con vinos terminados, debemos tener en cuenta como hemos dicho anteriormente, que la materia prima será muy sensible a procesos térmicos, y que la elevada presencia de compuestos volátiles hace que las condiciones del proceso deban estar muy controladas para respetar las condiciones organolépticas del producto de origen.

Un aspecto muy importante en la elaboración de vinos totalmente desalcoholizados es la estabilidad a lo largo del tiempo. En los vinos, el alcohol tiene una función claramente bactericida y/o bacteriostática, eliminado o inhibiendo la flora presente y manteniéndola en niveles bajos, incapaces de producir una alteración sensorial. Sin embargo, al retirar el alcohol y modificar otras características (subir el $\mathrm{pH}$ o añadir azúcares fermentables), el producto resultante es microbiológicamente muy inestable.

También se está investigando en el campo de la desoxigenación, ya que la eliminación de oxígeno disuelto permite mejorar el mantenimiento de la calidad de los vinos a largo plazo, evitando que los compuestos aromáticos se oxiden, reduciéndose así su concentración en el vino [2].

\subsection{TÉCNICAS QUE ACTÚAN SOBRE EL MOSTO}

a) Vendimia anticipada

Como indicamos anteriormente, adelantar la vendimia hace que no se alcance el punto óptimo de madurez de los compuestos fenólicos, lo que hace que se extraigan taninos agresivos que darán lugar a un vino más astringente. Esta astringencia junto con el mayor carácter vegetal genera en definitiva, un vino desequilibrado.

b) Tratamiento enzimático del mosto con Glucosa Oxidasa (GOX)

Es una de las técnicas más utilizada en la reducción de los azúcares fermentables del mosto, esta enzima cataliza la oxidación de la glucosa a gluconolactona (ácido glucónico $\delta$-lactona) en presencia de oxígeno molecular. La eficacia de la oxidación de la glucosa depende de la concentración de enzima, el pH del mosto, la concentración 
de oxígeno disuelto, el tiempo de actuación y la temperatura [16]. Todas estas variables se tienen que optimizar para que la actuación de la enzima sea correcta, lo que puede dar lugar a varios problemas:

- El pH del mosto debe encontrarse entre 5.5 - 6.0, necesitando en ocasiones la desacidificación del mosto.

- La necesidad de oxígeno provoca la oxidación de otros compuestos que afectan negativamente a las características organolépticas de los vinos obtenidos con estas cepas vínicas.

- Una elevada concentración de ácido glucónico aumentaría la acidez total desequilibrando el vino final.

\subsection{TÉCNICAS QUE ACTUAN SOBRE EL PRODUCTO FINAL}

a) Evaporación con calor y vacío:

Para la evaporación convencional se necesitan altas temperaturas, como mínimo $50^{\circ} \mathrm{C}$, lo que perjudica organolépticamente el vino final [42-43]. Este problema podría solucionarse con la evaporación a vacío, pero la pérdida de aromas es inevitable.

Ventajas:

- Se trata una cantidad pequeña de vino eliminando completamente el alcohol y luego se mezcla con el resto para ajustar el grado.

Inconvenientes:

- Mayor pérdida de aromas.

- Necesidad de realizar varias pasadas para eliminar 4-5\%vol por tratamiento.

b) Destilación a vacío con Columna de Conos Rotatorios (SCC):

La técnica de columna de conos rotatorios o Spinning Cone Column (SCC), consiste en una columna de extracción gas-líquido donde se produce una transferencia de masa entre ambas fases, permitiendo la separación de componentes en función de su punto de ebullición. El vino pasaría en sentido descendente por la columna formada por un sistema de conos rotatorios y fijos, en los que se formarían unas películas muy finas y turbulentas. En sentido ascendente, una corriente de vapor obtenida por el mismo vino extrae los compuestos volátiles del vino que serían recuperados en la parte superior de la SCC mediante un sistema de condensadores. De esta forma, los 
componentes de menor peso molecular se concentran en la fase vapor y los de peso mayor en el líquido. Para favorecer una extracción eficaz en la que se reduzca el tiempo de operación y que evite la degradación de los componentes, el proceso se desarrolla en condiciones de vacío [44].

Esta técnica surgió a principios de los años 90 y se puede utilizar de dos formas: o bien se elimina el etanol deseado sobre el conjunto del volumen del vino, o bien se trata sólo una parte para una desalcoholización intensa y luego se une de nuevo con un volumen de vino sin desalcoholizar con el fin de obtener el grado de alcohol deseado. Es necesario tratar cerca del $10 \%$ del volumen de vino por porcentaje de volumen de etanol a disminuir $[17,40]$

Ventajas:

- Desalcoholización parcial o total del vino.

- Reduce los tiempos de permanencia del vino respecto a la evaporación.

- Posibilidad de recuperar la mayor parte de los aromas, aunque parte se pierden en la etapa de desalcoholización si no se han separado bien en la etapa de desaromatización.

- Eliminar el dióxido de azufre del mosto sulfitado.

- Reducir la acidez volátil.

- Eliminar malos olores y componentes como acetato de etilo y acetaldehido, disminuir aromas de TCA (2,4,6-tricloroanisol) y aromas producidos por Brettanomyces (4-etilfenoly4-etilguayacol).

- Eliminar parte del agua y concentrar el vino.

- Permanencia de los compuestos polifenólicos en el vino desalcoholizado, la actividad antioxidante puede ser menor en el vino desalcoholizado porque existen otros componentes antioxidantes como el dióxido de azufre que se eliminan en la etapa de retirada de alcohol del vino [45].

Inconvenientes:

- Incidencia del efecto térmico sobre la calidad sensorial del vino tratado.

- El procedimiento debe realizarse al vacío. En función de los parámetros de funcionamiento de las columnas de rectificación es posible, industrialmente, operar a temperaturas de $30^{\circ} \mathrm{C}[16]$.

- Aumento del coste y tiempo de operación: El principio del tratamiento consta de dos fases, en la primera fase se extrae la fracción volátil aromática en poco volumen mediante condensación, mientras que la segunda está pensada para 
eliminar el etanol. Posteriormente, la fracción aromática se reintroduce en el vino desalcoholizado.

- Se deben utilizar volúmenes elevados para que la aplicación de la técnica sea viable.

c) Destilación a vacío y extracción con $\mathrm{CO}_{2}$ supercrítico:

Tras la técnica de destilación a vacío, se utiliza la extracción con $\mathrm{CO}_{2}$ supercrítico para separar los aromas del alcohol. Este fluido supercrítico se consigue comprimiendo el gas a una temperatura superior a la temperatura crítica del fluido, lo que aumentará su capacidad de extracción.

El proceso de extracción se lleva a cabo en una columna en la que el fluido supercrítico es bombeado a contracorriente respecto a la mezcla volátil aroma/alcohol. Esta técnica se está utilizando a escala piloto, debido a su elevado coste, además tiene el inconveniente de la eliminación de algunos componentes aromáticos con la eliminación del alcohol.

d) Adsorción:

Se utilizan resinas tales como copolímeros de estireno y divinilbenceno o gel de sílice para adsorber el alcohol, su principal inconveniente es que no se ha utilizado a escala industrial.

e) Crioconcentración:

La concentración de alimentos líquidos mediante congelación, implica una reducción de la temperatura del producto de forma controlada con el objetivo de conseguir una congelación parcial hasta obtener una mezcla de cristales de hielo en un fluido concentrado. La concentración por congelación, se aplica para concentrar muchos alimentos como zumo de naranja, vinagre, cerveza y vinos; permitiendo obtener mejores resultados en la concentración de bebidas alcohólicas.

Para obtener vinos desalcoholizados, los cristales de hielo formados, permiten por tanto la separación de agua, eliminando el alcohol de la parte líquida por destilación a vacío u otra técnica. Posteriormente el paso del agua al estado líquido permitirá que el único componente eliminado sea el alcohol [20].

Ventajas: 
- Bajas temperaturas del proceso, por lo que no se producen pérdidas de aromas o componentes volátiles importantes en la calidad del producto.

- Ausencia de interfase líquido-vapor en la separación.

Inconvenientes:

- Falta de viabilidad de equipos desde el punto de vista industrial, es un proceso caro.

- Se necesita una técnica complementaria para poder eliminar el alcohol de la fracción líquida.

\subsection{TÉCNICAS QUE ACTUAN EN EL PROCESO DE FERMENTACIÓN}

Realizar la fermentación parcial del mosto tiene el inconveniente de la presencia de azúcares residuales que pueden dar lugar a refermentaciones. Para evitarlo se podría pasteurizar el producto final, pero esto daría lugar a una pérdida de compuestos volátiles que afectaría a las características organolépticas del vino [16]. Por ello, las nuevas investigaciones aplican técnicas en el transcurso de la fermentación o actúan en el metabolismo de las levaduras, para reducir el grado alcohólico de los vinos finales:

a) Destilación a vacío

Se trata de eliminar parte del grado alcohólico cuando ha transcurrido la mitad de la fermentación alcohólica [46].

Ventajas:

- La velocidad de la fermentación incrementa debido a la eliminación de parte del alcohol que actúa como inhibidor de la fermentación. Esto nos permite que la fermentación alcohólica se complete de forma más fácil.

Inconvenientes:

- Al eliminar parte de alcohol en el transcurso de la fermentación, disminuye la concentración de compuestos derivados del metabolismo de las levaduras (glicerol, acetato) y compuestos aromáticos.

- Se pierden el $25 \%$ de los alcoholes de fusel y los ésteres, aunque parte de ellos se recuperan en la segunda fase de la fermentación alcohólica.

- Se produce un $19 \%$ más de isobutanol y glicerol. 
b) Extracción con $\mathrm{CO}_{2}$

Se realiza la transferencia de compuestos volátiles de un líquido a un gas impulsado por la diferencia de concentración entre las dos fases. Las ventajas e inconvenientes son similares al caso anterior, ya que también se actuará cuando la fermentación alcohólica ha llegado a la mitad de su finalización [46]. Las únicas diferencias que podemos hacer notar son las siguientes:

- En el análisis sensorial sí se detectan diferencias entre el vino desalcoholizado y el vino sin tratar, con efectos ligeramente negativos para el primero.

- La técnica es más cara y no suele utilizarse comercialmente.

- Se pierden el $45 \%$ de los alcoholes de fusel y los ésteres, aunque parte de ellos se recuperan en la segunda fase de la fermentación alcohólica.

- Se produce un $32 \%$ más de isobutanol y glicerol.

c) Levaduras con bajo rendimiento de alcohol

Se están llevando a cabo investigaciones para la selección genética de clones de levaduras y bacterias capaces de hacer frente a los altos niveles alcohólicos, y/o de reducir su producción a partir de la fermentación de los azúcares contenidos en el mosto.

Se han utilizado cepas de Saccharomyces cerevisiae, pero la reducción de concentración de alcohol era menos de 1\% vol. La selección de cepas de diferentes géneros como Pichia y Williopsis han demostrado tener una reducción de alcohol mayor, pero las características organolépticas son inferiores a los vinos obtenidos con Saccharomyces cerevisiae [16].

d) Ingeniería genética de levaduras

La ingeniería metabólica de levaduras se basa en el redireccionamiento metabólico de los azúcares del mosto, reduciéndose la producción de etanol e incrementando la biomasa celular o los productos finales de fermentación como el glicerol o el ácido láctico [16, 47].

Las futuras investigaciones están encaminadas a mejorar la eficiencia del proceso sin poner en riesgo la calidad del vino y la salud de los consumidores.

Ventajas:

- Técnicas más selectivas. 
- No se necesitan equipamientos costosos.

Inconvenientes:

- Si la reducción de etanol observada en los vinos producidos con las cepas transgénicas es significativa, los productos finales de fermentación (lactato, glicerol, acetato, etc.) que se producen, impactan de forma negativa en la calidad final del vino [48-49].

- Hay cepas que presentan deficiencias de crecimiento durante la fermentación, así como la imposibilidad de fermentar más de $100 \mathrm{~g} / \mathrm{L}$ de glucosa.

- La producción de etanol es un carácter cuantitativo de muchos genes y proteínas, de modo que muchas de las mutaciones potencialmente interesantes tendrán un efecto mínimo por sí mismas en la producción de etanol, siendo necesaria la acumulación de diversas mutaciones para obtener efectos apreciables [50]. Además, estas cepas deberían ser útiles desde el punto de vista enológico.

- Otra limitación sería la dificultad de reproducir a pequeña escala las condiciones de fermentación industrial [51].

- Las levaduras obtenidas serían consideradas organismos genéticamente modificados (OGM) por la legislación europea, lo que acarrearía una importante serie de limitaciones a su uso y comercialización, además de que la OIV no ha aceptado todavía la utilización enológica de los OGM.

\section{PROCESOS DE MEMBRANA}

La tecnología de membranas ha sido objeto de un gran interés en los últimos años, gracias sobre todo a la industria química. Ésta dedica el $80 \%$ de su consumo energético a procesos de separación y concentración de sustancias, lo cual ocasiona una gran demanda de técnicas avanzadas en separación, que sean limpias, respeten el medio ambiente y tengan gran ahorro energético.

Una membrana se puede considerar una barrera o película selectiva entre dos medios fluidos, que permite la transferencia de determinados componentes de un medio al otro a través de ella y evita o restringe el paso de otros componentes. El transporte de componentes a través de la membrana se realiza siempre aplicando una fuerza impulsora, en nuestro caso esta fuerza impulsora se consigue con gradientes de presión. 


\subsection{OTRAS APLICACIONES:}

Actualmente, son muchos los problemas de separación que se pueden solucionar con las membranas comercializadas en el mercado, como la concentración y purificación de disoluciones macromoleculares, la separación de electrólitos y no electrólitos de bajo peso molecular de soluciones acuosas, el fraccionamiento de la mezcla de gases, la separación selectiva de iones metálicos pesados y la difusión controlada de componentes activos en el campo de la biomedicina y la biología.

La aplicación de la tecnología de membranas como proceso ha ido evolucionando a medida que se han desarrollado mejoras en las propiedades físicas y químicas de las membranas, mejoras en las aplicaciones y en la ingeniería de procesos. Por tanto, las membranas han resultado mejores técnica y económicamente que otras tecnologías tradicionales. Existen, por tanto, tecnologías modernas y procesos bastante fiables industrialmente de microfiltración (MF), ultrafiltración (UF), nanofiltración (NF) y ósmosis inversa $(\mathrm{Ol})$. En la figura 1.1 se muestra la capacidad de retención de cada membrana.

Las principales aplicaciones de las membranas en procesos de separación se encuentran en el sector químico, en el tratamiento de aguas residuales o en la producción de agua potable o agua de uso industrial. Desde 1970 las membranas de ósmosis inversa han sido utilizadas para desalinización de agua de mar para conseguir agua dulce y para purificación de agua.

La membrana de ósmosis inversa es semipermeable, permitiendo que pase el disolvente pero no los solutos. Este proceso requiere unas presiones altas, normalmente de 2-17 bar para agua dulce y 40-70 bar para agua salada contando que tiene unos 24 bar de presión osmótica que debe ser superada.

Algunas de las aplicaciones de esta técnica de ósmosis inversa son: la purificación de agua potable (en los Estados Unidos, estos sistemas de purificación se utilizan en la red doméstica), la purificación de agua de lluvia y aguas residuales y concentración en la industria láctea. En la industria enológica esta tecnología se puede aplicar para: 
Microfiltración

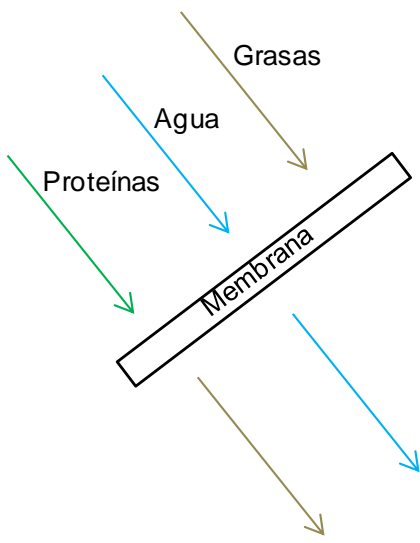

Nanofiltración

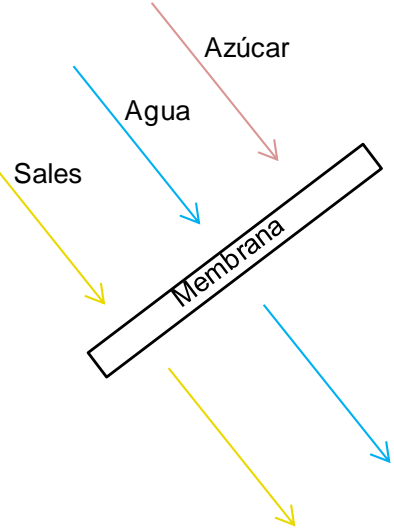

Ultrafiltración

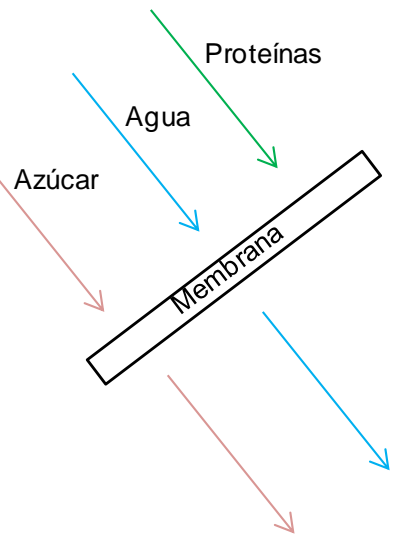

Ósmosis Inversa

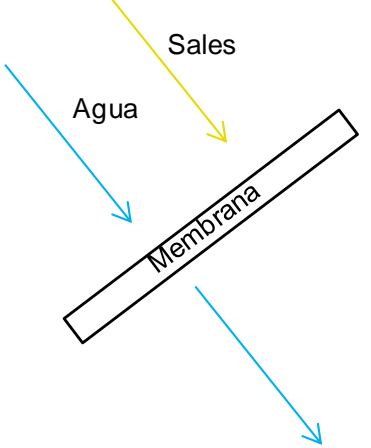

Figura 1.1 Retención de las membranas de filtración.

- Concentración de mostos: Su principal ventaja es la de evitar los procesos de tratamiento de calor (como ocurría con el método clásico de concentración de mostos que era la evaporación a vacío y que agotaba los aromas varietales), que lo hace adecuado para sustancias sensibles al calor como las proteínas y enzimas que se encuentran en la mayoría de los productos alimenticios [52]. Este mosto concentrado o rectificado (después de concentrar el mosto, se necesita una técnica adicional de intercambio iónico), permite enriquecer mostos con baja concentración de azúcar para la producción de vino. Aunque el uso de esta técnica antes era mal visto en la industria del vino, ahora es bien considerada y ampliamente usada; se estima que 60 máquinas de osmosis inversa estaban en uso en Burdeos en 2002. En este caso la ósmosis inversa se utiliza para extraer el exceso de agua del mosto de uva y enriquecer el mosto. Aumentando el nivel de azúcar así como concentrando los ácidos 
orgánicos y aromas se consigue mejorar la estructura y color del futuro vino. Esta técnica es utilizada hoy en día por muchos de los mejores Chateaux de Burdeos. Pero el mosto concentrado además de azúcar tendrá varias sustancias (como polifenoles, ácidos orgánicos y sales) que serían también añadidas. Además el mosto rectificado generaba el problema de la regeneración de resinas.

Para evitar estos problemas y los de elevado consumo energético de esta técnica, se han estudiado técnicas diferentes a la ósmosis inversa como pervaporación, destilación osmótica [42] y membranas de nanofiltración [5354]. La nanofiltración es una alternativa a estas técnicas, en la que se consume menos energía, hay menos ensuciamiento de membrana y se ajustan niveles de componentes como ácidos y sales [5], además de que permite preservar vitaminas y compuestos volátiles. Algunos autores utilizan una membrana de ósmosis inversa seguida de otra de nanofiltración para concentrar el mosto, antes de estas dos filtraciones se realizaría una microfiltración para clarificar el mosto. Los valores máximos de retención de azúcar serán para alta velocidad de recirculación, alta presión y baja temperatura. Este proceso combinado de concentración de azúcar por ósmosis inversa (60 bar y $20 \stackrel{\circ}{\circ}$ ) y nanofiltración (70 bar y $40^{\circ} \mathrm{C}$ ) permite una optimización económica respecto a la evaporación [55].

- Eliminar moléculas de ácido acético y/o acetato de etilo (primer paso de ósmosis inversa retirando agua y compuestos de bajo peso molecular como el ácido acético en el permeado, y segundo paso de separación del ácido acético con una membrana de intercambio aniónico, mezclando el resto con el retenido de la etapa anterior) [56-57]. Esta práctica sólo se realiza en los países en los que está autorizado (Estados Unidos, Australia y Suiza, entre otros), en la Unión Europea todavía no es una práctica admitida según el Reglamento (CE) № $1622 / 2000$.

Otras membranas con aplicación en la industria alimentaria son las de microfiltración y ultrafiltración, ya que pueden trabajar a altas temperaturas y garantizan una desinfección y esterilización perfectas de los sistemas en que se manipulan alimentos, a la vez que se mantienen sus cualidades organolépticas. Centrándonos en la industria enológica, las membranas tendrían las siguientes aplicaciones: 
- Clarificación de mostos, vinos e incluso lías: en la clarificación del vino, existen varias etapas de filtración, desde el desbaste hasta la esterilización, que pueden ser sustituidas por microfiltración o ultrafiltración $[19,58]$, ya que pueden aceptar una alta concentración de sólidos.

Los sistemas de filtración convencionales que existen en las bodegas, son mayoritariamente filtros de placas y de tierras, ambos son sistemas estáticos, es decir, la separación se produce por la presión de filtrado y las partículas son retenidas en el interior del soporte por tamizado $(>1 \mu \mathrm{m})$ y por adsorción $(<1$ $\mu \mathrm{m})$. Los problemas generales de estos filtros son: la colmatación, que el tamaño de poro no está definido y pueden pasar microorganismos, la retención de partículas de mayor tamaño que el poro por adsorción, la contaminación de las tierras agotadas y las mermas de producto producidas, puesto que las tierras adsorben 4.5 veces su peso en vino. La filtración con membranas, puede acabar con todas estas desventajas debido a su funcionamiento: el tamaño de poro está definido; se esteriliza el producto (las bacterias y levaduras son mayores que el corte de las membranas); se retienen las partículas en superficie, produciéndose sólo tamizado; la filtración es tangencial, para eliminar el problema de colmatación de los filtros; no hay mermas de producto; no se producen vertidos contaminantes y tiene lugar un elevado ahorro económico [11, 58-59].

- Retención del potasio y la acidificación del vino (estabilización tartárica), mediante membranas de electrodiálisis aunque también se podría utilizar microfiltración y nanofiltración [19,60].

- Reducción de acidez volátil del vino: la empresa Australiana Memstar tiene un sistema integrado de ósmosis inversa y resinas de intercambio iónico, este proceso es interesante en el caso de paradas de fermentación. La reducción de acidez volátil o ácido málico también se podría realizar uniendo dos etapas de ósmosis inversa [19].

- Elaborar vinos dulces evitando cantidades excesivas de sulfuroso, utilizando la técnica de microfiltración, ya que permite eliminar microorganismos del vino [11].

\subsection{REDUCCIÓN DEL GRADO ALCOHÓLICO DEL VINO:}

Como hemos indicado anteriormente, además de para concentración de mostos o de vinos, cuando se tiene una falta de madurez, o aumentar la acidez en mostos que 
provienen de climas extremadamente calurosos, se pueden utilizar las membranas para disminuir el grado alcohólico del mosto o vino [61].

A continuación describiremos las técnicas más importantes de desalcoholización de vinos que utilizan membranas:

a) Membranas de ósmosis inversa:

Esta técnica permite ajustar el grado alcohólico de diferentes formas, mediante dos procesos de ósmosis inversa utilizando membranas con diferente permeabilidad al etanol [62], o con un primer paso de ósmosis inversa retirando el agua y alcohol en el permeado, y un segundo paso de destilación para eliminar el alcohol y poder añadir esa agua al vino tratado [19].

Ventajas:

- Desalcoholización parcial o total del vino.

- Reducción de la acidez volátil

- Se trata una cantidad pequeña de vino eliminando completamente el alcohol y luego se mezcla con el resto para ajustar el grado.

Inconvenientes:

- El vino debe clarificarse y filtrarse previamente a la entrada de las membranas de osmosis inversa.

- En desalcoholización total del vino es necesario separar el agua y el alcohol por destilación para reponer el agua.

b) Membrana de ultrafiltración seguida de membrana de nanofiltración:

En la primera operación se pretende retener el conjunto de macromoléculas y constituyentes fenólicos. Una parte de los azúcares que se intentan eliminar están en el permeado de ultrafiltración, que será concentrado por nanofiltración. El retenido de ultrafiltración y el permeado de nanofiltración juntos constituyen el mosto pobre en azúcar. En el proceso Redux® propuesto por Vaslin Bucher el volumen eliminado, es aproximadamente de un $15 \%$ con una disminución del $2 \%$ del volumen de etanol [40, 63-64]. 
Ventajas:

- Al no ser un proceso térmico, se obtienen vinos con más fruta, frescura y redondez, eliminando los olores a cocido o quemado que aportarían estas técnicas.

Inconvenientes:

- Tenemos un volumen que no se utilizaría (el que corresponde al retenido de la etapa de filtración).

c) Destilación osmótica con contactor de membrana:

Se está poniendo a punto una nueva técnica de desalcoholización de vinos por membrana llamada destilación osmótica o también pertracción evaporativa. Es un proceso de separación basado en membranas en el que una fase líquida, generalmente una disolución acuosa que contiene uno o más compuestos volátiles, circula a través de un contactor de membrana hidrofóbico, mientras que una segunda disolución acuosa entra en sentido contrario por la membrana y actúa como líquido extractor, ya que en esta segunda fase, los compuestos volátiles son solubles. De esta forma, la membrana actúa como un espacio de vapor a través del cual cualquier componente volátil puede migrar mediante convección o difusión. La fuerza impulsora del transporte es la diferencia de presión de vapor de los componentes entre las dos fases líquidas, ya que el etanol es uno de los compuestos más volátiles del vino y su transferencia ocurre más rápidamente [27, 65].

El flujo de eliminación del etanol aumenta por el incremento de la velocidad de la solución de extracción, la temperatura y la velocidad de alimentación, pero tendremos menor concentración de etanol con estas condiciones [66].

Ventajas:

- Concentra solutos a bajas temperaturas y presiones, con mínimo daño térmico o mecánico y mínimas pérdidas de dichos solutos

- Menor consumo energético que otras técnicas de desalcoholización del mercado (ósmosis inversa, columna de conos rotatorios), puesto que no precisa tratar el vino a altas presiones ni temperaturas.

- El líquido extractante es agua por lo que es barato y no peligroso. 
Inconvenientes:

- En la mayoría de las pruebas realizadas se utilizan disoluciones alcohólicas o disoluciones sintéticas de vino, en las que en la parte desalcoholizada se pierden aromas en más de un 50\% y otros desaparecen completamente (como los aromas hidrofóbicos, por su afinidad con la membrana) [27]. Se debe tener en cuenta que cuando se desalcoholizan vinos reales la eliminación de alcohol es menor debido a la diferencia de composición [66].

- La concentración de los aromas decrece rápidamente al inicio de la filtración, debido a la gran diferencia de concentración de las dos disoluciones.

- Para desalcoholizaciones totales: los parámetros enológicos y los compuestos fenólicos de los vinos obtenidos no tienen diferencias significativas respecto a los vinos sin tratar. Las pérdidas de aroma son grandes para altas reducciones de alcohol, llegando a reducirse el $100 \%$ de los aromas cuando el tiempo de residencia de la disolución de alimentación en el interior de la membrana es alto [27, 67]. Esto es así, debido a velocidades de flujo de la disolución de alimentación bajas (en definitiva, mayores tiempos de operación).

- Los contactores de membrana por el momento sólo pueden utilizarse para gestionar los gases disueltos en el vino, tanto en vinos tranquilos como en vinos de aguja según la Resolución OIV-OENO 499-2013.

- En estudios en los que se disminuye el grado de alcohol de vino en $2 \%$ vol, se han determinado unas condiciones de trabajo óptimas (bajos caudales, pH bajo del agua de extracción y alta relación volumen de alimentación/volumen del líquido extractor), que disminuyen el flujo de compuestos aromáticos a través de la membrana para conservarlos en el vino [65].

d) Membrana de ósmosis inversa seguida de contactores de membrana:

Las dificultades de los distintos procedimientos residen en la preservación del aroma original, por lo que es necesario encontrar procedimientos de recuperación de la fracción aromática. Las soluciones se encuentran en la optimización de los contactores de membrana desarrollados para la recuperación y la concentración de aromas, efluentes acuosos o absorbentes de aromas. La empresa Memsatar propone un sistema integrado que asocia una membrana de osmosis inversa con un módulo de membranas de contacto; éstas separan preferentemente los compuestos hidrófobos de las moléculas de etanol que se reintroducen a continuación en el retenido de la 
ósmosis inversa. El tratamiento se produce por lotes, reduciéndose el alcohol a cada paso entre el 0.9 y el $1.5 \%[19,40,60]$.

En cuanto a las ventajas e inconvenientes, se deben tener en cuenta las de las dos tecnologías por separado.

e) Pervaporación

Es un proceso de separación con membranas no porosas aplicado a mezclas líquidas de compuestos miscibles, en el que a partir de una corriente de alimentación se obtienen dos corrientes mediante la aplicación de vacío en el lado de la membrana. Se obtiene el permeado en forma de vapor que posteriormente se condensa, en nuestro caso es la fracción de mayor concentración de alcohol [43]. La otra fracción será la parte del líquido de alimentación cuya separación se busca.

Ventajas:

- Desalcoholización parcial o total del vino.

- Esta técnica puede ser utilizada para la recuperación de aromas del vino, tras el uso de membranas de nanofiltración para la retirada de alcohol y aromas en el permeado [68].

Inconvenientes [69]:

- Las altas temperaturas decrecen la capacidad de separación y favorecen la pérdida de aromas, aunque aumentarían el flujo de permeado y se podría disminuir la superficie activa de la membrana.

- Se obtienen pérdidas de aromas de hasta el $70 \%$ en el permeado; se podría destilar esta fracción para recuperar algunos aromas, pero podría aumentar ligeramente la concentración de alcohol del vino final.

- Altos costes de operación debido principalmente al equipo de refrigeración necesario para la condensación.

\section{NUESTRAS MEMBRANAS (NUESTRO PROCESO DE SEPARACIÓN)}

El desarrollo de la ósmosis inversa en la concentración de mostos se realizó en paralelo a la microfiltración para la clarificación, sin embargo, en el caso de la osmosis inversa existe el problema de que la membrana es muy selectiva y permite el paso además del agua, de pequeñas moléculas o iones por la membrana [19]. Además de 
concentrar carbohidratos, estas membranas también retendrían otros componentes naturales del mosto como ácido málico, lo que afectaría al balance sensorial final. También explicamos anteriormente, que esta membrana daría lugar a mucho consumo de energía y provocaría mucho ensuciamiento.

Las membranas de nanofiltración además de sus aplicaciones en el tratamiento de aguas residuales o la recuperación de ácido láctico en medios de fermentación, pueden utilizarse en solitario o con otras técnicas de membrana para solucionar estos problemas en la concentración de mostos [53-54]. También se podrían utilizar para la concentración de un vino tinto, dando lugar a un permeado de agua y etanol y un retenido con más sustancias que las membranas de micro- y ultrafiltración. En el trabajo realizado por Banvolgyi en 2006 [28], se muestra como a temperaturas de $30^{\circ} \mathrm{C}$ el vino no sufre degradación térmica preservando sus características sensoriales, además la retención de los ácidos y el extracto sin azúcar fue mayor, mientras que la retención de alcohol fue menor, lo cual es una ventaja porque el vino final contiene menos alcohol.

La nanofiltración por sí sola sirve para desalcoholizar parcialmente un vino, pero la disolución hidroalcohólica del permeado se tendrá que destilar para eliminar el alcohol y reintroducir esa agua al vino. Esta desalcoholización se realiza después de la fermentación maloláctica para vinos tintos y después de la fermentación alcohólica para blancos. Desalcoholizando el vino y reduciendo dos grados de alcohol, los polifenoles y el potasio serían fuertemente retenidos por la membrana, al contrario que los ácidos. El vino desalcoholizado final tendrá una acidez total inferior y un pH ligeramente mayor. En cuanto a la acidez volátil y los polifenoles no sufren prácticamente modificación respecto al vino inicial [60].

\subsection{MEMBRANAS}

En este trabajo no realizaremos una desalcoholización parcial de vino, sino que utilizaremos como materia prima el mosto sin fermentar al que le eliminaremos el azúcar. De este modo intentaremos preservar los aromas del vino final, principal problema de todas las técnicas de desalcoholización que hemos descrito, mejorando así la calidad final del vino elaborado. Además, la reducción de azúcar en el mosto permite menores riesgos de paradas de fermentación, un enriquecimiento en el vino de compuestos fenólicos y macromoléculas y menos problemas legales con el alcohol [19]. 
El objetivo será la reducción de azúcar en mostos para la obtención de vinos con una ligera reducción del grado alcohólico. La reducción de azúcar se conseguirá mediante la filtración con membranas con uno o dos pasos de filtración, y los mostos obtenidos se mezclarán en las proporciones apropiadas con mosto sin tratar o con el retenido de la primera etapa de filtración. Con ello, se busca reducir la concentración de alcohol de los vinos en dos grados alcohólicos aproximadamente, según el reglamento CE 606/2009, por lo que debemos ajustar la concentración de azúcar del mosto antes de fermentar para cumplir este requisito.

Para elegir la membrana de separación, el tamaño de poro de la membrana puede ser lo menos importante en el caso de la nanofiltración, porque el paso estará afectado por las características físico-químicas de los solutos y la energía que se necesitará en la separación (gradiente de presión necesario para que se produzca el paso de los solutos a través de la membrana). En los fenómenos de separación influyen fenómenos físicos (retención, permeabilidad), fenómenos químicos ( $\mathrm{pH}$, difusión) y electroquímicos (carga de las moléculas y de la membrana) [53, 60].

Como indicamos anteriormente, hay un modelo patentado por Vaslin Bucher (Redux®) para reducir la graduación alcohólica de vinos tratando el mosto [40, 63-64]. Éste combina membranas de ultrafiltración que permiten el paso de azúcar, con membranas de nanofiltración que retienen este azúcar. El permeado de la nanofiltración que contiene el agua y los ácidos, se reincorpora al concentrado de la ultrafiltración que mantiene los polifenoles, antocianos y color (el volumen que se elimina en el retenido de la etapa de nanofiltración, será proporcional a la concentración de azúcar obtenida en el paso de nanofiltración). El grado de concentración máxima depende de la resistencia de la membrana de nanofiltración a la presión $[19,60]$. Es evidente que el éxito de un proceso de este tipo está ligado a las características de bajo ensuciamiento y al cut-off de la membrana de ultrafiltración seleccionada.

Las membranas de nanofiltración retienen moléculas orgánicas (200-1000 Da) más pequeñas que las membranas de ultrafiltración y retienen menos iones monovalentes que la ósmosis inversa [54]. Con el uso de estas membranas conseguimos la permeación de un disolvente, retenciones moderadas de solutos iónicos monovalentes y altas de divalentes o superiores. También se produce la retención de solutos no iónicos de bajo peso molecular. Los tamaños de poro son del orden de $1 \mathrm{~nm}$ y las presiones utilizadas entre 10-60 bar. 
Por todo lo expuesto, utilizaremos membranas comercializadas por GE-Osmonic. Se ha pensado en estas membranas porque existe un gran abanico comercial tanto en ultrafiltración como en nanofiltración y en osmosis inversa, teniendo la posibilidad de hacer pruebas iniciales con membranas planas a escala laboratorio y la posibilidad de usar módulos espirales con diversas escalas de volumen de tratamiento. Usamos una membrana de ultrafiltración (UF-GH) y tres de nanofiltración (NF-HL, NF-DL y NF-DK). Las membranas utilizadas son membranas de poliamida fabricadas por polimerización interfacial sobre un soporte poroso de polisulfona. En la figura 1.2 se muestra la estructura de dichas membranas:

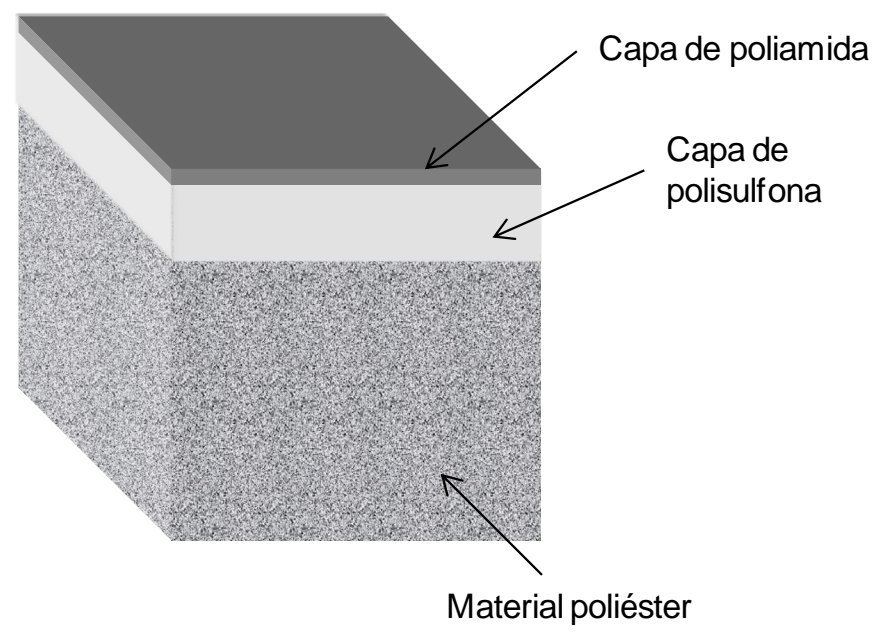

Figura 1.2 Composición de las membranas de filtración.

\subsection{ESTRUCTURA}

Dependiendo del proceso de fabricación, podemos encontrar membranas:

- Laminares: Láminas planas que dependiendo de su flexibilidad, podrían utilizarse para fabricar módulos.

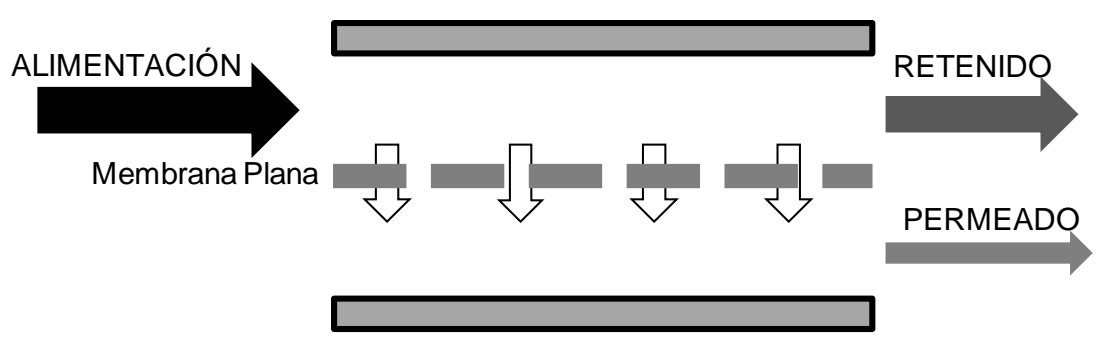

Figura 1.3 Módulo de membranas laminares. 
- Tubulares: Tubos porosos con diámetros entre 5-25 mm y longitud 600-6000 $\mathrm{mm}$, pudiendo ser de un solo canal o multicanales. Si hablamos de membranas cerámicas, son los más usados a escala industrial, sobre todo por sus posibilidades de limpieza con agentes agresivos y altas temperaturas.

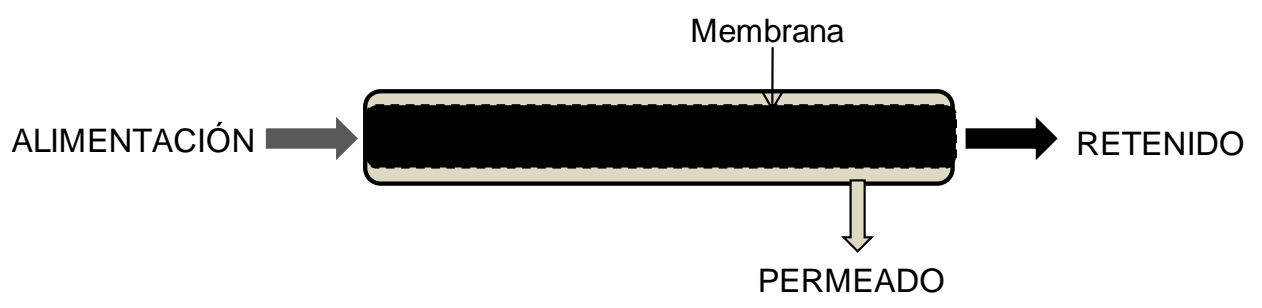

Figura 1.4 Módulo de membranas tubulares.

- Fibras huecas: Microtubos porosos de diámetro entre 0.2-1.25 mm. Suelen utilizarse en paquetes formados por un gran número de fibras, teniendo la ventaja que la relación entre el área de membrana efectiva y el volumen del módulo es muy alta.

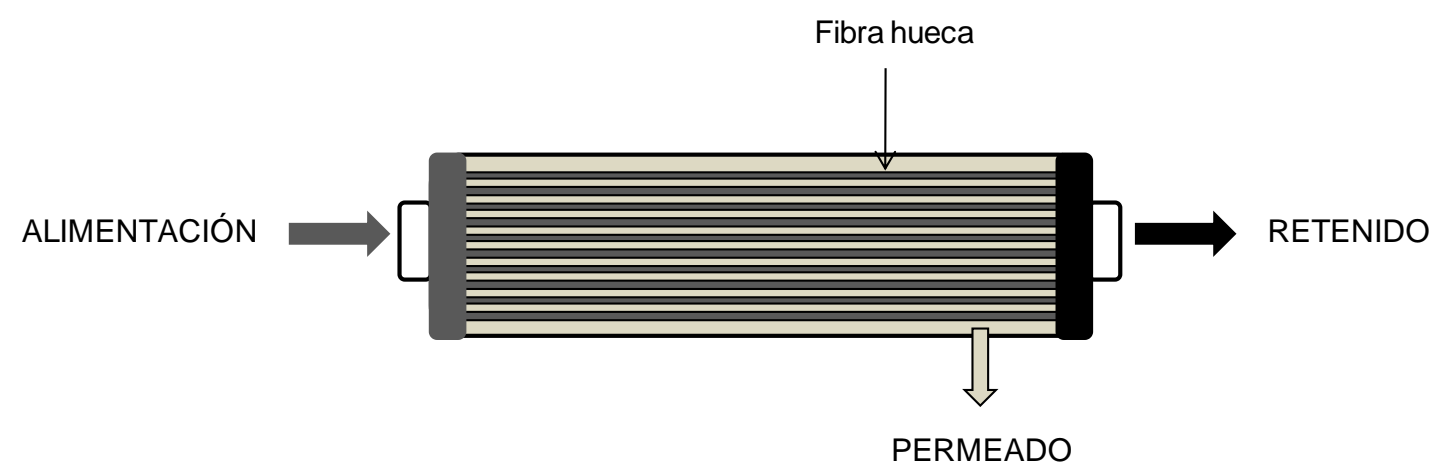

Figura 1.5 Módulo de fibras huecas.

- Membranas Espirales: Las membranas espirales, se fabrican utilizando membranas laminares que se colocan una sobre otra, intercalando una malla porosa entre cada lámina y se enrollan sobre un eje central, quedando un cilindro que se coloca en el interior de un tubo o cartucho, como se muestra en la figura 1.6 [70]. La capa activa de la lámina se orienta hacia el exterior, de forma que el flujo de permeado va en dirección desde el exterior hacia el interior, y los solutos quedan retenidos en esta superficie activa. Una vez el permeado pasa al otro lado de la capa activa, una malla porosa entre las láminas es la encargada de conducirlo hacia el interior del tubo o eje central. Entre las dos capas activas se coloca una malla sintética, que conduce la disolución de alimentación por toda la superficie de la membrana. Dado que se 
necesita flexibilidad en los materiales que la forman, los módulos espirales se fabrican con membranas poliméricas.

A causa de su diseño compacto y su gran área de membrana por elemento, las membranas espirales se utilizan típicamente para aplicaciones de alto flujo con cantidades mínimas de sólidos es suspensión. Su ventaja reside en su bajo material y costo operativo, además de que presentan una buena relación área volumen, al igual que las fibras huecas.

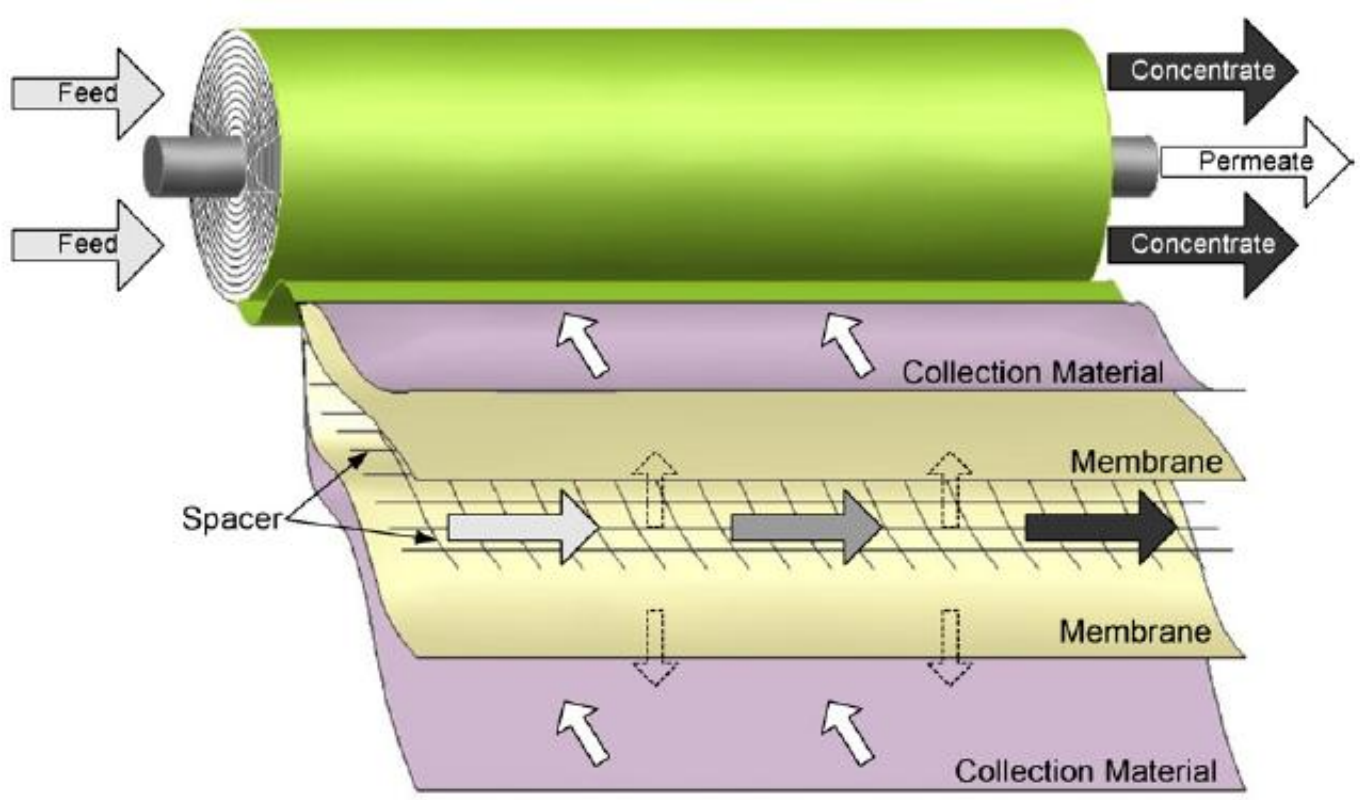

Figura 1.6 Esquema de un módulo de membrana espiral [71].

En nuestro trabajo se utilizan en primer lugar membranas planas en una celda de laboratorio para hacer las pruebas con disoluciones de azúcar y mosto comercial y comprobar que la elección de las membranas ha sido correcta. Posteriormente se utilizan los módulos de membranas espirales (spiral wound module) de esas mismas membranas para filtrar además los mostos de uva de las distintas campañas.

\subsection{TRANSPORTE}

En todo el proceso de membrana, existen tres corrientes:

Alimentación: Disolución que se quiere tratar.

> Permeado: Corriente que es capaz de pasar a través de la membrana. Está constituido por el solvente y algunos solutos. Es rico en sustancias con tendencia a atravesar la membrana. 
$>$ Retenido o concentrado: Corriente que no ha pasado a través de la membrana. Ha perdido parte de los componentes de la disolución de alimentación y, por tanto, aumenta la concentración de sustancias que no pueden atravesar la membrana.

En la figura siguiente, se representa el proceso general de separación por membranas, en el que se distinguen las tres corrientes. La alimentación es separada en una corriente más concentrada o retenido y en una corriente menos concentrada 0 permeado.

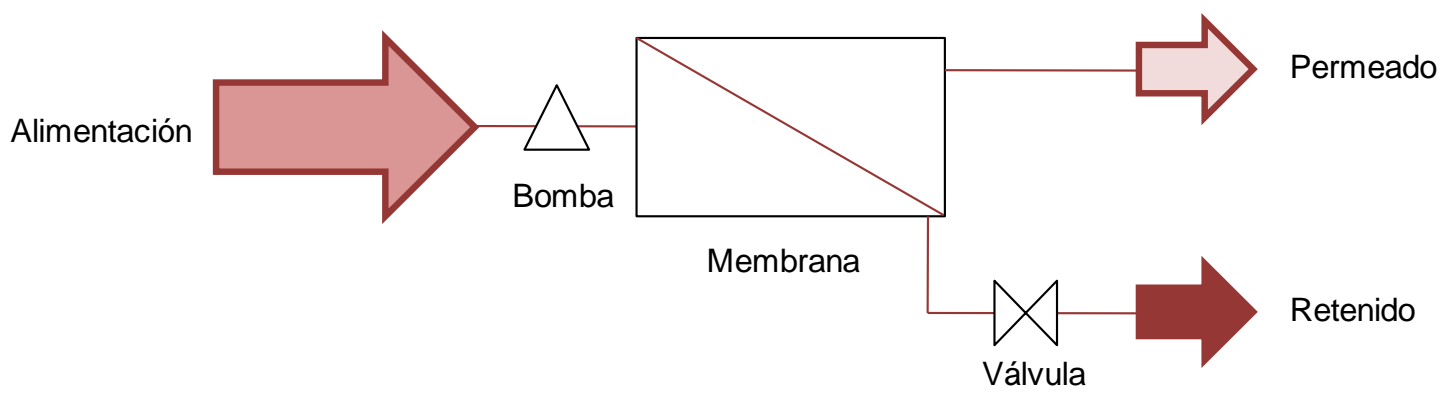

Figura 1.7 Representación esquemática de un proceso de separación por membrana.

En nuestro caso, utilizaremos el permeado de la primera etapa de ultra- o nanofiltración de mostos para que pase a una segunda etapa de nanofiltración o para mezclar directamente con mosto sin filtrar. Cuando se realiza una segunda etapa, la fracción de permeado de esta segunda etapa es lo que utilizaremos para mezclar con vino testigo o con el retenido de la primera filtración. Con el proceso de doble etapa la única fracción que no sería utilizada es el retenido de la segunda filtración, es decir una disolución con alta concentración de azúcar. Este subproducto se podría utilizar para la elaboración de vinos dulces, con la ventaja de que al no ser un proceso en el que se obtenga alcohol no se tendría que utilizar un tratamiento especial para este subproducto. Cuando se opta por un etapa única, el subproducto es el retenido, que tambien es utilizable para la obtención de vinos dulces.

Una vez que se ha elegido la tecnología adecuada, se comparan las calidades de los vinos obtenidos con el original, comprobando que esta disminución de alcohol no afecta a las cualidades gustativas del vino [24]. 


\section{CONCLUSIONES}

Debido al cambio climático, se prevé la contracción del área apta para la producción de vino en algunas zonas, y la ampliación en otras. El tipo de vino que produce una región es el resultado de un clima determinado, esto quiere decir que los cambios climáticos influyen tanto en la variabilidad como en la cosecha vinícola y se pueden introducir alteraciones en los tipos de vino, como el aumento del grado alcohólico.

Además de este factor, la demanda de vinos de baja graduación, que sean menos ardientes en boca y que no enmascaren la fruta y el sabor del vino es cada vez mayor. También existe una mayor preocupación por seguir un estilo de vida saludable, y estos vinos de baja graduación aumentarían los efectos beneficiosos para la salud.

Después de la revisión de todas las tecnologías utilizadas para la reducción de grado alcohólico en el vino, y teniendo en cuenta la multitud de componentes que contituye el mosto, se decide utilizar la tecnología de membranas para nuestro estudio. La aplicación de las membranas de nanofiltración para la elaboración de una nueva gama de productos de contenido alcohólico reducido supondrá una innovación importante, ya que, hasta el momento los procesos de membrana utilizados en el sector vitivinícola son básicamente la ultrafiltración y la ósmosis inversa, y sólo se utilizaban en algunos casos membranas de nanofiltración con el fin de concentración de mostos. De esta forma, el sector se prepara para las nuevas demandas, como ya se está haciendo en otros países tanto de tradición vitivinícola como nuevos productores.

El trabajo realizado para la elaboración de vinos con menor graduación alcohólica, permitirá además el asentamiento de los vinos desalcoholizados en el mercado y la aceptación de estos productos por enólogos y profesionales además de los consumidores.

\section{REFERENCIAS}

1. Statistical report on world vitiviniculture 2013, Organisation Internationale de la Vigne et du Vin (OIV).

2. La mejora de la calidad y la reducción del grado alcohólico centran las investigaciones en el sector vitivinícola. Alimentaria, Octubre 2013. 447: p. 2439.

3. Togores, J. H., Tratado de Enología. Mundi-Prensa ed. 2003.

4. Togores, J. H., La calidad del vino desde el viñedo, ed. Mundi-Prensa. 2010. 
5. Santos, F. R., Catarino, I., Geraldes, V., and Pinho, M. N. d., Concentration and Rectification of Grape Must by Nanofiltration.American Journal of Enology and Viticulture, 2008. 59(4): p. 446-450.

6. Bejerano, P. C. and Zapater, J. M. M., Estructura y composición de la uva y su contribución al vino. Revista de Enología Científica y Profesional, 2013. 139.

7. Ortega-Heras, M., González-SanJosé, M. L., and Beltrán, S., Aroma composition of wine studied by different extraction methods. Analytica Chimica Acta, 2002. 458(1): p. 85-93.

8. Ortega-Heras, M., González-Sanjosé, M. L., and González-Huerta, C., Consideration of the influence of aging process, type of wine and oenological classic parameters on the levels of wood volatile compounds present in red wines. Food Chemistry, 2007. 103(4): p. 1434-1448.

9. Pérez-Magariño, S., Sánchez-Iglesias, M., Ortega-Heras, M., González-Huerta, C., and González-Sanjosé, M. L., Colour stabilization of red wines by microoxygenation treatment before malolactic fermentation.Food Chemistry, 2007. 101(3): p. 881-893.

10. Flanzy, C., Enología: Fundamentos científicos y tecnológicos. Mundi-Prensa ed. 2002.

11. El Rayess, Y., Albasi, C., Bacchin, P., Taillandier, P., Raynal, J., MiettonPeuchot, M., and Devatine, A., Cross-flow microfiltration applied to oenology: A review.Journal of Membrane Science, 2011. 382(1-2): p. 1-19.

12. ORDEN AYG/1405/2008, de 21 de julio, por la que se aprueba el Reglamento de la denominación de origen «Rueda» y de su Consejo Regulador. Denominación Origen Rueda. (p.16123).

13. ORDEN 29-5-1987, por la que se reconoce la Denominación de Origen «Toro» y aprueba su Reglamento y el de su Consejo Regulador.Denominación Origen Toro. (p.16337).

14. Gregory V. Jones, Michael A. White, Owen R. Cooper, and Storchmann, K., Climate Change and Global Wine Quality. Climatic Change, 2005. 73: p. 319343.

15. Jones, G. V., Climate Change: Observations, Projections, and General Implications for Viticulture and Wine Production, in CONCLIVIT. 10-14 Abril 2007: Zaragoza.

16. Schmidtke, L. M., Blackman, J. W., and Agboola, S. O., Production Technologies for Reduced Alcoholic Wines.Journal of Food Science, 2012. 77(1): p. R25-R41. 
17. Perez-Magarino, S., Ortega-Heras, M., Rodriguez-Bencomo, J. J., Cano-Mozo, E., Gonzalez-Huerta, C., and Herrera, P. Estudio de desalcoholización parcial en vinos blancos y tintos. in 31st OIV World Congress of Vine and Wine. 15-20 June 2008. Verona; Italy.

18. Desalcoholización y vinos de bajo contenido alcohólico Revista de Enología Científica y Profesional, Agosto 2007. 84.

19. Massot, A., Mietton-Peuchot, M., Peuchot, C., and Milisic, V., Nanofiltration and reverse osmosis in winemaking. Desalination, 2008. 231(1-3): p. 283-289.

20. Pickering, G. J., Low- and Reduced-alcohol Wine: A Review. Journal of Wine Research, 2000. 11(2): p. 129-144.

21. Alston, J. M., Fuller, K. B., Lapsley, J. T., Soleas, G., and Tumber, K. P., Splendide Mendax: False Label Claims about High and Rising Alcohol Content of Wine. Annual Meeting, July 24-26, 2011 Pittsburgh, Pennsylvania, American Association of Wine Economist.

22. Meillon, S., Dugas, V., Urbano, C., and Schlich, P., Preference and Acceptability of Partially Dealcoholized White and Red Wines by Consumers and Professionals. American Journal of Enology and Viticulture, 2010. 61(1): p. $42-52$.

23. Meillon, S., Urbano, C., Guillot, G., and Schlich, P., Acceptability of partially dealcoholized wines - Measuring the impact of sensory and information cues on overall liking in real-life settings. Food Quality and Preference, 2010. 21(7): p. 763-773.

24. Masson, J., Aurier, P., and d'hauteville, F., Effects of non-sensory cues on perceived quality: the case of low-alcohol wine. International Journal of Wine Business Research, 2008. 20(3): p. 215-229.

25. d'Hauteville, F., Consumer Acceptance of Low Alcohol Wines. International Journal of Wine Marketing, 1994. 6(1): p. 35-48.

26. Murcia, J. L., El sector cree en la apuesta por los vinos desalcoholizados.La Semana Vitivinícola, 2009. 3279: p. 2340-2342.

27. Diban, N., Athes, V., Bes, M., and Souchon, I., Ethanol and aroma compounds transfer study for partial dealcoholization of wine using membrane contactor. Journal of Membrane Science, 2008. 311(1-2): p. 136-146.

28. Banvolgyi, S., Kiss, I., Bekassy-Molnar, E., and Vatai, G., Concentration of red wine by nanofiltration.Desalination, 2006. 198(1-3): p. 8-15.

29. Lamuela, R. M., Andres-Lacueva, C., and Estruch, R., Vino y salud.JANO, 2006. 1617: p. 39-43. 
30. Covas, M. I., Gambert, P., Fitó, M., and de la Torre, R., Wine and oxidative stress: Up-to-date evidence of the effects of moderate wine consumption on oxidative damage in humans. Atherosclerosis, 2010. 208(2): p. 297-304.

31. Renaud, S. and de Lorgeril, M., Wine, alcohol, platelets, and the French paradox for coronary heart disease.The Lancet, 1992. 339(8808): p. 15231526.

32. Vinos sin alcohol: capacidad antioxidante y contribución a la ingesta de antioxidantes de la dieta. Alimentaria, Noviembre 2011. 428: p. 93-97.

33. Vino y salud. Alimentaria, Junio 2013. 444: p. 73-76.

34. Estruch, R. and Lamuela-Raventós, R., Alcohol, wine and cardiovascular disease, two sides of the same coin.Internal and Emergency Medicine, 2010. 5(4): p. 277-279.

35. Das, M. and Das, D. K., Resveratrol and cardiovascular health. Molecular Aspects of Medicine, 2010. 31(6): p. 503-512.

36. Rotches-Ribalta, M., Andres-Lacueva, C., Estruch, R., Escribano, E., and UrpiSarda, M., Pharmacokinetics of resveratrol metabolic profile in healthy humans after moderate consumption of red wine and grape extract tablets. Pharmacological Research, 2012. 66(5): p. 375-382.

37. Zamora-Ros, R., Urpi-Sarda, M., Lamuela-Raventós, R. M., Martínez-González, M. Á., Salas-Salvadó, J., Arós, F., Fitó, M., Lapetra, J., Estruch, R., and Andres-Lacueva, C., High urinary levels of resveratrol metabolites are associated with a reduction in the prevalence of cardiovascular risk factors in high-risk patients. Pharmacological Research, 2012. 65(6): p. 615-620.

38. International Code of Oenological Practices. 2012: Office international de la vigne et du vin (O.I.V.).

39. Desalcoholización de vinos: nuevas definiciones y procedimientos adoptados por la OIV. Asamblea General 2012 de la OIV [cited 2012 09-11]; Available from: http://www.oiv.int/oiv/info/esdealcoolisation.

40. Michel Moutounet, Magali Bes, and Escudier, J.-L., Las tecnologías de elaboración de vinos con bajo nivel de etanol. Revista de Enología Científica y Profesional, Agosto 2007. 84.

41. Nuevas bebidas basadas en vino desalcoholizado: innovación y desarrollo desde el consumidor.Alimentaria, Octubre 2013. 447: p. 55-58.

42. Bui, V. A., Nguyen, M. H., and Muller, J., A laboratory study on glucose concentration by osmotic distillation in hollow fibre module. Journal of Food Engineering, 2004. 63(2): p. 237-245. 
43. Takács, L., Vatai, G., and Korány, K., Production of alcohol free wine by pervaporation.Journal of Food Engineering, 2007. 78(1): p. 118-125.

44. Matarromera elabora el llamado "vino sin alcohol". Alimentaria, Noviembre 2010. 418: p. 87-89.

45. Belisario-Sánchez, Y. Y., Taboada-Rodríguez, A., Marín-Iniesta, F., and LópezGómez, A., Dealcoholized Wines by Spinning Cone Column Distillation: Phenolic Compounds and Antioxidant Activity Measured by the 1,1-Diphenyl-2picrylhydrazyl Method. Journal of Agricultural and Food Chemistry, 2009. 57(15): p. 6770-6778.

46. Aguera, E., Bes, M., Roy, A., Camarasa, C., and Sablayrolles, J. M., Partial Removal of Ethanol during Fermentation to Obtain Reduced-Alcohol Wines.American Journal of Enology and Viticulture, 2010. 61(1): p. 53-60.

47. Otero, R. C., Revisión bibliográfica de las levaduras genéticamente modificadas para reducir el alcohol en vinos Revista de Enología Científica y Profesional, Septiembre 2007. 85.

48. Heux, S., Cachon, R., and Dequin, S., Cofactor engineering in Saccharomyces cerevisiae: Expression of a H2O-forming $\mathrm{NADH}$ oxidase and impact on redox metabolism. Metabolic Engineering, 2006. 8(4): p. 303-314.

49. Heux, S., Sablayrolles, J.-M., Cachon, R., and Dequin, S., Engineering a Saccharomyces cerevisiae Wine Yeast That Exhibits Reduced Ethanol Production during Fermentation under Controlled Microoxygenation Conditions.Applied and Environmental Microbiology, 2006. 72(9): p. 5822-5828.

50. González, R., Barcenilla, J. M., and Tabera, L., Cepas vínicas de Saccharomyces cerevisiae con bajo rendimiento en etanol Revista de Enología Científica y Profesional, Octubre 2007. 86.

51. Erten, H. and Campbell, I., The Production of Low-Alcohol Wines by Aerobic Yeasts. Journal of the Institute of Brewing, 2001. 107(4): p. 207-215.

52. Rektor, A., Kozak, A., Vatai, G., and Bekassy-Molnar, E., Pilot plant ROfiltration of grape juice. Separation and Purification Technology, 2007. 57(3): p. 473-475.

53. Versari, A., Ferrarini, R., Parpinello, G. P., and Galassi, S., Concentration of Grape Must by Nanofiltration Membranes. Food and Bioproducts Processing, 2003. 81(3): p. 275-278.

54. Ferrarini, R., Versari, A., and Galassi, S., A preliminary comparison between nanofiltration and reverse osmosis membranes for grape juice treatment. Journal of Food Engineering, 2001. 50(2): p. 113-116. 
55. Kiss, I., Vatai, G., and Bekassy-Molnar, E., Must concentrate using membrane technology.Desalination, 2004. 162(0): p. 295-300.

56. Mínguez, S., Las resinas de intercambio de uso en enología. Revista de Enología Científica y Profesional, 2003. 32.

57. Rodriguez, D. and Smith, C. R. Reducción de acidez volátil en vinos por medio de adsorción selectiva de ácido acético de un permeato separado del vino por Osmosis Inversa. Vinovation, Inc. and Oenovation International LLC.

58. Cassano, A., Mecchia, A., and Drioli, E., Analyses of hydrodynamic resistances and operating parameters in the ultrafiltration of grape must.Journal of Food Engineering, 2008. 89(2): p. 171-177.

59. Castellanos, L. and Guindel, M. J., Nuevas técnicas de filtración de vinos por membrana, in XII Congreso Nacional de Enólogos. 2006: Sta Cruz de Tenerife.

60. Massot, A., Noilet, P., Milisic, V., and Mietton-Peuchot, M., Nanofiltration et osmose inverse en oenologie. Bulletin de l'OIV, 2008. 81(932-934): p. 531-540.

61. Mínguez, S., Nuevas posibilidades tecnológicas al alcance del enólogo, in XII Congreso Nacional de Enólogos. 2006: Sta Cruz de Tenerife.

62. K. Bui, R. Dick, G. Moulin, and Galazy, P., A Reverse Osmosis for the Production of Low Ethanol Content Wine.American Journal of Enology and Viticulture, 1986. 37(4): p. 297-300.

63. Bonnet, J. and De Vilmorin, H., Procedimiento de reducción controlada del nivel de azúcar en zumos de frutas y dispositivo para la puesta en práctica de dicho procedimiento.VASLIN BUCHER 2007 ES 2267025.

64. Ferment, E., Noilet, P., Godart, L., Weisser, M., Riou, C., and Vuchot, P. Diminution du taux d'alcool dans les vin AOC Cotes du Rhone. Comparatif de trois methodes. in 31st OIV World Congress of Vine and Wine. 6th General Assembly of the OIV. 15-20 June 2008. Verona, Italy.

65. Diban, N., Arruti, A., Barceló, A., Puxeu, M., Urtiaga, A., and Ortiz, I., Membrane dealcoholization of different wine varieties reducing aroma losses. Modeling and experimental validation. Innovative Food Science \& Emerging Technologies, 2013. 20(0): p. 259-268.

66. Varavuth, S., Jiraratananon, R., and Atchariyawut, S., Experimental study on dealcoholization of wine by osmotic distillation process. Separation and Purification Technology, 2009. 66(2): p. 313-321.

67. Liguori, L., Russo, P., Albanese, D., and Di Matteo, M., Evolution of quality parameters during red wine dealcoholization by osmotic distillation. Food Chemistry. 140(1-2): p. 68-75. 
68. Catarino, M. and Mendes, A., Dealcoholizing wine by membrane separation processes. Innovative Food Science \& Emerging Technologies, 2011. 12(3): p. 330-337.

69. Verhoef, A., Figoli, A., Leen, B., Bettens, B., Drioli, E., and Van der Bruggen, B., Performance of a nanofiltration membrane for removal of ethanol from aqueous solutions by pervaporation. Separation and Purification Technology, 2008. 60(1): p. 54-63.

70. Schaefer, A. I., Fane, A. G., and Waite, T. D., Nanofiltration: principles and applications. 2003, New York: Elsevier Advanced Technology.

71. Li, Y.-L. and Tung, K.-L., The effect of curvature of a spacer-filled channel on fluid flow in spiral-wound membrane modules. Journal of Membrane Science, 2008. 319(1-2): p. 286-297. 



\section{CAPÍTULO 2 CARACTERIZACIÓN DE MEMBRANAS. FILTRACIONES CON DISOLUCIÓN DE AZÚCAR Y MOSTO TINTO COMERCIAL.}

\section{INTRODUCCIÓN}

La aplicación de la tecnología de membranas a cualquier proceso de separación requiere disponer de una membrana adecuada que proporcione un grado aceptable de separación, alto flujo de permeado y bajo nivel de ensuciamiento. Para poder elegir la membrana adecuada para la filtración de los mostos elaborados en la próxima campaña, con el fin de obtener mostos de baja concentración de azúcar, se realizó un estudio bibliográfico de las membranas que pudiesen ser útiles para este fin. Como resultado de este estudio (ya indicamos en el capítulo anterior) se ha seleccionado una membrana de ultrafiltración $(\mathrm{GH})$ y tres de nanofiltración ( $\mathrm{HL}, \mathrm{DL}$ y $\mathrm{DK})$, todas comercializadas por GE-Osmonic.

La primera parte del trabajo consistió en caracterizar todas las membranas, determinando de esta forma, cuál es la que tiene mejores propiedades para nuestro propósito.

La caracterización de las membranas se logra tras el estudio de la constitución, estructura y comportamiento funcional de la misma, por medio de métodos y técnicas adecuadas. Es necesario conocer el mayor número de parámetros posibles para relacionarlos con su funcionamiento en condiciones experimentales similares a la aplicación de dicha membrana.

Los parámetros de caracterización se dividen en tres grupos: físico-químico, estructurales y funcionales [1]:

a) Caracterización físico-química: se analiza la membrana para conocer los materiales o los compuestos que forman parte de ella, sus características hidrofóbicas, su densidad de carga, adsorción, etc.

b) Caracterización estructural: se suelen determinar los siguientes parámetros,

- Distribución estadística de tamaños de poro.

- Morfología y tamaño medio de los poros.

- Densidad superficial y volumétrica de los poros. 
- Porosidad en volumen o fracción de volumen ocupada por los huecos.

- Rugosidad de la superficie de la membrana.

- Tortuosidad, haciendo un estudio del área ocupada en la superficie de la membrana y el volumen de los poros en el interior de la membrana, ya que, en general, los poros no son cilíndricos.

c) Caracterización funcional: Se estudian parámetros como la permeabilidad, los coeficientes de retención y difusión, las características de adsorción, o la compatibilidad física, química y mecánica de la membrana.

Para determinar todos estos parámetros se disponen de técnicas instrumentales de caracterización. Algunas de ellas son las siguientes (figura 2.1):

a) Técnicas microscópicas, entre las que podemos distinguir:

- Microscopía electrónica: Con estas técnicas, se obtienen imágenes topográficas superficiales y transversales de la membrana, a partir del estudio de los electrones reflejado o transmitidos por la muestra. De acuerdo con esto podemos hablar de microscopía electrónica de barrido (SEM) y microscopía electrónica de transmisión (TEM), respectivamente.

- Microscopía de sonda de barrido: comprende la microscopía de efecto túnel (STM) para muestras conductoras y la microscopía de fuerza atómica (AFM) para cualquier tipo de muestra. En este caso, una sonda o punta recorre la superficie de la membrana. Como resultado se obtienen imágenes topográficas con resolución a escala nanométrica. Al mismo tiempo también es posible obtener información de características eléctricas y magnéticas de la muestra a partir de los resultados de interacción entre la punta y la superficie en condiciones adecuadas. En el caso de la microscopía de fuerza atómica (AFM) además, tiene la ventaja de que no se necesita preparación previa de la muestra.

b) Técnicas de penetración de fluidos, tenemos dos grandes grupos:

- Métodos de desplazamiento de fluidos: Se mide la presión necesaria para hacer pasar un fluido a través de una membrana previamente empapada en un líquido no miscible con el anterior. Así se estima el tamaño de poro medio y la distribución de tamaño de muchas membranas. 
- Porosimetría de mercurio: En este caso se mide la presión que hay que aplicar para meter un líquido (mercurio) en el interior de los poros de una membrana seca.

c) Métodos basados en la adsorción-desorción de gas, podemos diferenciar:

- Porosimetría de adsorción-desorción: a partir de la medida del volumen de gas adsorbido/desorbido por un sólido a temperatura contante (isoterma de adsorción-desorción) en función de la presión. Permite obtener parámetros como la distribución de tamaño de poro o la superficie activa de la membrana.

- Permoporometría: Esta técnica está basada en el bloqueo controlado de los poros por condensación de vapor y medida simultánea de un flujo de gas a contracorriente a través de la membrana. El vapor escogido no debe ser muy afín al material de la membrana para evitar el hinchamiento de ésta, en el caso de las membranas orgánicas. En el transcurso de la experiencia, no debe haber una diferencia de presión hidrostática entre ambos lados de la membrana, de manera que el transporte de gas a través de ella se haga sólo por difusión. De este análisis es posible obtener información de la estructura del poro, y la distribución de tamaños de los poros de la membrana.

d) Técnicas basadas en la solidificación capilar (Termoporometría), donde conoceremos la distribución de tamaños de poro a partir del estudio de la distribución de la temperatura de fusión y solidificación de un líquido en el interior de los poros.

e) Técnicas basadas en el comportamiento funcional (Prueba de retención de solutos): permiten obtener la distribución de tamaño de poros a partir de las medidas de retención y de flujo para solutos de varios pesos moleculares y características conocidas.

f) Métodos espectroscópicos: resonancia magnética nuclear (RMN), espectroscopía de transformada de Fourier en el infrarrojo (FTIR), etc. Estas técnicas proporcionan información de la estructura molecular de la membrana y su composición química.

g) Técnicas de caracterización eléctrica: se estudian las interacciones membrana-soluto, con técnicas como la microscopía de fuerza eléctrica (EFM) 
con la que podemos obtener la distribución de cargas eléctricas sobre la superficie de la muestra.

h) Técnicas de medida de hidrofobicidad e hidrofilicidad: estos términos son muy importantes en la caracterización de las membranas, puesto que condicionan el ensuciamiento por adhesión de moléculas en su superficie. La hidrofobicidad se puede estudiar a través del ángulo de contacto entre la membrana y un fluido (mayor ángulo de contacto con agua, más hidrofóbica es la membrana) o por medidas de tensión superficial.

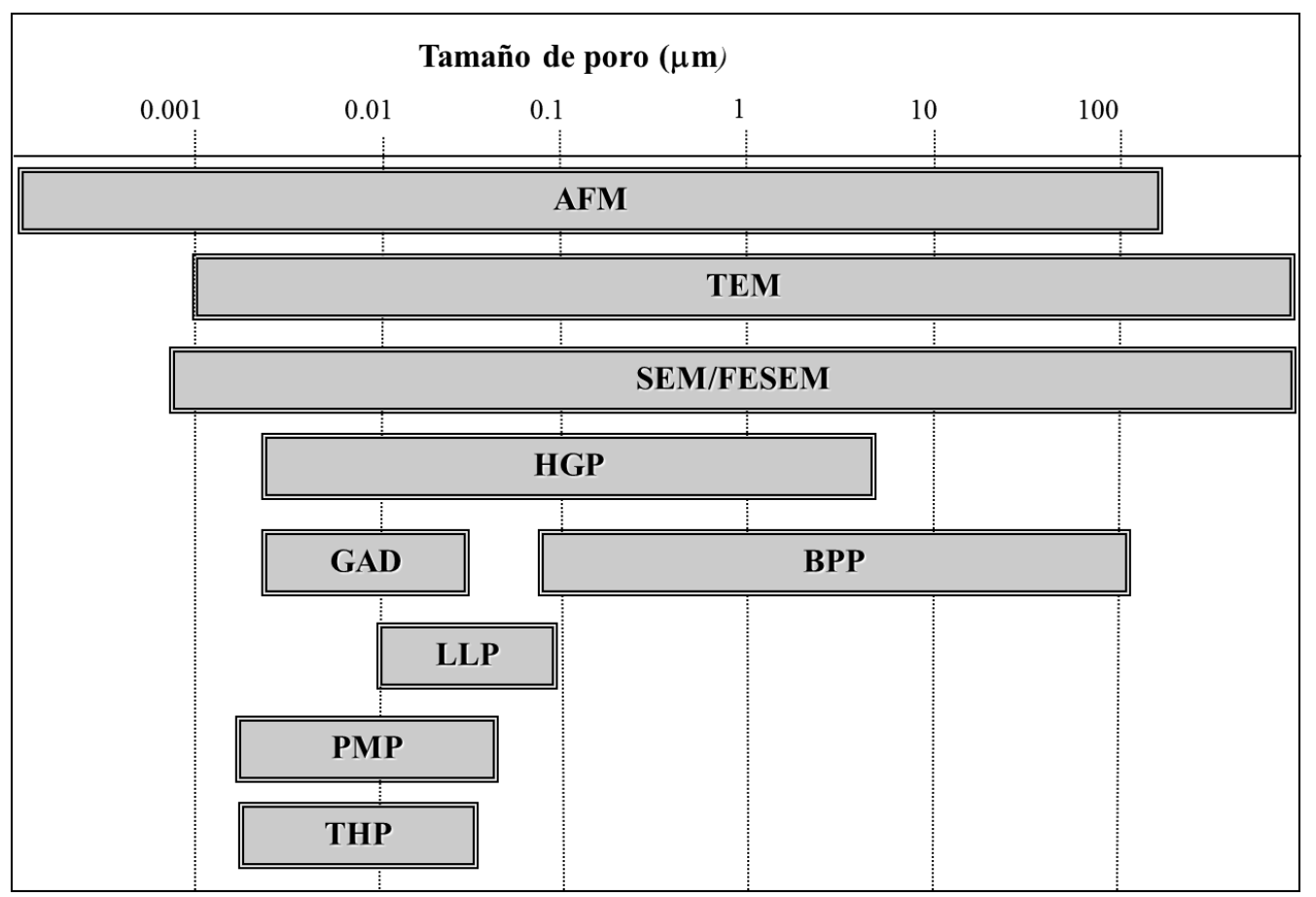

Figura 2.1 Rangos de tamaños de poro detectables según el método utilizado.

La elección de la/s técnica/s de caracterización va a venir determinada por qué parámetros o información van a ser más útiles en cada caso concreto. En este trabajo, por el tipo de aplicación que pretendemos, va a interesar más conocer parámetros funcionales tales como la permeabilidad de las membranas o la retención, por lo que nos vamos a centrar en una caracterización funcional.

Para llevar a cabo dicha caracterización, tanto de las membranas planas, como de los módulos de membrana espiral, se realizaron estudios de permeabilidad y de coeficientes de retención de cada una de ellas, utilizando polietilenglicoles (PEGs), una disolución de azúcar, y mostos tintos comerciales haciendo que estos dos últimos 
tengan una concentración similar a los mostos de uva elaborados en campañas posteriores.

\section{CARACTERIZACIÓN FUNCIONAL: TEORÍAS Y MODELOS}

Como ya se ha comentado, las membranas en nuestro caso se van a usar en la filtración de mostos de uva para la reducción de azúcar, con el fin de obtener vinos de baja graduación alcohólica.

En membranas de nanofiltración, la disolución de alimentación interacciona químicamente con la membrana. Este mecanismo de interacción, dependerá de las propiedades físico-químicas de las moléculas presentes en la disolución y del tipo de material de la membrana.

Para el estudio del transporte a través de la membrana, se determinará la permeabilidad de agua de cada una de las membranas, y se realizarán medidas de retención observada utilizando solutos no cargados. Para el estudio del transporte a través de las capas límite de las membranas, se calcularán los valores de retención verdadera.

Al filtrar una disolución, parte del ensuciamiento es reversible y parte irreversible. Ambos producen una disminución del flujo debido a la deposición de las moléculas coloidales, esto da lugar a la formación de una capa de gel en la superficie de la membrana, la adsorción o formación de cake por los coloides orgánicos y el bloqueo de los poros por las moléculas que pueden penetrar en las membranas [2].

Debido a la presencia de estos procesos, existen varios modelos de transporte, tanto para predecir el flujo a través de la membrana, como para describir cómo influyen las capas adyacentes a la membrana en el transporte de las distintas especies [3]. En nuestro trabajo se utilizarán distintos modelos para conocer, tanto el transporte a través de la membrana, como en las capas límites adyacentes a ésta.

\subsection{PERMEABILIDAD HIDRÁULICA}

El flujo en volumen de agua por unidad de área a través de la membrana, $J_{v}$, es directamente proporcional a la caída de presión, $\Delta p$, de acuerdo con la expresión:

$$
J_{v}=L_{p} \cdot \Delta p
$$

donde $L_{p}$ es la permeabilidad hidráulica de la membrana y depende de la estructura geométrica de la membrana. No obstante hay que tener en cuenta que la membrana está formada por un material polimérico cuya estructura puede ser alterada por el 
contacto con el fluido utilizado, con la temperatura, con la presión y con el tiempo sometido a esta presión durante el proceso de caracterización. Por esto es habitual estabilizar la membrana (su estructura) a la máxima presión de trabajo durante un tiempo, especificando las condiciones de estabilización de la membrana al dar los valores de permeabilidad. Después de la estabilización de la membrana se mide el flujo en función de la presión desde valores de alta a baja presión. Un comportamiento lineal de estos datos permite asegurar que la membrana está estabilizada.

Además, el ajuste lineal de $J_{v}$ frente a $\Delta p$ nos permite determinar $L_{p}$ de acuerdo con la ecuación (1). Conociendo la permeabilidad de la membrana a un determinado fluido, tenemos una idea de su capacidad para permitir que un fluido la atraviese sin alterar su estructura interna.

\subsection{RETENCIÓN DE SOLUTOS NO CARGADOS}

En las membranas de nanofiltración (NF) el proceso de separación va a venir restringido por el tamaño de poro y por la interacción de cargas entre la membrana y el soluto. En este apartado, con el fin de considerar sólo efectos de tamaño se trabajó con solutos no cargados, por lo que, la interacción entre el soluto y la membrana será principalmente de tipo estérico.

La retención observada, $R_{o}$, de una membrana se define como:

$$
R_{o}(t)=1-\frac{C_{p}}{C_{0}}
$$

donde, $C_{p}$, es la concentración de permeado y, $C_{0}$, la concentración de alimentación [2].

Este coeficiente de retención es función de las características de la propia membrana, del soluto (peso molecular, tamaño) y de las variables de operación: presión, velocidad de recirculación, temperatura, $\mathrm{pH}$, viscosidad, dispositivo experimental, agitación, etc.

Para eliminar los efectos de las variables de operación, se suele determinar un parámetro que sólo dependa de las características estructurales de la membrana y del soluto a filtrar. Este parámetro es el coeficiente de retención verdadera de la membrana, $R$.

$$
R(t)=1-\frac{C_{p}}{C_{m}}
$$


Donde, $C_{m}$, es la concentración en la superficie de la membrana. En la ecuación (3), se ha expresado una dependencia temporal del coeficiente de retención verdadera, porque a lo largo del proceso de filtración $C_{m}$ suele variar como consecuencia del proceso de concentración de la disolución.

Para conocer $C_{m}$, y con ello el valor de retención verdadera, se debe tener en cuenta el fenómeno de polarización de la concentración. Este fenómeno aparece en todos los procesos de membrana, ya que el transporte selectivo provoca una acumulación de las sustancias retenidas en la superficie adyacente de la membrana.

Para reducir este fenómeno y tener mayor eficacia en el proceso, se utilizan nuevos diseños que tratan de homogeneizar la concentración de la disolución, por agitación o por recirculación tangencial del retenido sobre la superficie de la membrana. Esto permite una menor acumulación superficial de las moléculas que no atraviesan la membrana.

Como consecuencia del fenómeno de polarización de la concentración, disminuirá la efectividad de la membrana por: reducción del flujo, disminución de la capacidad de separación y aumento del ensuciamiento en la superficie de la membrana.

Para determinar la concentración que tenemos en la superficie de la membrana en el proceso de filtración, se pueden aplicar diferentes métodos que se basan en modelos de transporte de materia a través del sistema estudiado.

En estos modelos, las propiedades del flujo dependen de las características geométricas de la membrana y de las propiedades del flujo en las capas adyacentes a la membrana, como por ejemplo: la velocidad de recirculación o la agitación del retenido, la geometría de la celda de filtración, la concentración de la disolución, la diferencia de presión entre las dos caras de la membrana, etc. Estas capas adyacentes se forman por la aparición de un gradiente de concentración debido al paso selectivo de las sustancias a través de la membrana (Capa límite de concentración), o por la formación de un gradiente de velocidad debido a la transferencia de cantidad de movimiento por el rozamiento del fluido con la superficie de la membrana (Capa límite de velocidad).

La resolución de este problema es compleja y requiere el uso de la física de fluidos. Para ello es necesaria la aplicación de las ecuaciones de transporte, las cuales se resuelven para el campo de velocidades del fluido y difusión del soluto, obteniendo una expresión con la que podemos calcular la concentración del soluto en cualquier punto de la disolución. Sin embargo, es una aproximación de difícil aplicación. 
No obstante, existen teorías mucho más simples que dan buenos resultados en la resolución de este problema. Éste es el caso de la Teoría de Película que explicamos a continuación:

\section{Teoría de Película}

Para describir la polarización por concentración, es necesario encontrar una relación entre la concentración de la alimentación, $C_{0}$ y la concentración en la superficie de la membrana $C_{m}$. Con la Teoría de película, estas concentraciones se relacionan mediante el coeficiente de transferencia de masa $K_{m}[4]$.

Para pequeñas velocidades de transferencia de masa, podemos expresar el flujo en volumen a través de la membrana, como:

$$
J_{v}=K_{m} \cdot \ln \left(\frac{C_{m}-C_{p}}{C_{o}-C_{p}}\right)
$$

Si la retención de la membrana respecto al soluto es total, el flujo a través de la membrana será exclusivamente de disolvente, por lo tanto:

$$
J_{v}=K_{m} \cdot \ln \left(\frac{C_{m}}{C_{0}}\right)
$$

El coeficiente de transferencia de masa estará relacionado con las características del flujo de retenido, tangencial a la superficie de la membrana, dependiendo del coeficiente de difusión de la disolución $D$ y del espesor de la capa de concentración $\delta_{c}$ [5], de forma:

$$
K_{m}=\left(\frac{D}{\delta_{c}}\right)
$$

Si conocemos el coeficiente de transferencia de masa del sistema, $K_{m}$, la ecuación (4) permite determinar la concentración en la superficie de la membrana, $C_{m}$, a partir de datos experimentales del flujo, $J_{v}$, la concentración de permeado, $C_{p}, y$ la concentración de retenido, $C_{0}$.

Existen varias maneras de determinar el coeficiente de transferencia de masa, dos de ellas son: la utilización de correlaciones adimensionales y la teoría de película suponiendo la existencia de un límite de flujo en el sistema. 
a) Correlaciones de números adimensionales:

Se han desarrollado una gran cantidad de correlaciones empíricas para calcular el coeficiente de transferencia de masa. Estas correlaciones vienen expresadas en función de un conjunto de números adimensionales que relacionan las variables características del sistema. Para fluidos Newtonianos la ecuación general tiene la forma:

$$
S h=A \cdot R e^{\alpha} S c^{\beta}
$$

Siendo $A, \alpha$ y $\beta$ constantes y $S h, R e$ y $S c$ los números de Sherwood, Reynolds y Schmidt respectivamente, cuyas expresiones son:

$$
\begin{aligned}
& S_{h}=\frac{K_{m} \cdot d_{h}}{D} \\
& R e=\frac{v \cdot \rho \cdot d_{h}}{\eta} \\
& S_{c}=\frac{\eta}{\rho \cdot D}
\end{aligned}
$$

El coeficiente $A$ depende de la geometría de la celda, de las condiciones de flujo y del flujo a través de la membrana, mientras que $\alpha$ y $\beta$, dependen sólo de las condiciones de flujo y del valor de Re y Sc.

El diámetro hidráulico de la membrana de la sección transversal del canal por la que circula el fluido sobre la membrana, $d_{h}$, se define como:

$$
d_{h}=4 \frac{\text { (Área transversal del caudal) }}{\text { (Perímetro mojado del caudal })}
$$

Esta ecuación se aplica para las celdas de canales de diferentes geometrías. Cuando utilizamos una celda de geometría cilíndrica agitada (stirred cell), el diámetro hidráulico se define como el radio de la celda [2].

b) Modelos que suponen un límite de flujo:

En los procesos de nanofiltración, sobre todo cuando se trabaja con disoluciones coloidales o con solutos de bajo peso molecular, a partir de un determinado valor de presión, el flujo permanece aproximadamente constante independientemente de la variación de presión; a este valor se le llama límite de flujo del proceso [2]. 
Como hemos dicho, estos modelos son una extensión de la teoría de película. Aunque se basan en la existencia de un flujo límite, las causas físicas que producen este límite pueden ser diversas. Nosotros analizaremos dos: cuando se trabaja con solutos de tipo salino (Modelo de la presión osmótica) y cuando se trabaja con solutos poliméricos o biológicos (Modelo de la capa de gel) [3].

- Modelo de la capa de gel, donde la caída de flujo se produce, además de por incremento de la concentración de las moléculas retenidas, por precipitación de éstas sobre la superficie de la membrana. Este proceso suele ocurrir cuando la concentración en la membrana debida a la polarización de la concentración excede la solubilidad de las moléculas orgánicas.

El modelo de la capa de gel se basa en el hecho de alcanzar un valor límite de flujo, el cual no aumentará aunque aumentemos el valor de la presión, ya que la capa de gel se compacta, aumentando la resistencia al transporte. El cambio en las condiciones de operación como la presión, la velocidad o la concentración de alimentación, cambiará las características de la capa de gel.

El modelo utilizado es similar al expresado anteriormente para la teoría de película, ya que lo único que varía es que en este caso la concentración en la superficie de la membrana, se sustituirá por la concentración de la capa de gel, $C_{g}$, como se muestra en la siguiente ecuación.

$$
J_{v, l i m}=K_{m} \cdot \ln \left(\frac{C_{g}-C_{p}}{C_{o}-C_{p}}\right)
$$

Si suponemos que la concentración de la capa de gel es constante, podemos conocer el coeficiente de transferencia de masa. Dependiendo de las condiciones experimentales utilizadas, podremos aplicar varios métodos:

El

Cuando expresamos la ecuación (12) en función de los coeficientes de retención verdadera y retención observada, teniendo en cuenta las ecuaciones (2) y (3), obtenemos la siguiente ecuación:

$$
\ln \left(\frac{1-R_{0}}{R_{0}}\right)=\ln \left(\frac{1-R}{R}\right)+\frac{J_{v}}{K_{m}}
$$

Cuando la ecuación (7) se aplica a un soluto determinado en un sistema determinado donde solo se varía la velocidad de circulación del retenido, el coeficiente de transferencia de masa se puede expresar como: 


$$
K_{m}=\phi^{\prime} v^{\alpha}
$$

donde $\phi^{\prime}$ es una constante para un soluto, una concentración y un sistema determinado. Introduciendo esto en la ecuación (13) obtenemos:

$$
\ln \left(\frac{1-R_{0}}{R_{0}}\right)=\ln \left(\frac{1-R}{R}\right)+\frac{J_{v}}{\emptyset^{\prime} v^{\alpha}}
$$

Como en condiciones de gelificación (limite de flujo) hemos supuesto que la concentración en la capa de gel es constante, la retención verdadera, $R$, también debe de ser constante, y además, será el valor de retención máxima, porque no podremos tener concentraciones mayores en la superficie de la membrana. En estas condiciones, medidas de retención observada y flujo para distintas velocidades de recirculación nos permiten ajustar la ecuación (15) a una recta donde: $J_{V} / v^{\alpha}$ es la variable independiente y $\ln \left(\left(1-R_{0}\right) / R_{0}\right)$ es la variable dependiente. El valor de $\alpha$ debe ser elegido en función de las condiciones de flujo del sistema. La pendiente de la recta nos da el inverso de $\phi$, que nos permite calcular $K_{m}$, para cada valor de $v$ y la ordenada nos permite determinar $R_{\max }$.

El_método de de variacción de la co conconentraçión.

Para utilizar este método se deben realizar medidas de flujo y concentración del permeado para diferentes concentraciones de alimentación, manteniendo constante la velocidad de recirculación del retenido. Si estas medidas se llevan a cabo en condiciones de gelificación, obtendremos el coeficiente de transferencia de masa como la pendiente de la representación de la siguiente ecuación:

$$
J_{v, \lim }=K_{m}\left[\ln \left(C_{g}-C_{p}\right)-\ln \left(C_{0}-C_{p}\right)\right]
$$

La retención máxima con este método se conocerá al obtener la concentración de la capa de gel en la superficie de la membrana, mediante la ordenada en el origen.

- Modelo de la presión osmótica, cuando las moléculas tratadas en un proceso de nanofiltración poseen pesos moleculares bajos (solutos salinos, azúcares, etc.), hay que considerar la presión osmótica entre las caras de la membrana, sobre todo cuando la concentración en la superficie de la membrana es alta. El 
incremento de concentración de solutos orgánicos o inorgánicos produce un aumento de la presión osmótica, que reduce la presión efectiva a través de la membrana y por tanto el flujo de permeado.

La diferencia de la presión osmótica producida por los solutos en el sistema puede calcularse de acuerdo a la siguiente ecuación:

$$
\Delta \Pi_{\text {org }}=A_{1} C+A_{2} C^{2}+A_{3} C^{3} \quad \operatorname{con} A_{i}=\frac{R_{g} T}{M_{w}}
$$

Siendo $A_{i}$ los coeficientes del virial, $R_{g}$ la constante de los gases ideales, $M_{w}$ el peso molecular de la sustancia orgánica y $T$ la temperatura absoluta de la disolución [2]. Si no se dispone de una ecuación que se ajuste a nuestro sistema, se suelen usar datos experimentales.

\subsection{DISTRIBUCIÓN DE TAMAÑO DE PORO}

Para evaluar la distribución del tamaño de poro de una membrana, podemos asumir que la retención se debe a un mecanismo de tamiz, donde para cada soluto de peso molecular determinado, hay una fracción de poros retentivos, mientras que el resto de los poros deja pasar libremente a las moléculas [6-7]. Por ello, podemos escribir el balance de masas para cada peso molecular como:

$$
J_{v} C_{p}=J_{v, t} C_{m}
$$

donde $J_{v, t}$ es el flujo en volumen de disolución transmitido a través de los poros que no retienen el soluto de este peso molecular. Si llamamos $J_{w, t}$ al flujo en volumen de agua transmitido a través de estos mismos poros, la relación entre ambos flujos se puede expresar en función del cociente de viscosidades:

$$
\frac{J_{v, t}}{J_{w, t}}=\frac{\eta\left(C_{m}\right)}{\eta(0)}
$$

donde $\eta\left(C_{m}\right)$ y $\eta(0)$ son las viscosidades de la disolución y del disolvente respectivamente [8]. Para $C_{m}$ bajas esta relación puede aproximarse a $1 \mathrm{y}$ de las ecuaciones (3), (18) y (19) puede escribirse:

$$
\begin{aligned}
& J_{w, t}=J_{v}(1-R) \\
& J_{w, r}=J_{v} R
\end{aligned}
$$

donde podremos conocer $J_{w, t}$ y $J_{w, r}$ (flujo de agua que pasa a través de los poros retentivos) a partir de $J_{v}$ para cada retención verdadera. Para conocer los flujos totales 
de soluto y de agua usamos los balances de masa que dan lugar a las siguientes ecuaciones:

$$
\begin{aligned}
& J_{s}=J_{v} C_{p} \\
& J_{w}=J_{v}-J_{s}
\end{aligned}
$$

$J_{s}$ es el flujo del soluto y $J_{w}$ es el flujo de agua total que se obtendrá mediante esta ecuación. Si representamos $J_{w, t} / J_{w}$ frente al peso molecular, $M_{w}$, o al tamaño del soluto, $r_{s}$, obtendremos la fracción acumulada del flujo que pasa a través de los poros de mayor tamaño que los del soluto. Si utilizamos varios solutos con diferentes tamaños, se obtendrá la distribución de tamaños de poro acumulada. Dado que los resultados experimentales son puntos discretos, éstos se pueden ajustar a una función continua que tenga asíntotas horizontales en 0 y en 1 para $J_{w, t} / J_{w}$. Se ha propuesto una función logicial del tipo:

$$
\frac{J_{w, t}}{J_{w}}=\frac{1}{\left[1+\left(r_{p} /<r_{p}>\right)^{C}\right]}
$$

Ya que posee una gran versatilidad para ajustarse a valores experimentales de este tipo. Donde <rp > y C son constantes evaluadas al ajustar los datos experimentales mediante la ecuación (24). El parámetro, <rp>, representa el punto de inflexión de la función, es decir el valor del máximo de la función derivada. En una distribución diferencial de probabilidad podemos asimilar este parámetro al valor más probable del radio de poro.

En el razonamiento anterior, hemos supuesto que el paso de las moléculas a través de los poros solo se ve impedida por un efecto de exclusión por tamaños, sin tener en cuenta como se realiza el transporte dentro de esos poros. Si queremos tener en cuenta, no sólo el efecto de exclusión por tamaños, sino que el transporte de soluto dentro del poro se realiza por mecanismos de convección y difusión pero impedidos por la fricción del soluto al atravesar los poros, tenemos que utilizar un modelo de transporte que dé cuenta de estos efectos. Este modelo se denomina modelo de fricción.

En dicho modelo, suponemos que los poros se orientan en la dirección $\mathrm{x}$, teniendo una longitud $\Delta x$ y un radio $r_{p}$. La ecuación de transporte (25),

$$
J s=-K_{d} \cdot D \cdot \frac{d C}{d x}+K_{c} \cdot J_{v} \cdot C
$$

relaciona el flujo del soluto no cargado con el coeficiente de difusión, $D$, el flujo en volumen, $J_{v}$, la concentración, $C$, el gradiente de concentración que tiene lugar a 
través de la membrana, $d C / d x$ y diferentes coeficientes, $K_{c}$ y $K_{d}$, que dan cuenta del efecto de fricción sobre la convección y sobre la difusión respectivamente. El coeficiente de partición para poros cilíndricos, $\phi$, que relaciona la concentración en el interior de los poros con la que se encuentra en el exterior, se define como:

$$
\phi=\frac{c_{0}}{c_{m}}=\frac{c_{\Delta x}}{c_{p}}=(1-\lambda)^{2}
$$

El coeficiente $\lambda$, se denomina factor de impedimento estérico (steric hindrance factor) y relaciona el tamaño del soluto con el del poro de la siguiente forma:

$$
\lambda=r_{s} / r_{p}
$$

Los coeficientes $K_{c}$ y $K_{d}$ relacionan las fuerzas entre las moléculas de soluto y las paredes del poro y se expresan como función de $\lambda$. De las múltiples expresiones disponibles para $K_{c}$ y $K_{d}$ las utilizadas en este trabajo han sido propuestas por Dechadilok y Deenen [9]. Éstas tienen un amplio rango de aplicabilidad y han sido utilizadas demostrando muy buenos resultados. Para poros cilíndricos:

$$
\begin{gathered}
\mathrm{K}_{\mathrm{c}}=\frac{1+3.867 \lambda-1.907 \lambda^{2}-0.834 \lambda^{3}}{1+1.867 \lambda-0.741 \lambda^{2}} \\
\mathrm{~K}_{\mathrm{d}}=\left(1+\frac{9}{8} \lambda \ln \lambda-1.5603 \lambda+0.52815 \lambda^{2}+1.9152 \lambda^{3}-2.8190 \lambda^{4}+0.27078 \lambda^{5}\right. \\
\left.+1.10115 \lambda^{6}-0.43593 \lambda^{7}\right) /(1-\lambda)^{2}
\end{gathered}
$$

Estas expresiones pueden corregirse debido a los efectos de presión, obteniendo las siguientes ecuaciones para poros cilíndricos [10]:

$$
\begin{gathered}
K_{c}^{\prime}=K c+K d \frac{16 \lambda^{2}}{9}(2-\phi) \\
K_{d}^{\prime}=K d \quad(31)
\end{gathered}
$$

Integrando la ecuación (25) desde la concentración del lado de la alimentación, $C_{m}$, hasta el lado del permeado, $C_{p}$, y usando las ecuaciones (22) y (26), se obtiene:

$$
R=1-\frac{c_{p}}{c_{m}}=1-\frac{K c \phi}{1-(1-K c \phi) e^{-P e}}
$$

Donde $P e$ es el número de adimensional de Péclet:

$$
P e=\frac{K c J v}{K d D}\left(\frac{\Delta x}{A_{k}}\right)
$$

siendo $\Delta x$ el espesor de la capa activa de la membrana y $A_{k}$ su porosidad. El ajuste de la ecuación (32) a los resultados experimentales de retención verdadera de un soluto 
determinado, permite obtener como parámetros de ajuste el radio de poro de la membrana usando la ecuación (25) y la relación espesor porosidad que aparece en la expresión del número de Péclet.

Los valores de retención se pueden relacionar con los flujos que pasan por los poros que transmiten la molécula estudiada mediante las ecuaciones (20) a (23). Los valores obtenidos de radio de poro de la membrana con cada soluto se representan frente a $\left(1-J_{w}, / J_{w}\right)$ según la ecuación (24), lo que daría lugar a la distribución de tamaño de poro de dicha membrana. Dicha ecuación relacionará el flujo de agua que pasa a través de los poros que no han sido retenidos y el flujo total de agua, respecto al radio de poro calculado para la membrana de estudio.

\section{MEDIDAS CON MEMBRANAS PLANAS}

\subsection{MATERIALES USADOS Y DISPOSITIVOS EXPERIMENTALES}

\subsection{1) Membranas}

Se ha trabajado con cuatro membranas planas fabricadas por GE Water \& Process Technologies. Una de ellas de ultrafiltración UF-GH, y tres de nanofiltración: NF-HL, NF-DK y NF-DL. Como hemos mencionado en el capítulo anterior, las membranas utilizadas son membranas de poliamida fabricadas por polimerización interfacial sobre un soporte poroso de polisulfona [11-12]. Específicamente en la bibliografía podemos encontrar que las membranas de nanofiltración ( $H L$, $D L$ y $D K$ ) son membranas de polipiperazinamida semiaromática, pero a diferencia de la membrana $\mathrm{HL}$, las membranas DL y DK están recubiertas, aunque el recubrimiento no ha sido identificado con exactitud [13-16]. Las características más importantes de estas membranas dadas por el fabricante se recogen en la tabla 2.1 .

Antes de la utilización de las membranas planas para proceder a su caracterización, se deben acondicionar con el fin de no tener variaciones de flujo a lo largo del tiempo de filtración [17], como consecuencia de las variaciones de la estructura polimérica o por penetración gradual del fluido en esta estructura. Para ello, sometemos a la membrana al flujo de agua a altas presiones, estabilizando tanto la estructura del polímero (deformación de la membrana) como la penetración del agua dentro de las estructuras porosas de menor tamaño, eliminando las posibles sustancias conservantes que pueda tener la membrana [18]. De este modo nos aseguramos que la disminución del flujo a lo largo del tiempo de filtración es debida al ensuciamiento de la membrana y no a modificaciones estructurales de la misma. 
Tabla 2.1 Características nominales de las membranas usadas.

\begin{tabular}{|c|c|c|c|c|}
\hline Membrana & UF-GH & NF-HL & NF-DL & NF-DK \\
\hline Cut- off o Retención & 2500 Dalton & $\begin{array}{c}98 \% \text { para } \\
\text { MgSO4 }\end{array}$ & $\begin{array}{c}96 \% \text { para } \\
\text { MgSO4 }\end{array}$ & $\begin{array}{c}98 \% \text { para } \\
\text { MgSO4 }\end{array}$ \\
\hline $\begin{array}{c}\text { Permeabilidad de agua } \\
\left(10^{-11} \mathrm{~m} /(\mathrm{s} \cdot \mathrm{Pa})\right)\end{array}$ & 0.911 & 2.664 & 2.117 & 1.503 \\
\hline $\begin{array}{c}\text { Presión de operación } \\
\left(10^{5} \mathrm{~Pa}\right)\end{array}$ & $5.5-9.3$ & $4.8-20.68$ & $4.8-27.6$ & $4.8-27.6$ \\
\hline $\begin{array}{c}\text { Presión máxima } \\
\left(10^{5} \mathrm{~Pa}\right)\end{array}$ & 27.60 & 41.37 & 41.37 & 41.37 \\
\hline $\begin{array}{c}\text { Temperatura máxima } \\
\left({ }^{\circ} \mathrm{C}\right)\end{array}$ & 50 & 50 & 50 & 50 \\
\hline $\mathrm{pH}$ recomendado & $2-10$ & $3-9$ & $3-10$ & $3-10$ \\
\hline pH limpieza & $1-11.5$ & $2-10.5$ & $2-10.5$ & $2-10.5$ \\
\hline Tolerancia al cloro & $\begin{array}{c}20-50 \\
(\mathrm{ppm} / \mathrm{día})\end{array}$ & $\begin{array}{c}1000 \\
(\mathrm{ppm} / \mathrm{h})\end{array}$ & $\begin{array}{c}1000 \\
(\mathrm{ppm} / \mathrm{h})\end{array}$ & $\begin{array}{c}1000 \\
(\mathrm{ppm} / \mathrm{h})\end{array}$ \\
\hline
\end{tabular}

\subsection{2) Solutos}

En este trabajo se estudiará la retención de la membrana utilizando varios solutos con pesos moleculares próximos al cut-off de las membranas (diámetro de poro de la membrana).

\section{Caracterización con PEGs}

Los polietilenglicoles (PEGs) o polioxietilenos, son poliéteres de cadena lineal formados por condensación en medio ácido de oxirano, se trata de moléculas con un alto grado de flexibilidad, por lo que puede existir rotación alrededor de todos los enlaces, aunque se produzcan impedimentos estéricos cuantificables por la energía potencial de las posibles conformaciones. Son solutos muy utilizados en caracterización de membranas, en nuestro caso se utilizará un rango de peso molecular desde $62.07 \mathrm{~g} / \mathrm{mol}$ hasta $194.23 \mathrm{~g} / \mathrm{mol}$, además gracias a las propiedades coloidales de los polietilenglicoles, se produce un ensuciamiento despreciable en la membrana [8].

Las disoluciones de PEGs utilizadas para caracterizar la membrana, son disoluciones de $1.0 \mathrm{~g} / \mathrm{L}$ de concentración, de los siguientes PEGs: etilenglicol (EG) Panreac síntesis $>99 \%$, dietilenglicol (DEG) Fluka purum $>98 \%$, trietilenglicol (TriEG) SigmaAldrich $>99 \%$ y tetratetilenglicol (TetraEG) Fluka purum> 97\%. En la tabla 2.2 se presentan algunas propiedades de interés de estos PEGs. 
Tabla 2.2 Principales características de los PEGs (densidades a 25ํㅡ).

\begin{tabular}{|c|c|c|c|c|}
\cline { 2 - 5 } \multicolumn{1}{c|}{} & EG & DEG & TriEG & TetraEG \\
\hline Fórmula molecular & $\mathrm{C}_{2} \mathrm{H}_{6} \mathrm{O}_{2}$ & $\mathrm{C}_{4} \mathrm{H}_{10} \mathrm{O}_{3}$ & $\mathrm{C}_{6} \mathrm{H}_{14} \mathrm{O}_{4}$ & $\mathrm{C}_{8} \mathrm{H}_{18} \mathrm{O}_{5}$ \\
\hline $\mathrm{M}_{\mathrm{W}}(\mathrm{g} / \mathrm{mol})$ & 62.068 & 106.120 & 150.173 & 194.226 \\
\hline Densidad $\rho\left(\mathrm{kg} / \mathrm{m}^{3}\right)$ & $1110^{1}$ & $1120^{2}$ & $1127^{2}$ & $1129^{2}$ \\
\hline & {$[19-20]$} \\
{$[21]$} &
\end{tabular}

\section{Estudios con Azúcares y mosto comercial}

La glucosa y fructosa $\left(\mathrm{C}_{6} \mathrm{H}_{12} \mathrm{O}_{6}\right)$ tienen un peso molecular de $180.16 \mathrm{~g} / \mathrm{mol}$ y la diferencia entre ellas es su estructura molecular (ver la figura 2.2).
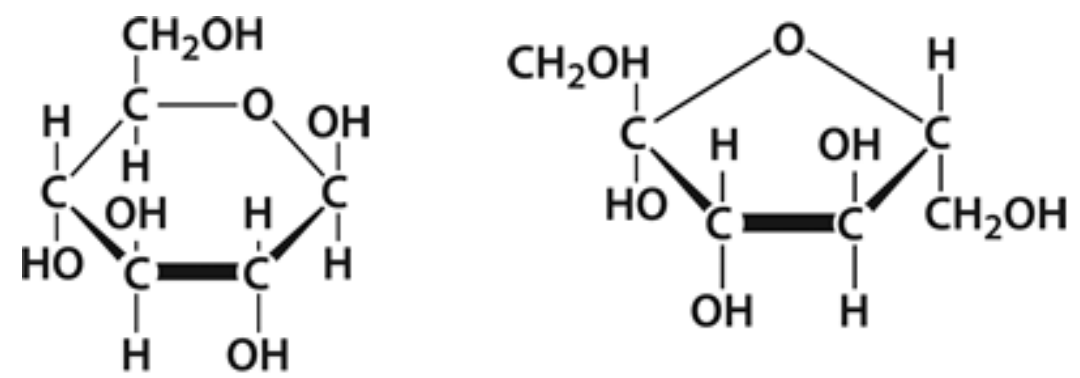

Figura 2.2 Estructura molecular de glucosa y fructosa

Las disoluciones de azúcar se prepararon como mezcla de glucosa y fructosa en la misma proporción que un mosto de uva, es decir, con una relación de glucosa/fructosa de 0.95 [22], y de la misma concentración a la del mosto de uva, aproximadamente $250 \mathrm{~g} / \mathrm{L}$; según se explicó en el capítulo anterior. En nuestro caso, se usó una concentración de $249.6 \mathrm{~g} / \mathrm{L}$.

El mosto tinto comercial utilizado es de marca GREIP®, es un zumo de uva a base de concentrado y con acidulantes para su conservación.

\subsection{3) Dispositivo experimental}

Para caracterizar nuestras membranas, se utilizarán dos equipos diferentes, dependiendo de los solutos a utilizar. Los componentes de dichos equipos se explicarán a continuación:

\section{Celda cilíndrica agitada:}

El equipo utilizado para la caracterización con PEGs se representa en las siguientes figuras: 


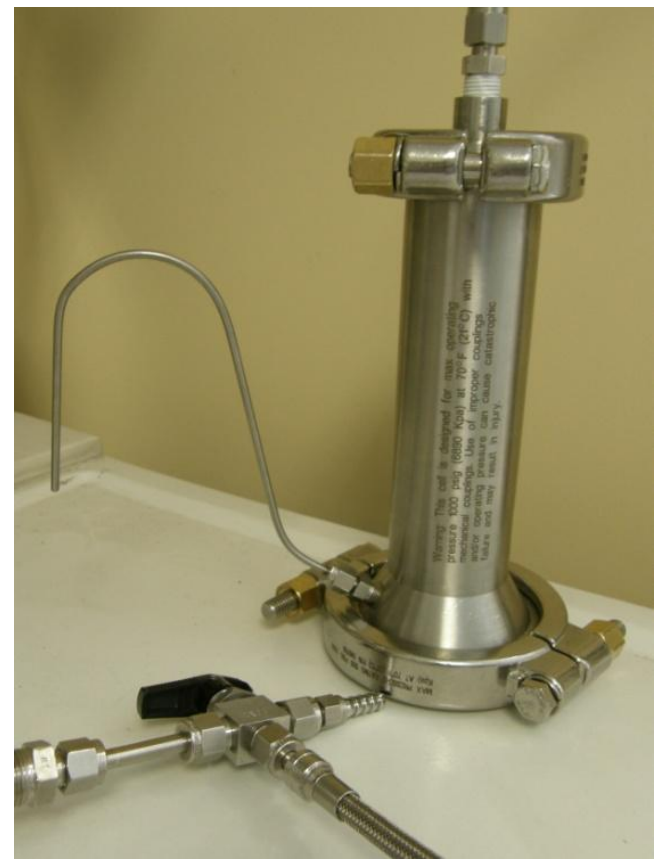

Figura 2.3 Imagen de la celda cilíndrica agitada

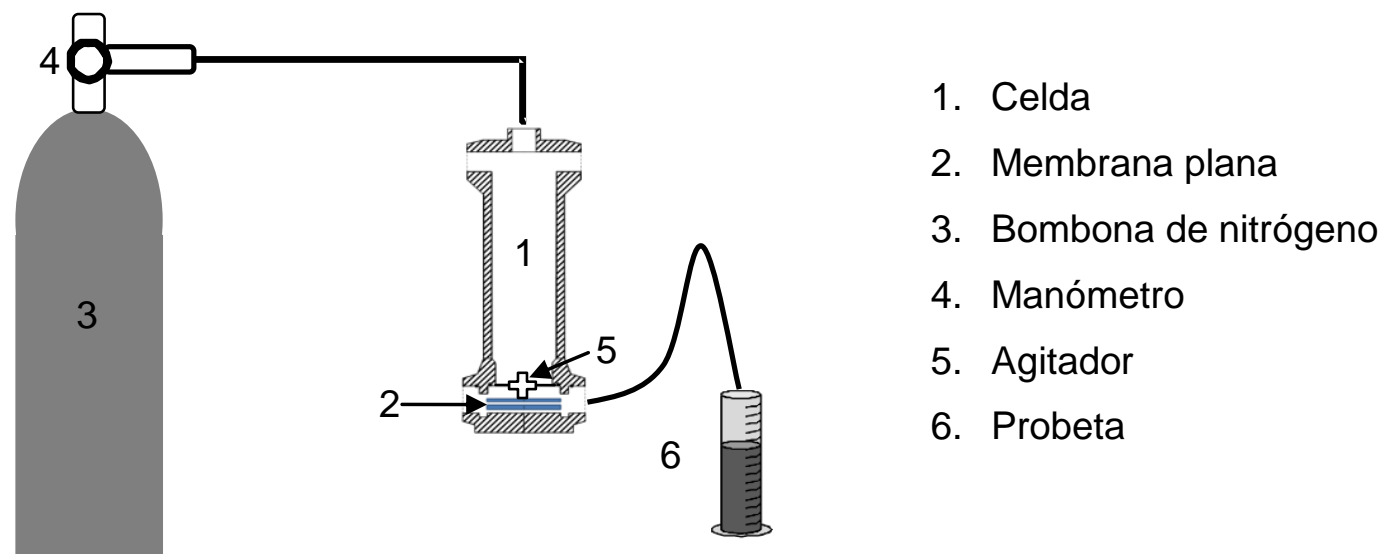

Figura 2.4 Esquema de la celda cilíndrica agitada

La celda cilíndrica agitada "Stirred Cell" (Sterlitech HP4750) (1), está construida en acero inoxidable, tiene una capacidad en volumen de $300 \mathrm{~mL}$ y es apta para la resistencia de elevadas presiones de filtración (hasta 69 bar). Las dimensiones de la celda son $5.1 \mathrm{~cm}$ de diámetro y $22.4 \mathrm{~cm}$ de altura.

La membrana plana (2) de $49 \mathrm{~mm}$ de diámetro, y $14.6 \mathrm{~cm}^{2}$ de área activa, se sitúa en la parte inferior de la celda, entre la disolución de alimentación y un disco de acero poroso que actúa como soporte. Como fuente de presión, se utiliza una bombona de 
nitrógeno (3), regulando dicha presión con el regulador Air Liquide DHP 240-50-10. EI valor de presión se mide con un manómetro ( \pm 1 bar) (4) a temperatura ambiente de $25^{\circ} \mathrm{C}$.

Dentro de la celda se encuentra un agitador magnético de teflón (5); este elemento agitará la disolución con el fin de reducir la polarización de la concentración que se produce en un proceso de filtración normal. A la salida de la celda utilizaremos una probeta (6) para conocer el flujo de permeado obtenido en la filtración.

La membrana utilizada en esta celda es la membrana plana de nanofiltración, NF-HL. Este dispositivo experimental se usó para la retención de solutos neutros con el fin de determinar la distribución de tamaños de poro de la membrana. La elección de la membrana NF-HL se basa en que de todas las membranas estudiadas para la filtración de la disolución de azúcar, ésta es la que dio mejores resultados respecto a las características de retención y flujo, y por tanto, la mejor candidata para la filtración de los mostos de uva, en cuanto a la retención de los componentes principales. Fue por tanto, la membrana que mejor deberíamos tener caracterizada para poder interpretar los resultados de nuestros estudios posteriores.

\section{Dispositivo de filtración tangencial:}

Para la caracterización de las membranas con azúcares y mosto comercial se uso un dispositivo que permite un flujo tangencial del retenido. El equipo utilizado, consta de un recipiente donde se encuentra la disolución de alimentación; una bomba (Tuthill ${ }^{\circledR}$ TXS2) y una celda de metacrilato para membranas planas. Como hemos mencionado el flujo es tangencial y discurre por un canal prismático de $110 \mathrm{~mm}$ de longitud, $60 \mathrm{~mm}$ de ancho y $0.5 \mathrm{~mm}$ de espesor [23]. Esto da un área de membrana de $6.6 \cdot 10^{-3} \mathrm{~m}^{2}$ y un área de la sección transversal al flujo de $3.0 \cdot 10^{-5} \mathrm{~m}^{2}$.

A la entrada y salida de esta celda se encuentran dos medidores de presión (P1 y P2) que van conectados a un ordenador. Este ordenador además de proporcionarnos los datos de presión, nos indica el flujo para el permeado de la filtración, ya que el permeado se recoge en un recipiente colocado sobre una balanza, que también va conectada al ordenador. El flujo del retenido se determina mediante un medidor de flujo que se encuentra después de la celda de filtración. Este equipo se muestra en la figura 2.5: 


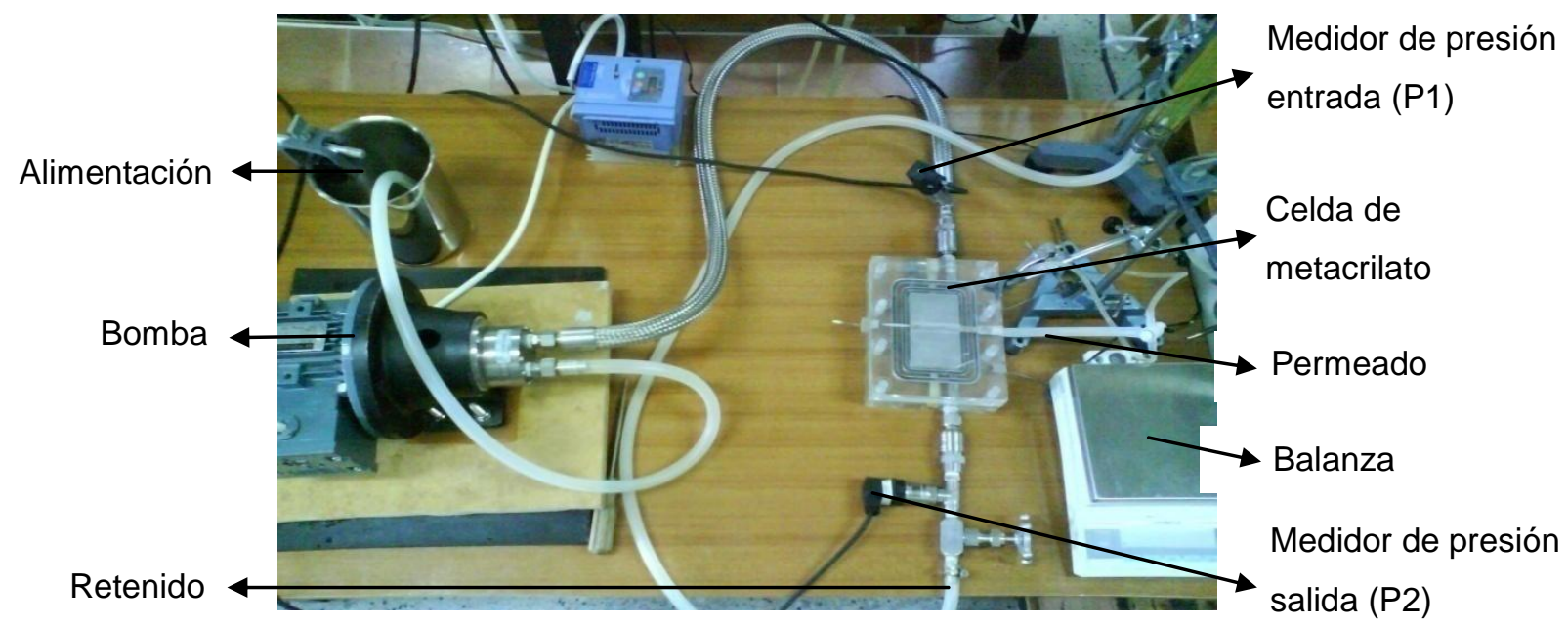

Figura 2.5 Equipo de filtración para membranas planas.

Las características experimentales son las siguientes:

a) Los transductores de presión P1 y P2, nos dan la presión relativa de entrada de la alimentación y salida del retenido en la celda de filtración, con un rango de presiones de 0-25 bar.

b) La medida de flujo de permeado se realiza, por pesada, con la balanza Sartorius modelo A $120 \mathrm{~S}$, cuyo error es $\pm 1 \times 10^{-7} \mathrm{~kg}$.

c) La presión y el flujo del sistema se controla con la variación de la velocidad de la bomba, por medio del variador de frecuencia y/o con la válvula de aguja que regula el paso de fluido a la salida de la celda. Los transductores de presión y de flujo proporcionan una salida de intensidad variable entre 4 y $20 \mathrm{~mA}$, que se relacionará con un valor de la magnitud física a determinar.

d) La variable temporal es controlada por el reloj interno del ordenador.

e) El programa de recogida de datos ha sido programado siguiendo el siguiente protocolo:

$\checkmark$ Al iniciar la toma de medidas, se comprueba que la conexión de todos los dispositivos es correcta, si no es así, el programa presenta un mensaje de "error detectado", dando la opción de corregir el error y continuar con la toma de medidas.

$\checkmark$ Cuando el sistema está conectado correctamente, aparecen unas pantallas que permiten la introducción de variables que controlarán el proceso de medida, se establece el nombre del fichero en el que se van a almacenar los datos, el intervalo de tiempo entre cada medida de presión, el rango de medida del flujo retenido, el valor del área de membrana expuesta, la 
cantidad de masa filtrada de permeado para la toma de cada valor de flujo, el \% de incremento de las medidas de flujo y finalmente la opción de imprimir los resultados.

$\checkmark$ Iniciada la toma de datos, en la pantalla se presentan los valores de la presión de entrada y salida de la celda, así como la presión media y el flujo de recirculación del retenido. Actuando sobre la velocidad de la bomba de impulsión con el variador de frecuencia y/o con la válvula de ajuste de presión de la celda, que se encuentra después del medidor de presión P2, seleccionamos el valor deseado para esta variable y finalmente activamos el proceso de medida.

$\checkmark$ Si el incremento en la masa de la balanza supera el valor programado se escriben los datos en el disco, los datos de salida son: la media aritmética y la desviación estándar de los valores de presión a la entrada $(\mathrm{kPa})$, a la salida $(\mathrm{kPa})$, valor medio de la presión entrada/salida $(\mathrm{kPa})$, flujo de retenido $(\mathrm{mL} / \mathrm{min})$ y flujo del permeado $(\mathrm{m} / \mathrm{s})$.

$\checkmark$ Para decidir si tomar otra medida de flujo o terminar el proceso se compara el último valor del flujo de permeado con el valor anterior, si esta diferencia es menor que el valor que hemos programado, la medida será estable y se finaliza el proceso, mientras que si ocurre lo contrario se hacen nuevas medidas.

En las medidas de permeabilidad el criterio de estabilidad de la membrana fue el siguiente: para una serie de valores de flujo de permeado, $J_{v}$ a una presión determinada, la diferencia entre $J_{v}(n)$ y $J_{v}(n-1)$ debe ser menor de $0.1 \%$.

$$
\frac{\mathrm{J}_{\mathrm{V}}(\mathrm{n}-1)-\mathrm{J}_{\mathrm{V}}(\mathrm{n})}{\mathrm{J}_{\mathrm{V}}(\mathrm{n})} 100<0.1
$$

La desventaja de este equipo respecto a la utilización de la celda Sterlitech es que se necesita una mayor cantidad de muestra, puesto que el volumen del circuito es mayor. Además las medidas no son tan rápidas ya que necesita un tiempo de estabilización. Por el contrario, al utilizar la celda de metacrilato se puede recircular la disolución, y el proceso es muy similar a un proceso real de separación.

\subsection{4) Métodos Analíticos}

\section{Medidas de concentración de PEGs}

Para la determinación de la concentración de los polietilenglicoles, se utiliza un refractómetro diferencial (Atago DD-5) previamente calibrado con agua milli-Q. Este 
refractómetro consta de una célula que transmite la luz y de un dispositivo fotoeléctrico que mide el ángulo de refracción entre la muestra y una muestra estándar que en nuestro caso es agua milli-Q, ya que es el disolvente de las disoluciones de PEGs medidas.

En primer lugar, se obtiene una línea de calibrado para cada PEG utilizado, es decir, obtendremos una relación de concentración de cada PEG (etilenglicol, dietilenglicol, trietilenglicol y tetraetilenglicol) con el índice de refracción, medido con una precisión de $10^{-3}$ relativo al agua. El intervalo de concentración utilizado en todas las líneas de calibrado será de 0.2 a $1.0 \mathrm{~g} / \mathrm{L}$ de PEG.

En este tipo de refractómetros la temperatura debe controlarse cuidadosamente, puesto que un aumento de la temperatura da lugar a una disminución de la densidad y la luz viajará más rápido a través de un medio de densidad más baja. Por lo tanto, el índice de refracción tiende a disminuir al aumentar la temperatura. Para solucionar este problema, se conecta un baño termostático al refractómetro para permitirnos trabajar a temperatura constante, en nuestro caso $25^{\circ} \mathrm{C}$.

El uso del refractómetro diferencial, nos permite utilizar una pequeña cantidad de muestra, aproximadamente $5 \mathrm{~cm}^{3}$, lo que es adecuado para la utilización de esta celda, ya que, partiendo de un volumen fijo en el interior de la misma, no se puede obtener mucho volumen de permeado sin alterar sustancialmente la concentración de la alimentación.

\section{Medidas de Concentración en disoluciones de azúcar y mosto comercial}

Se aplican diferentes métodos analíticos de medida de la concentración de azúcar; durante la filtración de las disoluciones se utilizará la refractometría diferencial con la disolución de azúcar, sin embargo, en la filtración del mosto tinto comercial se utiliza además del refractómetro diferencial, un refractómetro de Abbe 2WA (absoluto) ya que dará lugar a medidas menos alteradas por los sólidos solubles. Una vez que se han realizado las experiencias de filtración, las concentraciones de alimentación, de permeado y los retenidos finales se analizan en la Estación Enológica del ITACyL (Instituto Tecnológico Agrario de Castilla y León) mediante un método enzimático, que es más exacto que las medidas refractométricas. Estos serán los datos utilizados en las comparaciones finales de retención para la selección de membranas.

Los tres métodos utilizados se describen a continuación: 
- El refractómetro diferencial, es el mismo que se utiliza en la caracterización con PEGs, sólo que en este caso, se utilizarán disoluciones de glucosa y fructosa en relación gluc/fruc=0.95 [22] de forma similar al mosto de uva, para obtener la línea de calibrado que relacione la concentración frente a los índices de refracción. El intervalo de concentraciones utilizados es de 0.0997-9.968 g/Ly la temperatura de medida será de $25.8^{\circ} \mathrm{C}$.

- El refractómetro absoluto (Abbe 2WA), consta de dos prismas entre los que se coloca la muestra. La medida es proyectada en el ocular, observando dos escalas graduadas: en una de ella se miden índices de refracción entre 1.3 y 1.7, y la segunda escala muestra valores de 0 a 95 \%ISS (Escala internacional para la sacarosa). Esta última escala está relacionada con la fracción másica de azúcar que podremos relacionar con los $\mathrm{g} / \mathrm{L}$ de azúcar que tiene la muestra [24].

Las ventajas de este equipo son que la medida del índice de refracción se lleva a cabo respecto al vacío en lugar de respecto a otro medio, lo que da lugar a una menor interferencia de otros solutos en la medida. Además se necesita muy poca cantidad de muestra (una gota) y el resultado es inmediato. No obstante es menos preciso que el refractómetro diferencial, ya que da el valor absoluto del índice de refracción y no su diferencia respecto a un disolvente.

Al igual que en el refractómetro diferencial, la temperatura influye en la medida de concentración de la disolución. La medida se debe corregir a la temperatura de referencia de $20^{\circ} \mathrm{C}$, para ello el refractómetro dispone de un tubo de goma que permite hacer circular agua para mantener constante la temperatura de la montura central, dado que esta cuestión influye notablemente sobre los valores de los índices de refracción de los líquidos.

- El método enzimático realizado por la Estación Enológica del ITACyL, además de ser más exacto por no presentar interferencias con otras sustancias presentes en el mosto, puede especificar la concentración de glucosa y fructosa por separado. Esto nos permite conocer si el proceso de filtración produce una variación de la relación glucosa/fructosa. Si el método de separación es apropiado, esta variación debería ser la mínima posible, para no modificar las proporciones iniciales de los dos azúcares. 
En el caso de la filtración del mosto tinto comercial con las diferentes membranas, además de la concentración de glucosa y fructosa, se mide la presencia de otras sustancias mayoritarias en el mosto. Estos componentes serán los polifenoles totales, los antocianos, el ácido tartárico y el potasio; de este modo tendremos más datos sobre las membranas óptimas para posteriores filtraciones. Estos análisis también son realizados en la Estación Enológica del ITACyL.

Los polifenoles totales, el ácido tartárico y el potasio se analizan según los métodos de análisis de la OIV (Organización Internacional de la viña y el vino) [25], por espectrofotometría, colorimetría y absorción atómica respectivamente. En el caso de los antocianos se utiliza el método espectrofotométrico [26].

\section{2. $\underline{\text { RESULTADOS }}$}

\subsection{1) Resultados con los PEG}

a) Permeabilidad hidráulica

Antes de las medidas de permeabilidad se realizó el acondicionamiento de la membrana plana en la celda Sterlitech. Para ello, se filtra agua milli-Q a una presión de 40 bar y sin agitación durante 35 minutos, que es el tiempo necesario para el paso de los $300 \mathrm{~mL}$ de agua que contiene la celda.

Cómo indicamos anteriormente, la membrana utilizada en la filtración con la celda cilíndrica agitada fue la membrana HL. Para determinar la permeabilidad de esta membrana, se realizaron medidas de flujo a distintas presiones (10, 20, 30 y 40 bar), también sin agitación. Estas medidas se repiten cuatro veces, tomando como permeabilidad de la membrana, el valor obtenido de la representación de la última experiencia, donde la membrana estará más estabilizada; este valor es de $3.33 \cdot 10^{-11} \mathrm{~m} /(\mathrm{s} \cdot \mathrm{Pa})$.

b) Retención observada

Con el fin de evitar la influencia del ensuciamiento de la membrana, aunque en estas condiciones será mínimo, se utilizó una muestra nueva cada vez que se cambia de soluto (en nuestro caso polietilenglicol), acondicionando la membrana como explicamos anteriormente.

El proceso de medida con cada PEG se realizó a cuatro presiones (10, 20, 30 y 40 bar) y a 5 velocidades de agitación diferentes para cada presión $(6.28,31.42,73.30$, 115.19 y $167.55 \mathrm{rad} / \mathrm{s})$. De este modo se podrá conocer la concentración en la 
superficie de la membrana utilizando los modelos de transporte explicados anteriormente. En concreto, se aplicará el método de la variación de la velocidad en condiciones de límite de flujo.

Teniendo en cuenta que la celda de filtración Sterlitech sólo puede contener un volumen de disolución de alimentación de $300 \mathrm{~mL}$, lo que se realiza en primer lugar es un estudio de estabilidad de la membrana en la filtración, de este modo se conoce el volumen necesario de permeado que se debe desechar, hasta conseguir una concentración de permeado constante. Para llevar a cabo este estudio, se realizaron medidas de concentración cada $5 \mathrm{~mL}$ de permeado a diferentes presiones $(10,20,30$ y 40 bar), utilizando la velocidad de agitación más alta de nuestro estudio, 167.55 $\mathrm{rad} / \mathrm{s}$. Los resultados obtenidos muestran que, para las dos presiones inferiores se deberían desechar los primeros $50 \mathrm{~mL}$ y para las dos presiones más altas hay que eliminar los primeros $70 \mathrm{~mL}$, antes de la medida de concentración de permeado.

De acuerdo con la ecuación (2), para determinar la retención observada, necesitamos conocer la concentración de permeado y alimentación a cada presión y la velocidad de agitación del proceso de filtración. Esta concentración de alimentación sería la de la celda durante la filtración en cada una de las condiciones. Como el volumen de alimentación no es constante ya que se ve incrementado a lo largo del tiempo, la retención observada se calcula utilizando la concentración de permeado una vez estabilizada la membrana y la concentración de la celda una vez terminada la experiencia.

La tendencia de los valores de la retención observada con todos los PEGs, es la siguiente:

1. Disminuye con el peso molecular. Como es lógico menor peso molecular, significa menor tamaño del soluto y menor retención.

2. Aumenta con el incremento de la velocidad de agitación. Al aumentar $\omega$, disminuye la concentración en la superficie de la membrana y por tanto la concentración del permeado.

3. Disminuye al aumentar la presión. Mayor presión significa mayor acumulación en la superficie y por tanto mayor concentración de permeado.

En la figura 2.6, se presenta la variación de la retención observada con la presión para distintas velocidades de agitación con tetraetilenglicol como ejemplo. En la figura 2.7, se presenta la variación de la retención observada con la velocidad de agitación para distintas presiones, tomando también el tetraetilenglicol como ejemplo. 


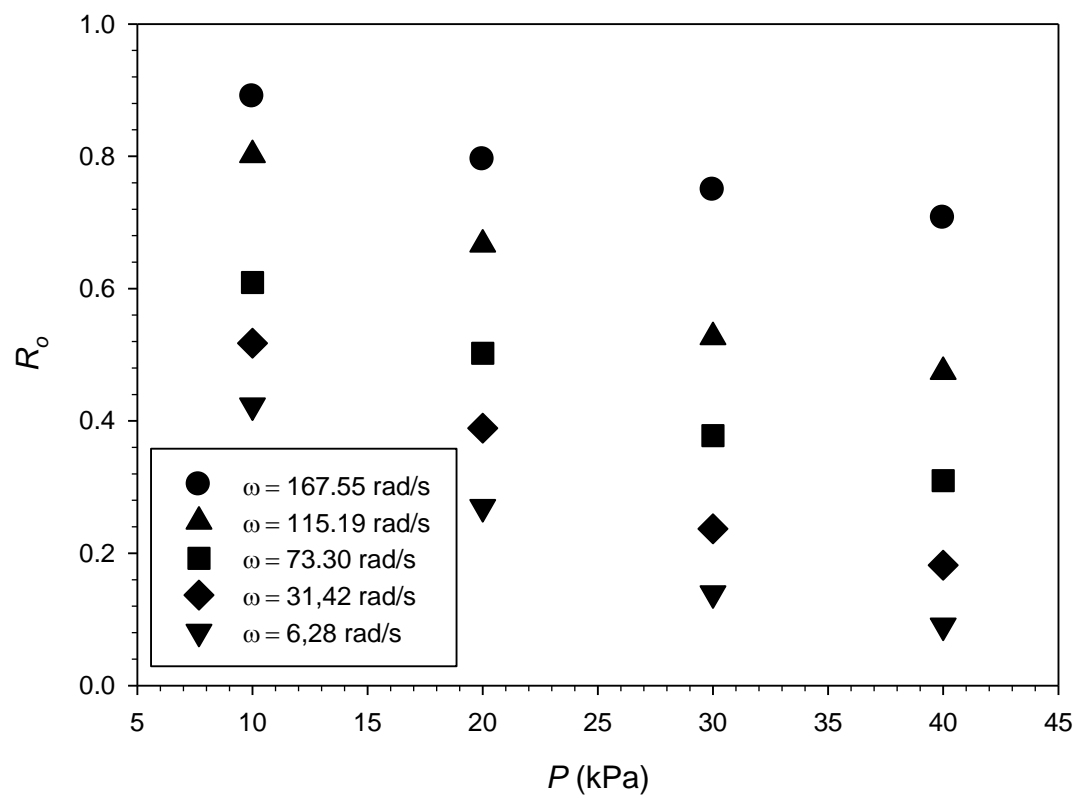

Figura 2.6 Retención observada frente a la presión a distintas velocidades.

Tetraetilenglicol con la membrana plana HL en la celda Sterlitech.

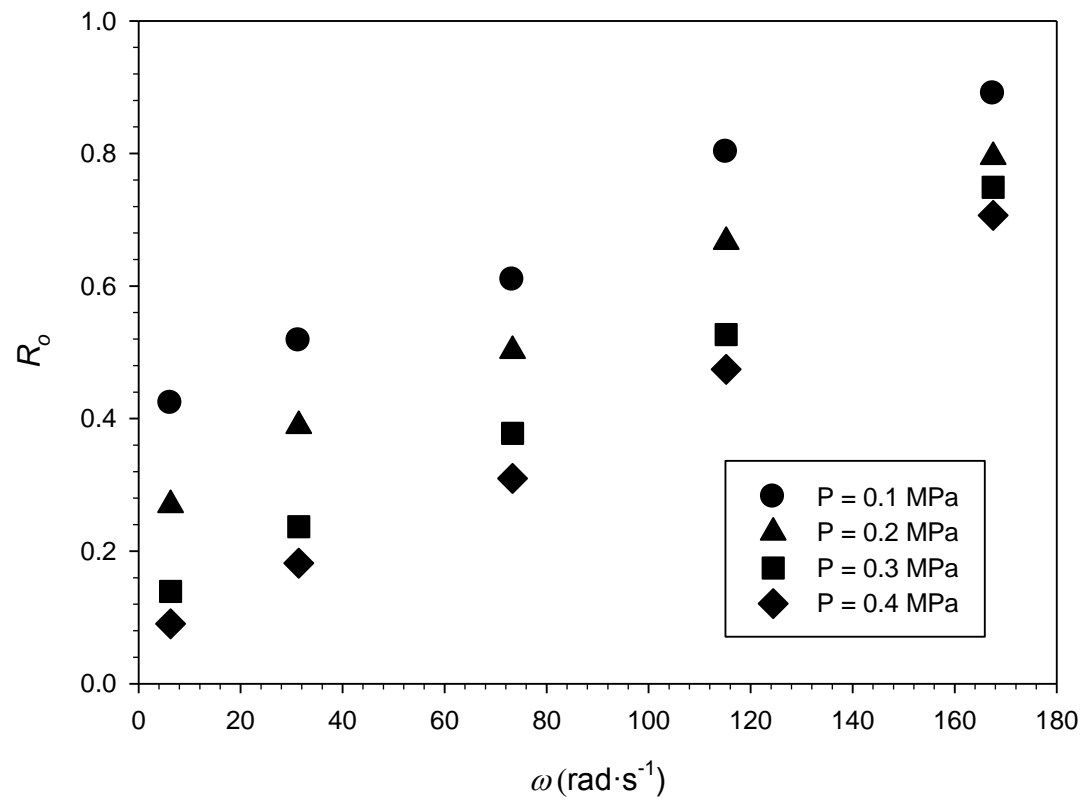

Figura 2.7 Retención observada frente a la velocidad de agitación para distintas presiones. Tetraetilenglicol con la membrana plana HL en la celda Sterlitech

En la figura 2.8 se presentan los valores de retención observada para todos los PEGs a la mayor presión aplicada, 40 bar en el caso de todos los PEG excepto el EG, en el que la mayor presión aplicada sería de 30 bar porque a 40 bar sólo se obtiene 
retención para la velocidad de agitación mayor ( $\omega=167.55 \mathrm{rad} / \mathrm{s})$, para el resto de velocidades la retención era cero. Se observa que en estas condiciones de presión el etilenglicol no es retenido por la membrana, $R_{0} \approx 0$. No obstante a presiones inferiores (30, 20 o 10 bar) la retención deja de ser cero. Como hemos mencionado, al aumentar el peso molecular de los solutos, tenemos una mayor retención observada.

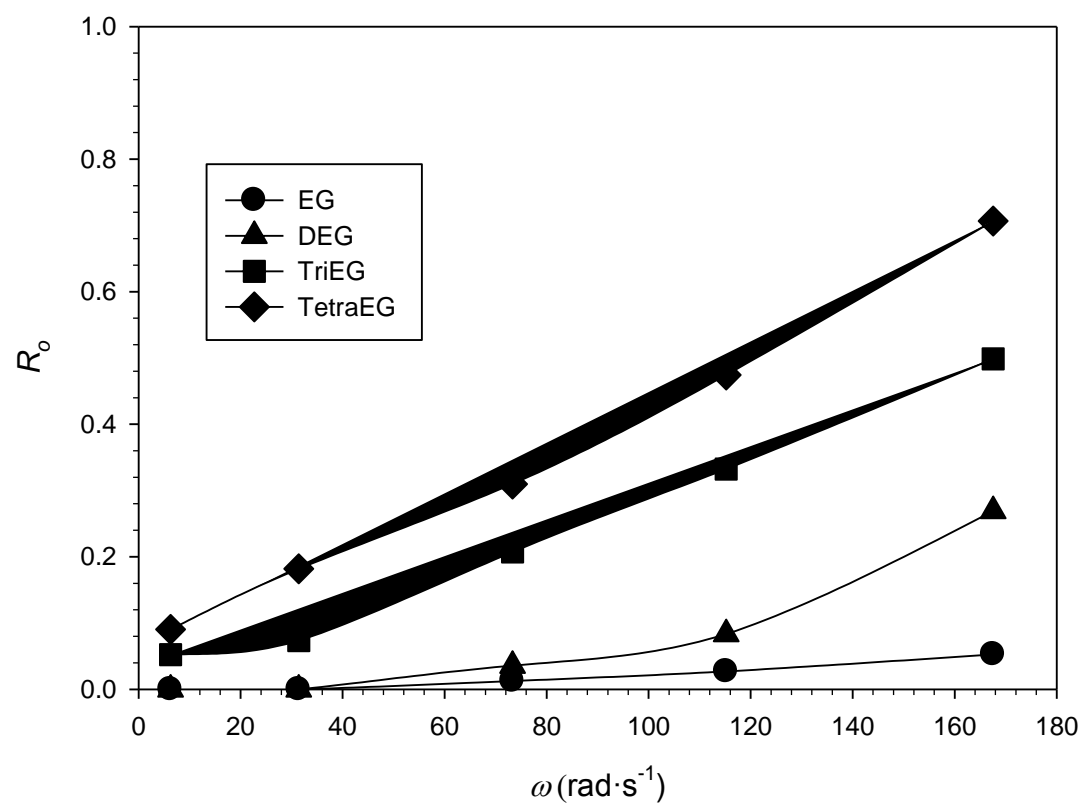

Figura 2.8 Retención observada de los PEGs respecto a la velocidad para la membrana plana $H L$ en la celda Sterlitech.

c) Retención verdadera

De acuerdo con la ecuación (3), para obtener el coeficiente de retención verdadera, $R$, de PEGs es necesario determinar la concentración en la superficie de la membrana. Como ya hemos mencionado, para ello, se utilizó el método de variación de velocidad basado en la teoría de película. El modelo supone la formación de la capa de gel para poder determinar el coeficiente de transferencia de masa, $K_{m}$, y la aplicación de la teoría de película permitirá calcular la concentración en la superficie de la membrana $C_{m}$. La aplicación de estas teorías ha sido expuesta en el apartado 2.2, aunque desarrollaremos las peculiaridades concretas al caso que nos ocupa.

En los siguientes puntos vamos a describir de forma concreta como se ha operado para la determinación del coeficiente de transferencia de masa, $K_{m}$, la concentración en la superficie de la membrana, $C_{m}$ y finalmente el coeficiente de retención verdadera, $R$ de la membrana objeto de estudio (NF-HL), en la caracterización con los PEG: 
$\checkmark$ Primero hay que considerar que con el rango de velocidades utilizado (6.28 $167.55 \mathrm{rad} / \mathrm{s}$ ), podemos distinguir diferentes tipos de flujo, caracterizados por el valor del número de Reynolds. Cuando la velocidad de fluido es baja, suponemos que el líquido se desplaza como capas que se deslizan entre sí, donde la velocidad de fluido en direcciones perpendiculares a su desplazamiento se considera despreciable, pudiendo hablar de Régimen Laminar, que viene caracterizado por números de Reynolds entre 8000 y 32000 [2]. Si la velocidad de flujo es mayor se forman remolinos, y hay transferencia de masa en direcciones perpendiculares al flujo, por lo que se utilizará Régimen Turbulento, esto se produce si tenemos números de 32000 $<\operatorname{Re}<82000$ [2]. En nuestro caso, tenemos transición entre régimen laminar y turbulento, en las dos primeras velocidades utilizadas y régimen turbulento cuando utilizamos las tres velocidades más altas.

$\checkmark$ Se aplica el método de variación de la velocidad (ecuaciones (14) y (15)) para determinar $K_{m}$. Como hemos mencionado, con la ordenada en el origen de esa misma representación, obtendremos la retención máxima de la membrana de estudio. Para aplicar este modelo, se utilizarán las tres velocidades más altas que se corresponden a un flujo turbulento, ya que las dos velocidades inferiores se encuentran en el estado de transición entre el régimen laminar y turbulento, y por tanto tendrán distinto valor de $\alpha$ en la ecuación (15).

$\checkmark$ Para aplicar la ecuación (7) en nuestra celda de geometría cilíndrica agitada, las expresiones de Sherwood, Reynolds y Schmidt (ecuaciones (8) a (10)) toman la siguiente forma:

$$
\begin{aligned}
& S_{h}=\frac{K_{m} \cdot r_{s c}}{D} \\
& \operatorname{Re}=\frac{\rho \cdot \omega \cdot r_{s c}^{2}}{\eta} \\
& S_{c}=\frac{\eta}{\rho \cdot D}
\end{aligned}
$$

siendo $\omega$ la velocidad angular media del fluido y $r_{s c}$ diámetro hidráulico de la celda definido como el radio de la celda en este caso. 
Los coeficientes de difusión, $D$, serán los de los solutos de nuestro estudio (EG, DEG, TriEG y TetraEG), es decir, los coeficientes de difusión de los PEGs utilizados. Estos valores se obtuvieron del modelo de Snijder, utilizado por Wang et al. [27] en medidas de los coeficientes de difusión para disoluciones acuosas, a diferentes concentraciones y temperaturas:

$$
\ln \left(D_{12}\right)=A_{1}+A_{2} / T+A_{3} C
$$

Para conocer el coeficiente de difusión a dilución infinita de los glicoles, tomamos $C\left(\mathrm{kmol} \cdot \mathrm{m}^{-3}\right)=0$ y $T=298.15 \mathrm{~K}$. Los valores de $\mathrm{A} 1$ y $\mathrm{A} 2$ aparecen descritos por Snijder et al. [27].

Hay varios autores que han calculado los coeficientes de difusión mediante diferentes ecuaciones, en la siguiente tabla indicaremos algunos de ellos, junto con los valores utilizados en este trabajo (ecuación (38)):

Tabla 2.3 Coeficientes de difusión a dilución infinita de disoluciones acuosas de glicoles, a presión atmosférica y temperatura de $25^{\circ} \mathrm{C}$ (los datos de la primera fila corresponden a la ecuación (38)).

\begin{tabular}{|c|c|c|c|c|}
\hline \multicolumn{5}{|c|}{$D_{\infty}\left(10^{-9} \mathrm{~m}^{2} \mathbf{s}^{-1}\right)$} \\
\hline Referencias & EG & DEG & TriEG & TetraEG \\
\hline$[27]$ & 1.103 & 0.874 & 0.694 & 0.592 \\
\hline$[28]$ & 1.189 & 0.8472 & 0.7367 & - \\
\hline$[29]$ & 1.160 & 0.897 & 0.762 & 0.666 \\
\hline$[30]$ & 1.135 & 0.896 & 0.758 & 0.664 \\
\hline
\end{tabular}

Además de para el cálculo del número de Schmidt, los coeficientes de difusión se utilizarán para evaluar el radio de los solutos según la ecuación de StokesEinsten:

$$
\mathrm{D}=\frac{\mathrm{kT}}{6 \pi \eta \mathrm{r}_{\text {Stokes }}}
$$

Donde $k$ es la constante de Boltzmann, $T$ la temperatura absoluta, $\eta$ la viscosidad $\left(\eta 25^{\circ} \mathrm{C}=0.890 \mathrm{mPa} \cdot \mathrm{s}\right.$ [21]) y $r$ el radio del soluto (normalmente denominado radio de Stokes, $\left.r_{\text {stokes }}\right)$. Los valores del radio de Stokes, junto con las difusividades usadas para su cálculo (ecuación (38)) se recogen en la tabla 2.4 . 
Tabla 2.4 Difusividades y radios de Stokes de los PEGs utilizados.

\begin{tabular}{|c|c|c|c|c|}
\cline { 2 - 5 } \multicolumn{1}{c|}{} & EG & DEG & TriEG & TetraEG \\
\hline$D_{\infty}\left(10^{-9} \mathrm{~m}^{2} \mathrm{~s}^{-1}\right)$ & 1.103 & 0.874 & 0.694 & 0.592 \\
\hline$r_{\text {Stokes }}(\mathrm{nm})$ & 0.222 & 0.281 & 0.354 & 0.414 \\
\hline
\end{tabular}

$\checkmark$ Para conocer la expresión de $K_{m}$ con nuestro sistema, se sustituyen los números adimensionales (ecuaciones (35) - (37)) en la ecuación (7).

$$
K_{m}=A r_{s c}^{2 \alpha-1} \rho^{\alpha-\beta} \eta^{\beta-\alpha} D_{\infty}^{1-\beta} \omega^{\alpha}=A^{\prime} \rho^{\alpha-\beta} \eta^{\beta-\alpha} D_{\infty}^{1-\beta} \omega^{\alpha}=A^{\prime \prime} D_{\infty}^{1-\beta} \omega^{\alpha}=A^{\prime \prime \prime} \omega^{\alpha}
$$

El parámetro $A^{\prime}$ depende de la constante A y de la geometría de la celda. $A^{\prime \prime}$ incluye la viscosidad y la densidad del líquido. Como ya indicamos anteriormente, debido a la baja concentración de las disoluciones usadas en estas experiencias, podemos suponer que los valores de la viscosidad y la densidad de las disoluciones son similares a los del agua pura $\left(\eta 25^{\circ} \mathrm{C}=0.890\right.$ $\mathrm{mPa} \cdot \mathrm{s}$, y $\rho=997 \mathrm{Kg} / \mathrm{m}^{3}$ ) [21]. A"' depende de todos los parámetros citados anteriormente, además del coeficiente de difusión a dilución infinita. Por lo tanto, el coeficiente de transferencia de masa será proporcional a $\omega^{\alpha}$ de forma similar a como se expresó en la ecuación (14).

$\checkmark$ Un análisis bibliográfico para celdas del tipo de las utilizadas en este apartado en régimen turbulento proponen correlaciones de números adimensionales del tipo [2]:

$$
\mathrm{Sh}=\mathrm{A} \cdot \mathrm{Re}^{0.75} \mathrm{Sc}^{1 / 3}
$$

Donde encontramos los valores de $\alpha$ y $\beta$ que habría que utilizar en la ecuación (40). Sustituyendo la ecuación (40) en la ecuación (13), tendremos:

$$
\ln \left(\frac{1-\mathrm{R}_{0}}{\mathrm{R}_{0}}\right)=\ln \left(\frac{1-\mathrm{R}}{\mathrm{R}}\right)+\frac{1}{\mathrm{~A}^{\prime \prime \prime}}\left(\frac{\mathrm{J}_{\mathrm{V}}}{\omega^{\alpha}}\right)
$$

Esta expresión relaciona linealmente los valores experimentales de la retención observada con $J_{v} / \omega^{\alpha}$. Cuando $J_{v}$ aumenta, la retención verdadera también lo hace hasta que alcanza un valor estable llamado retención máxima. Utilizando los valores experimentales de mayor flujo (mayor presión aplicada), podremos calcular $A^{\prime \prime \prime}$ como la inversa de la pendiente y valor de $R_{\max }$ de la membrana a 
partir de la ordenada en el origen, para cada soluto. En la figura 2.9 se representa este ajuste.

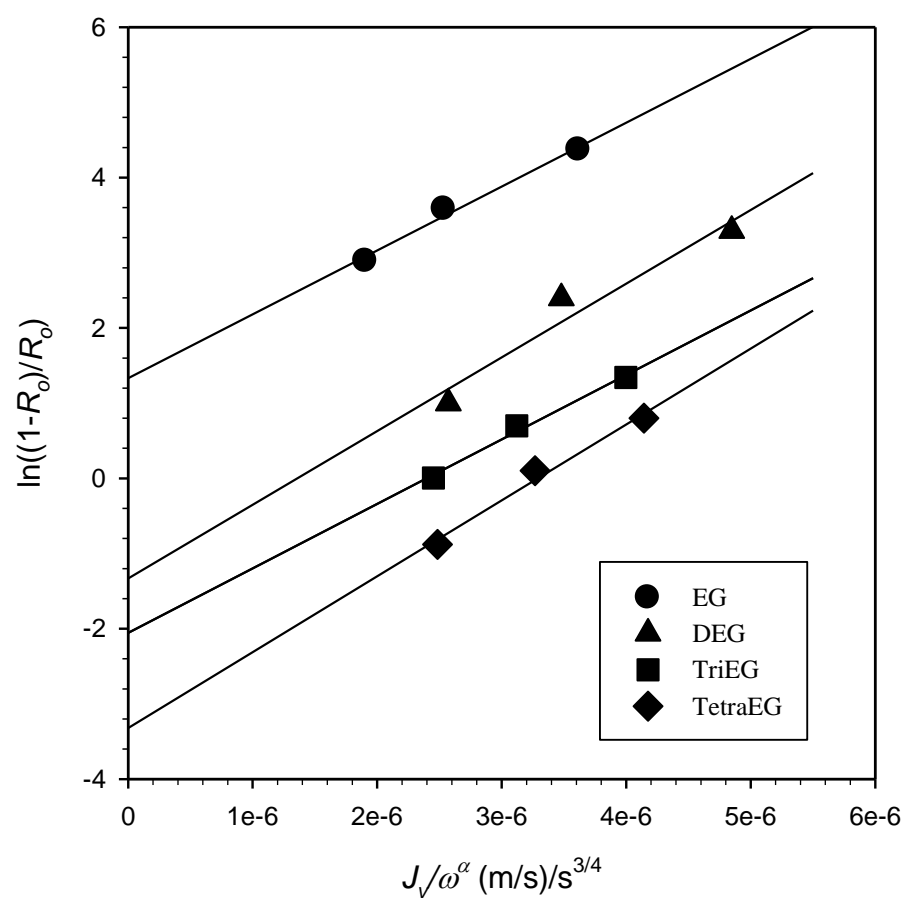

Figura 2.9 Datos experimentales de $\ln \left(\left(1-R_{0}\right) / R_{0}\right)$ frente $J_{v} / \omega^{\alpha}$. ( $\longrightarrow$ Ajuste lineal de la ecuación (42).

Se obtiene un coeficiente $A^{\prime \prime}$ para cada soluto. Con el coeficiente de difusión obtenemos el valor $A^{\prime \prime}$ que consideramos común a todos los solutos, ya que suponemos que la densidad y la viscosidad de la disolución no dependen del tipo de soluto. Con las propiedades de la disolución y las que definen la variable geométrica determinamos $A$, que sólo depende de la geometría de la celda y del régimen de flujo (obviados los efectos de succión). En cualquier caso con la expresión de la ecuación (40) podemos determinar el coeficiente de transferencia de masa, $K_{m}$, para un soluto y una velocidad de agitación determinados.

$\checkmark$ Con los valores obtenidos de dichos coeficientes de transferencia de masa, se puede calcular la concentración en la superficie de la membrana despejando, $C_{m}$ en la ecuación (4), para cada terna de datos experimentales: $C_{p}, C_{0}$ y $J_{V}$ :

$$
\mathrm{Cm}=\mathrm{Cp}+(\mathrm{Co}-\mathrm{Cp}) \mathrm{e}^{\mathrm{J}_{\mathrm{v}} / \mathrm{K}_{\mathrm{m}}}
$$


Finalmente, podremos conocer las retenciones verdaderas correspondientes a la ecuación (3).

En la figura 2.10 se representan las retenciones verdaderas en función de la presión, para la máxima velocidad de agitación y el valor de retención máxima.

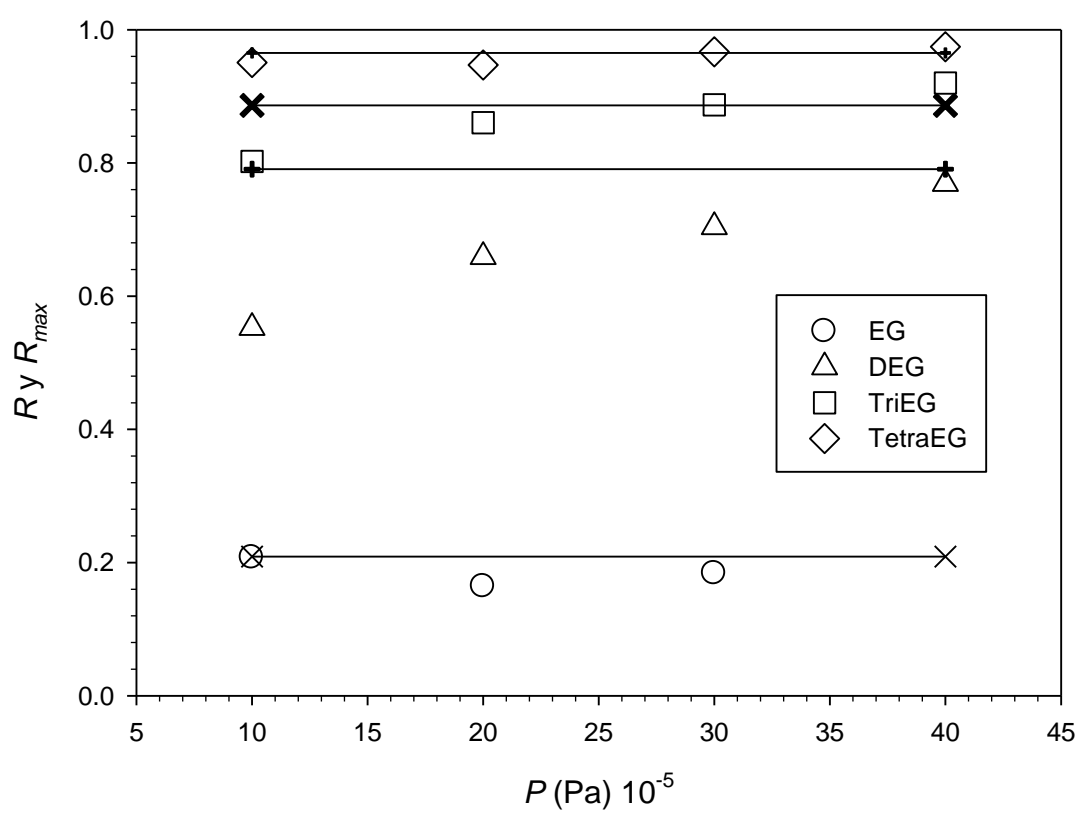

Figura 2.10 Retenciones verdaderas (símbolos) y máximas (líneas) de los PEGs respecto a la presión, para la membrana plana HL en la celda Sterlitech.

En la figura 2.11 se representan las retenciones verdaderas en función de la velocidad de agitación para la máxima presión de trabajo y el valor de retención máxima. La tendencia esperada sería que al aumentar la velocidad, la retención verdadera tiende a la retención máxima. No obstante el error experimental enmascara algo este comportamiento. Se observa de forma clara en las retenciones bajas donde la diferencia entre $R$ y $R_{\max }$ es más acusada, mientras que para retenciones próximas a uno, ambos valores son muy similares.

De acuerdo con lo expuesto, si retomamos la ecuación (3) podemos observar que:

1. Al aumentar la diferencia de presión a través de la membrana, aumentará el flujo de permeado. Esto da lugar a un aumento en la concentración de la superficie de la membrana $C_{m}$ y por lo tanto un aumento de la concentración de permeado, $C_{p}$, que deriva en una disminución de la retención observada, $R_{o}$, como vimos en la figura 2.6. Es más difícil determinar el comportamiento de la retención verdadera, ya que depende 
del balance entre el transporte difusivo y el convectivo. Un análisis detallado de las ecuaciones de transporte sobre y a través de la membrana predice un aumento de la importancia del transporte convectivo con la presión que se traduce en una disminución del cociente $C_{p} / C_{m}$ [31]. Esto supone el aumento de $R$ con $\Delta P$ que se observa como tendencia general en la figura 2.10. Los errores experimentales magnificados a valores de concentraciones de permeado pequeñas enmascaran este comportamiento para valores de $R$ próximo a cero.

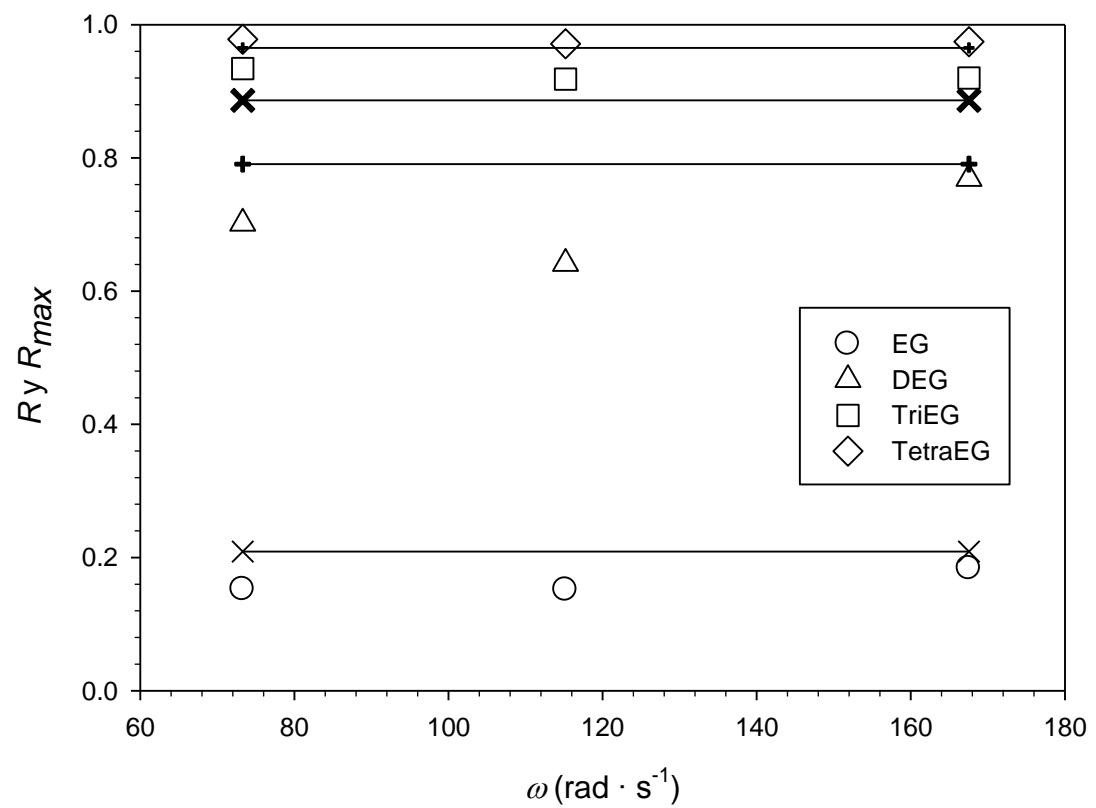

Figura 2.11 Retenciones verdaderas (símbolos) y máximas (líneas)

de los PEGs respecto a la velocidad de agitación, para una presión

$$
P=40 \text { bar. }
$$

2. El coeficiente de retención observada y verdadera aumentan con la velocidad de agitación del retenido (figuras 2.7 y 2.11). No obstante, la retención verdadera se mantiene casi constante debido a que $K_{m}$ aumenta con $\omega$ de acuerdo con la ecuación (40) haciendo disminuir $C_{m}$ y por consiguiente $C_{p}$ en la misma proporción.

3. El aumento del coeficiente de retención verdadera y observada con el peso molecular del soluto, se produce por la dificultad de paso de solutos mayores a través de la membrana (figuras $2.8,2.10$ y 2.11). 
En la figura 2.12 se representan los datos del coeficiente de retención verdadera junto con el comportamiento predicho por el modelo y los valores de $R_{\max }$. Excepto para los valores de menor retención (EG), donde los errores experimentales son grandes porque requieren medidas de retención muy pequeñas, el ajuste del modelo predice bien los datos experimentales y tiende al valor de retención máxima para valores de flujo altos.

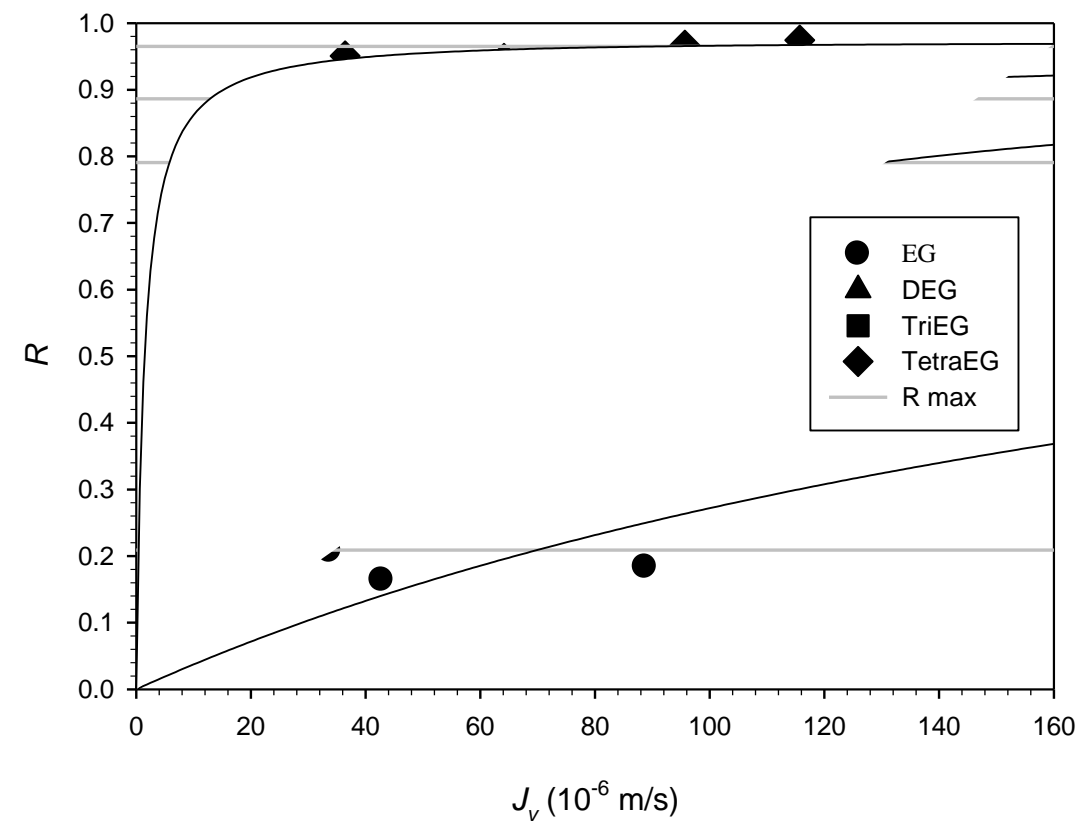

Figura 2.12 Retención verdadera en función de $J_{v}$. Las líneas sólidas negras, representan el comportamiento teórico usando el radio de poro ajustado. Las líneas solidas grises representan el coeficiente de retención máxima para cada soluto.

La utilización del modelo de transporte de materia a través de los poros representado por la ecuación (32), junto con la teoría de película (ecuación (13)), permite predecir los valores de retención observada a partir de las distribuciones de retención verdadera obtenidas, de esta forma comprobaremos la bondad del modelo. En las figuras 2.13.a y b, se representan dos ejemplos de valores de retención observada junto con el ajuste dado por el modelo. La línea de trazos de la figura 2.13.a representa el valor máximo que el modelo predice para el coeficiente de retención observado para esas condiciones de medida. 

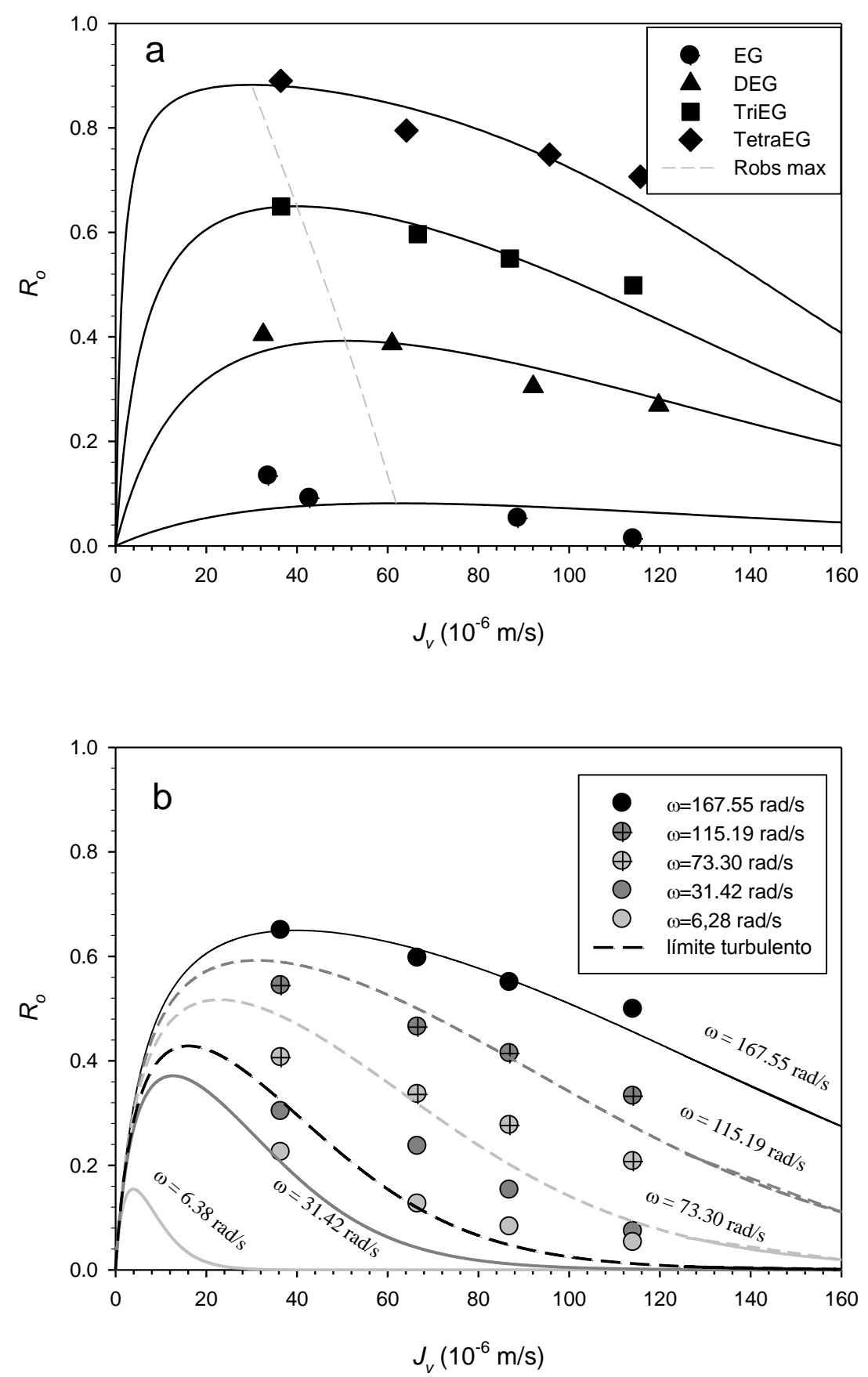

Figura 2.13 Retención observada frente a $J_{v}$. a) Para $\omega=167.55 \mathrm{rad} / \mathrm{s}$. Símbolos para los valores experimentales y línea sólida para el comportamiento teórico usando el radio de poro calculado con el modelo. b) Ejemplo del TriEG a diferentes velocidades de agitación y representación del límite turbulento.

En la figura 2.13.b se observa un mejor ajuste para los datos obtenidos en régimen turbulento (valores por encima de la curva de trazos). Esto es esperable ya que los datos del coeficiente de transferencia de masa se han obtenido en régimen turbulento. 
d) Distribución de tamaños

Con los resultados de retención máxima y el modelo expuesto en el apartado 2.3 para el cálculo de la distribución de tamaños obtenemos las variables que permiten el ajuste de la ecuación (24). Estas variables se recogen en la tabla 2.5.

Tabla 2.5 Radio de poro obtenido para cada PEG frente a $\left(1-J_{w, t} / J_{w}\right)$ para la membrana.

\begin{tabular}{|c|c|c|}
\cline { 2 - 3 } \multicolumn{1}{c|}{} & $\boldsymbol{r}_{\boldsymbol{p}}(\mathbf{m})$ & $\left(\mathbf{1}-\boldsymbol{J}_{w, t} / \boldsymbol{J}_{w}\right)$ \\
\hline Etilenglicol & $3.4090 \mathrm{E}-10$ & 0.1829 \\
\hline Dietilenglicol & $3.6842 \mathrm{E}-10$ & 0.7687 \\
\hline Trietilenglicol & $4.4809 \mathrm{E}-10$ & 0.9199 \\
\hline Tetraetilenglicol & $4.9183 \mathrm{E}-10$ & 0.9743 \\
\hline
\end{tabular}

El ajuste de los datos de la tabla 2.5 a la ecuación (24) se representa en la figura 2.14:

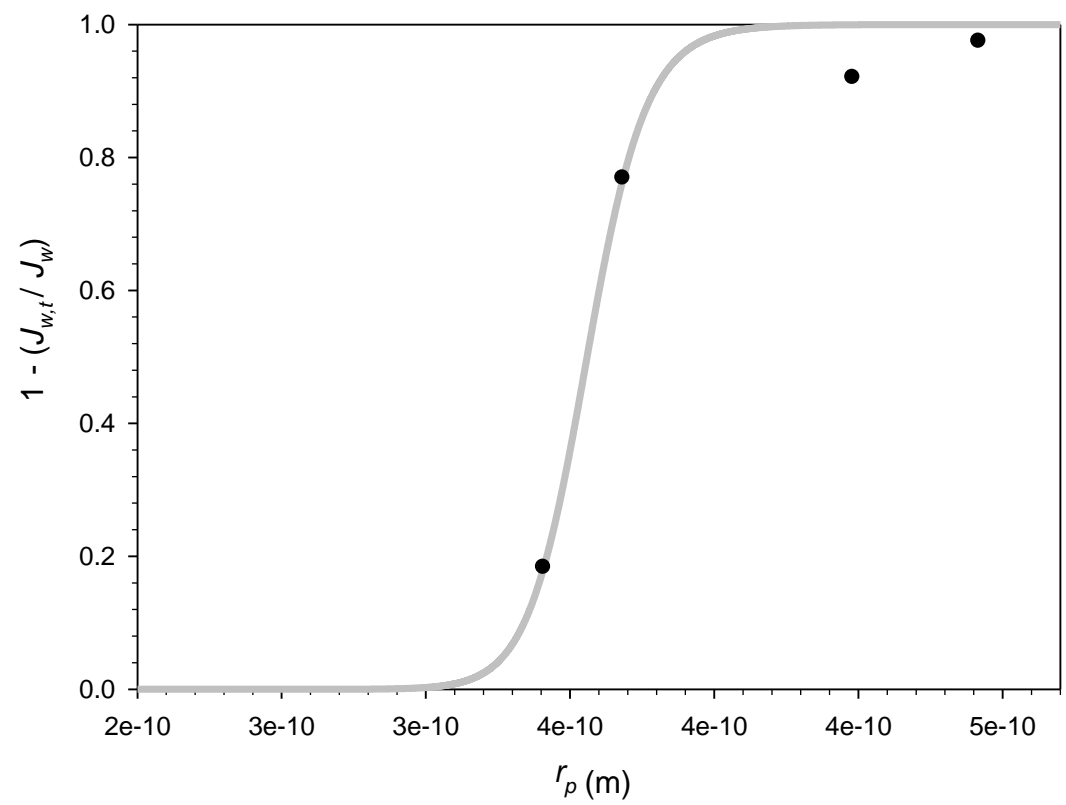

Figura 2.14 Ajuste de los datos de la tabla 2.5 a la ecuación (24).

La curva de ajuste representa la distribución acumulada de radio de poro de la membrana. Derivando de la ecuación (24) y haciendo uso de los parámetros de ajuste, podemos obtener la distribución diferencial de radios de poro de la membrana (figura 2.14). El radio de poro medio obtenido a través del ajuste es $0.3559 \pm 0.0041 \mathrm{~nm}$. Como se observa en la figura 2.15, el comportamiento se ajusta bien a una distribución 
gausiana. El ajuste a la distribución gausiana da un valor de radio de poro medio de $\mu=0.3557 \mathrm{~nm}$ y una desviación estándar de $\sigma=6.739 \cdot 10^{-5} \mathrm{~nm}$.

A continuación indicamos algunos de esos valores obtenidos por otros autores o por otras técnicas. En nuestro grupo se ha obtenido un valor de $0.54 \mathrm{~nm}$ mediante análisis de las imágenes de AFM. Hussain et al. obtuvo $0.48 \mathrm{~nm}$ filtrando glucosa a diferentes presiones [12]. Este mismo valor es el que indica Braeken, et al. en su artículo [32] como "facilitado por el fabricante" para la membrana Desal HL. Como vemos la mayor parte de los resultados dan valores cercanos al radio de poro obtenido. No obstante, hay que tener en cuenta que los valores de AFM suelen dar valores de tamaño del poro mayores que los obtenidos por otras técnicas debido a la convolución de la punta de la sonda con la superficie de la membrana. El resultado de $0.48 \mathrm{~nm}$ obtenido a partir de glucosa tampoco es discordante con el nuestro. En este caso hay que tener en cuenta que se han usado valores de retención de un solo soluto de peso molecular $180 \mathrm{~g} / \mathrm{mol}$ (glucosa). Si nosotros usamos el valor de radio de poro obtenido a partir de los datos del TetraEG (peso molecular $194.2 \mathrm{~g} / \mathrm{mol}$ ) obtenemos un valor de radio de poro: $\left\langle r_{p}\right\rangle=0.4918 \pm 0.0038 \mathrm{~nm}$.

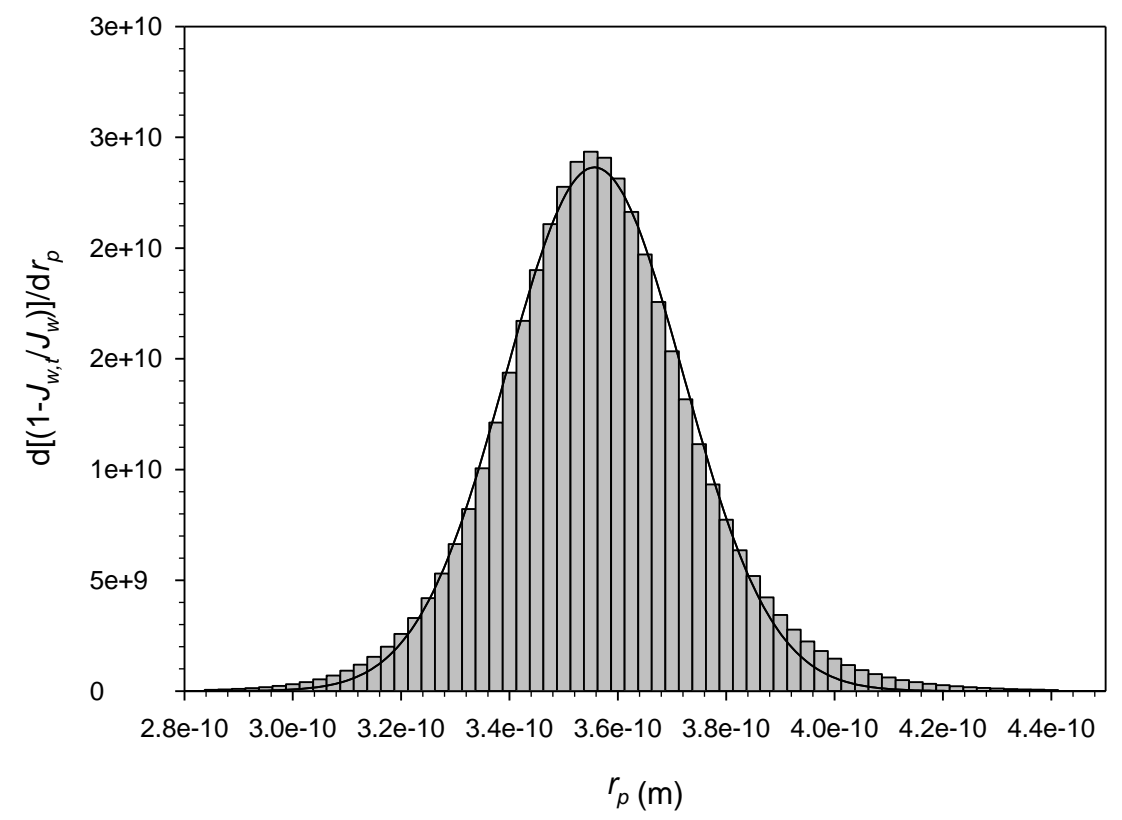

Figura 2.145 Distribución diferencial de tamaños de poro de la membrana HL. 


\subsection{2) Resultados con la disolución de azúcar}

Como hemos explicado anteriormente el objetivo del trabajo es utilizar estas membranas para la separación de azúcares en mostos. Por ello es importante estudiar el comportamiento de los azucares mayoritarios presentes en los mostos de uva con las membranas candidatas para realizar este proceso. Como hemos dicho en el apartado 3.1.2, se utilizaron como solutos glucosa y fructosa con una concentración similar a la del mosto de uva.

\section{a) Permeabilidad hidráulica}

El acondicionamiento de las membranas planas en la celda de metacrilato, se realiza pasando por ella agua milli-Q durante una hora, con un flujo de recirculación entre 3 y $6 \mathrm{~L} / \mathrm{min}$ dependiendo de la membrana. Se aplicó una presión de acondicionamiento de 15 bar para las membranas NF-GH y NF-DL y 20 bar para las membranas NF-HL y NF-DK. Después de este tiempo, la membrana adquiere un valor de flujo constante, por lo que podremos decir que la membrana se ha estabilizado.

Igual que hemos hecho para la membrana $\mathrm{HL}$ en la celda cilíndrica, la permeabilidad de la membrana se determina tomando valores de flujo a distintas presiones 1, 2, 4, 6, 8 y 10 bar en el caso de las membranas $G H$ y $D L$ y a 2, 5, 8, 10, 15 y 20 bar para las membranas $\mathrm{HL}$ y DK. Estas medidas se hacen al menos por duplicado. A continuación se muestran los datos de la última medida de cada membrana, ya que el sistema estará más estabilizado.

Estas medidas de permeabilidad se realizaron con las membranas nuevas y con las membranas después de haber sido usadas en la filtración de las disoluciones de azúcar y de haber sido lavadas con agua milli-Q. Los resultados se presentan en las tablas 2.6 y 2.7 .

Tabla 2.6 Permeabilidad de las membranas planas nuevas.

\begin{tabular}{|c|c|c|c|c|}
\hline Membrana & UF-GH & NF-HL & NF-DL & NF-DK \\
\hline$L_{p}\left(10^{-11} \mathrm{~m} /(\mathrm{Pa} \cdot \mathrm{s})\right)$ & 1.363 & 4.084 & 1.715 & 1.658 \\
\hline
\end{tabular}

Tabla 2.7 Permeabilidad de las membranas planas después de filtrar las disoluciones de azúcar.

\begin{tabular}{|c|c|c|c|c|}
\hline Membrana & UF-GH & NF-HL & NF-DL & NF-DK \\
\hline$L_{p}\left(10^{-11} \mathrm{~m} /(\mathrm{Pa} \cdot \mathrm{s})\right)$ & 1.215 & 4.025 & 1.931 & 1.463 \\
\hline
\end{tabular}


Lo primero que se observa es que la membrana NF-HL presenta una permeabilidad del orden de tres veces superior al resto.

La permeabilidad de las membranas, después de pasar la disolución de azúcar, es menor que la obtenida al pasar agua, excepto en el caso de la membrana DL, porque esta membrana la estabilizamos a 15 bar, pero trabajamos con ella a 20 bar, ya que su flujo a 15 bar era demasiado bajo. Una estabilización a 20 bar habría dado resultados similares a las otras membranas. Es decir, que la filtración de azúcar solo produce un pequeño ensuciamiento de la membrana (del orden del $10 \%$ o menor).

b) Retención observada.

Se han utilizado velocidades de recirculación comprendidas entre 1.7 y $3.3 \mathrm{~m} / \mathrm{s}$ y presiones entre 5 y 20 bar, dependiendo de la membrana. Las medidas de concentración se repiten varias veces con cada membrana, hasta que el sistema alcanza el estado estacionario y por tanto, la concentración de permeado permanece constante.

Como en el apartado anterior, con la ecuación (2) y los valores de la concentración del permeado y de alimentación a cada presión de filtración calculamos los valores de retención observada de azúcar para todas las membranas. Los valores de $R_{o}$ en función de la presión se representan en la figura 2.16.

Como era de esperar, la membrana de ultrafiltración presenta menor retención que las de nanofiltración. En las membranas de nanofiltración, a mayor diferencia de presión, se produce una retención menor, lo que se correspondería con la tendencia general, como hemos visto y analizado en el apartado anterior [31]. Por el contrario, la membrana de ultrafiltración (NF-GH), da mayor retención para mayor presión. Esta tendencia no es la tendencia general [31], pero puede deberse a un aumento del fouling tanto en la superficie de la membrana como en el interior de los poros. Es decir, a presiones altas pasa una gran cantidad de moléculas de azúcar a través de la membrana. Esta membrana debe poseer una mayor afinidad a los azúcares que las de nanofiltración, creando una pseudomembrana que es capaz de aumentar la capacidad de retención de la misma.

Aunque la relación encontrada para la retención observada de las membranas utilizadas en la filtración de la disolución de azúcar es $D K>D L>H L>G H$, este comportamiento no es fiable, ya que como se observa en la figura 2.15 las medidas de retención se han hecho a distintas velocidades para adaptar la velocidad de recirculación a la potencia de la bomba y la permeabilidad de la membrana. Será 
necesario calcular la retención verdadera para que esta comparación tenga un sentido práctico.

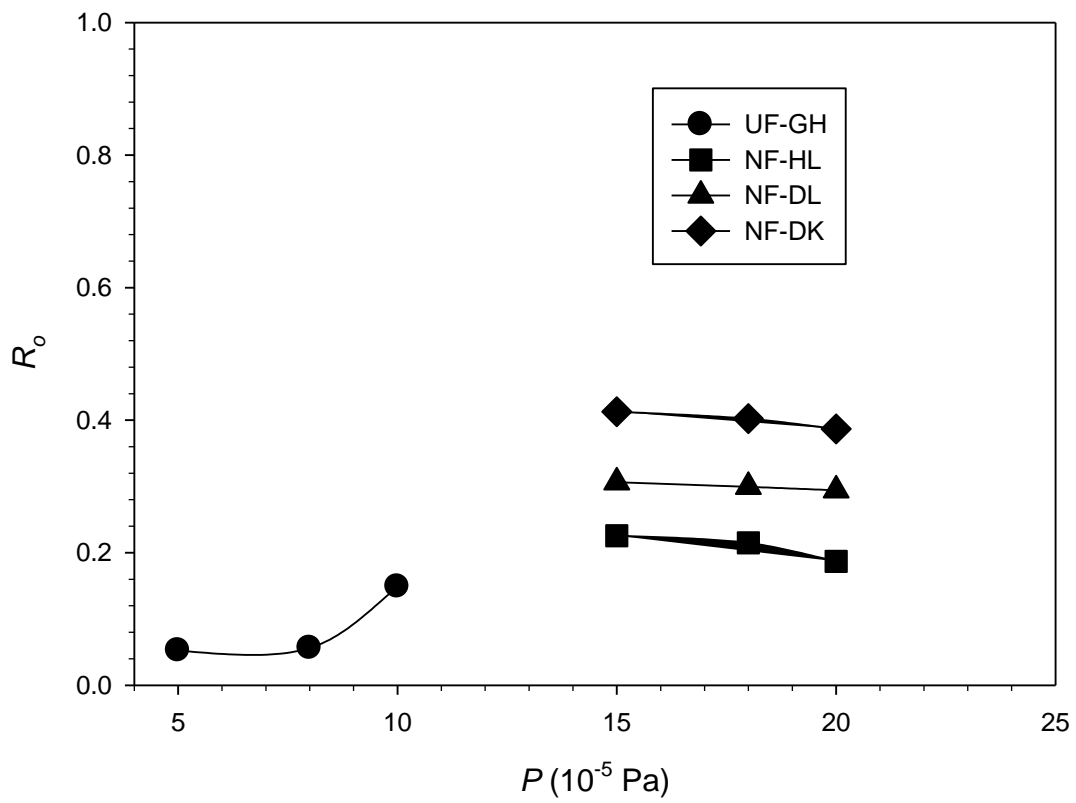

Figura 2.15 Retenciones observadas de una disolución de azúcar con las membranas planas. Velocidades de recirculación $G H$ y $D L=3.3 \mathrm{~m} / \mathrm{s}, D K=2.78 \mathrm{~m} / \mathrm{s}$ y

$$
H L=1.7 \mathrm{~m} / \mathrm{s} .
$$

\section{c) Retención verdadera}

En la caracterización de la membrana plana con los azúcares, se utiliza la teoría de película para conocer la polarización de la concentración de las capas límite de la membrana por medio del coeficiente de transferencia de masa. Esto nos permite determinar la concentración en la superficie de la membrana y obtener la retención verdadera (ecuación (3)). El método se ha descrito de manera general en el apartado 2.2, y al igual que en el apartado 3.2.1 describimos las particularidades de la celda agitada en la filtración de PEGs, aquí mencionaremos las particularidades del la celda tangencial plana con la filtración de azúcares. En los siguientes puntos describimos este proceso para el cálculo de $R$ :

$\checkmark$ Primero es necesario calcular los números adimensionales $S h$, Re y Sc, que nos permitirán determinar el tipo de régimen de flujo y posteriormente calcular el coeficiente de transferencia de masa.

Para determinar el $R e$ (ecuación (9)), se debe conocer la viscosidad y la densidad de la disolución. Aunque no es una disolución diluida (250g/L), 
tomamos la viscosidad y la densidad del agua a 25ํㅡ: $0.890 \mathrm{mPa} \cdot \mathrm{s}$ y 997 $\mathrm{Kg} / \mathrm{m}^{3}$, respectivamente. El diámetro hidráulico de la membrana plana se obtiene a partir de las dimensiones de la sección transversal al flujo de recirculación $(60 \mathrm{~mm} \times 0.5 \mathrm{~mm})$ con la ecuación (11) [33]. Finalmente, la velocidad a través del canal, se calcula como flujo de recirculación entre área de la superficie transversal del canal de la membrana $\left(30 \mathrm{~mm}^{2}\right)$. Los valores máximos de $R e$ obtenidos están situados entre 1700 y 3300 . Con esto podemos considerar que nos encontramos en régimen laminar [34-35].

Para calcular el número de Schmidt mediante la ecuación (10), necesitamos conocer la difusividad de los solutos en la disolución, además de la densidad y la viscosidad de la disolución, cuyos valores indicamos anteriormente. Como valor del coeficiente de difusión de nuestra disolución hemos tomado el valor medio del coeficiente de los dos azúcares presentes, para lo cual hemos tomado $6.7 \cdot 10^{-10} \mathrm{~m}^{2} / \mathrm{s}$ como coeficiente de difusión de la glucosa [21] y $6.84 \cdot 10^{-10} \mathrm{~m}^{2} / \mathrm{s}$ para la fructosa [36].

De acuerdo con esto, para determinar el Sherwood, teniendo en cuenta la geometría de la membrana (siendo $d_{h}$ el diámetro hidráulico y $L$ la longitud del canal sobre la membrana) y considerando régimen laminar, utilizaremos la ecuación de Graez-Léveque [3]:

$$
\mathrm{Sh}=1.85\left(\frac{\mathrm{d}_{\mathrm{h}}}{\mathrm{L}} \cdot \mathrm{Re} \cdot \mathrm{Sc}\right)^{\frac{1}{3}}
$$

Una vez conocido el Sherwood, se calcula el coeficiente de transferencia de masa, $K_{m}$, sustituyendo en la ecuación (8).

$\checkmark$ Para conocer la concentración en la superficie de la membrana una vez que tenemos los valores de $K_{m}$, se utiliza la ecuación (43).

Los valores de retención verdadera, obtenidos tras la filtración de las disoluciones de azúcar a través de las membranas planas, se representan en la figura 2.16. 


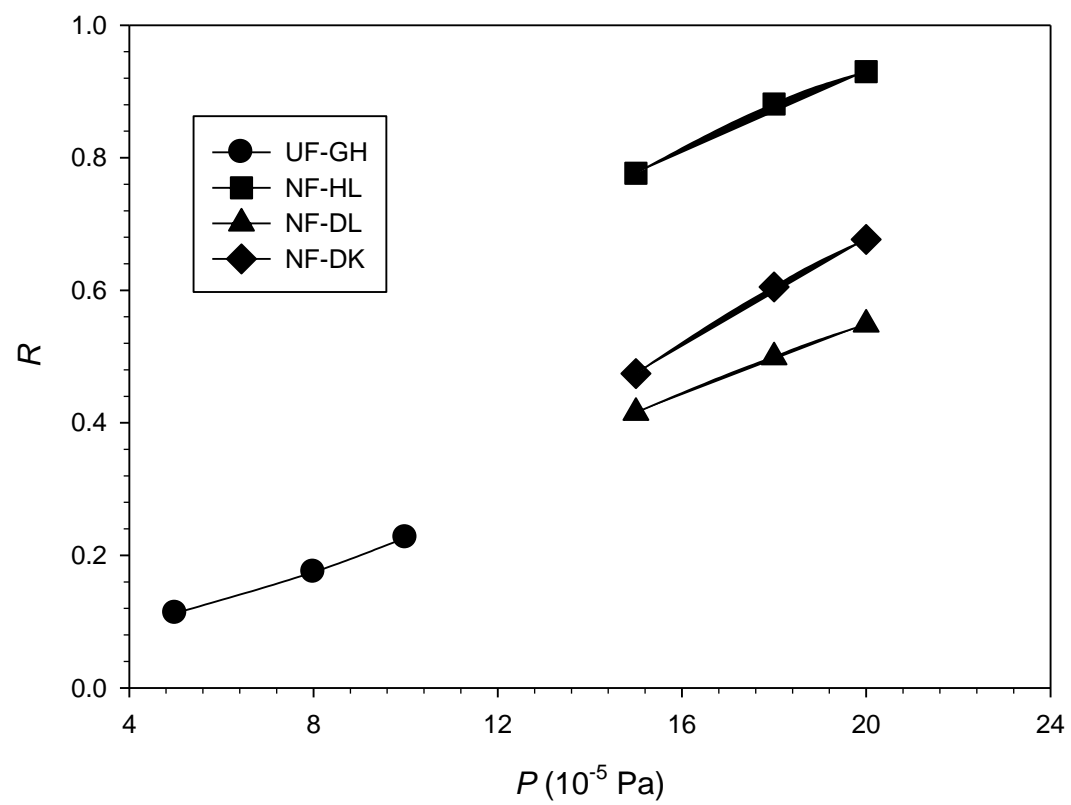

Figura 2.16 Coeficientes de retención verdadera en función de la presión con la disolución de azúcar, para las membranas estudiadas. Velocidades de recirculación: $G H$ y $D L=3.3 \mathrm{~m} / \mathrm{s}, D K=2.78 \mathrm{~m} / \mathrm{s}$ y $H L=1.7 \mathrm{~m} / \mathrm{s}$.

Vemos que con todas las membranas se observa un aumento de la retención verdadera a medida que aumentamos la presión aplicada. Este comportamiento es similar al encontrado para los PEGs y ya fue interpretado en ese apartado.

Si comparamos el comportamiento con el de la figura 2.16, vemos que el orden de retenciones verdaderas es distinto que el de observadas. En el caso de las retenciones verdaderas el orden de mayor a menor retención es el siguiente: membrana NF-HL, NF-DK, NF-DL y UF-GH. Como vemos la membrana NF-HL que presentaba la menor retención observada entre las membranas de nanofiltración, pasa a ser la de mayor retención verdadera. Este resultado es lógico si se tiene en cuenta que la retención observada de la membrana NF-HL estaba medida a la menor velocidad de recirculación.

\subsection{3) Resultados con el mosto tinto comercial}

Los resultados obtenidos al filtrar el mosto tinto comercial se presentan a continuación [37]: 
a) Permeabilidad hidráulica

La permeabilidad de las membranas antes de la filtración de los mostos, es la que se obtiene después de la filtración de la disolución de azúcar, expresada en la tabla 2.7. En este caso se aprovechó el montaje experimental de las membranas en la experiencia anterior, ya que la variación de la permeabilidad con azúcar era muy pequeña.

b) Retención observada

La filtración del mosto tinto comercial tiene lugar a la presión máxima aplicable para cada membrana, es decir, 10 bar para la membrana de ultrafiltración y 20 bar para las membranas de nanofiltración. La velocidad de recirculación del mosto es de $3.3 \mathrm{~m} / \mathrm{s}$ para la membrana de ultrafiltración y 2.2 m/s para las membranas de nanofiltración.

En el estudio de retención observada del mosto tinto comercial, además del azúcar que es el fin de nuestro estudio, se analizan las sustancias mayoritarias en el mosto tinto como son los polifenoles, los antocianos, el ácido tartárico y el potasio.

Los valores de retención de azúcar de los mostos comerciales son analizados por duplicado. En primer lugar, se miden en el transcurso de la filtración para comprobar la variación de la retención respecto al tiempo por refractometría. Además las fracciones finales son analizadas en la Estación Enológica del ITACyL mediante un método más exacto que es el método enzimático, como se explicó anteriormente en el apartado 3.1.4 de métodos analíticos de caracterización de azúcares.

Para la membrana DL no obtenemos datos de retención, ya que a pesar del elevado tiempo de filtración (3 días), no se obtuvo permeado para poder medir su concentración.

Los datos obtenidos son los que se muestran en la siguiente tabla:

Tabla 2.8 Retención observada de azúcar, filtrando un mosto tinto comercial con membranas planas.

\begin{tabular}{|c|c|c|c|c|c|c|}
\cline { 2 - 7 } \multicolumn{1}{c|}{} & \multicolumn{4}{c|}{ ITACyL } & \multicolumn{2}{c|}{ VALLADOLID } \\
\cline { 2 - 7 } \multicolumn{1}{c|}{} & $\begin{array}{c}\text { Glucosa } \\
\mathbf{( g / L )}\end{array}$ & $\begin{array}{c}\text { Fructosa } \\
\mathbf{( g / L )}\end{array}$ & $\begin{array}{c}\text { Azúcar } \\
\text { total (g/L) }\end{array}$ & $\begin{array}{c}\text { Retención } \\
\text { observada }\end{array}$ & $\begin{array}{c}\text { Azúcar } \\
\text { total (g/L) }\end{array}$ & $\boldsymbol{R}_{\mathbf{o}}$ \\
\hline Alimentación & 59.0 & 74.0 & 133.0 & & 169.67 & \\
\hline UF-GH & 48.0 & 47.5 & 95.5 & 0.282 & 154.92 & 0.125 \\
\hline NF-HL & 5.5 & 9.0 & 14.5 & 0.891 & 18.03 & 0.94 \\
\hline NF-DK & 14.5 & 19.0 & 33.5 & 0.748 & 33.59 & 0.802 \\
\hline
\end{tabular}


El azúcar total viene dado como la suma de glucosa y fructosa. En la uva, la relación entre ambos azúcares es de casi 1 y es importante que se mantenga así para que la fermentación alcohólica se lleve a cabo sin problemas. En nuestro caso, vemos que el mosto tinto comercial de alimentación, tiene una relación mayor que 1 entre fructosa y glucosa; esto se puede deber a que, al eliminar azúcar del mosto de uva para su comercialización, se rebaja más la cantidad de glucosa que de fructosa.

En la figura 2.17 se aprecia que en todos los casos como tendencia general, a pesar de que las velocidades de recirculación no son iguales, la retención observada de la membrana al filtrar mosto es mayor que la obtenida con agua y azúcar. La causa debe ser que en el mosto se encuentran componentes que favorecen la formación de una película en la superficie de la membrana que dificulta aún más el paso de los solutos, y por lo tanto aumenta los valores de retención de la membrana [38].

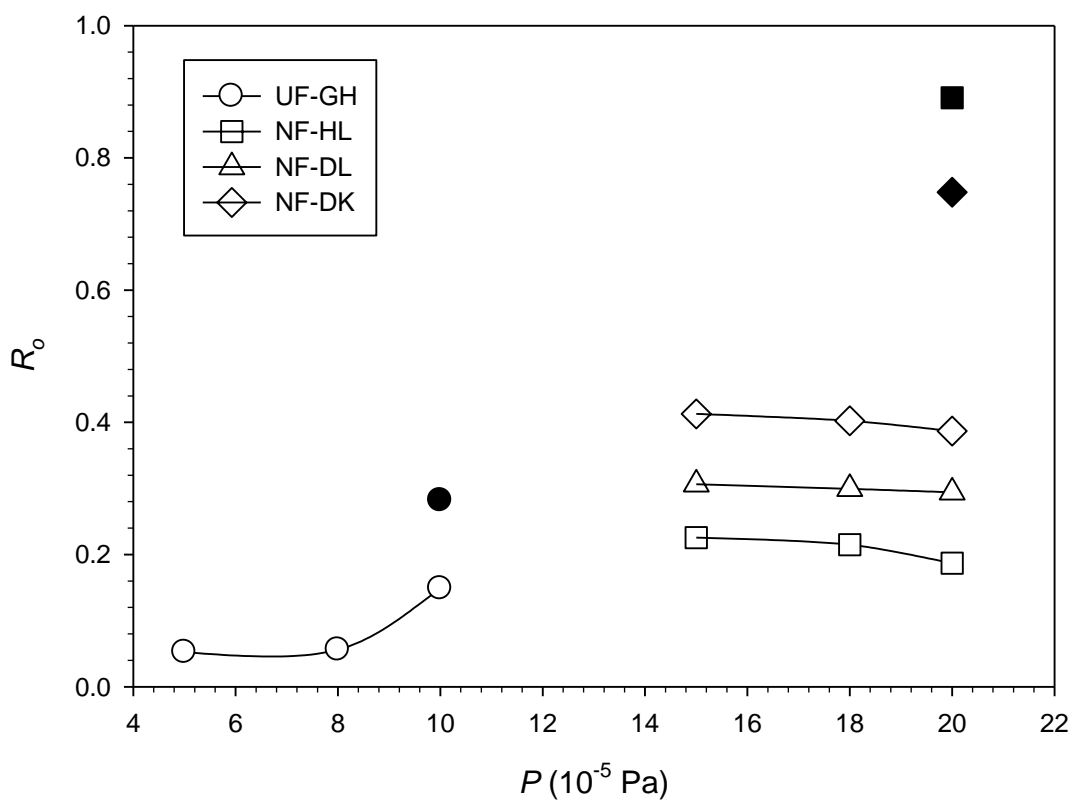

Figura 2.17 Coeficiente de retención de azúcar observada en función de la presión. Para la disolución de azúcar (símbolos blancos) y para el mosto comercial (símbolos negros).

Si comparamos las dos membranas de nanofiltración que se han medido a la misma velocidad, vemos que la NF-HL presenta mayor retención de azúcar que la NF-DK.

Si tenemos en cuenta otros componentes importantes del mosto, los coeficientes de retención observada calculados son los que se muestran en la siguiente tabla: 
Tabla 2.9 Concentración y retención observada de los componentes más importantes de un mosto tinto comercial filtrado con membranas planas.

\begin{tabular}{|c|c|c|c|c|c|c|c|c|}
\cline { 2 - 9 } \multicolumn{1}{c|}{} & $\begin{array}{c}\text { POLIFENOLES } \\
\text { TOTALES } \\
(\mathbf{m g} / \mathbf{L})\end{array}$ & $\% \boldsymbol{R}_{\boldsymbol{o}}$ & $\begin{array}{c}\text { ANTOCIANOS } \\
(\mathbf{m g} / \mathbf{L})\end{array}$ & $\% \boldsymbol{R}_{\boldsymbol{o}}$ & $\begin{array}{c}\text { TARTÁRICO } \\
(\mathbf{m g} / \mathbf{L})\end{array}$ & $\% \boldsymbol{R}_{\boldsymbol{o}}$ & $\begin{array}{c}\text { POTASIO } \\
(\mathbf{m g} / \mathbf{L})\end{array}$ & $\% \boldsymbol{R}_{\boldsymbol{o}}$ \\
\hline Alimentación & 1210 & & 70 & & 100 & & 770 & \\
\hline UF-GH & 246 & 79.67 & 15 & 78.57 & 65 & 35.00 & 480 & 37.66 \\
\hline NF-HL & 27 & 97.77 & 0 & 100.00 & 40 & 60.00 & 210 & 72.73 \\
\hline NF-DK & 35 & 97.11 & 0 & 100.00 & 40 & 60.00 & 320 & 58.44 \\
\hline
\end{tabular}

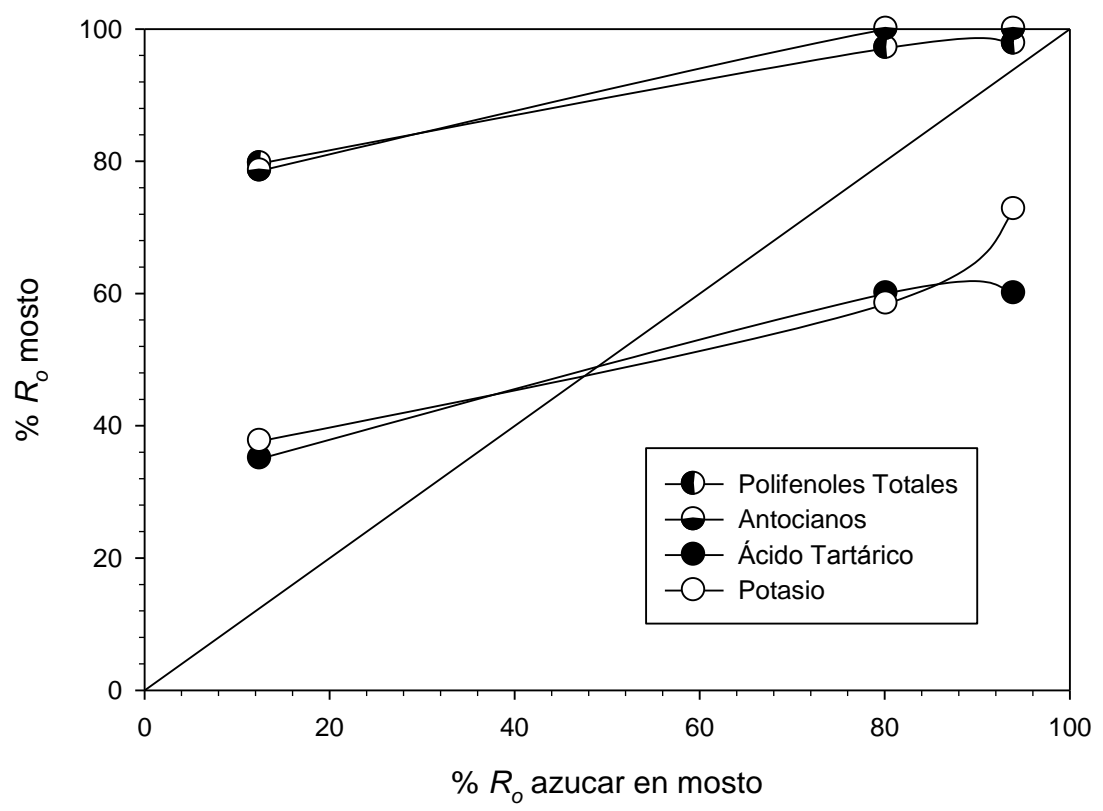

Figura 2.18 Coeficiente de retención observada de los compuestos relevantes de alto y bajo peso molecular del mosto en función de la retención de azúcar.

Como vemos, todas las membranas testeadas presentan retenciones importantes para estos compuestos que deben mantenerse en las concentraciones originales del mosto para producir un vino de buena calidad. Por ello a la hora de diseñar el proceso de filtración para la reducción de azúcar tendremos que tener en cuenta estas retenciones para construir un mosto con concentraciones similares de estos otros compuestos.

Si representamos la retención de estos compuestos en función de la retención de azúcar en el mosto (figura 2.18), se ve que hay una tendencia a incrementar la retención de estos compuestos relevantes al aumentar la retención de azúcar. La bisectriz de la gráfica nos permite ver que con las membranas de nanofiltración los compuestos de alto peso molecular están por encima de la curva y los de bajo por debajo. Esto indica que la reconstrucción del mosto final se puede hacer con las 
membranas de nanofiltración si recuperamos las grandes moléculas en el primer retenido y las pequeñas en los permeados sucesivos.

c) Retención verdadera

Igual que para las disoluciones de azúcar en esta celda tangencial, el coeficiente de transferencia de masa, $K_{m}$, se calcula con las ecuaciones (8) a (10) y la ecuación (44). A partir de los valores experimentales de flujo de permeado y concentración de permeado y retenido se calcula la concentración en la superficie de la membrana, $C_{m}$, usando la ecuación (43). Como en los casos anteriores, la retención verdadera se calcula con la ecuación (3). Los resultados obtenidos a la presión de trabajo se muestran en la tabla 2.10.

Tabla 2.10 Retención verdadera de los azúcares en la filtración del mosto tinto comercial.

\begin{tabular}{|c|c|c|}
\hline Membrana & $\mathbf{P}\left(\mathbf{1 0}^{\mathbf{5}} \mathbf{P a}\right)$ & $\boldsymbol{R}$ \\
\hline UF-GH & 10 & 0.303 \\
\hline NF-HL & 20 & 0.891 \\
\hline NF-DK & 20 & 0.748 \\
\hline
\end{tabular}

En la filtración del mosto tinto comercial, el orden de retención verdadera es el mismo que el de retención observada. Si comparamos con la figura 2.17, en las membranas de NF la retención verdadera es sólo ligeramente mayor que la observada, mientras que para la UF-GH el aumento de la retención verdadera es mayor.

Si comparamos las retenciones verdaderas de las membranas con la disolución de azúcar (figura 2.16) y con las de los mostos tintos comerciales a las mismas presiones de trabajo, comprobamos que las retenciones verdaderas son similares en los dos casos (sobre todo teniendo en cuenta que las velocidades de recirculación son distintas en ambas experiencias). Esto puede ser debido a que la retención verdadera depende sólo de la estructura de la propia membrana y no de las capas adyacentes a la misma, que estarán influenciadas por las condiciones de operación.

d) Caída de Flujo

La idoneidad de una membrana en un proceso de separación está condicionada por la retención, el flujo y su vida útil. La vida útil de una membrana viene determinada por su resistencia al ensuciamiento y que se puede cuantificar por su caída de flujo en función del tiempo. 
Para comparar distintas membranas estas caídas de flujo se suelen normalizar respecto a su flujo inicial. En la figura 2.20 se representa el flujo relativo (flujo a un tiempo determinado de la filtración respecto al flujo inicial) frente al tiempo transcurrido de filtración para nuestro mosto comercial. Se observa que las membranas de nanofiltración tienen un comportamiento muy similar, por lo que desde este punto de vista, las dos serian igualmente idóneas. Este comportamiento es esperable porque se trata de membranas de material y tamaños de poro similares. Por el contrario, la caída de flujo de la membrana de ultrafiltración GH es mayor. En este caso es previsible que el material de la membrana sea diferente y tenga más afinidad a algunos de los compuestos del mosto (polifenoles, antocianos, etc.). Además en este caso tenemos un tamaño de poro sensiblemente mayor de forma que algunos compuestos de alto y medio peso molecular pueden entrar en los poros y producir un bloqueo de estos.

Para la membrana DL no se obtienen valores de flujo, ya que como indicamos anteriormente, la presión aplicada no era suficiente para obtener permeado al filtrar el mosto comercial.

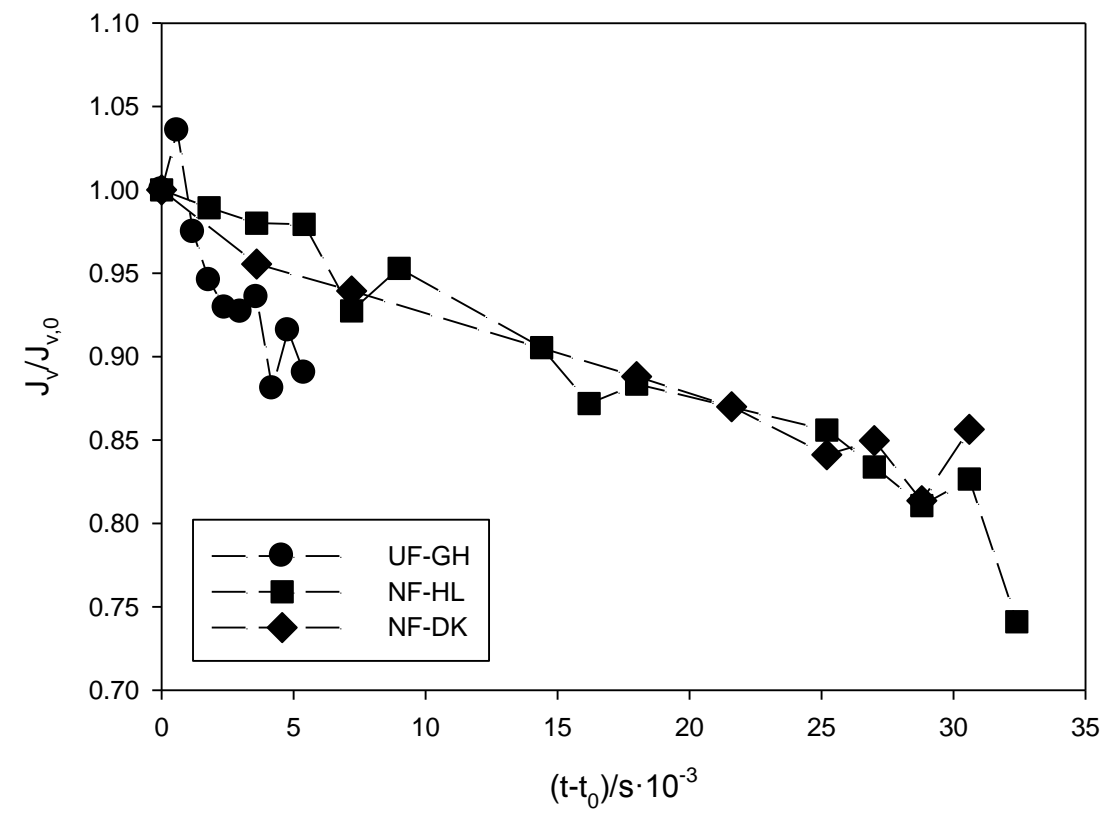

Figura 2.19 Flujo relativo frente al tiempo de filtración para membranas planas, tras la filtración de un mosto comercial modificado.

Con todos los datos de permeabilidad y retención verdadera obtenidos, se podría decidir que la membrana que mejor se adapta a nuestras condiciones de trabajo, es la membrana de nanofiltración HL. En primer lugar esta membrana tiene una mayor 
permeabilidad, tanto la membrana nueva como después de pasar la disolución de azúcar. $Y$ en segundo lugar, el valor de retención verdadera de azúcar, tanto tras la filtración de la disolución de azúcar como del mosto tinto comercial es mayor que para las demás membranas estudiadas. Apoyando a la elección de esta membrana, se puede tener en cuenta también que, la retención observada de los demás componentes importantes en un vino al filtrar el mosto tinto comercial, son mayores para la membrana $\mathrm{HL}$, que para las demás membranas de nanofiltración, y por supuesto, la membrana de ultrafiltración GH.

\section{MEDIDAS CON MÓDULOS ESPIRALES}

Después de la caracterización de las membranas planas, se realizó la caracterización de estas mismas membranas en configuración de módulo espiral. Estos módulos serán los que se utilizarán para la filtración de los mostos reales porque permiten el tratamiento de grandes volúmenes de mosto. Aunque se trata de las mismas membranas, puede haber cambios de comportamiento debido a la diferente configuración del módulo.

\subsection{MATERIALES USADOS Y DISPOSITIVOS EXPERIMENTALES}

\subsection{1) Membranas}

Las características de los módulos espirales dadas por el fabricante (General Electric Water \&Process Technologies) se recogen en la tabla 2.11.

Para poder utilizar los módulos espirales, en primer lugar tenemos que hacer pasar agua milli-Q a través del módulo, ya que éste dispone de una solución conservante para prevenir a la membrana del crecimiento microbiológico y de las bajas temperaturas. Para ello, ponemos el sistema a la mayor presión que nos permita alcanzar la bomba con agua.

El siguiente paso, sería el acondicionamiento de la membrana, estabilizando la misma como en el caso de las membranas planas, pasando agua milli- $Q$ hasta que alcancemos un valor de flujo constante. El flujo de recirculación fue casi nulo ya que el alto flujo del módulo absorbía casi todo el caudal suministrado por la bomba. Los valores de presión, flujo y tiempo empleado en estas dos etapas, se muestran en la tabla 2.12. 
Tabla 2.11 Especificaciones de los módulos espirales dados por el fabricante.

\begin{tabular}{|c|c|c|c|c|}
\hline $\begin{array}{l}\text { NOMENCLATURA } \\
\text { DEL FABRICANTE }\end{array}$ & GH1812C-28D & HL2540FM & DL1812C-28D & DK1812C-28D \\
\hline Membrana & UF-GH & $\mathrm{NF}-\mathrm{HL}$ & NF-DL & NF-DK \\
\hline Dimensiones (cm) & $30.5 \times 4.70$ & $101.6 \times 6.1$ & $30.5 \times 4.70$ & $30.5 \times 4.70$ \\
\hline $\begin{array}{l}\text { Retención media } \\
\qquad \mathrm{MgSO}_{4}(\mathrm{a})\end{array}$ & & $98 \%{ }^{*}$ & $96 \%$ ** & $98 \%$ ** \\
\hline MWCO (Dalton) & 2500 & & & \\
\hline Área efectiva $\left(\mathrm{m}^{2}\right)$ & 0.37 & 2.5 & 0.37 & 0.37 \\
\hline Espaciado (m) & $7.0 \cdot 10^{-4}$ & $7.6 \cdot 10^{-4}$ & $7.0 \cdot 10^{-4}$ & $7.0 \cdot 10^{-4}$ \\
\hline $\begin{array}{l}\text { Flujo de permeado } \\
\text { típico de operación } \\
\qquad(\mathrm{L} / \mathrm{min})(\mathrm{b})\end{array}$ & $0.049-0.210$ & $0.625-1.458$ & $0.049-0.210$ & $0.049-0.210$ \\
\hline $\begin{array}{c}\text { Presión máxima de } \\
\text { operación (kPa) }\end{array}$ & 2760 & 3103 & $\begin{array}{l}4137\left(\mathrm{~T}^{\mathrm{a}}<35^{\circ} \mathrm{C}\right) \\
3000\left(\mathrm{~T}^{\mathrm{a}}>35^{\circ} \mathrm{C}\right)\end{array}$ & $\begin{array}{l}4137\left(\mathrm{~T}^{\mathrm{a}}<35^{\circ} \mathrm{C}\right) \\
3000\left(\mathrm{~T}^{\mathrm{a}}>35^{\circ} \mathrm{C}\right)\end{array}$ \\
\hline $\begin{array}{l}\text { Temperatura máxima } \\
\text { de operación }\end{array}$ & $50^{\circ} \mathrm{C}$ & $50^{\circ} \mathrm{C}$ & $50^{\circ} \mathrm{C}$ & $50^{\circ} \mathrm{C}$ \\
\hline $\begin{array}{c}\text { Temperatura máxima } \\
\text { de limpieza }\end{array}$ & $50^{\circ} \mathrm{C}$ & $40^{\circ} \mathrm{C}$ & $40^{\circ} \mathrm{C}$ & $40^{\circ} \mathrm{C}$ \\
\hline pH operación & $2-10$ & $3-9$ & $3-9$ & $3-9$ \\
\hline pH limpieza & $1-11.5$ & $2-10.5$ & $2-10.5$ & $2-10.5$ \\
\hline $\begin{array}{l}\text { Máxima caída de } \\
\text { presión }(\mathrm{kPa})\end{array}$ & 103 & 83 & 103 & 103 \\
\hline Tolerancia al cloro & 20-50 ppm/día & 1000 ppm/h & $500 \mathrm{ppm} / \mathrm{h}$ & $500 \mathrm{ppm} / \mathrm{h}$ \\
\hline
\end{tabular}

(a) Retención media después de 24 h de filtración. Disolución de $\mathrm{MgSO}_{4}$ de 2000 ppm de concentración, operando a $25^{\circ} \mathrm{C}, \mathrm{pH}=7.5$ y $15 \%$ de recuperación.

* Presión de $690 \mathrm{kPa}$

** Presión de $760 \mathrm{kPa}$

(b) Presión típica de operación para la membrana HL de 483-2069 KPa. Para el resto de membranas este dato no es facilitado por el fabricante. 
Tabla 2.12 Tiempo de eliminación de conservante y condiciones de acondicionamiento de los módulos de membrana espirales.

\begin{tabular}{|c|c|c|c|c|}
\hline \multirow{2}{*}{$\begin{array}{c}\text { Módulo } \\
\text { membrana }\end{array}$} & $\begin{array}{c}\text { Eliminar } \\
\text { conservante }\end{array}$ & \multicolumn{3}{|c|}{ Acondicionamiento } \\
\cline { 2 - 5 } & Tiempo (h) & $\begin{array}{c}\text { Presión } \\
\left(10^{5} \mathrm{~Pa}\right)\end{array}$ & $\begin{array}{c}\text { Flujo de Recirculación } \\
(\mathrm{L} / \mathrm{min})\end{array}$ & $\begin{array}{c}\text { Tiempo } \\
(\mathrm{h})\end{array}$ \\
\hline GH1812C & 1 & 19 & 0.5 & 2 \\
\hline HL2540FM & 2 & 10 & 0.5 & 2 \\
\hline DL1812C & 2 & 18.5 & 1.0 & 2 \\
\hline DK1812C & 1 & 17 & 0.5 & 2 \\
\hline
\end{tabular}

El método de limpieza utilizado con los módulos de membrana después de su utilización es el siguiente:

a) Se pasa agua por el interior del módulo durante 1 hora, para eliminar las sustancias que se han podido quedar adheridas a la superficie de la membrana. Se recircula durante 30 minutos agua milli-Q, lo que nos sirve para medir la permeabilidad después de las filtraciones.

b) Se recircula una disolución de Dodecil Sulfato Sódico $0.1 \%$, que ha sido previamente ajustada a un $\mathrm{pH}$ de 9 , con $\mathrm{NaOH}$ y $\mathrm{HCl}$, durante 1 hora.

c) Después se elimina el detergente de nuevo con agua durante 1 hora y se vuelve a recircular agua milli-Q, midiendo la permeabilidad después da la limpieza.

d) Si el módulo de membrana no va a seguir utilizándose, se almacena en una carcasa que contiene una disolución de fenol a $\mathrm{pH}=6$ para su conservación.

\subsection{2) Solutos}

Como disolución de alimentación se utilizan 2 litros de una disolución de azúcar de concentración $215.74 \mathrm{~g} / \mathrm{L}$ y el mismo volumen de mosto tinto comercial modificado. Este mosto se obtiene añadiendo glucosa y fructosa al mosto comercial hasta obtener unas concentraciones similares a los mostos de uva. En nuestro caso se añadió glucosa mas fructosa hasta alcanzar una concentración total de azúcar de $253.81 \mathrm{~g} / \mathrm{L}$, a fin de realizar ensayos con una disolución lo más próxima posible a los mostos reales de nuestro estudio. 


\subsection{3) Dispositivo experimental}

El equipo utilizado para las filtraciones de disolución de azúcar y mostos comerciales, es similar al utilizado para membranas planas, las principales diferencias son las siguientes:

- Antes del regreso del retenido al recipiente donde se encuentra la disolución de alimentación, la disolución de azúcar o el mosto comercial pasarán por un intercambiador de calor para evitar el aumento de la temperatura producido por la fricción del fluido dentro del módulo de membrana.

- Los módulos espirales (Serie Thin Film Membrane comercializados por GE Water \& Process Technologies), se introducen en la carcasa adecuada para las dimensiones del módulo. El módulo HL2540FM, con un área de membrana de $2.5 \mathrm{~m}^{2}$, se introduce en una carcasa de acero inoxidable de gran espesor, fabricado por la misma empresa que los módulos de membrana (General Electric Water \& Process Technologies), y que soportan presiones de trabajo máximas de 30 bar. Por el contrario, los módulos GH1812C, DL1812C y DK1812C, con área de membrana de $0.37 \mathrm{~m}^{2}$, se introducen en un módulo de chapa de acero inoxidable, fabricado por Sepra (Separation Process Application) y que soportan presiones de trabajo máximas de 40 bar.

- Para el módulo espiral DL1812C en la filtración de la disolución de azúcar, se utiliza una bomba que puede aplicar presiones de hasta 69 bar (Wanner Hydra-cell G-03-XInox/Viton), y no la bomba Tuthill ${ }^{\circledR}$ TXS2 que se utilizó para la filtración de las membranas planas y de los demás módulos. La utilización de esta bomba nos permite utilizar mayores velocidades de recirculación, disminuyendo el proceso de fouling y favoreciendo, por lo tanto, la filtración de la disolución.

- Como el flujo de permeado es muy superior al de las membranas planas, en lugar del método de pesada usamos un método volumétrico. Medimos el tiempo de llenado de una probeta de $10 \mathrm{~mL}$.

En la figura 2.21 se muestra el esquema del sistema de filtración. 


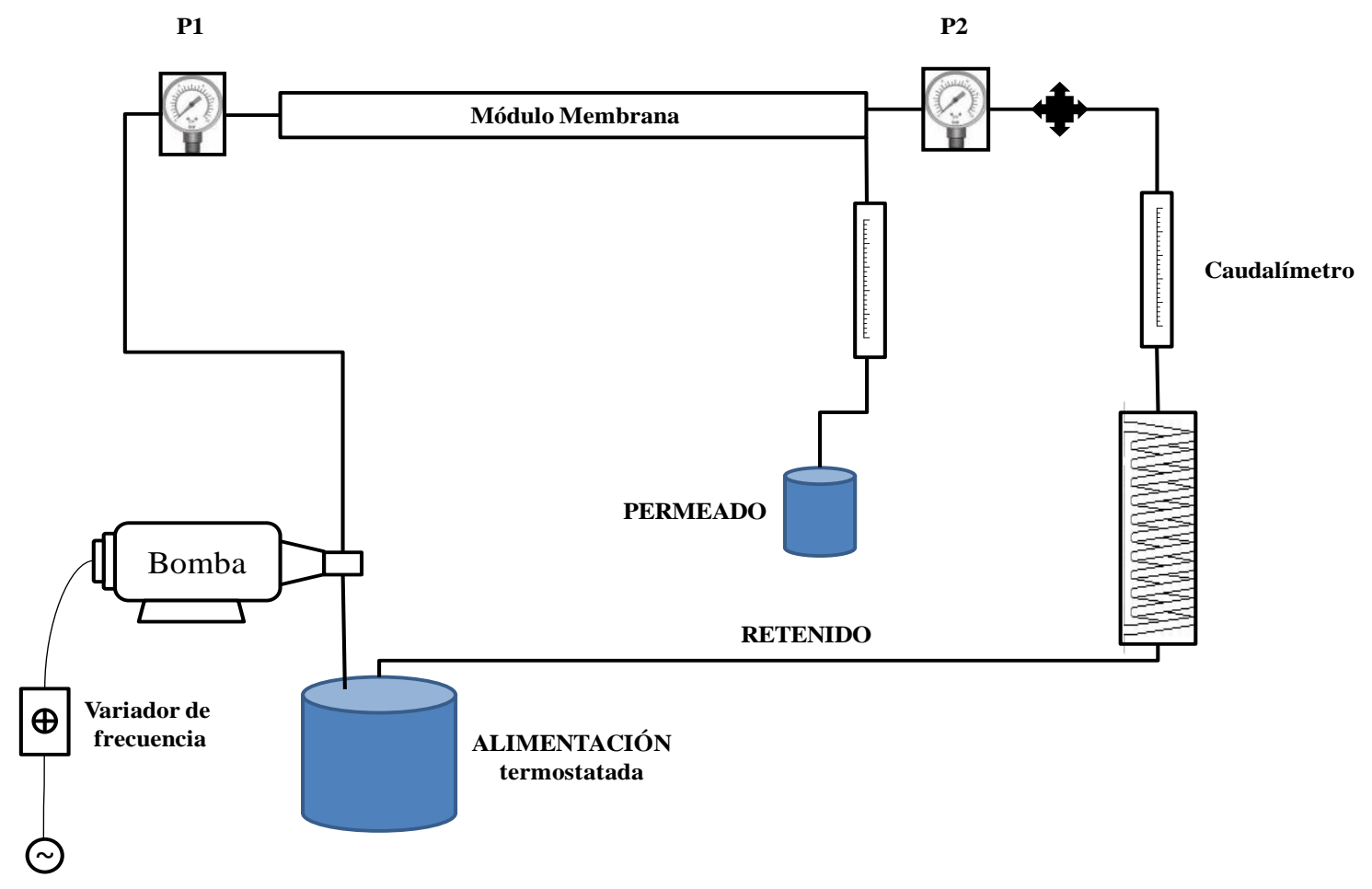

Figura 2.20 Equipo de filtración para el módulo de membrana.

Las condiciones de filtración en el caso de la disolución de azúcar son las que se muestran en la tabla 2.13. Para cada membrana tenemos unos valores de presión diferentes, puesto que cada membrana tiene unos intervalos de presión de operación propios.

Tabla 2.13 Condiciones de filtración de la disolución de azúcar con módulos de membranas espirales.

\begin{tabular}{|c|c|c|}
\hline \multirow{2}{*}{$\begin{array}{c}\text { Módulo } \\
\text { membrana }\end{array}$} & Disolución de azúcar \\
\cline { 2 - 3 } & Presión $\left(10^{5} \mathrm{~Pa}\right)$ & $\begin{array}{c}\text { Flujo de Recirculación } \\
(\mathrm{L} / \mathrm{min})\end{array}$ \\
\hline GH1812C & $10 / 15 / 18 / 20 / 22$ & 1.0 \\
\hline HL2540FM & $8 / 10 / 12 / 14$ & 1.0 \\
\hline DL1812C & $10 / 15 / 18 / 20$ & 6.0 \\
\hline DK1812C & $10 / 15 / 18 / 20$ & 1.0 \\
\hline
\end{tabular}

Para la filtración de este mosto comercial modificado, se utilizará la mayor presión alcanzada por la bomba con cada módulo de membrana, de este modo, los parámetros de filtración con cada tipo de membrana son diferentes, y se muestran en la tabla 2.14. 
Tabla 2.14 Condiciones de filtración del mosto comercial con módulos de membranas espirales.

\begin{tabular}{|c|c|c|}
\hline \multirow{2}{*}{$\begin{array}{c}\text { Módulo } \\
\text { membrana }\end{array}$} & \multicolumn{2}{|c|}{ Mosto comercial } \\
\cline { 2 - 3 } & Presión $\left(10^{5} \mathrm{~Pa}\right)$ & $\begin{array}{c}\text { Flujo de Recirculación } \\
(\mathrm{L} / \mathrm{min})\end{array}$ \\
\hline GH1812C & 22 & 1.0 \\
\hline HL2540FM & 19 & 1.0 \\
\hline DL1812C & 20 & 2.0 \\
\hline DK1812C & 20 & 1.0 \\
\hline
\end{tabular}

\subsection{4) Métodos Analíticos}

Para el análisis de la concentración de azúcar, tanto de la disolución de azúcar como del mosto tinto comercial modificado se utilizará tanto el refractómetro diferencial Atago DD-5, como el refractómetro absoluto Abbe 2WA explicados anteriormente, pero además se utiliza un polarímetro para evitar las interferencias con otras partículas sólidas de la muestra. Con el polarímetro (Zuzi 404), se detectará la concentración de azúcar (moléculas que rotan frente a la luz polarizada), en lugar de los sólidos disueltos, como ocurre con los refractómetros. La precisión de este método, depende de la presencia o no de otras especies ópticamente activas.

Como hemos mencionado, el polarímetro detecta las sustancias ópticamente activas, en nuestro caso, la glucosa y la fructosa, ya que poseen carbonos asimétricos que hacen rotar el plano de polarización de la luz polarizada de una lámpara de sodio que atraviesa la disolución. La rotación angular de la luz polarizada ( $\alpha$, en grados), producida por soluciones de sustancias ópticamente activas, es proporcional al camino óptico de la luz al atravesar la disolución ( $l$ en dm), a la concentración de la sustancia ópticamente activa ( $C$ en $\mathrm{g} / 100 \mathrm{~mL}$ ), y a la naturaleza de la misma. El ángulo de rotación medio específico de la sustancia de actividad óptica, medido a $20^{\circ} \mathrm{C}$ bajo la luz de sodio $\left([\alpha]^{20}\right)$, viene dado por [39]:

$$
\alpha \cdot 100=[\alpha]_{D}^{20} \cdot l \cdot C
$$

Cuando existen varias especies activas, para conocer el ángulo de rotación de la disolución, se suma el de las diferentes sustancias disueltas. En nuestra muestra, encontramos glucosa $\left([\alpha]^{20}{ }_{D}=52.5^{\circ}\right)$ y fructosa $\left([\alpha]^{20}{ }_{D}=-91.9^{\circ}\right)$ en proporción prácticamente equimolecular, por lo que las medidas de nuestros ángulos de rotación 
con el polarímetro, son negativas, ya que se desvía la luz polarizada hacia la izquierda.

En las medidas polarimétricas se deben tener en cuenta distintos parámetros:

- La temperatura: los coeficientes de temperatura pueden ser positivos o negativos. Las determinaciones se suelen hacer a $20^{\circ} \mathrm{C}$. La glucosa prácticamente mantiene su poder rotatorio en +52.5 entre 0 y $100^{\circ} \mathrm{C}$, en cambio la fructosa varía significativamente su poder rotatorio con la temperatura, pasa de $\operatorname{ser}[\alpha]^{20}{ }_{D}=-92.5\left(20^{\circ} \mathrm{C}\right)$ a $[\alpha]^{87} \mathrm{D}=-52.5\left(87^{\circ} \mathrm{C}\right)$, valor igual pero de signo contrario al de la glucosa, o sea que a $87^{\circ} \mathrm{C}$ se anula el poder rotatorio del azúcar invertido. Los valores del poder rotatorio de la fructosa varían con las distintas referencias de $\left([\alpha]^{20}{ }_{D}=-91.0\right.$ a $-93.5^{\circ}$, pero nosotros utilizaremos los datos proporcionados por el fabricante para nuestra muestra, $\left([\alpha]^{20} \mathrm{D}=-91.9^{\circ}\right.$.

- La naturaleza del solvente. Para algunas sustancias ópticamente activas, la medida varía con el solvente usado; en nuestro caso el disolvente sería agua, por lo que no tendremos variaciones en la medida por este motivo, ya que las referencias usadas son para disolución acuosa.

- Mutarrotación: muchos azúcares presentan el fenómeno de mutarrotación, debido a la existencia de dos estereoisómeros que difieren en su rotación específica. Cuando se cristaliza desde una solución, se separa sólo una de las formas, pero cuando el estereoisómero separado por cristalización se disuelve, es parcialmente convertido en el otro estereoisómero hasta llegar a un equilibrio con la mezcla de los dos. Ese equilibrio estará determinado por la concentración, la temperatura y el solvente, y requiere un cierto tiempo para alcanzarse. Por eso las soluciones recientemente preparadas de azúcares van variando lentamente su poder rotatorio. Después de realizar pruebas de mutarrotación, midiendo a diferentes tiempos el ángulo de rotación de disoluciones de glucosa, fructosa y una mezcla de ambas; se pudo comprobar que la concentración de las muestras variaba, debido a la mutarrotación de la glucosa, ya que el isómero $\alpha$-glucosa tiene $[\alpha]^{20}=+113,4$ y la $\beta$-glucosa $[\alpha]^{20}{ }_{D}=$ $+19,7$ [40]. Por lo tanto, en el equilibrio de ambas formas de glucosa $[\alpha]^{20}{ }_{D}=$ $+52,5$ y necesitaba un tiempo para que se alcance este equilibrio. La mutarrotación de la fructosa es más rápida y alcanza rápidamente el equilibrio hasta el valor de $[\alpha]^{20}=-91.9^{\circ}$. En la tabla 2.15 se muestra la variación temporal de disoluciones que contienen glucosa debido al efecto de la 
mutarrotación. Los valores de concentración se calculan mediante la ecuación (45).

Tabla 2.15 Valores de concentración obtenidos con el polarímetro, de distintas disoluciones de glucosa y/o fructosa, respecto al tiempo de medida.

\begin{tabular}{|c|c|c|}
\hline & $\mathbf{t}=\mathbf{0}$ & $\mathbf{t}=\mathbf{2 4} \mathbf{h}$ \\
\hline $10 \mathrm{~g} / \mathrm{L}$ Glucosa & 17.14 & 10.48 \\
\hline $10 \mathrm{~g} / \mathrm{L}$ Fructosa & 9.25 & 10.88 \\
\hline $100 \mathrm{~g} / \mathrm{L}$ Glucosa & 147.62 & 101.90 \\
\hline $100 \mathrm{~g} / \mathrm{L}$ Fructosa & 96.84 & 100.10 \\
\hline $240 \mathrm{~g} / \mathrm{L}$ Glucosa + Fructosa & 43.15 & 238.57 \\
\hline
\end{tabular}

- Presencia de ácidos, álcalis y sales neutras: la rotación del azúcar es afectada por muchas sustancias disueltas $(\mathrm{HCl}$, sales inorgánicas). El $\mathrm{HCl}$ tiene efecto de aumentar la rotación negativa al igual que las sales neutras $\left(\mathrm{NaCl}, \mathrm{NH}_{4} \mathrm{Cl}\right.$, $\mathrm{CaCl}_{2}, \mathrm{C}_{2} \mathrm{O}_{4} \mathrm{~K}_{2}$, etc.). El efecto de ambos parece deberse a la capacidad de solvatación de las mismas, lo que produciría un efecto similar a un aumento de la concentración del azúcar en la solución. En nuestro caso, tenemos tan sólo las interferencias debidas a las sales neutras, ya que la presencia de ácidos y sales afectaría a la hidrólisis de la sacarosa, pero no a la glucosa y fructosa por separado [41]. El error asumido de la presencia de sales neutras es poco importante. Además, las medidas de concentración de azúcar en las que utilizamos el método de polarización, son para analizar la evolución de la concentración del permeado durante la filtración respecto al tiempo. Al ser una medida relativa quita importancia a la existencia de un error sistemático porque el objetivo de esta parte del estudio es analizar la evolución del proceso. Estos resultados no se utilizan para los análisis químicos posteriores de los vinos resultantes, ya que para ello las medidas de concentración se obtienen por el método enzimático (anteriormente comentado) que es más exacto para poder comparar los vinos resultantes con y sin proceso de filtración.

Las medidas de concentración con polarímetro se realizan proyectando la luz de la lámpara de sodio a través del condensador, del filtro de color y del polarizador, convirtiéndose en una luz polarizada plana y lineal. Esta luz pasa una placa de cuarzo de media longitud de onda y se descompone en dos haces, partiéndose su campo visual en tres partes. Cuando introducimos el tubo con muestra, si la disolución tiene 
actividad óptica el plano de luz polarizada rota un ángulo determinado. Girando el polarizador hasta que tengamos tres zonas iluminadas de igual intensidad, podemos leer el ángulo de rotación en la escala. Esta escala tiene un rango de medida de $\pm 180^{\circ}$ con divisiones de una unidad, pero además de esta escala tenemos lectura mediante Vernier, que nos permitirá apreciar hasta 0.05․ Una vez conocido el ángulo de rotación de la disolución y con la ecuación (45), descrita anteriormente, calcularemos la concentración de la disolución.

\subsection{MATERIALES USADOS Y DISPOSITIVOS EXPERIMENTALES}

\subsection{1) Resultados con la disolución de azúcar}

a) Permeabilidad hidráulica

Una vez que las membranas han sido acondicionadas, se hacen medidas del flujo en función de la presión, en el intervalo de presión adecuado para el rango de flujo de cada membrana. Igual que con las membranas planas, a partir de estos datos, calculamos la permeabilidad de cada módulo de membrana espiral. Los valores de flujo en volumen por unidad de presión se dividen por el área de membrana nominal dada por el fabricante (tabla 2.11) para obtener la permeabilidad.

En la tabla 2.16, se muestran los valores de permeabilidad de cada membrana espiral nueva, y las permeabilidades, después de filtrar la disolución de azúcar de concentración similar a los mostos de uva.

Tabla 2.16 Permeabilidades de los módulos de membranas espirales nuevos, antes y después de la filtración de la disolución de azúcar en el intervalo de presiones adecuado para cada módulo.

\begin{tabular}{|c|c|c|c|c|}
\hline \multirow{2}{*}{$\begin{array}{c}\text { Módulo } \\
\text { membrana }\end{array}$} & $\begin{array}{c}\text { Intervalo de } \\
\text { presiones } \\
\text { (bar) }\end{array}$ & Módulo nuevo & $\begin{array}{c}\text { Antes de la } \\
\text { disolución de azúcar }\end{array}$ & $\begin{array}{c}\text { Después de la } \\
\text { disolución azúcar }\end{array}$ \\
\cline { 3 - 5 } & & \multicolumn{3}{|c|}{$L_{p}\left(10^{-11} \mathrm{~m} /(\mathrm{s} \cdot \mathrm{Pa})\right)$} \\
\hline GH1812C & $8-18$ & 0.574 & 0.574 & 0.497 \\
\hline HL2540FM & $2-10$ & 1.933 & $0.987^{1}$ & 1.670 \\
\hline DL1812C & $8-18$ & 1.649 & $1.359^{1}$ & 1.066 \\
\hline DK1812C & $6-15$ & 0.692 & $0.796^{1}$ & 0.619 \\
\hline
\end{tabular}

${ }^{1}$ Estas membranas han sufrido diversos procesos de filtración de mostos, limpieza y almacenamiento. 
Analizando en primer lugar los valores de la permeabilidad de los módulos de membrana nuevos y comparándola con la obtenida en las membranas planas (tabla 2. 6), observamos que en todos los casos la permeabilidad de los módulos es menor que la de las membranas planas lo que puede deberse a dos motivos:

- El área efectiva del módulo de membrana es menor que la que se indica en las especificaciones, ya que la superficie efectiva de las membranas se ve reducida por la existencia de un separador reticular en contacto con ésta.

- Acondicionamiento de las membranas planas o módulos espirales a valores diferentes de presión. En el caso de la membrana $\mathrm{HL}$ y $\mathrm{DK}$, el acondicionamiento de la membrana plana tiene lugar a una presión mayor (20 bar) que en el módulo espiral (10 y 12,5 bar respectivamente), de este modo, los poros se abrirán más en la membrana plana dando lugar a un mayor flujo y una mayor permeabilidad. En el caso de la membrana GH y DL aplicamos mayor presión de acondicionamiento en los módulos espirales (19 y 18.5 bar respectivamente) que en las membranas planas (15 bar), por lo que, la permeabilidad del módulo espiral debería ser mayor que la de la membrana plana, pero no es así, por lo que la disminución de la permeabilidad del módulo respecto a la membrana plana, sólo puede explicarse mediante la causa anterior.

Como se muestra en la tabla 2.16 los módulos de membrana HL y DL presentan permeabilidades menores antes de la filtración de la disolución de azúcar que las medidas como membrana nueva. Esto se debe a que ha sido usada previamente en otros procesos de filtración de mosto Verdejo y Tinta de Toro. Lo habitual es que estos procesos produzcan una disminución de la permeabilidad respecto al módulo de membrana nuevo, como ocurre con las membranas $\mathrm{HL}$ y $\mathrm{DL}$, y no un aumento de permeabilidad como vemos en el módulo DK. No obstante no es raro encontrar casos en que los proceso limpieza o las sustancias químicas usadas como conservantes o antibactericidas ataquen parciamente al material de la membrana aumentando su permeabilidad. Esto parece ser lo que ocurre con el modulo de la membrana DK.

Como se muestra en la tabla 2.16, como regla general, los valores de permeabilidad después de pasar la disolución de azúcar son menores que el valor antes de pasar la disolución. Esto se debe al fenómeno de "fouling" o ensuciamiento al paso de la disolución de alimentación por la membrana. No obstante, con la membrana HL ocurre lo contrario, aumentando la permeabilidad de forma significativa después de pasar la 
disolución de azúcar. Esto debe ser una consecuencia de la historia del propio módulo de membrana, pues si analizamos los valores de las membranas HL planas antes y después de filtrar azúcar (tablas 2.6 y 2.7) la permeabilidad disminuía ligeramente. La única explicación lógica del comportamiento encontrado en este apartado, para la membrana $\mathrm{HL}$, es que durante el proceso de filtración de azúcar hemos procedido además a la liberación de sustancias adheridas a la membrana, procedentes de otros procesos de filtración.

\section{b) Retención observada}

Como hemos mencionado anteriormente, utilizando la ecuación (2), se obtiene la retención observada de los módulos de membrana analizados. Al igual que para las membranas planas, las medidas utilizadas son la concentración de alimentación y la de permeado tras la filtración de la disolución de azúcar. Los valores de concentración utilizados para el cálculo de las retenciones, tanto la observada como la verdadera, son los obtenidos con el polarímetro. En la tabla 2.17 se muestran las concentraciones de alimentación y permeado, junto con los coeficientes de retención observada, a la máxima presión de trabajo. En la primera columna se especifica la presión usada con cada módulo de membrana.

Tabla 2.17 Concentración de alimentación, concentración de permeado, reducción de grado alcohólico y retención observada de los módulos espirales durante la filtración de una disolución de azúcar a la presión máxima aplicada.

\begin{tabular}{|c|c|c|c|c|}
\hline Módulo membrana & $\boldsymbol{C}_{\boldsymbol{0}}(\mathbf{g} / \mathbf{L})$ & $\boldsymbol{C}_{\boldsymbol{p}}(\mathbf{g} / \mathbf{L})$ & $\begin{array}{c}\text { Grados de alcohol } \\
\text { probable } \\
\text { reducidos (\%v/v) }\end{array}$ & $\boldsymbol{R}_{\boldsymbol{0}}(\%)$ \\
\hline GH1812C (20 bar) & 177.66 & 137.06 & 2.32 & 22.86 \\
\hline HL2540FM (14 bar) & 215.74 & 81.22 & 7.69 & 62.35 \\
\hline DL1812C (20 bar) & 210.66 & 142.13 & 3.92 & 32.53 \\
\hline DK1812C (20 bar) & 261.42 & 119.29 & 8.12 & 54.37 \\
\hline
\end{tabular}

En la tabla 2.17 se muestra el valor de los grados alcohólicos reducidos en el permeado por el paso a través de las membranas. Para obtener estos valores se ha usado un factor habitual en enología para determinar el grado alcohólico de mostos, y que consiste en dividir la concentración de azúcar por 17.5 [42]. Este valor de conversión de azúcar a alcohol depende de las referencias utilizadas [22, 40, 43-44], ya que es un dato que varía dependiendo del rendimiento de la fermentación. 
Como vemos, todas las membranas reducirían sensiblemente el grado alcohólico con una primera pasada del mosto. No obstante, hay que tener en cuenta que a la hora de diseñar el proceso global se requiere la recuperación de otros componentes de alto y bajo peso molecular presentes en el mosto. De acuerdo con esto, se buscaría una membrana con alta retención para el azúcar.

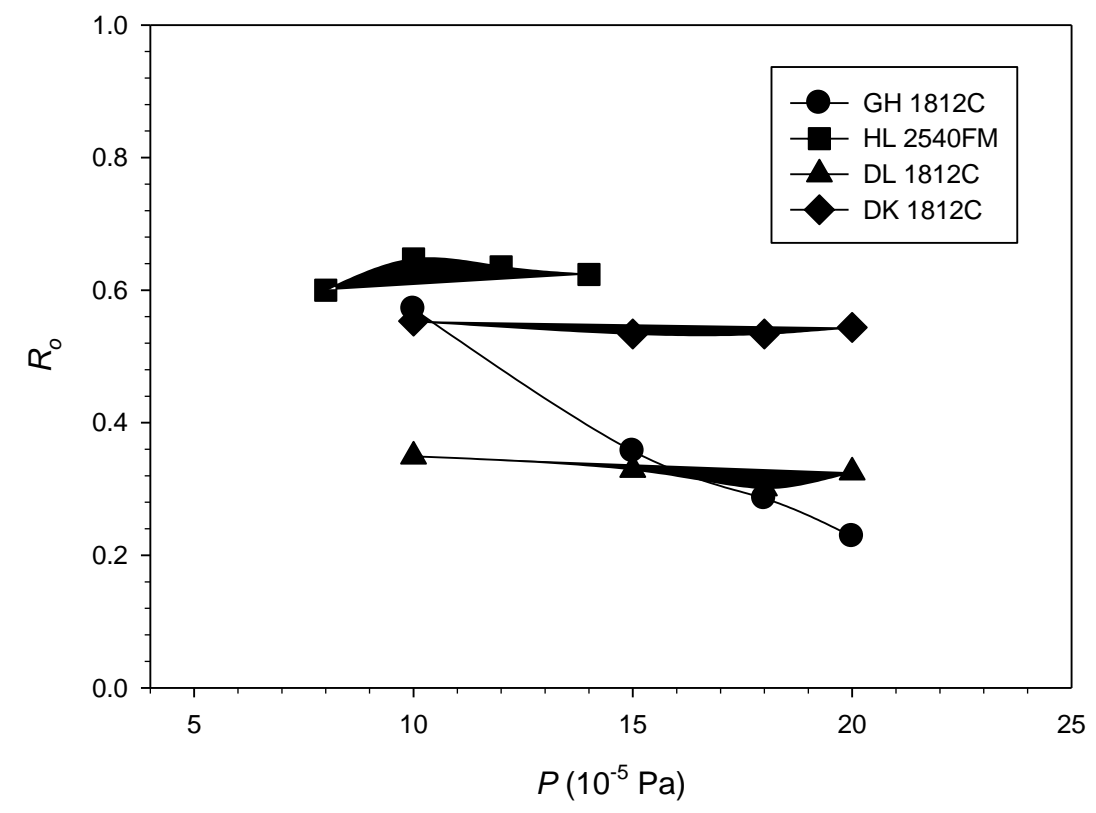

Figura 2.21 Retenciones observadas de la disolución de azúcar con los módulos de membranas espirales.

En la figura 2.22 se muestra la evolución de la retención observada. El comportamiento es el habitual en estos casos, una disminución de $R_{0}$ con la presión. No obstante, en algunos casos esta disminución viene precedida de un aumento inicial, tal como predice el modelo de transferencia de materia (ver figura 2.13). La membrana DK, parece presentar un ligero aumento, aunque puede ser debido a errores experimentales. Aun así, sería esperable que a mayores presiones terminásemos encontrando una disminución de la retención observada. Se observa que la disminución es más acusada con membranas de menor retención (GH1812C) que con las de nanofiltración. Comparando los resultados con las membranas planas, observamos una clara discrepancia (ver figura 2.16). Mientras que en aquel caso el orden de retención observada era $\mathrm{DK}>\mathrm{DL}>\mathrm{HL}>\mathrm{GH}$, ahora vemos en la figura que es $H L>D K>D L>G H$. Estas discrepancias podrían ser debidas a las distintas condiciones de operación debido a la geometría de la celda de filtración, la velocidad de 
recirculación, etc. Sin embargo, pensamos que las altas retenciones encontradas con las membranas planas pueden ser debidas a que con áreas de membrana tan pequeña, este sistema no estuviese aún en estado estacionario y los valores de la figura 2.16 tengan un cierto error para las membranas DK y DL.

c) Retención verdadera

Para el cálculo de la retención verdadera de los módulos de membrana con los azúcares, se utilizan las mismas ecuaciones que para las membranas planas. No obstante, en este caso tenemos que hacer las siguientes consideraciones para el cálculo de los números adimensionales:

$\checkmark$ El diámetro hidráulico lo suponemos igual al espaciado dado en las especificaciones de los módulos (ver tabla 2.11).

$\checkmark$ La velocidad a través del canal, se calcula como flujo de recirculación (ver tabla 2.14) dividido por el área de la superficie transversal del canal de la membrana. Esta área se calcula como la longitud de la membrana desenrollada (calculada dividiendo el área por la longitud del módulo, que sería el ancho de la membrana), por el diámetro hidráulico. Los datos de velocidad tangencial obtenidos se muestran en la tabla tabla 2.18.

Al igual que con la filtración de membranas planas, en la filtración con los módulos de membranas se obtiene régimen laminar [45-46]: En este caso los valores del número de Re son 7.5 para el módulo de membrana HL, 15.4 para los módulos GH y DK y 92.5 para el módulo DL.

$\checkmark$ Para el cálculo del coeficiente de transferencia de masa $K_{m}$ y la concentración en la superficie de la membrana $C_{m}$, se utilizan las mismas ecuaciones que para las membranas planas.

Tabla 2.18 Área transversal y velocidad transversal de los módulos de membrana.

\begin{tabular}{|c|c|c|}
\hline Módulo membrana & At $\left(\mathbf{1 0}^{-4} \mathbf{~ m}^{\mathbf{2}}\right)$ & Vt $(\mathbf{m} / \mathbf{s})$ \\
\hline GH1812C (20 bar) & 8.47 & 0.0197 \\
\hline HL2540FM (14 bar) & 18.7 & 0.0089 \\
\hline DL1812C (20 bar) & 8.47 & 0.1181 \\
\hline DK1812C (20 bar) & 8.47 & 0.0197 \\
\hline
\end{tabular}

Las retenciones verdaderas para la misma presión de trabajo de las disoluciones de azúcar se muestran en la tabla 2.19. 
Tabla 2.19 Retenciones verdaderas de los módulos espirales en la filtración de una disolución de azúcar a la máxima presión aplicada.

\begin{tabular}{|c|c|}
\hline Módulo membrana & $\boldsymbol{R}(\%)$ \\
\hline GH1812C (20 bar) & 35.04 \\
\hline HL2540FM (14 bar) & 63.32 \\
\hline DL1812C (20 bar) & 41.47 \\
\hline DK1812C (20 bar) & 54.82 \\
\hline
\end{tabular}

En la figura 2.22 están representados los valores de retención verdadera en función de la presión. Tanto en la figura como en la tabla podemos comparar la retención verdadera con la observada. Las mayores diferencias se observan con los módulos de menor retención DL1812C y sobre todo GH1812C.

El comportamiento esperable es que la retención verdadera aumente o se mantenga constante con la presión. Esto es lo que se observa, dentro del margen de error experimental, con los módulos de membrana de nanofiltración. En el caso de la membrana $\mathrm{GH}$, hay una caída significativa de $R$ con la presión. Esto nos lleva a pensar que el modelo para el cálculo de $R$ con esta membrana no es el apropiado. En este caso, debido a la baja retención, la alta transferencia de masa, hubiera hecho necesario corregir el cálculo de coeficiente de transferencia de masa considerando el efecto de succión [47].

Como se puede comprobar, el módulo de membrana de mayor retención verdadera es el HL2540FM, después seguiría la membrana de nanofiltración DK1812C, el DL1812C y por último la membrana de ultrafiltración GH1812C. Este orden de retención es el mismo que obtuvimos para las membranas planas.

\subsection{2) Resultados con el mosto tinto comercial}

\section{a) Permeabilidad hidráulica}

Los valores de permeabilidad obtenidos después de la filtración de los mostos tintos comerciales con los módulos de membrana espiral, se muestran en la tabla 2.20.

Para comparar la permeabilidad antes y después de la filtración del mosto tinto comercial, consideramos que la permeabilidad antes de la filtración se corresponde a la obtenida después de la filtración de la disolución de azúcar (última columna de la tabla 2.16), puesto que este sería el estado de la membrana antes del proceso de filtración de mostos. El comportamiento esperado es una disminución de la 
permeabilidad de la membrana después de la filtración de mostos debida al efecto de ensuciamiento. No obstante vemos que la permeabilidad no siempre disminuye, sino que se mantiene aproximadamente constante. Este comportamiento puede ser debido a que durante el proceso de almacenamiento de la membrana, en algunos casos, haya ganado permeabilidad por eliminación de sustancias adheridas a la superficie. En cualquier caso, lo verdaderamente importante, es que la membrana no sufre disminuciones de permeabilidad significativas por la presencia del mosto.

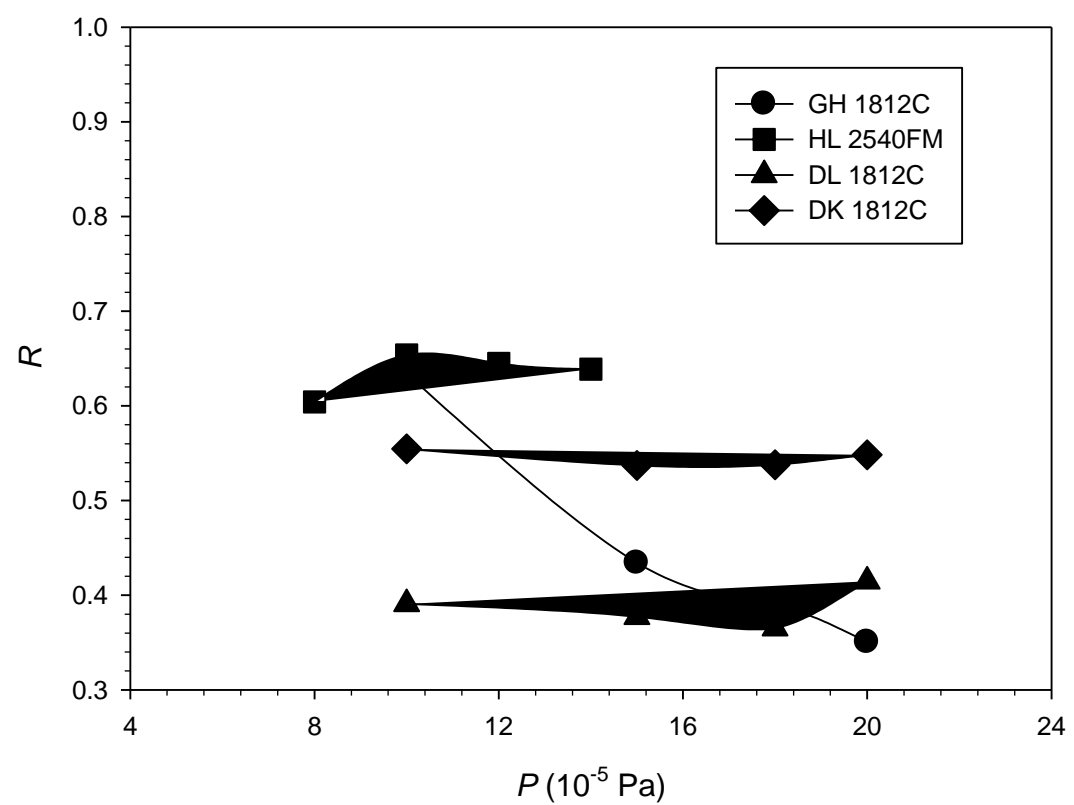

Figura 2.22 Retenciones verdaderas de la disolución de azúcar con los módulos de membranas espirales.

Los procesos de limpieza de la membrana dan variaciones difíciles de explicar. Es posible que aunque el detergente limpie la capa superficial de la membrana, sus moléculas sean del tamaño de algunos de los poros, taponando parte de éstos durante el proceso de limpieza. Sin embargo, después del almacenamiento de los módulos de membrana en fenol, se obtienen unos valores muy próximos a los de la permeabilidad inicial de los módulos espirales, lo que nos indica que la recuperación de la funcionalidad de la membrana con el tratamiento de limpieza aplicado, es adecuada. 
Permeabilidades de los módulos de membranas espirales después de la filtración de los mostos comerciales y de la posterior limpieza.

\begin{tabular}{|c|c|c|c|}
\hline \multirow{2}{*}{ Módulo membrana } & $\begin{array}{c}\text { Después del } \\
\text { mosto } \\
\text { comercial }\end{array}$ & $\begin{array}{c}\text { Después de la } \\
\text { limpieza con } \\
\text { detergente }\end{array}$ & $\begin{array}{c}\text { Después de la } \\
\text { limpieza con } \\
\text { fenol }\end{array}$ \\
\cline { 2 - 4 } & \multicolumn{3}{|c|}{$L_{p}\left(10^{-11} \mathrm{~m} /(\mathrm{s} \cdot \mathrm{Pa})\right)$} \\
\hline GH1812C & 0.502 & 0.462 & 0.497 \\
\hline HL2540FM & 1.761 & 1.173 & $--^{1}$ \\
\hline DL1812C & 1.027 & $--{ }^{1}$ & 1.287 \\
\hline DK1812C & 0.619 & 0.748 & 0.760 \\
\hline
\end{tabular}

${ }^{1}$ Valores no determinados

b) Retención observada

El mosto tinto comercial modificado, como ya dijimos, se obtiene añadiendo glucosa y fructosa al mosto comercial hasta obtener unas concentraciones similares a los mostos de uva.

La retención observada de los módulos de membrana se calcula como explicamos en el caso de la filtración de la disolución de azúcar. Al igual que en ese caso, las concentraciones se miden con el polarímetro. Los resultados de las concentraciones, reducción probable de grado alcohólico y retención observada se muestran en la tabla 2.21 para la presión de trabajo.

Tabla 2.21 Concentración de alimentación, concentración de permeado, reducción de grado alcohólico y retención observada para los módulos espirales en la filtración de mosto comercial modificado.

\begin{tabular}{|c|c|c|c|c|}
\hline Módulo membrana & $\boldsymbol{C}_{\boldsymbol{0}}(\mathbf{g} / \mathbf{L})$ & $\boldsymbol{C}_{\boldsymbol{p}}(\mathbf{g} / \mathbf{L})$ & $\begin{array}{c}\text { Grados de alcohol } \\
\text { probable reducidos }\end{array}$ & $\boldsymbol{R}_{\boldsymbol{0}}$ \\
\hline GH1812C (22 bar) & 190.36 & 152.28 & 0.73 & 20.00 \\
\hline HL2540FM (19 bar) & 253.81 & 65.99 & 10.73 & 74.00 \\
\hline DL1812C (20 bar) & 203.05 & 126.90 & 4.35 & 37.50 \\
\hline DK1812C (20 bar) & 228.43 & 101.52 & 7.25 & 55.56 \\
\hline
\end{tabular}


c) Retención verdadera

La retención verdadera se calcula del mismo modo que para la disolución de azúcar. Los valores de retención obtenidos tras la filtración del mosto tinto comercial modificado se presentan en la tabla 2.22.

Tabla 2.22 Retenciones verdaderas de los módulos espirales tras la filtración de mosto comercial modificado.

\begin{tabular}{|c|c|}
\hline Módulo membrana & $\boldsymbol{R}$ \\
\hline GH1812C (22 bar) & 26.18 \\
\hline HL2540FM (19 bar) & 74.50 \\
\hline DL1812C (20 bar) & 40.80 \\
\hline DK1812C (20 bar) & 55.63 \\
\hline
\end{tabular}

El módulo de membrana con el que mayor retención de azúcar se obtiene, es el módulo HL2540FM, después tendríamos las otras dos membranas de nanofiltración, DL1812C y DK1812C, y finalmente la membrana de ultrafiltración GH1812C. Es el mismo orden que obtuvimos con las membranas planas, teniendo en cuenta que la membrana plana NF-DL no se pudo utilizar para la filtración del mosto tinto comercial, puesto que no se podía aplicar la presión suficiente en la filtración.

Del mismo modo, el orden de retención verdadera del mosto tinto comercial modificado, coincide con el de la disolución de azúcar para los módulos de membranas espirales. De forma similar a las disoluciones de azúcar, los valores de $R$ y $R_{0}$ son más similares para las membranas más retentivas (HL2540FM y DK1812C) que para las menos retentivas (DL1812C y GH1812C).

d) Caída de Flujo

Al igual que para las membranas planas con mosto, con los módulos espirales es importante conocer la vida útil de las membranas. Para realizar este análisis se ha medido la caída de flujo en función del tiempo para los tres módulos de membrana de nanofiltración (ver figura 2.23). No se obtienen los datos del módulo de la membrana de ultrafiltración, GH1812C, puesto que la filtración era mucho más rápida que las posibles medidas de flujo, ya que la cantidad de mosto comercial modificado a filtrar no era muy grande (2 litros). Por el contrario, la membrana DK, al tener menor permeabilidad, necesita mayores tiempos para filtrar esos dos litros que las otras membranas de nanofiltración. Vimos en la figura 2.19 que las membranas NF-HL y NF-DK tenían un comportamiento muy similar, no obstante en este caso hay notables 
diferencias. El flujo del módulo con la membrana HL cae más rápidamente que el de la DK, lo que dará lugar a un mayor ensuciamiento de la membrana por mayor retención de compuestos de alto peso molecular. Esta diferencia tiene que ser debida a la diferencia de la configuración entre ambos módulos, la distinta carga de las membranas (al pH del mosto, la membrana HL está cargada negativamente y la DK positivamente) [48], y a la diferente velocidad transversal entre ambas membranas (ver tabla 2.18). Téngase en cuenta que las membranas UF-GH, NF-DK y NF-DL tienen distinto tipo de módulo que la NF-HL (ver tabla 2.11).

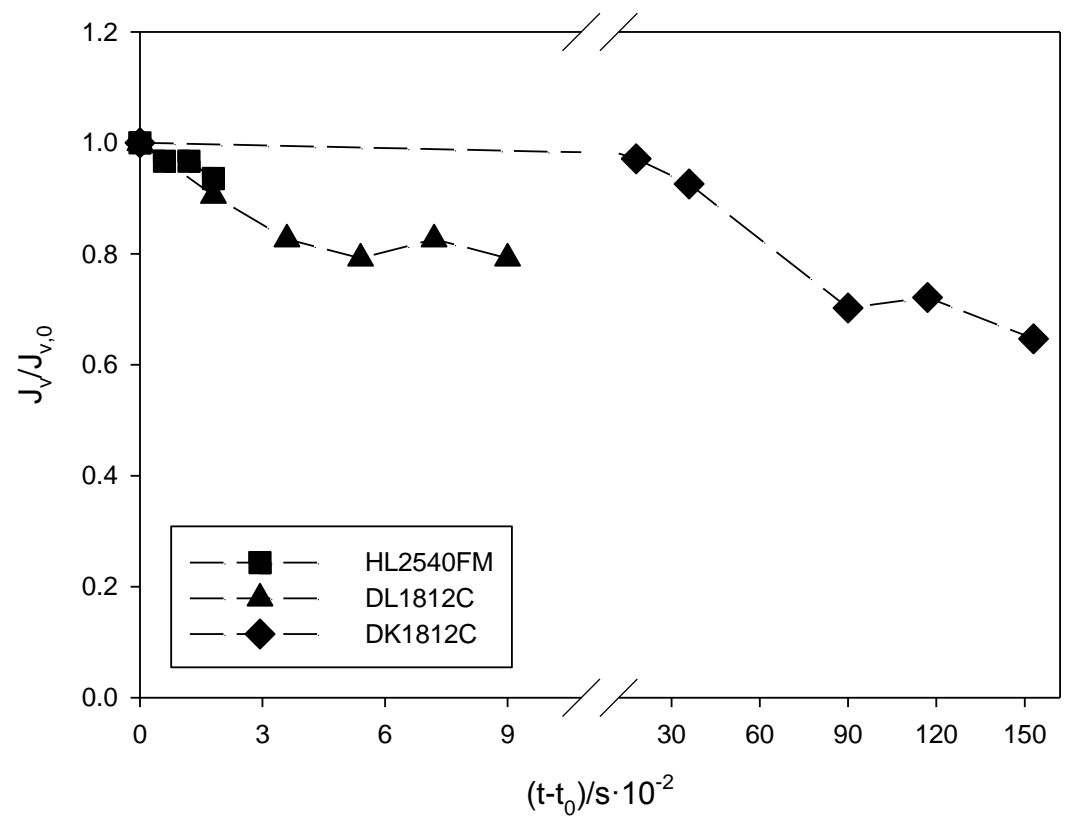

Figura 2.23 Flujo relativo frente al tiempo de filtración para módulos espirales, tras la filtración de mosto comercial modificado.

Por otra parte, en la membrana $\mathrm{DL}$, el flujo cae más rápidamente que en la membrana DK. En este caso estamos comparando dos módulos con la misma configuración, tamaño, área de membrana y espaciado. Aunque la velocidad tangencial es diez veces mayor en la DL que en la DK, lo que debería provocar un menor ensuciamiento en la DL, la explicación a este comportamiento puede deberse a dos factores:

- La menor retención de la membrana DL frente a la DK haría que sustancias de mayor tamaño podrían estar en los poros bloqueándolos.

- Su distinta carga eléctrica al $\mathrm{pH}$ del mosto ( $\mathrm{pH} 3$ ). En esas condiciones la membrana DK está cargada positivamente mientras que la DL tiene carga negativa [48]. La membrana DL tendrá con gran afinidad por moléculas positivas provocando esa caída de flujo más acusada. 


\section{CONCLUSIONES}

Para la elección de las membranas, el valor de retención observada no debería ser considerado como un parámetro absoluto ya que en las membranas de nanofiltración, el mecanismo de exclusión por tamaño no es el más importante. Se deben tener en cuenta, además, los efectos de adsorción, concentración de polarización, la dependencia con la presión y la concentración de alimentación.

Respecto a la retención, deberíamos considerar como valor de referencia la retención verdadera con cada sustancia. Si tenemos fijado el valor de la concentración de alimentación, deberíamos tender a trabajar con la mayor velocidad de alimentación que permita el sistema. Respecto a la presión, debemos aumentarla hasta alcanzar el flujo límite, para el cual valores superiores de presión no suponen un aumento significativo del flujo. Respecto al valor de retención apropiado, tendremos que buscar una membrana cuya retención observada en las condiciones de trabajo sea del orden del $50 \%$. Esto permitirá dejar pasar sin dificultad las sustancias de bajo peso molecular, retener las de alto y dejar pasar parcialmente los azúcares. Así se permitiría el diseño de un proceso de eliminación de azúcar con una doble filtración del primer permeado, recomponiendo un mosto con el segundo permeado y el retenido.

Respecto al flujo, deberíamos buscar la membrana con mayor permeabilidad, ya que esto acortaría el tiempo del proceso, evitando problemas como la desnaturalización de sustancias, la pérdida de aromas, la aparición de efectos de oxidación, etc. Junto con esto debemos buscar una membrana que tenga un material con la menor afinidad posible por las sustancias presentes en el mosto, ya que así reducimos el ensuciamiento de la superficie y por tanto el tiempo de filtración.

Finalmente hay que tener en cuenta la configuración y la geometría del módulo, ya que una geometría apropiada puede permitir una mayor efectividad en el proceso.

Después de la caracterización de las tres membranas de nanofiltración y la membrana de ultrafiltración, decidimos elegir la membrana HL para la filtración de los mostos de uva Verdejo y Tinta de Toro, de la primera campaña 2007/2008. Esta membrana tiene un alto valor de permeabilidad, además de ser la membrana con mayor retención verdadera de azúcar, tanto en la filtración de disoluciones de azúcar como de mostos comerciales.

La membrana elegida ha mostrado poseer una distribución de tamaños de poro en un rango aceptable, lo que permite alcanzar esas retenciones parciales de azúcar en 
mostos. Finalmente comentar que el modelo ensayado para el estudio de la membrana $\mathrm{HL}$ con solutos neutros, (Teoría de película en la capa de polarización y modelo de fricción en los poros) permite estimar la retención observada y verdadera en función de los parámetros de operación. Esto nos permitirá preseleccionar las condiciones de operación más apropiadas para la aplicación reduciendo el número de ensayos.

\section{LISTA DE SÍMBOLOS}

\section{Latinos}

A Constante

$A_{k}$ Porosidad de la membrana

C Concentración

$C_{0}$ Concentración de alimentación

$C_{g}$ Concentración en la capa de gel

$C_{m}$ Concentración en la superficie de la membrana

$C_{p}$ Concentración de permeado

$D$ Coeficiente de difusión de la disolución

$d_{h}$ Diámetro hidráulico

$J_{S}$ Flujo del soluto

$J_{v}$ Flujo en volumen a través de la membrana

$J_{v, l i m}$ Flujo límite

$J_{v, t}$ Flujo en volumen transmitido a través de los poros que no retienen el soluto

$J_{w}$ Flujo de agua total

$J_{w, r}$ Flujo de agua que pasa a través de los poros retentivos

$J_{w, t}$ Flujo de agua transmitido a través de los poros que no retienen el soluto 
k Constante de Boltzmann

$K_{c}$ Coeficiente del efecto de fricción

$K_{c}^{\prime}$ Coeficiente del efecto de fricción corregido por efecto de la presión

$K_{d}$ Coeficiente del efecto de difusión

$K_{d}^{\prime}$ Coeficiente del efecto de difusión corregido por efecto de la presión

$K_{m}$ Coeficiente de transferencia de masa

$l$ Camino óptico

L Longitud del canal sobre la membrana

$L_{p}$ Permeabilidad hidraúlica

$M_{w}$ Peso molecular

$R$ Retención verdadera

$R_{g}$ Constante de los gases ideales

$R_{\max }$ Retención máxima

$R_{o}$ Retención observada

$r_{p}$ Radio de poro

$r_{s}$ Radio de soluto

$\mathrm{r}_{\mathrm{sc}}$ Diámetro hidráulico de la celda agitada

$\mathrm{r}_{\text {Stokes }}$ Radio de Stokes

Pe Número adimensional de Péclet

Re Número adimensional de Reynolds

Sc Número adimensional de Schmidt

Sh Número adimensional de Sherwood

$T$ Temperatura

$v$ Velocidad de recirculación 


\section{Griegos}

$\alpha$ Constante (en la ecuación 7)

$\alpha$ Ángulo de rotación

$\beta$ Constante

$\Delta p$ Caída de presión

$\Delta x$ Espesor de la capa activa de la membrana

$\Delta \Pi$ Diferencia de presión osmótica

$\delta_{c}$ Espesor de la capa de concentración

$\eta$ Viscosidad

$\lambda$ Factor de impedimento estérico

$\rho$ Densidad

$\phi$ Coeficiente de partición para poros cilíndricos

$\omega$ Velocidad angular

\section{REFERENCIAS}

1. Palacio, L., Caracterización estructural y superficial de membranas microporosas. Universidad de Valladolid, 1998.

2. Schaefer, A. I., Fane, A. G., and Waite, T. D., Nanofiltration: principles and applications. 2003, New York: Elsevier Advanced Technology.

3. Prádanos, P., Estudio y caracterización de membranas de ultrafiltración. Su aplicación a procesos de interés enológico. Universidad de Valladolid, 1994.

4. Otero, J. A., Mazarrasa, O., Villasante, J., Silva, V., Prádanos, P., Calvo, J. I., and Hernández, A., Three independent ways to obtain information on pore size distributions of nanofiltration membranes. Journal of Membrane Science, 2008. 309(1-2): p. 17-27.

5. Prádanos, P., Arribas, J. I., and Hernández, A., Mass transfer coefficient and retention of PEGs in low pressure cross-flow ultrafiltration through asymmetric membranes. Journal of Membrane Science, 1995. 99(1): p. 1-20. 
6. Prádanos, P. and Hernández, A., Cross-flow ultrafiltration of proteins through asymmetric polysulfonic membranes: I. Retention curves and pore size distributions. Biotechnology and Bioengineering, 1995. 47(6): p. 617-625.

7. García-Martín, N., Silva, V., Carmona, F. J., Palacio, L., Hernández, A., and Prádanos, P., Pore size analysis from retention of neutral solutes through nanofiltration membranes. The contribution of concentration-polarization. Desalination, 2014. 344(0): p. 1-11.

8. Ochoa, N. A., Prádanos, P., Palacio, L., Pagliero, C., Marchese, J., and Hernández, A., Pore size distributions based on AFM imaging and retention of multidisperse polymer solutes: Characterisation of polyethersulfone UF membranes with dopes containing different PVP. Journal of Membrane Science, 2001. 187(1-2): p. 227-237.

9. Dechadilok, P. and Deen, W. M., Hindrance Factors for Diffusion and Convection in Pores. Industrial \& Engineering Chemistry Research, 2006. 45(21): p. 6953-6959.

10. Silva, V., Prádanos, P., Palacio, L., and Hernández, A., Alternative pore hindrance factors: What one should be used for nanofiltration modelization? Desalination, 2009. 245(1-3): p. 606-613.

11. B. Kwon, S. L., M.B. Gu and J. Cho, Minimization of membrane organic fouling and haloacetic acids formation by controlling amino sugars and/or polysaccharide-like substances included in colloidal NOM MiWater Science and Technology: Water Supply, 2003. 3: p. 223-228.

12. A. A. Hussain, M. E. E. A., and I. S. Al-Mutaz, Prediction of Charge Density for Desal-HL Nanofiltration Membrane from Simulation and Experiment using Different Ion Radii. Separation Science and Technology, 2007. 42: p. 43-57.

13. Tang, C. Y., Kwon, Y.-N., and Leckie, J. O., Effect of membrane chemistry and coating layer on physiochemical properties of thin film composite polyamide $R O$ and NF membranes: I. FTIR and XPS characterization of polyamide and coating layer chemistry. Desalination, 2009. 242(1-3): p. 149-167.

14. Tang, C. Y., Kwon, Y.-N., and Leckie, J. O., Effect of membrane chemistry and coating layer on physiochemical properties of thin film composite polyamide $R O$ and NF membranes: II. Membrane physiochemical properties and their dependence on polyamide and coating layers. Desalination, 2009. 242(1-3): p. 168-182.

15. Religa, P., Kowalik-Klimczak, A., and Gierycz, P., Study on the behavior of nanofiltration membranes using for chromium(III) recovery from salt mixture solution. Desalination, 2013. 315(0): p. 115-123. 
16. Boussu, K., Van der Bruggen, B., Volodin, A., Van Haesendonck, C., Delcour, J. A., Van der Meeren, P., and Vandecasteele, C., Characterization of commercial nanofiltration membranes and comparison with self-made polyethersulfone membranes. Desalination, 2006. 191(1-3): p. 245-253.

17. Labanda, J., Vichi, S., Llorens, J., and López-Tamames, E., Membrane separation technology for the reduction of alcoholic degree of a white model wine. LWT - Food Science and Technology, 2009. 42(8): p. 1390-1395.

18. Ferrarini, R., Versari, A., and Galassi, S., A preliminary comparison between nanofiltration and reverse osmosis membranes for grape juice treatment. Journal of Food Engineering, 2001. 50(2): p. 113-116.

19. Zemánková, K., Troncoso, J., and Romaní, L., Excess volumes and excess heat capacities for alkanediol+water systems in the temperature interval (283.15-313.15)K. Fluid Phase Equilibria, 2013. 356(0): p. 1-10.

20. Nain, A. K., Densities and volumetric properties of (formamide + ethanol, or 1propanol, or 1,2-ethanediol, or 1,2-propanediol) mixtures at temperatures between $293.15 \mathrm{~K}$ and $318.15 \mathrm{~K}$. The Journal of Chemical Thermodynamics, 2007. 39(3): p. 462-473.

21. Lide, D., CRC Handbook of Chemistry and Physics. 75th ed. 1994: CRC Press.

22. Togores, J. H., La calidad del vino desde el viñedo, ed. Mundi-Prensa. 2010.

23. Martínez, F., Martín, A., Malfeito, J., Palacio, L., Prádanos, P., Tejerina, F., and Hernández, A., Streaming potential through and on ultrafiltration membranes: Influence of salt retention. Journal of Membrane Science, 2002. 206(1-2): p. 431-441.

24. Refractometers for the measurement of the sugar content of grape must. OIML R 124, 1997.

25. Compendium of international Methods of wine and must Analysis (OIV) 2011. 1.

26. Paronetto, L., Polifenoli e tecnica enologica. Selepress ed. 1977, Milan (Italy).

27. Wang, M.-H., Soriano, A. N., Caparanga, A. R., and Li, M.-H., Mutual diffusion coefficients of aqueous solutions of some glycols. Fluid Phase Equilibria, 2009. 285(1-2): p. 44-49.

28. Fernández-Sempere, J., Ruiz-Beviá, F., Colom-Valiente, J., and Más-Pérez, F., Determination of Diffusion Coefficients of Glycols. Journal of Chemical \& Engineering Data, 1996. 41(1): p. 47-48.

29. Paduano, L., Sartorio, R., D'Errico, G., and Vitagliano, V., Mutual diffusion in aqueous solution of ethylene glycol oligomers at $25^{\circ} \mathrm{C}$. Journal of the Chemical Society, Faraday Transactions, 1998. 94(17): p. 2571-2576. 
30. Callendar, R. and Leaist, D., Diffusion Coefficients for Binary, Ternary, and Polydisperse Solutions from Peak-Width Analysis of Taylor Dispersion Profiles. Journal of Solution Chemistry, 2006. 35(3): p. 353-379.

31. Rautenbach, R. and Albrecht, R., Membrane Processes, ed. John Wiley and Sons. 1989.

32. Braeken, L., Bettens, B., Boussu, K., Van der Meeren, P., Cocquyt, J., Vermant, J., and Van der Bruggen, B., Transport mechanisms of dissolved organic compounds in aqueous solution during nanofiltration. Journal of Membrane Science, 2006. 279(1-2): p. 311-319.

33. Huisman, I. H., Prádanos, P., and Hernández, A., The effect of protein-protein and protein-membrane interactions on membrane fouling in ultrafiltration. Journal of Membrane Science, 2000. 179(1-2): p. 79-90.

34. Hoek, E. M. V. and Elimelech, M., Cake-Enhanced Concentration Polarization: A New Fouling Mechanism for Salt-Rejecting Membranes. Environmental Science \& Technology, 2003. 37(24): p. 5581-5588.

35. Choi, H., Zhang, K., Dionysiou, D. D., Oerther, D. B., and Sorial, G. A., Influence of cross-flow velocity on membrane performance during filtration of biological suspension. Journal of Membrane Science, 2005. 248(1-2): p. 189199.

36. Venâncio, A. and Teixeira, J. A., Characterization of sugar diffusion coefficients in alginate membranes. Biotechnology Techniques, 1997. 11: p. 183-185.

37. García-Martín, N., Palacio, L., Prádanos, P., Hernández, A., Ortega-Heras, M., Pérez-Magariño, S., and González-Huerta, D. C., Evaluation of several ultraand nanofiltration membranes for sugar control in winemaking. Desalination, 2009. 245(1-3): p. 554-558.

38. Jonsson, G., Prádanos, P., and Hernández, A., Fouling phenomena in microporous membranes. Flux decline kinetics and structural modifications. Journal of Membrane Science, 1996. 112(2): p. 171-183.

39. Levine, I. N., Fisicoquímica. 4 ed. Vol. 2. 1996: Mc Graw Hill.

40. Ribéreau-Gayon, P., Glories, Y., Maujean, A., and Dubourdieu, D., Handbook of Enology: The Chemistry of Wine Stabilization and Treatments. 2 ed, ed. Ltd John Wiley \& Sons. Vol. 2. 2006.

41. Vosburgh, W. C., The optical rotation of mixtures of sucrose, gluxose and fructose. Journal of the American Chemical Society, 1921. 43(2): p. [219]-232.

42. Ribéreau-Gayon, P., Dubourdieu, D., Donèche, B., and Lonvaud, A., Handbook of Enology: The Microbiology of Wine and Vinifications. 2 ed, ed. L. John Wiley \& Sons. Vol. 1. 2006. 
43. Ribéreau-Gayon, P., Glories, Y., Maujean, A., and Dubourdieu, D., Tratado de Enología: Química del Vino. Estabilización y Tratamientos, ed. Mundi-Prensa. Vol. 2. 2003.

44. Barceló, J. G., Técnicas Analíticas para Vinos, ed. GAB. 1990.

45. Nyström, M., Butylina, S., and Platt, S., NF retention and critical flux of small hydrophilic/hydrophobic molecules. Membrane Technology, 2004. 2004(10): p. 5-8.

46. Lin, C.-J., Shirazi, S., Rao, P., and Agarwal, S., Effects of operational parameters on cake formation of CaSO4 in nanofiltration. Water Research, 2006. 40(4): p. 806-816.

47. Silva, V., Geraldes, V., Alves, A. M. B., Palacio, L., Pradanos, P., and Hernandez, A., Multi-ionic nanofiltration of highly concentrated salt mixtures in the seawater range. Desalination, 2011. 277(1-3): p. 29-39.

48. Al-Amoudi, A., Williams, P., Mandale, S., and Lovitt, R. W., Cleaning results of new and fouled nanofiltration membrane characterized by zeta potential and permeability. Separation and Purification Technology, 2007. 54(2): p. 234-240. 



\section{CAPÍTULO 3 DISEÑO DEL PROCESO DE FILTRACIÓN.}

\section{INTRODUCCIÓN}

Después de los ensayos de caracterización de las diferentes membranas estudiadas, tanto de nanofiltración como de ultrafiltración, se concluye, como se ha visto en el capítulo 2, que la utilización de la membrana de nanofiltración HL es la más apropiada para la filtración tanto del mosto blanco de la variedad Verdejo, como del mosto tinto de la variedad Tinta de Toro [1-2].

\section{MATERIALES USADOS Y DISPOSITIVOS EXPERIMENTALES}

\subsection{MEMBRANAS}

El módulo de membrana de nanofiltración HL2540FM, utilizado para la filtración de la disolución de azúcar y el mosto tinto comercial descrito en el capítulo anterior, sufre una etapa de eliminación del conservante, lavado con agua del grifo durante dos horas y agua milli-Q durante otras dos horas. Después de la eliminación del conservante, tendrá lugar el acondicionamiento de la membrana, pasando agua milli- $Q$ hasta que alcancemos un valor de flujo constante, aplicando las condiciones mostradas en la tabla 2.12 del capítulo anterior. Tras este acondicionamiento, se puede comenzar la filtración del mosto.

\subsection{ELABORACIÓN Y PREPARACIÓN DE MOSTOS}

Los mostos utilizados para las filtraciones son los siguientes:

> Mosto blanco de la variedad Verdejo (D.O. Rueda): la uva se vendimia en Septiembre de 2007 y la obtención de este mosto se realizó siguiendo el método tradicional de elaboración en blanco.

Se llevaron a cabo las siguientes etapas: despalillado, estrujado, sulfitado y prensado. Después del prensado, al mosto obtenido, se le añaden enzimas pectolíticas para favorecer su desfangado. Tras el desfangado, este mosto ha sido filtrado previamente por una malla de 0.8 micras, para eliminar sólidos y partículas que interfieran en el proceso de filtración. El mosto que finalmente ha sido utilizado para la nanofiltración tiene una concentración de azúcar de 209 g/L y una turbidez de 9.5 NTU. 
> Mosto tinto de la variedad Tinta de Toro (D.O. Toro): la uva se vendimia en Septiembre de 2007 y al igual que el mosto blanco, se siguieron los métodos tradicionales para elaboración de uva tinta. Los pasos a seguir fueron: despalillado y estrujado, en esta etapa, la masa fue sulfitada y prensada inmediatamente para su conservación inmediata hasta que fue añadida a los mostos con menor contenido en azúcar para realizar la fermentación alcohólica.

El mosto resultante de la fase de estrujado, se desfangó y se filtró previamente por placas de 3 micras y a continuación otra de 0.8 micras. El mosto obtenido finalmente tiene una concentración de azúcar de $244 \mathrm{~g} / \mathrm{L}$ y la turbidez 3.6 NTU.

Como hemos indicado, ambos mostos contienen una dosis prefermentativa de sulfuroso para proteger el mosto en el proceso de filtración. La dosis prefermentativa máxima es de $50 \mathrm{mg} / \mathrm{L}$, aunque generalmente el mosto blanco tuvo una dosis superior (30-40 mg/L) que el mosto tinto (25-30 mg/L) [3].

Las levaduras utilizadas para la fermentación de los mostos en los dos casos son Saccharomyces cerevisiae; en el caso de los mostos blancos se utiliza la levadura comercial IOC 18-2007 del Institut Oenologique de Champagne, y para los mostos tintos la levadura comercial Excellence SP de Lamothe-Abiet.

\subsection{DISPOSITIVO EXPERIMENTAL}

El equipo utilizado es el que se describe en el apartado 4.1.3 del capítulo 2 para las medidas con módulos de membrana espiral. La única diferencia respecto a este esquema es la utilización de una unidad refrigerante en el depósito de alimentación [45].

Este equipo de frío (SELECTA Frigedor-Reg) consta de un serpentín que se introduce en el depósito de alimentación, en el cuál se introduce también una sonda de temperatura. De este modo, se controla la temperatura digitalmente, manteniendo constante dicha temperatura en el valor seleccionado.

Las condiciones de filtración con cada mosto se explican a continuación:

- Mosto Verdejo: En el depósito de alimentación del sistema de filtración se añaden 30 litros de mosto. Después, se introduce el serpentín del refrigerador y se ajusta la temperatura a $3^{\circ} \mathrm{C}$ para que no tener problemas de fermentación del mosto. La presión aplicada debe ser superior a la presión osmótica para 
poder obtener permeado [6], por lo tanto, para tener un flujo de recirculación aceptable $(1 \mathrm{~L} / \mathrm{min})$, se ajusta la presión a 24 bar.

Después de esta primera filtración, se lava el sistema con agua del grifo durante dos horas y con agua milli-Q una hora. Una vez lavado el módulo, el permeado que hemos obtenido en esta primera filtración, se vuelve a filtrar, utilizando una presión de 22 bar, que da lugar a un flujo de recirculación de 1.5 L/min (no podemos utilizar la presión de 24 bar porque el flujo de recirculación se hace 0 , lo que provocaría el calentamiento del módulo y del mosto que pasa por él).

Como hemos mencionado, en el primer proceso de filtración la temperatura se mantuvo a $3^{\circ} \mathrm{C}$, esto provocó que se formase un pequeño bloque de hielo alrededor del serpentín del refrigerador. Este hecho no tiene importancia en la primera etapa porque la filtración se detiene cuando se ha filtrado del orden del $50 \%$ del mosto, como se verá más adelante. En la segunda etapa tiene interés agotar lo máximo posible el volumen del tanque de alimentación y la formación de hielo sería un inconveniente. Por esta causa, en la segunda etapa se termostató la alimentación a $6^{\circ} \mathrm{C}$, evitándose la formación de hielo.

Mosto Tinta de Toro: Al igual que con el mosto Verdejo, se filtrarán 30 litros de mosto y se aplicará la mayor presión para obtener un flujo de recirculación aceptable [6] de $1.5 \mathrm{~L} / \mathrm{min}$; esta presión será de 24 bar. Se regulará el equipo de frío a $6^{\circ} \mathrm{C}$, ya que al tratarse de un mosto tinto tendrá mayor concentración de sólidos y el proceso de filtración será más lento [7]. De este modo se evitará la formación de hielo alrededor del serpentín a temperaturas más bajas.

En la segunda filtración, después de lavar el sistema como en el caso anterior, se mantiene la temperatura a $6^{\circ} \mathrm{C}$. En este caso utilizamos una presión de 22.8 bar, consiguiendo un flujo de recirculación de $1 \mathrm{~L} / \mathrm{min}$.

\subsection{MÉTODOS ANALÍTICOS}

Para conocer de forma rápida e inmediata la concentración de azúcar en la filtración de los mostos Verdejo y Tinta de Toro, se utiliza el refractómetro de Abbe tanto para el mosto blanco como para el mosto tinto. Aunque hay cierta interferencia por el contenido de otras sustancias presentes, la inmediatez de la medida y la necesidad de solo una gota de muestra nos decantó por esta opción, sobre todo teniendo en cuenta que en el permeado, una gran parte de las sustancias originales no están presentes. En el caso de los mostos tintos, el contenido de otras sustancias es mucho más alto 
que en blanco, por esta razón para mosto tinto se utilizó además un polarímetro (Zuzi 404). Una vez que se han realizado las experiencias de filtración, las concentraciones de alimentación, de permeado y los retenidos finales se analizan en la Estación Enológica del ITACyL por personal adscrito al centro mediante un método enzimático, que será un método más exacto que los anteriores. Por ello, utilizaremos estos últimos datos para los cálculos de retención de la membrana.

La explicación de todos los métodos de medida de concentración de azúcar, se explicó en el capítulo anterior, cuando se describieron los métodos de análisis de la concentración de azúcar tanto en la filtración de la disolución de azúcar como la de los mostos tintos comerciales (apartados 3.1.4 y 4.1.4).

Todas las sustancias de bajo peso molecular $(\mathrm{pH}$, acidez total, acidez volátil, ácido tartárico, ácido málico y potasio), el grado alcohólico y parte de los análisis de color (polifenoles totales, índice de color y \% de color), se analizan según los métodos de análisis de la OIV (Organización Internacional de la viña y el vino) [8]. Para el resto de los compuestos coloreados (antocianos, ésteres tartáricos, taninos, catequinas y flavonoles) se utiliza el método espectrofotométrico [3, 9-11]. Estos análisis también son realizados en la Estación Enológica del ITACyL.

El análisis aromático de los diferentes vinos elaborados se realiza en la Universidad de Burgos por el Dpto. de Biotecnología y Ciencia de los Alimentos, los compuestos volátiles se aislaron mediante una extracción líquido-líquido. Se introducen $250 \mathrm{~mL}$ de vino, $5 \mathrm{~mL}$ de diclorometano y $50 \mu \mathrm{L}$ de un patrón interno (1000 $\mu \mathrm{g} / \mathrm{L}$ de 2-octanol) en un matraz al que se le ha eliminado previamente el oxígeno mediante nitrógeno. El matraz se colocó en un baño de hielo y se agitó a 150 rpm durante $3 \mathrm{~h}$. Por último, se extrae la fase orgánica y se almacena a $-80^{\circ} \mathrm{C}$ hasta el análisis. Cada muestra se extrajo dos veces [12]. La fracción volátil se analiza mediante cromatografía de gases, de acuerdo con el método propuesto por Ortega-Heras et al. [13].

\section{RESULTADOS}

\subsection{PERMEABILIDAD HIDRÁULICA}

Como vimos en el capítulo anterior (ecuación (1)), para determinar la permeabilidad del módulo espiral HL, se necesitan medidas de flujo de volumen de permeado por unidad de área de membrana para distintos valores de presión. En nuestro caso medimos el flujo para presiones aplicadas de 2, 4, 6, 8 y 10 bar. 
En la tabla 3.1, se muestran los valores de permeabilidad después de filtrar el mosto Verdejo y Tinta de Toro.

Tabla 3.1 Permeabilidad hidráulica con la membrana nueva, después del paso de mosto Verdejo y Tinta de Toro y después de los procesos de limpieza.

\begin{tabular}{|c|c|c|c|c|c|}
\hline Proceso & $\begin{array}{c}\text { Membrana } \\
\text { nueva }\end{array}$ & $\begin{array}{c}\text { Después de } \\
\text { la filtración } \\
\text { de mosto } \\
\text { Verdejo }\end{array}$ & $\begin{array}{c}\text { Después } \\
\text { de la } \\
\text { primera } \\
\text { limpieza* }\end{array}$ & $\begin{array}{c}\text { Después de } \\
\text { la filtración } \\
\text { de mosto } \\
\text { Tinta de Toro }\end{array}$ & $\begin{array}{c}\text { Después } \\
\text { de la } \\
\text { segunda } \\
\text { limpieza* }\end{array}$ \\
\hline$L_{p}\left(10^{-11} \mathrm{~m} /(\right.$ Pa.s $\left.)\right)$ & 1.933 & 1.250 & 1.530 & 1.567 & 1.580 \\
\hline
\end{tabular}

*La limpieza de la membrana se lleva a cabo con una sustancia con propiedades de detergente (dodecil sulfato sódico $0.1 \%$, tamponado a $\mathrm{pH}=9$ ) [14].

Después de la filtración del mosto tinta de Toro, tenemos más permeabilidad que al filtrar el mosto Verdejo. Esto se produce, por eliminación de sustancias del mosto blanco que se han quedado adheridas sobre el módulo de membrana, y que se eliminan al filtrar el mosto tinto. Este fenómeno ya se ha visto en filtración de los mostos tintos comerciales.

\subsection{CURVAS TIEMPO-FLUJO}

En la filtración del mosto blanco, se realizan medidas de flujo de permeado cada 30 minutos para ambos procesos (nanofiltración del mosto original y nanofiltración del permeado obtenido en el primer proceso). Se realizan medidas de flujo con frecuencia diferente, si nos referimos a la primera o a la segunda filtración del mosto tinto. En el mosto tinto, se hacen medidas de flujo de permeado cada hora, en la primera filtración ya que dicha filtración es más lenta, debido a que el mosto tinto tiene más componentes que pueden ser retenidos que el mosto blanco. En la segunda filtración, las medidas de flujo se toman cada 30 minutos, porque ésta filtración es más rápida.

Estas medidas de flujo de permeado en función del tiempo permiten conocer la evolución de los efectos de ensuciamiento de la membrana y del aumento de la presión osmótica.

En las figuras $3.1 \mathrm{a}$ y $\mathrm{b}$ se presenta la cinética de flujo de permeado de mosto. En ella se compara como cae el flujo de mosto en términos del flujo inicial de agua $\left(J_{v} / J_{v, 0}\right)$ frente al tiempo, para los dos mostos (blanco y tinto) y para las dos etapas de filtración. Podemos ver que la caída es mucho más significativa en el caso de los tintos 
que en los blancos. Esta caída de flujo es esperable ya que deben aparecer varios factores que incentivan este proceso [15-16]:

1. Aumento de la presión osmótica, debido al incremento de la concentración en la superficie de la membrana de moléculas pequeñas $\left(C_{m}\right.$, pequeñas), por incremento de su concentración en el retenido $\left(C_{r}\right.$, pequeñas).

2. Aumento de la capa de gelificación en la superficie de la membrana, debido al aumento de la concentración de las moléculas grandes y coloides en la superficie de la membrana ( $C_{m}$, grandes).

3. Aumento de la viscosidad del fluido que pasa por los poros de la membrana, (el retenido tiene más concentración de sustancias, a medida que avanza la filtración).

4. Ensuciamiento, debido a la adhesión reversible o irreversible de moléculas en la superficie de la membrana o en el interior de los poros.
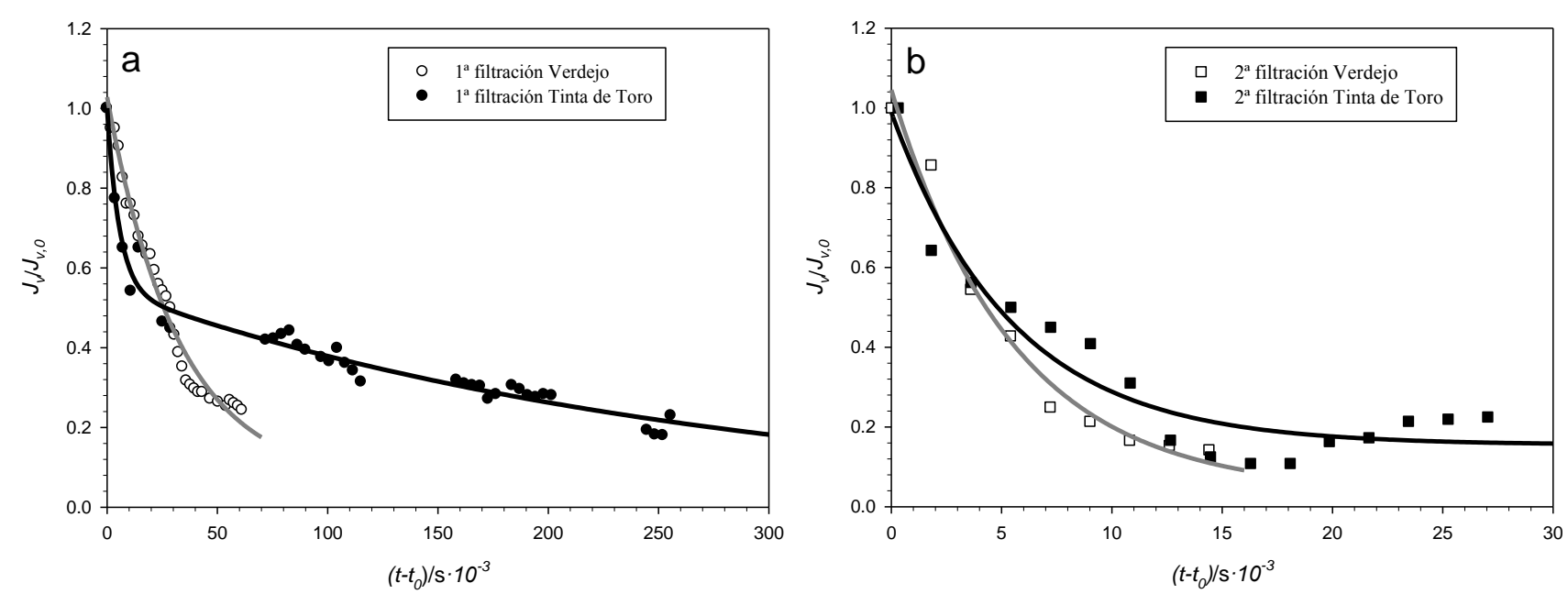

Figura 3.1 Flujo relativo frente al tiempo de filtración para los mostos Verdejo y

Tinta de Toro, (a) primera etapa de filtración y (b) segunda etapa de filtración.

La contribución de los puntos 2, 3 y 4 es mucho más significativa en el caso de los tintos, ya que hay una concentración mucho mayor de moléculas grandes como proteínas, polifenoles, etc. [7], que tienen gran importancia en la formación de la capa de gel y contribuyen de manera significativa en los mecanismos de ensuciamiento. 
Cuando todos estos factores que intervienen en el proceso son tenidos en cuenta, la evolución del flujo de volumen de permeados puede escribirse como:

$$
J_{V}(t)=\frac{\Delta P-\Delta \pi(t)}{\eta(t) R_{s y s}(t)}
$$

donde $\Delta p$ es el gradiente de presión aplicado, $\Delta \pi$ es el gradiente de presión osmótica en cual depende de la diferencia de concentración entre las dos caras de la membrana, $\eta(\mathrm{t})$ es la viscosidad de la disolución y $R_{\text {sys }}(\mathrm{t})$, es la resistencia del sistema, la cual es la suma de una serie de contribuciones:

$$
R_{\text {sys }}(t)=R_{m}+R_{g}(t)+R_{f}(t)
$$

donde $R_{m}$ es la resistencia de la membrana, $R_{g}$ la resistencia de la capa de gel y $R_{f}(\mathrm{t})$ es la resistencia debida el ensuciamiento por adsorción reversible o irreversible de las moléculas sobre la membrana [17-19].

La importancia de estos procesos se incrementa con el tiempo. El primero de los efectos se puede evaluar con facilidad usando el modelo de presión osmótica. El segundo y tercer proceso pueden explicarse usando el modelo de capa de gel con concentración de alimentación variable y como consecuencia del incremento de la viscosidad. El tercer efecto puede ser modelado con diferentes mecanismos cinéticos de ensuciamiento. Estos pueden aparecer simultáneamente aunque con diferentes proporciones a través del proceso [7, 15, 20-21].

- Bloqueo de poros "Pore blocking" que aparece cuando las moléculas tienen un tamaño similar al tamaño de poro. La molécula bloquea el poro anulando su flujo y disminuyendo la permeabilidad de la membrana. En nuestro caso este fenómeno puede producirse por la presencia de las moléculas de glucosa y fructosa y otras de tamaño similar.

- Adsorción en las paredes del poro, reduciendo su tamaño efectivo y por lo tanto el flujo. Este efecto está asociado también a un aumento de la retención.

- Adsorción superficial y acumulación de una capa en la superficie de la membrana. A este efecto se le denomina formación de una torta o "cake". Este "cake" juega el papel de una pseudomembrana que cambia la permeabilidad y la selectividad de la membrana original. Esta capa suele estar formada por moléculas que son más grandes que el tamaño del poro, junto con la contribución de otras pequeñas que se adsorben al polímero y/o se quedan atrapadas en el entramado de esta capa. Se diferencia de la capa de 
polarización de la concentración en su carácter irreversible, y sólo puede ser eliminado por un proceso de limpieza.

La contribución del efecto de presión osmótica debe ser similar para ambos mostos, blancos y tintos, porque la concentración de moléculas pequeñas (sales minerales, azucares, ácidos orgánicos y otras moléculas de pequeño tamaño) es similar en ambos casos, ya que como veremos más adelante la concentración de este tipo de moléculas es similar en ambos mostos. Este hecho se manifiesta en la figura 3.1.b, la cual muestra un comportamiento muy similar para ambos mostos en la segunda filtración. La dramática caída que aparece en la primera filtración es atribuida a la presencia de moléculas de gran tamaño. La contribución de la capa de gel, el incremento de la viscosidad y la formación de una torta, es mucho más significativo en el caso de los mostos tintos, porque hay una concentración mucho mayor de moléculas grandes como proteínas, polifenoles, etc. (ver figura 3.1.a), como veremos más adelante. Los mostos blancos presentan también grandes caídas de flujo en la primera etapa de filtración, pero más lentas que en el caso de los tintos. Esto hace que la filtración de mosto blanco termine antes, ya que en menor tiempo de filtración pasa la misma cantidad de permeado que en tintos. Para la segunda etapa, el mosto blanco presenta también altos flujos, pero decrece más rápido que los tintos porque el tiempo de filtración total es menor, de forma que el efecto de la presión osmótica aumenta más rápidamente, acelerando la reducción de flujo.

La importancia del mecanismo de ensuciamiento se muestra en las figuras 3.2.a y 3.2.b. En las segundas filtraciones, después del lavado con agua, se pone de manifiesto la gran importancia del mecanismo de ensuciamiento, ya que como el primer permeado (P1) tiene menor concentración de moléculas grandes, el flujo inicial del segundo proceso es mayor que el inicial del primero. A este efecto se le debe sumar la disminución de la presión osmótica por la reducción de azúcar y otras sustancias de bajo peso molecular. Todo esto provoca que el tiempo del segundo proceso sea más corto que el primero, para ambos mostos. En estas graficas se muestra claramente que en la primera etapa el mosto blanco permea mucho mas rápido. 

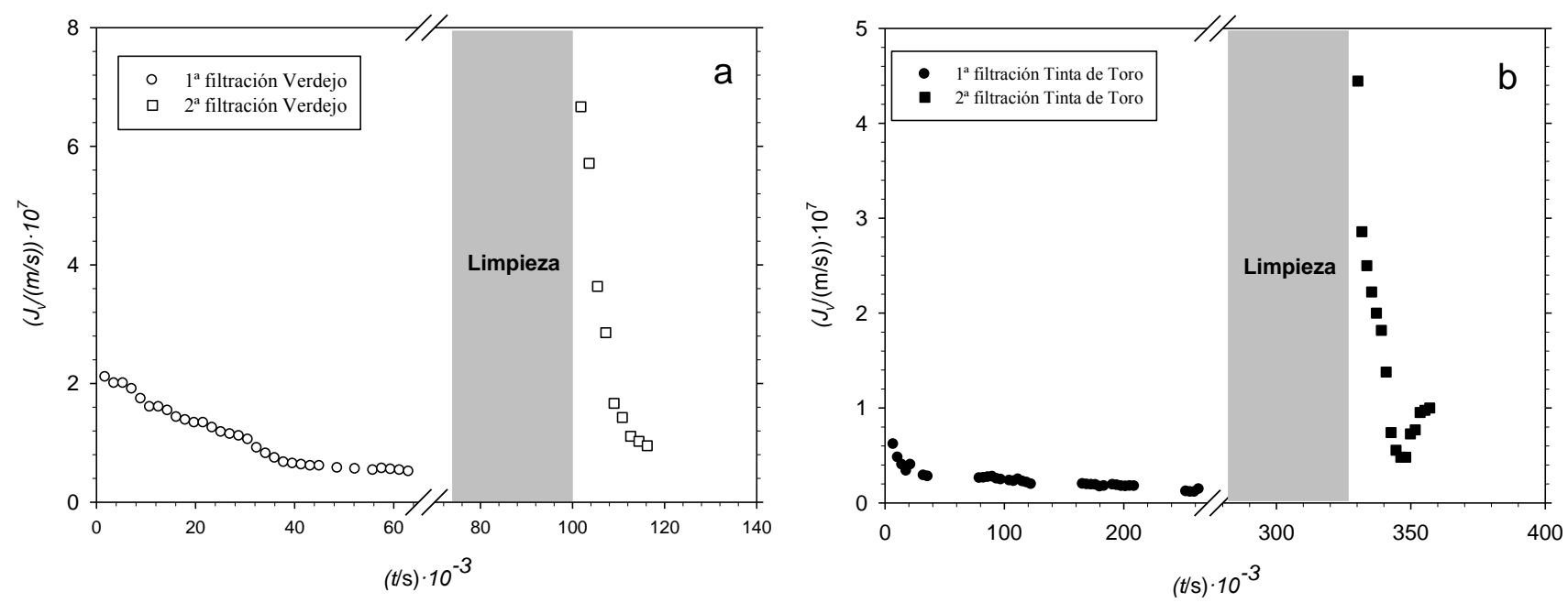

Figura 3.2 Curvas de caída de flujo frente al tiempo para las dos etapas de nanofiltración: mosto variedad Verdejo (a) y mosto variedad Tinta de toro (b)

\subsection{RETENCIÓN DE AZÚCAR}

Todos estos procesos causan cambios en la retención de la membrana a lo largo del tiempo. Para estudiar este efecto para ambos mostos, se ha determinado la concentración de azúcar en función del tiempo tanto para el permeado como para el retenido. Como ya hemos mencionado, en el caso de mostos blancos, la concentración se ha medido por refractometría, mientras que en los mostos tintos se ha usado polarimetría para evitar las interferencias de otras sustancias presentes.

Para ambos mostos, la retención observada se ha calculado al igual que para las membranas planas y para los módulos espirales, con la ecuación (2) del capítulo 2. Y también de la misma forma que en el capítulo 2, la retención verdadera se ha calculado usando la teoría de película.

\subsection{1) Retención observada}

\section{A) Mosto Verdejo}

En el mismo proceso de filtrado de los 30 litros de mosto blanco, en el cuál se midieron las caídas de flujo, se determinó la concentración del permeado cada 30 minutos tanto en la primera como en la segunda filtración. A continuación, se calcula la concentración del tanque de alimentación en función del tiempo mediante un balance de masas, obteniendo de este modo los valores de retención observada del módulo $\mathrm{HL}$ con el mosto blanco. En la primera filtración, además de la concentración de 
azúcar, se realizan medidas de turbidez cada hora. En el caso de la segunda filtración no se hizo seguimiento de la turbidez, ya que los valores eran muy próximos a cero.

En ambos caso, los resultados obtenidos muestran que:

- La concentración de permeado aumenta con el tiempo, ya que el tanque de alimentación cada vez tiene mayor concentración de azúcar, que da lugar a un aumento de polarización de la concentración y de la presión osmótica, además del efecto de fouling que modifica la retención de la membrana.

- En general, en la primera filtración la turbidez aumenta con el tiempo, pero es muy próxima a cero, en todas las medidas.

- La retención disminuye con el tiempo tanto en la primera como en la segunda filtración, aunque en la segunda filtración es más rápida la disminución de la retención, puesto que la membrana se ensucia en cada paso de filtración.

En la figura 3.3 (símbolos blancos) se pude observar con claridad este comportamiento.

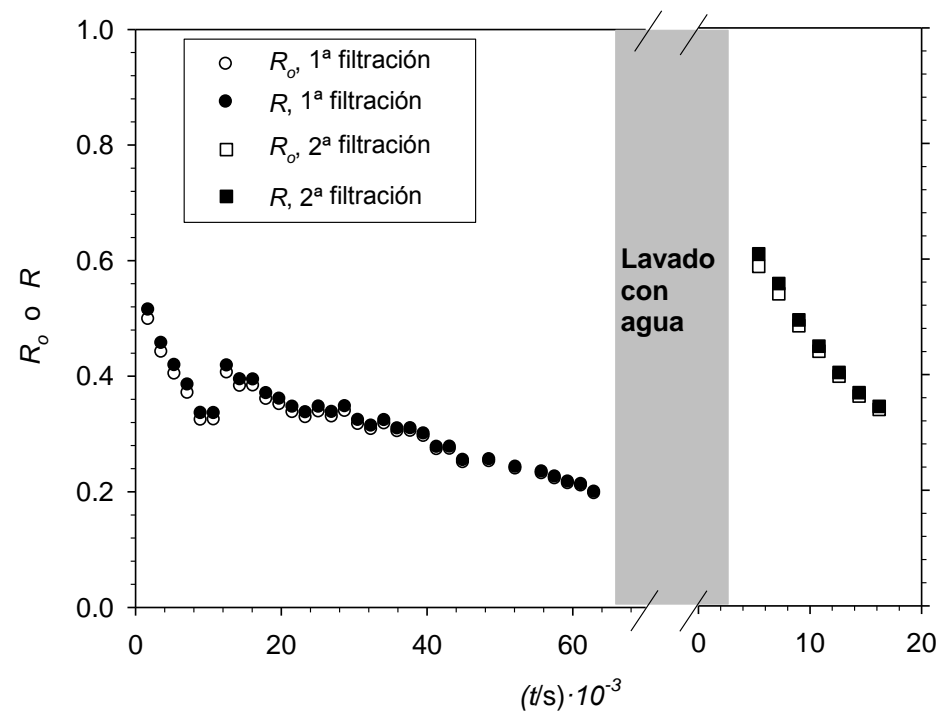

Figura 3.3 Retención observada y retención verdadera del mosto Verdejo.

B) Mosto Tinta de Toro

Al igual que en la filtración del mosto Verdejo, se mide la concentración del permeado (cada 30 minutos tanto en la primera como en la segunda filtración) y se calcula la de alimentación en función del tiempo para conocer la retención del mosto tinto en esta membrana. Además de la concentración de azúcar, también se realizan medidas de turbidez durante la filtración. En este caso sí que fue posible detectar una evolución de 
la turbidez con el tiempo en la segunda filtración. Al contrario que en la primera filtración en la se tomaron medidas cada hora, en la segunda, debido a la rapidez del proceso se tomaron medidas cada 30 minutos.

Los resultados obtenidos en estas filtraciones son las mismas que en la filtración de mosto blanco, aunque con el mosto tinto, se consigue una mayor retención final. En la figura 3.4 (símbolos blancos), se muestran la evolución de la retención observada para el mosto Tinta de Toro. Se aprecia una caída de la retención observada en función del tiempo, aunque más acusada en la segunda filtración, debido, entre otros factores a la variación de la concentración de alimentación. En este caso el efecto del ensuciamiento es más acusado, como hemos visto cuando hemos analizado la caída de flujo. Esto hace que en los primeros momentos del proceso, se forme una pseudomembrana por deposición de compuesto de alto peso molecular, que provocan una mayor constancia en la retención observada de la primera etapa, que para el caso de los mostos blancos.

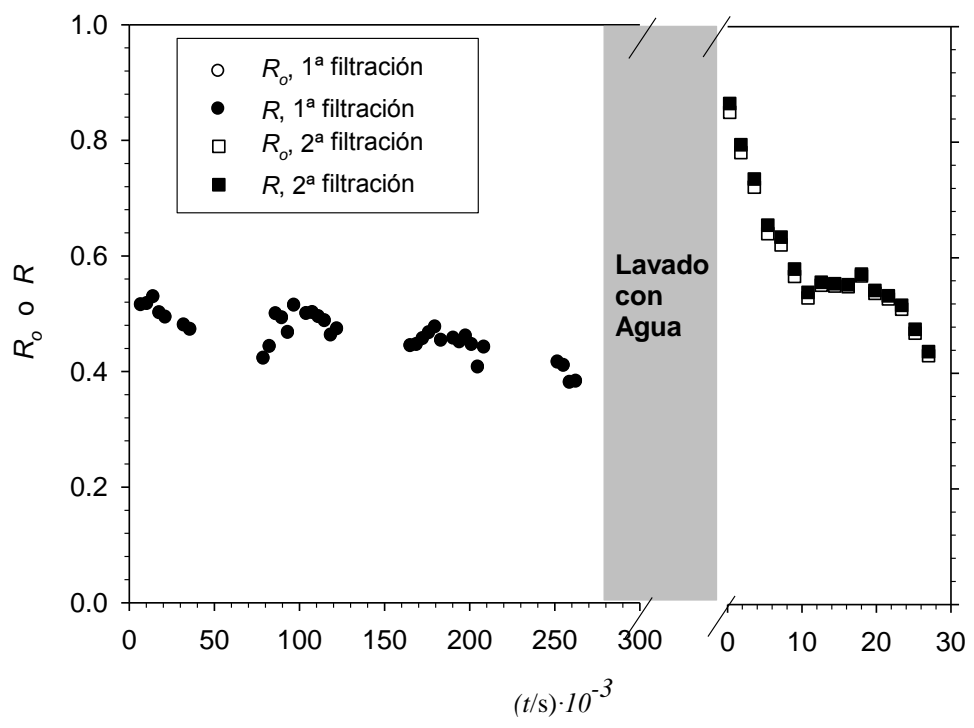

Figura 3.4 Retención observada y retención verdadera del mosto Tinta de Toro.

\subsection{2) Retención verdadera}

La retención verdadera se calcula como se explicó en el capítulo anterior cuando se filtró la disolución de azúcar o el mosto comercial modificado con los módulos de membrana (apartados 4.2.1 y 4.2.2). Se utiliza por tanto, la teoría de película para conocer la polarización de la concentración en las capas límite de membrana por medio del coeficiente de transferencia de masa $\left(K_{m}\right)$. 
Para ello, además de las medidas de concentración de permeado $\left(C_{p}\right)$ y concentración de alimentación $\left(C_{o}\right)$ respecto al tiempo que hemos indicado anteriormente, se utiliza el flujo respecto al tiempo en el transcurso de la filtración. Todos estos datos se utilizarán para conocer la concentración en la superficie de la membrana $\left(C_{m}\right)$ mediante la siguiente ecuación:

$$
C_{m}=C_{p}+\left(C_{o}-C_{p}\right) e^{J_{v} / K_{m}}
$$

que no es más que otra forma de expresar la ecuación (4) del capítulo 2 y que junto con la ecuación (3) del mencionado capítulo nos permiten obtener la retención verdadera.

\section{A) Mosto Verdejo}

La figura 3.3 (símbolos negros) muestra la retención verdadera junto con la retención observada, frente al tiempo de filtración. Al igual que en la retención observada, se separan los dos pasos de filtración por la etapa de limpieza. Podemos ver que la retención observada no difiere mucho de la retención verdadera, debido a que la formación de la capa de gel del azúcar es poco importante, no aumentando mucho la concentración en la superficie de la membrana por ésta y otras partículas de gran tamaño. En la segunda etapa, la retención verdadera no se mantiene constante, aunque se han eliminado la mayoría de las partículas grandes. Esto se debe a que hay un importante efecto de la presión osmótica, ya que aumenta la concentración de partículas pequeñas en la superficie de la membrana.

B) Mosto Tinta de Toro

La figura 3.4 (símbolos negros), muestra la evolución de la retención verdadera en ambas etapas para este mosto, comparando con la retención observada donde se pueden hacer las mismas consideraciones que en el mosto Verdejo. La diferencia principal, es que la retención de azúcar es mayor en la segunda etapa de filtración en el mosto tinto, puesto que al tener mayor cantidad de sustancias coloidales, podrán adherirse a la superficie de la membrana, aumentando el poder de retención de la membrana original.

\subsection{RENDIMIENTO DE LA FILTRACIÓN}

Como resumen de los datos de retención y pérdida de flujo en las filtraciones, podemos calcular el rendimiento conseguido tras la filtración del mosto blanco y el mosto tinto. En la tabla 3.2 se muestran las cantidades obtenidas de cada una de las corrientes del proceso de nanofiltración. 
Tabla 3.2 Volúmenes obtenidos de cada una de las corrientes del proceso de nanofiltración.

\begin{tabular}{|c|c|c|}
\hline & $\mathbf{V}_{\text {Blanco }}(\mathbf{L})$ & $\mathbf{V}_{\text {Tinto }}(\mathbf{L})$ \\
\hline $\mathrm{T}$ & 30 & 30 \\
\hline $\mathrm{P} 1$ & 14 & 12 \\
\hline $\mathrm{R} 1$ & 16 & 18 \\
\hline $\mathrm{P} 2$ & 12 & 10 \\
\hline $\mathrm{R} 2$ & 2 & 2 \\
\hline
\end{tabular}

T representa el volumen de mosto testigo usado para la fermentación y en este caso el volumen de mosto de partida usado para la nanofiltración. P1 y R1 son el permeado y el retenido, respectivamente, obtenidos de la primera etapa de filtración. Como se ha mencionado en segunda etapa de nanofiltración se filtra el permeado de la primera etapa (P1), siendo P2 y R2, los permeados y retenidos obtenidos en esta segunda etapa.

Este rendimiento puede ser expresado, tanto en valores de reducción de concentración de azúcar, como en pérdida de volumen de mosto en el proceso.

\subsection{1) Concentración de azúcar}

Para los datos de concentración de azúcar en los lotes (T, P1, P2, R1, y R2) se utilizan los valores obtenidos por el método enzimático y que se comentarán más adelante (ver apartado 4.1.1). En la siguiente tabla, se muestran los porcentajes de reducción de azúcar, r, conseguidos en cada paso de filtración y el valor de reducción total después del proceso completo. Note que $\mathrm{C}_{\mathrm{p}}^{\mathrm{t}}$ es la concentración en el tanque de permeado y $\mathrm{C}_{\mathrm{r}}^{\mathrm{t}}$ en el de retenido una vez que se ha finalizado el proceso.

Tabla 3.3 Reducción de azúcar en los procesos de filtración del mosto Verdejo y mosto Tinta de Toro.

\begin{tabular}{|c|c|c|c|c|}
\hline & 1a filtración & $2^{a}$ filtración & $\begin{array}{c}\text { Ambas } \\
\text { filtraciones }\end{array}$ & Mosto Inicial \\
\hline & $r=1-\frac{C_{p}^{t}(P 1)}{C_{r}^{t}(R 1)}$ & $r=1-\frac{C_{p}^{t}(P 2)}{C_{r}^{t}(R 2)}$ & $r=1-\frac{C_{p}^{t}(P 2)}{C_{r}^{t}(R 1)}$ & $r=1-\frac{C_{p}^{t}(P 2)}{C_{r}^{t}(T)}$ \\
\hline Mosto Blanco (\%) & 49.1 & 58.4 & 60.4 & 44.8 \\
\hline Mosto Tinto (\%) & 49.0 & 62.8 & 63.1 & 57.1 \\
\hline
\end{tabular}


Podemos comprobar que, mientras que en la primera filtración, la retención de azúcar es similar tanto en mosto blanco como en tinto, en el segundo proceso de filtración, las dos filtraciones juntas o la relación respecto al mosto inicial, la reducción de azúcar es más significativa en el mosto tinto. Este comportamiento era de esperar debido a la gran cantidad de sustancias coloidales en mostos tintos, lo que creará una película sobre la superficie de la membrana con capacidad propia de retención además de la propia retención de la membrana.

\subsection{2) Volumen final}

Teniendo en cuenta los volúmenes de las distintas partes del proceso de nanofiltración mostrados en la tabla 3.2 y las concentraciones de azúcar correspondientes, se hicieron dos mezclas para obtener mostos con menor concentración de azúcar que el mosto original. Así, una vez fermentados estos mostos proporcionarán vinos con menor contenido en alcohol. Se plantearon dos posibilidades: mezclar el permeado de la segunda etapa (P2) con el mosto testigo (T) y mezclar el permeado de la segunda etapa (P2) con el retenido de la primera etapa (R1). Este análisis se detallará más adelante.

El volumen de mosto que se pierde, en el sentido que no se emplea para la obtención del vino de bajo contenido alcohólico, cuando se realizan las mezclas $R 1+P 2$ es $R 2$, cuando mezclamos T+P2 se pierden R1 y R2. La pérdida de volumen de mosto que tiene lugar en las diferentes filtraciones realizadas en este trabajo, teniendo en cuenta la cantidad de litros de vino que podemos elaborar con el volumen de permeado final obtenido (P2), se representan en la siguiente tabla:

Tabla 3.4 Pérdida de volumen de mosto en los procesos de filtración.

\begin{tabular}{|c|c|c|}
\cline { 2 - 3 } \multicolumn{1}{c|}{} & $\begin{array}{c}\text { \% volumen de } \\
\text { mosto Verdejo }\end{array}$ & $\begin{array}{c}\text { \% volumen de mosto } \\
\text { Tinta de Toro }\end{array}$ \\
\hline $\mathrm{T}+\mathrm{P} 2$ & 51.4 & 50 \\
\hline $\mathrm{R} 1+\mathrm{P} 2$ & 11.0 & 9.5 \\
\hline
\end{tabular}

\section{ANÁLISIS QUÍMICOS}

Dada la gran cantidad de sustancias que intervienen en la composición de mostos y vinos, dividiremos el estudio analítico de cada producto en tres grupos de sustancias: azúcares, otras sustancias de pequeño peso molecular y polifenoles. 


\subsection{ANÁLISIS DE MOSTOS}

En el análisis de mostos, se detalla la composición del mosto testigo, de los dos permeados (primer y segundo paso de filtración) y de los dos retenidos. Es decir, estos análisis se realizan antes de elaborar las mezclas de mostos o vinos para la preparación de los vinos finales.

\subsection{1) $\underline{\text { Azúcares }}$}

En las tablas 3.5 y 3.6 se muestran los resultados de las determinaciones de azúcar (por varios métodos), para los mostos testigo (T) de Verdejo y Tinta de Toro, y para los tanques finales de permeado $(P)$ y retenido $(R)$ después de cada proceso. Con los errores propios de cada método podemos decir que los resultados obtenidos son similares para todos los métodos utilizados (refractométrico, polarimétrico y enzimático). En el mosto tinto, podemos observar que la concentración de azúcar medida con el polarímetro es más elevada a la que obtenemos con el refractómetro; esto puede deberse a la interferencia de otras sustancias que pueden aumentar el índice de refracción.

Tabla 3.5 Concentración de azúcar total determinado por refractometría, glucosa y fructosa determinado por el método enzimático, índice de azúcares y alcohol probable, del mosto Verdejo.

\begin{tabular}{|c|c|c|c|c|c|c|}
\hline $\begin{array}{c}\text { Mosto } \\
\text { Verdejo }\end{array}$ & $\begin{array}{c}\text { Azúcar } \\
\text { (a) }\end{array}$ & $\begin{array}{c}\text { Glucosa } \\
\text { (b) }\end{array}$ & $\begin{array}{c}\text { Fructosa } \\
\text { (b) }\end{array}$ & $\begin{array}{c}\text { Glucosa + } \\
\text { Frutosa) } \\
\text { (b) }\end{array}$ & $\begin{array}{c}\text { Glucosa/ } \\
\text { Frutosa }\end{array}$ & $\begin{array}{c}\text { Alcohol } \\
\text { Probable } \\
\text { (c) }\end{array}$ \\
\cline { 2 - 7 } & $\mathbf{g} / \mathbf{L}$ & $\mathbf{g} / \mathbf{L}$ & $\mathbf{g} / \mathbf{L}$ & $\mathbf{g} / \mathbf{L}$ & & $\%$ vol \\
\hline $\mathrm{T}$ & 209.1 & 109.0 & 94.0 & 203 & 1.2 & 12.1 \\
\hline $\mathrm{P} 1$ & 126.2 & 78.0 & 66.0 & 144 & 1.2 & 8.6 \\
\hline $\mathrm{P} 2$ & 86.6 & 61.0 & 51.0 & 112 & 1.2 & 6.7 \\
\hline $\mathrm{R} 1$ & 277.9 & 144.0 & 139.0 & 283 & 1.0 & 16.8 \\
\hline $\mathrm{R} 2$ & 270.5 & 141.0 & 128.0 & 269 & 1.1 & 16.0 \\
\hline
\end{tabular}

(a) Tablas de equivalencia del refractómetro Brix-molaridad según Reglamento CEE $2676 / 90$

(b) Concentración obtenida mediante método enzimático.

(c) \%vol estimado según el Reglamento CEE 2676/90 
Tabla 3.6 Concentración de azúcar total determinado por refractometría y polarimetría, glucosa y fructosa determinado por el método enzimático, índice de azúcares y alcohol probable, del mosto Tinta de Toro.

\begin{tabular}{|c|c|c|c|c|c|c|c|}
\hline \multirow{2}{*}{$\begin{array}{c}\text { Mosto } \\
\text { Tinta de } \\
\text { Toro }\end{array}$} & $\begin{array}{l}\text { Azúcar } \\
\text { (a) }\end{array}$ & $\begin{array}{l}\text { Azúcar } \\
\text { (b) }\end{array}$ & $\begin{array}{c}\text { Glucosa } \\
\text { (c) }\end{array}$ & $\begin{array}{c}\text { Fructosa } \\
\text { (c) }\end{array}$ & $\begin{array}{c}\text { (Glucosa + } \\
\text { Frutosa) } \\
\text { (c) }\end{array}$ & $\begin{array}{l}\text { Glucosa/ } \\
\text { Frutosa }\end{array}$ & $\begin{array}{c}\text { Alcohol } \\
\text { Probable } \\
\text { (d) }\end{array}$ \\
\hline & $g / L$ & $g / L$ & $g / L$ & $g / L$ & $g / L$ & & \%vol \\
\hline $\mathrm{T}$ & 244.0 & 253.81 & 135.0 & 128.5 & 263.5 & 1.1 & 15.1 \\
\hline $\mathrm{P} 1$ & 145.9 & 159.90 & 81 & 75 & 156 & 1.1 & 8.9 \\
\hline $\mathrm{P} 2$ & 94.0 & 101.52 & 59.2 & 53.8 & 113 & 1.1 & 6.4 \\
\hline $\mathrm{R} 1$ & 294.0 & 329.95 & 149.0 & 157.0 & 306 & 0.9 & 17.5 \\
\hline $\mathrm{R} 2$ & 292.0 & 312.18 & 153.5 & 150.5 & 304 & 1.0 & 17.4 \\
\hline
\end{tabular}

(a) Tablas de equivalencia del refractómetro Brix-molaridad según Reglamento CEE 2676/90

(b) Concentración obtenida mediante método polarimétrico.

(c) Concentración obtenida mediante método enzimático.

(d) \%vol estimado según experiencias de la Estación Enológica del ITACYL.

Una vez que se conoce el contenido de azúcar, se puede relacionar este valor (utilizamos la concentración de azúcar que resulta del método enzimático, más exacto), con el grado alcohólico probable al que daría lugar ese mosto después de fermentar; para ello se pueden tomar la relación de azúcar y grado alcohólico de distintos autores.

Existen unas tablas que relacionan los grados Brix con los $\mathrm{g} / \mathrm{L}$ de azúcar, y estos con los grados de alcohol probable [22]. Para la realización de estas tablas se tiene en cuenta que la riqueza probable de alcohol de un mosto depende del rendimiento de las levaduras de fermentación, que oscila entre 16 y 17 gramos por litro de azúcares por cada grado alcohólico [23] o entre 16.5 y $18 \mathrm{~g}$ según la referencia [24]. En otras referencias, como el libro Tratado de Enología (Vol I) [3], se considera que 1 grado alcohólico probable de vino serán $17 \mathrm{~g} / \mathrm{L}$ de azúcar. En cualquier caso, el tipo de fermentación y de elaboración puede influir ligeramente en los valores considerados. Lo que se cumple es que en la elaboración de vinos blancos, el rendimiento azúcar/alcohol es mejor que en el caso de los tintos, donde debido a las operaciones de remontados se pierde una apreciable cantidad de alcohol y su rendimiento es por lo tanto más bajo. 
Según la normativa de la Comunidad Europea y de acuerdo al Reglamento CEE 2676/90 por el que se determinan los métodos de análisis comunitarios aplicables al sector del vino, se utiliza el valor de $16.83 \mathrm{~g} / \mathrm{L}$ de azúcar por cada grado alcohólico. En nuestro caso y debido a la experiencia de la Estación Enológica en la realización e investigación de fermentaciones, se estima que el valor indicado por la normativa se debe aplicar a vinos blancos. En el caso de los vinos tintos, se utilizarán las tablas de conversión obtenidas de las experiencias de fermentaciones de mostos tintos en la Estación Enológica del ITACyL.

En cuanto a estos parámetros clásicos enológicos, azúcar y alcohol probable, la aplicación del tratamiento con membranas, modifica sólo la concentración total de azúcar del mosto inicial y por lo tanto el contenido de alcohol probable, pero la proporción de fructosa y glucosa en el mosto testigo es igual a la del permeado final (P2), lo que es favorable para el equilibrio del futuro vino. En la última columna de estas tablas se presenta el grado alcohólico probable de los vinos que se obtendrían a partir de estos mostos, tal como acabamos de mencionar. Como se puede ver en el caso de blanco podríamos pasar de vinos de 12.1 grados a vinos de 6.7 grados y el tintos de 15.1 a 6.4. No obstante nuestro objetivo no es una reducción tan drástica del grado alcohólico sino una pequeña reducción, que como hemos dicho, se conseguiría mezclando el permeado final con el retenido inicial o con el mosto testigo. De esta forma se recuperan otras sustancias importantes en el proceso de elaboración del vino que no han pasado a los permeados.

\subsection{2) Sustancias de bajo peso molecular}

En las tablas 3.7 y 3.8 , se presentan los resultados de los análisis de otras sustancias de bajo peso molecular relevantes en la composición de mostos.

Tabla 3.7 $\quad p H$, acidez total (AT), ácido tartárico (TH2), ácido málico (MH2) y potasio en el mosto Verdejo.

\begin{tabular}{|c|c|c|c|c|c|}
\hline $\begin{array}{c}\text { Mosto } \\
\text { Verdejo }\end{array}$ & $\mathbf{p H}$ & $\mathbf{A T}$ & $\mathbf{T H 2}$ & $\mathbf{M H 2}$ & Potasio \\
\cline { 2 - 6 } & & $\mathbf{g} / \mathbf{l}$ & $\mathbf{g} / \mathbf{l}$ & $\mathbf{g} / \mathbf{l}$ & $\mathbf{~} \mathbf{g} / \mathbf{l}$ \\
\hline $\mathrm{T}$ & 3.37 & 4.79 & 2.8 & 4.0 & 1090 \\
\hline $\mathrm{P} 1$ & 3.68 & 4.56 & 2.0 & 4.0 & 1030 \\
\hline $\mathrm{P} 2$ & 3.23 & 4.16 & 2.0 & 3.6 & 880 \\
\hline $\mathrm{R} 1$ & 3.35 & 5.11 & 3.6 & 4.0 & 1010 \\
\hline $\mathrm{R} 2$ & 3.35 & 4.59 & 2.9 & 4.0 & 1220 \\
\hline
\end{tabular}


Tabla 3.8 $\quad p H$, acidez total (AT), ácido tartárico (TH2), ácido málico (MH2, y potasio en el mosto Tinta de Toro.

\begin{tabular}{|c|c|c|c|c|c|}
\hline $\begin{array}{c}\text { Mosto Tinta } \\
\text { de Toro }\end{array}$ & $\mathbf{p H}$ & $\mathbf{A T}$ & $\mathbf{T H 2}$ & $\mathbf{M H 2}$ & Potasio \\
\cline { 2 - 6 } & & $\mathbf{g} / \mathbf{l}$ & $\mathbf{g} / \mathbf{l}$ & $\mathbf{g} / \mathbf{l}$ & $\mathbf{~} \mathbf{g} / \mathbf{l}$ \\
\hline $\mathrm{T}$ & 3.76 & 3.78 & 2.1 & 3.8 & 1820 \\
\hline $\mathrm{P} 1$ & 3.75 & 3.45 & 1.6 & 3.7 & 1700 \\
\hline $\mathrm{P} 2$ & 3.75 & 3.45 & 1.5 & 3.8 & 1630 \\
\hline $\mathrm{R} 1$ & 3.74 & 3.80 & 1.9 & 3.8 & 1920 \\
\hline $\mathrm{R} 2$ & 3.75 & 3.57 & 2.2 & 3.4 & 1720 \\
\hline
\end{tabular}

La tendencia general es una ligera disminución de estas sustancias en los permeados y un aumento en sus retenidos correspondientes. Pero estas variaciones son muy pequeñas para la mayor parte de estos compuestos, por lo cual, deben tener mucha menos importancia en la aparición del gradiente de presión osmótica que en el caso de los azúcares. La retención de estas sustancias estará relacionada con su peso molecular, además de con su carga, ya que las membranas de nanofiltración poseen carga eléctrica. La membrana $\mathrm{HL}$ tiene un punto isoeléctrico de 3.3 , por lo que al pH del mosto (3.37-3.76) estará ligeramente cargada negativamente [14]. El efecto de la carga junto con los efectos dieléctricos explican la retención de iones como el potasio pese a su bajo peso molecular $\left(\mathrm{M}_{\mathrm{w}}=39.1 \mathrm{~g} / \mathrm{mol}\right)$ [25]. En el caso de ácido málico $\left(\mathrm{M}_{\mathrm{W}}=134.09 \mathrm{~g} / \mathrm{mol}, \mathrm{pK}=3.40\right)$, las variaciones están asociadas más al error en el método de determinación que al proceso de filtración. Sin embargo, el ácido tartárico $\left(\mathrm{M}_{\mathrm{W}}=150 \mathrm{~g} / \mathrm{mol}, \mathrm{pK}=3.03\right.$ ) con peso molecular algo mayor y un pK menor (mayor ionización) sufre mayor retención que el málico. Además, muchas de estas sustancias se encuentran asociadas a otras de alto peso molecular, de forma que son retenidas por la membrana a pesar de su pequeño tamaño.

\subsection{3) Familias fenólicas y color}

El tercer grupo de sustancias que vamos a estudiar son las familias fenólicas, que están relacionadas principalmente con el color. Son sustancias de pesos moleculares mayores que los azúcares, y por esta razón presentan un alto grado de retención, lo que obligará a recuperar estas sustancias en las mezclas de mostos finales usados para elaborar los vinos. 

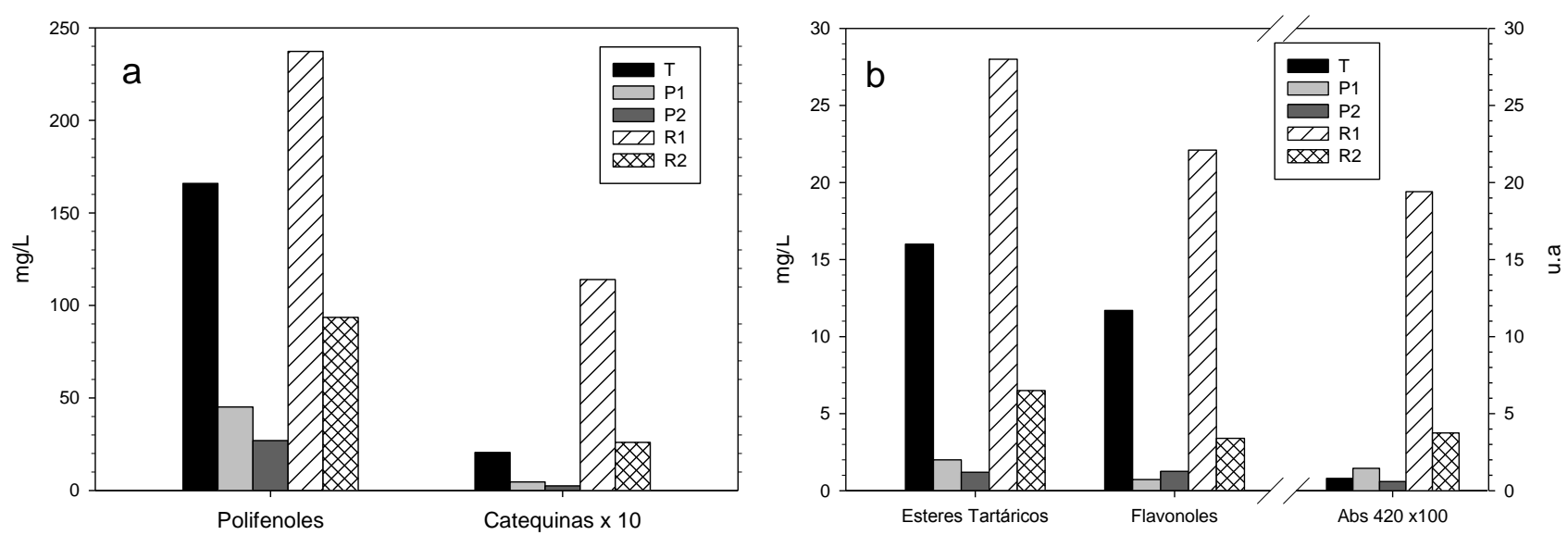

Figura 3.5 Concentración de los compuestos relacionados con el color y absorbancia a $420 \mathrm{~nm}$ del mosto testigo (T), los retenidos (R1 y R2) y permeados (P1 y P2) obtenidos durante el proceso de filtración del mosto Verdejo. (a) polifenoles totales y catequinas (b) ésteres tartáricos, flavonoles y absorbancia a $420 \mathrm{~nm}$.

En el mosto Verdejo, como se muestra en la figura 3.5, la relación entre las concentraciones de retenido (R1) y permeado (P2) es del orden de 10 veces para los polifenoles totales y los flavonoles, y algo más alta (unas 30 veces) para las catequinas y los esteres tartáricos. Esto permite que la mezcla del permeado con el retenido o con el mosto testigo, de lugar a un mosto que fermente con proporciones similares de estos compuestos. El análisis de la absorbancia a $420 \mathrm{~nm}$ (responsable principal del color en mostos blancos) presenta un comportamiento más difícil de interpretar ya que además de que aunque la relación (R1/P2) es del orden de 30 (similar a los polifenoles), los permeados tienen índices de color similares al original. Este comportamiento puede deberse a un aumento del color por procesos de oxidación o de otro tipo, y que habrá que evitar en el futuro.

En la figura 3.6.a se presentan los resultados del proceso para los polifenoles totales, los antocianos y las catequinas para los mostos tintos (Tinta de Toro). La relación $\mathrm{R} 1 / \mathrm{P} 2$ es del orden de 30 , para los polifenoles totales, del orden de 200 veces para las catequinas y más de 5000 veces para los antocianos. En este caso la retención es mucho mayor que para los blancos, debido al mayor abanico de compuestos y a su mayor concentración en los mostos tintos, (la retención es casi 4 veces mayor que en blancos tanto para catequinas como para polifenoles totales). 

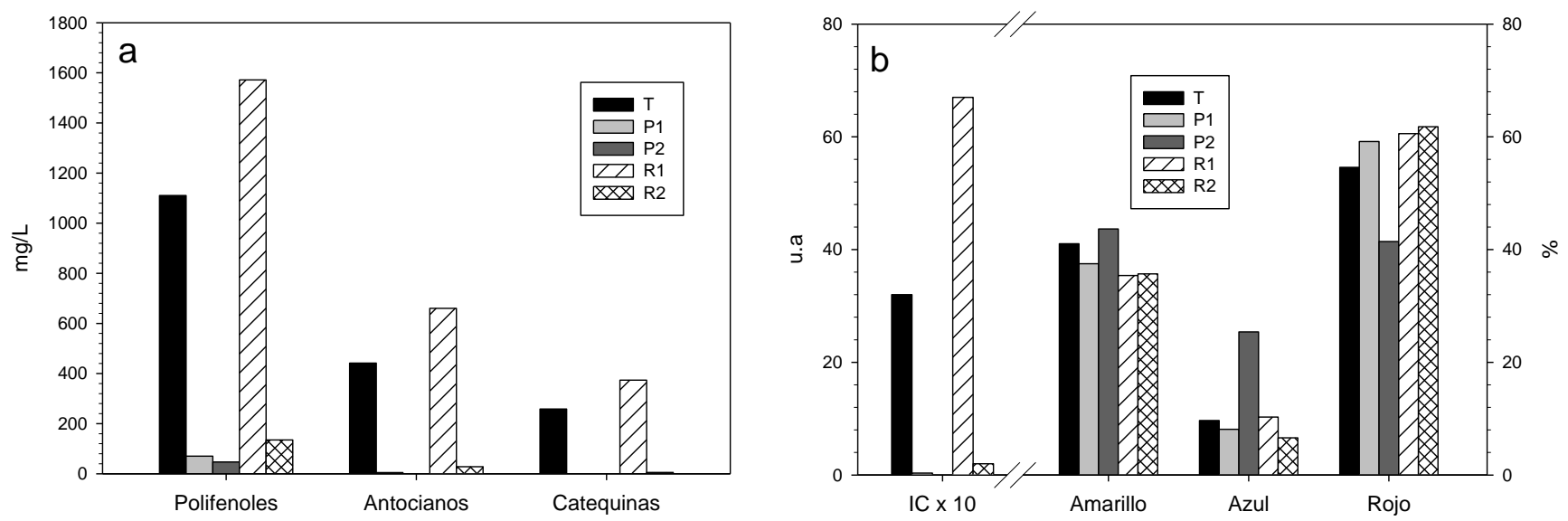

Figura 3.6 Concentración de los compuestos relacionados con el color del mosto testigo $(T)$, los retenidos ( $R 1$ y $R 2$ ) y permeados (P1 y $P 2)$ obtenidos durante el proceso de filtración del mosto Tinta de Toro. (a) polifenoles totales, antocianos y catequinas (b) intensidad colorante (IC) y porcentajes de rojo, azul y amarillos.

En la figura 3.6.b, se muestran los resultados del análisis de color en el mosto tinto. Se observa una reducción muy fuerte del índice de color debido a que las sustancias involucradas en el color de los mostos tintos tienen un alto peso molecular, además de un fuerte carácter coloidal que las mantiene asociadas entre sí o a otras sustancias de alto peso molecular [26]. Analizando la variación de los colores fundamentales se observa con claridad la reducción del rojo en el segundo permeado y el aumento en el retenido respecto al mosto testigo. Al tratarse de la variación porcentual, esto se refleja en un comportamiento inverso para los otros dos colores, aunque el incremento del componente amarillo en P2 puede deberse también a efectos de oxidación durante la filtración [3]. El aumento del color rojo en el primer retenido respecto al mosto original se debe al aumento de concentración de antocianos, no obstante el color rojo también aumenta en el primer permeado porque como hemos indicado, además de tener en cuenta la retención de compuestos coloreados en las filtraciones, se deben valorar otros factores, como podría ser la degradación oxidativa de los antocianos por oxigenación en el proceso nanofiltración. De hecho, por este motivo, el permeado 1 tiene menos concentración de antocianos pero más color rojo ya que cuando tenemos mayor efecto de oxidación, los antocianos se encontrarán en forma de catión flavilium que tiene la característica de presentar una coloración roja [3]. 
Los resultados de los análisis de estos compuestos muestran como, además de reducir el contenido de azúcar en los mostos, la membrana también retiene un alto porcentaje de compuestos fenólicos presentes en el mosto, ya que tanto en el permeado de primera fase (P1), como el permeado de segunda fase (P2), muestra menores niveles de polifenoles totales, catequinas y antocianos (en el caso de vinos tintos), que el mosto testigo (T). Como en nuestro caso, los volúmenes de permeado de la segunda filtración (P2) y el retenido inicial (R1) son los que van a ser utilizados posteriormente para hacer la mezcla que dé lugar a vinos de menor grado alcohólico, los únicos componentes que se perderán, cuando se realiza la mezcla $\mathrm{P} 2+\mathrm{R} 1$, son los que forman parte del retenido de la segunda filtración (R2).

\subsection{ELABORACIÓN Y ANÁLISIS DE VINOS}

Como hemos indicado anteriormente, el objetivo de este trabajo es la obtención de vinos con menos grado alcohólico, para ello se utilizan los permeados de las filtraciones realizadas con los módulos de membranas. Estos permeados con menor concentración de azúcar que el mosto inicial, se mezclan con el mosto sin filtrar (mosto testigo) o con el retenido, para reducir aproximadamente dos grados alcohólicos en el vino final después de las fermentaciones. El control de las fermentaciones se lleva a cabo en la bodega experimental de la Estación Enológica del ITACyL por personal adscrito al centro. La fermentación de la mezcla P2+T se ha realizado para compararla con P2+R1 y analizar los efectos del proceso de nanofiltración sobre los retenidos. Es decir, la existencia de posibles oxidaciones o degradaciones de las sustancias de alto peso molecular. Como hemos visto en la tabla 3.3 este método conlleva pérdidas de mosto del orden del 50\%, y el proceso no sería aplicable desde el punto de vista económico, a no ser que se piense en un aprovechamiento de los mostos retenidos. Una posible aplicación de estos mostos sería la obtención de vinos dulces o vinos enriquecidos en alcohol que tienen una gran demanda en el norte de Europa [27].

\subsection{1) Vino Verdejo}

La elaboración llevada a cabo es la que se describe a continuación:

- La fermentación alcohólica de todos los experimentos se llevaron a cabo por duplicado, en tanques de cuatro litros, inoculando levaduras comerciales para llevar a cabo la fermentación y controlando la temperatura en el proceso. Las mezclas se realizaron de acuerdo a la tabla siguiente: 
Tabla 3.9 Proporciones de testigo, permeado de segunda filtración y retenido de primera filtración, utilizadas en la fermentación del mosto Verdejo

\begin{tabular}{|c|c|c|c|}
\hline $\begin{array}{c}\text { Mezclas del } \\
\text { mosto Verdejo }\end{array}$ & Testigo (L) & $\begin{array}{c}\text { Permeado 2 } \\
\text { (L) }\end{array}$ & $\begin{array}{c}\text { Retenido 1 } \\
\text { (L) }\end{array}$ \\
\hline $\mathrm{T}+\mathrm{P} 2$ & 2.3 & 1.2 & \\
\hline $\mathrm{R} 1+\mathrm{P} 2$ & & 2.3 & 1.2 \\
\hline
\end{tabular}

Además de los vinos de bajo contenido alcohólico se fermentan el vino testigo para comparar (T) y todos los retenidos que no se usaron para la realización de las mezclas. A continuación se detallan todos los mostos que se fermentaron:

1.- Vino testigo, de la fermentación del mosto testigo. (T)

2.- Vino de bajo contenido en alcohol 1 , mezclando el mosto testigo y una parte del permeado de segunda filtración con membrana (P2), de forma que se reduzca el contenido de alcohol probable, aproximadamente en $2 \%$ vol. (T+P2) 3.- Vino de bajo contenido en alcohol 2, se mezcla el permeado de la segunda nanofiltración (P2), con el retenido de la primera filtración (R1), en las proporciones adecuadas para obtener un vino final con un contenido en alcohol similar al vino anterior. $(\mathrm{R} 1+\mathrm{P} 2)$

4.- Vino del retenido 1 , se obtiene de la fermentación del retenido conseguido en la primera filtración. (R1)

5.- Vino del retenido 2, obtenido de la fermentación del retenido de la segunda filtración. (R2)

- Una vez que la fermentación se ha completado, los vinos fueron embotellados y almacenados para su posterior análisis. En la tabla 3.10 se muestran los resultados medios de las réplicas de una analítica convencional de los vinos blancos.

Los vinos obtenidos, $\mathrm{T}+\mathrm{P} 2$ y $\mathrm{R} 1+\mathrm{P} 2$ tienen respectivamente, 2.5 y $3.3 \%$ vol menos que el vino testigo, en ambos casos la reducción lograda fue más que los $2^{\circ}$ que se querían reducir inicialmente, la diferencia obtenida se atribuye a la dificultad de determinar las proporciones exactas para mezclar el mosto testigo o retenido con el mosto permeado, basándonos en los azúcares detectados en el mosto inicial.

Se debe tener en cuenta que los vinos de menor contenido en alcohol, tienen mayores niveles de ácido tartárico y potasio que los otros vinos producidos, probablemente 
debido a que en estos vinos de mayor graduación, el tartárico reacciona con el potasio del vino, precipitando como bitartrato potásico [3].

Tabla 3.10 Parámetros enológicos clásicos del vino Verdejo tras la fermentación alcohólica, A.Total: acidez total; A.V: acidez volátil; TH2: ácido tartárico; MH2: ácido málico.

\begin{tabular}{|c|c|c|c|c|c|c|c|c|}
\hline \multirow{2}{*}{$\begin{array}{c}\text { Vino } \\
\text { Verdejo }\end{array}$} & $\mathbf{p H}$ & A.Total & A.V. & TH2 & MH2 & Potasio & Azúcar & Grado \\
\cline { 2 - 9 } & & $\mathbf{g} / \mathbf{L}$ & $\mathbf{g} / \mathbf{L}$ & $\mathbf{g} / \mathbf{L}$ & $\mathbf{g} / \mathbf{L}$ & $\mathbf{~} \mathbf{g} / \mathbf{L}$ & $\mathbf{g} / \mathbf{l}$ & $\%$ vol \\
\hline $\mathrm{T}$ & 3.05 & 7.42 & 0.21 & 2.8 & 2.9 & 675 & 1.65 & 12.71 \\
\hline $\mathrm{T}+\mathrm{P} 2$ & 3.08 & 7.78 & 0.13 & 4.1 & 2.9 & 945 & 1.64 & 10.14 \\
\hline $\mathrm{R} 1+\mathrm{P} 2$ & 3.06 & 7.78 & 0.13 & 4.2 & 2.8 & 915 & 1.66 & 9.34 \\
\hline $\mathrm{R} 1$ & 3.14 & 7.43 & 0.35 & 2.8 & 2.7 & 660 & 2.12 & 16.82 \\
\hline $\mathrm{R} 2$ & 3.07 & 8.17 & 0.18 & 2.3 & 2.7 & 790 & 1.77 & 13.71 \\
\hline
\end{tabular}

En esta tabla (3.10), se muestra que, en el caso de otros parámetros enológicos estudiados, no hay diferencias significativas entre los diferentes vinos elaborados y el vino testigo, lo cual ratifica la viabilidad del método. En las figuras 3.7 y 3.8 , que se muestran a continuación, vemos la concentración de los polifenoles y otros compuestos relacionados con el color, para cada uno de los vinos obtenidos.

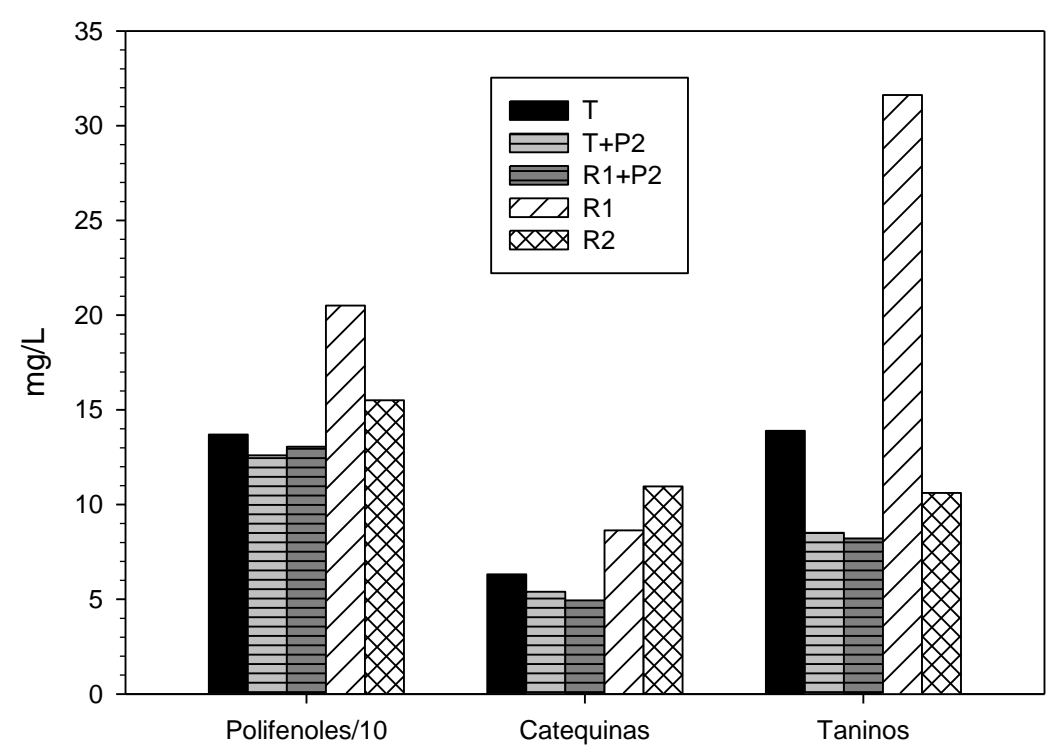

Figura 3.7 Contenido en polifenoles totales, catequinas y taninos de los distintos vinos Verdejo elaborados. 


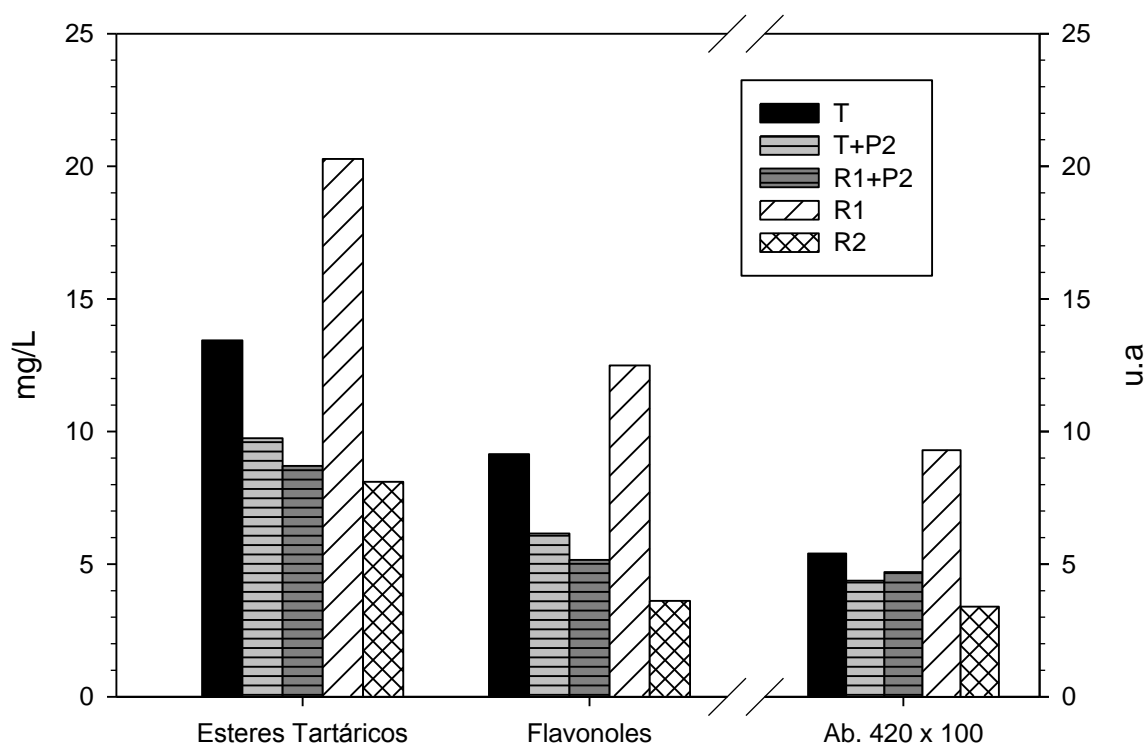

Figura 3.8 Contenido en ésteres tartáricos, flavonoles y color (Absorbancia a 420 $n m)$ de los distintos vinos Verdejo elaborados.

Aunque hay una pequeña disminución de polifenoles totales e índice de color a 420 $\mathrm{nm}$ en los vinos de baja graduación alcohólica frente al testigo, la mayor pérdida, se produce en el caso de los taninos, aumentando la acumulación de sustancias en el retenido 1 como era de esperar.

\subsection{2) Vino Tinta de Toro}

La elaboración del vino tinto sigue un proceso similar al caso del mosto Verdejo, pero en este caso, además de la fracción del testigo o retenido y del permeado, se añade la cantidad adecuada de la pasta que fue retirada antes de la filtración y que ha permanecido a una temperatura de $4^{\circ} \mathrm{C}$ durante la filtración de la parte líquida.

Otra diferencia es que el mosto testigo no se mezcla con las fracciones filtradas de las membranas, antes de la fermentación alcohólica, sino que se fermentan por separado el testigo, el permeado de segunda filtración y el retenido de primera filtración y se mezclan posteriormente para realizar la segunda fermentación (fermentación maloláctica). El proceso de elaboración, por tanto, es el siguiente:

- Fermentaciones alcohólicas de mosto sin tratar, permeado de segunda filtración y retenido de primera filtración. La fermentación alcohólica se realiza en tanques de 35 litros porque se tiene que introducir la pasta además de las 
fracciones líquidas (y como se realiza la fermentación antes de hacer las mezclas y duplicar las pruebas necesitamos un depósito más grande), para la fermentación maloláctica se utilizan depósitos de menor tamaño. Se inoculan levaduras comerciales al igual que en el mosto Verdejo y se controla la temperatura en el proceso de fermentación. Las cantidades utilizadas de pasta y mosto en las fermentaciones se muestran en la siguiente tabla:

Tabla 3.11 Proporciones de pasta, testigo, permeado de segunda filtración y retenido de primera filtración, utilizadas en la fermentación alcohólica del mosto Tinta de Toro.

\begin{tabular}{|c|c|c|c|c|}
\hline $\begin{array}{c}\text { Pruebas de } \\
\text { mosto Tinta de } \\
\text { Toro }\end{array}$ & $\begin{array}{c}\text { Pasta } \\
\text { (Kg) }\end{array}$ & $\begin{array}{c}\text { Testigo } \\
\text { (L) }\end{array}$ & $\begin{array}{c}\text { Permeado } \\
\text { (L) }\end{array}$ & $\begin{array}{c}\text { Retenido } \\
\text { (L) }\end{array}$ \\
\hline $\mathrm{T}$ & 3.6 & 9 & & \\
\hline $\mathrm{P} 2$ & 3.6 & & 9 & \\
\hline $\mathrm{R} 2$ & 3.6 & & & 9 \\
\hline
\end{tabular}

- Una vez que la fermentación alcohólica se ha completado, se retira la pasta, se trasiega el vino y se realizan las mezclas para reducir el grado alcohólico del vino final en $2 \%$ vol de alcohol. Estas mezclas realizarán la fermentación maloláctica en tanques de 4 litros por duplicado, de acuerdo a las cantidades mostradas en la tabla 3.12 .

Tabla 3.12 Proporciones de testigo, permeado de segunda filtración y retenido de primera filtración, utilizadas en la fermentación maloláctica del mosto Tinta de Toro.

\begin{tabular}{|c|c|c|c|}
\hline $\begin{array}{c}\text { Pruebas de } \\
\text { mosto Tinta de } \\
\text { Toro }\end{array}$ & $\begin{array}{c}\text { Testigo } \\
\text { (L) }\end{array}$ & $\begin{array}{c}\text { Permeado } \\
\text { (L) }\end{array}$ & $\begin{array}{c}\text { Retenido } \\
\text { (L) }\end{array}$ \\
\hline $\mathrm{T}+\mathrm{P} 2$ & 3 & 1 & \\
\hline $\mathrm{R} 1+\mathrm{P} 2$ & & 1.9 & 2.1 \\
\hline
\end{tabular}

- Tras la fermentación alcohólica de las fracciones filtradas T, P2 y R1 y las mezclas realizadas según la tabla 3.12, se realiza la fermentación maloláctica de los vinos que describimos a continuación:

1.- El vino Testigo (T) por la fermentación del mosto testigo con la pasta. 
2.- El vino de bajo contenido en alcohol 1: se mezcla una parte de vino testigo, con la cantidad necesaria del vino obtenido de la fermentación del permeado de segunda filtración, para reducir $2 \%$ vol. ( $T+P 2)$

3.- Vino de bajo contenido en alcohol 2: se obtiene por mezcla de la fermentación del retenido, con la cantidad necesaria del vino formado por la fermentación del permeado de segunda filtración, para reducir 2 $\%$ vol. $(\mathrm{R} 1+\mathrm{P} 2)$

- Posteriormente los vinos son embotellados para su análisis.

Los análisis de los vinos han sido realizados después de la fermentación alcohólica y tras la fermentación maloláctica. En la tabla 3.13 se muestran los análisis obtenidos después de la fermentación alcohólica, los cuales son similares a los del vino Verdejo, ya que las membranas utilizadas para la filtración, reducen el contenido en azúcar, y no en ácido málico, tartárico o potasio. La única diferencia apreciable es la variación en el grado alcohólico de todos los vinos respecto al testigo. Se aprecia que en este caso la reducción de los dos vinos de bajo contenido alcohólico $(T+P 2)$ y $(R 1+P 2)$ es muy próxima a los 2 grados.

Tabla 3.13 Parámetros enológicos clásicos de los vinos testigo, de las distintas fracciones de filtración y de las mezclas tras el proceso de fermentación alcohólica en mostos de la variedad Tinta de Toro, A. Total: acidez total; A. V: acidez volátil; TH2: ácido tartárico; MH2: ácido málico.

\begin{tabular}{|c|c|c|c|c|c|c|c|c|}
\hline $\begin{array}{c}\text { Vino } \\
\text { Tinta de } \\
\text { Toro }\end{array}$ & pH & A. Total & A.V. & TH2 & MH2 & Potasio & Azúcar & Grado \\
\cline { 2 - 9 } & & $\mathbf{g} / \mathbf{L}$ & $\mathbf{g} / \mathbf{L}$ & $\mathbf{g} / \mathbf{L}$ & $\mathbf{g} / \mathbf{L}$ & $\mathbf{~} \mathbf{g} / \mathbf{L}$ & $\mathbf{g} / \mathbf{L}$ & $\%$ vol \\
\hline T & 3.69 & 6.58 & 0.55 & 3.6 & 3.2 & 1760 & 1.50 & 14.82 \\
\hline P2 & 3.64 & 5.86 & -- & -- & -- & -- & -- & 7.82 \\
\hline R1 & 3.80 & 6.29 & -- & -- & -- & -- & -- & 17.54 \\
\hline T+P2 & 3.70 & 6.73 & 0.46 & 3.6 & 3.3 & 1730 & 1.30 & 12.96 \\
\hline R1+P2 & 3.70 & 6.02 & 0.41 & 3.7 & 3.3 & 1630 & 1.30 & 12.73 \\
\hline
\end{tabular}

El uso de membranas de nanofiltración, no permite que compuestos de mayor peso molecular que el azúcar, pasen a través de la membrana, por ello, en el vino testigo, están presentes los polifenoles, antocianos, catequinas y taninos, pero en el permeado de segunda filtración (P2), se pierden estos compuestos, concentrándose lógicamente en el retenido de primera filtración (R1), como se puede ver en la figura 3.9. 


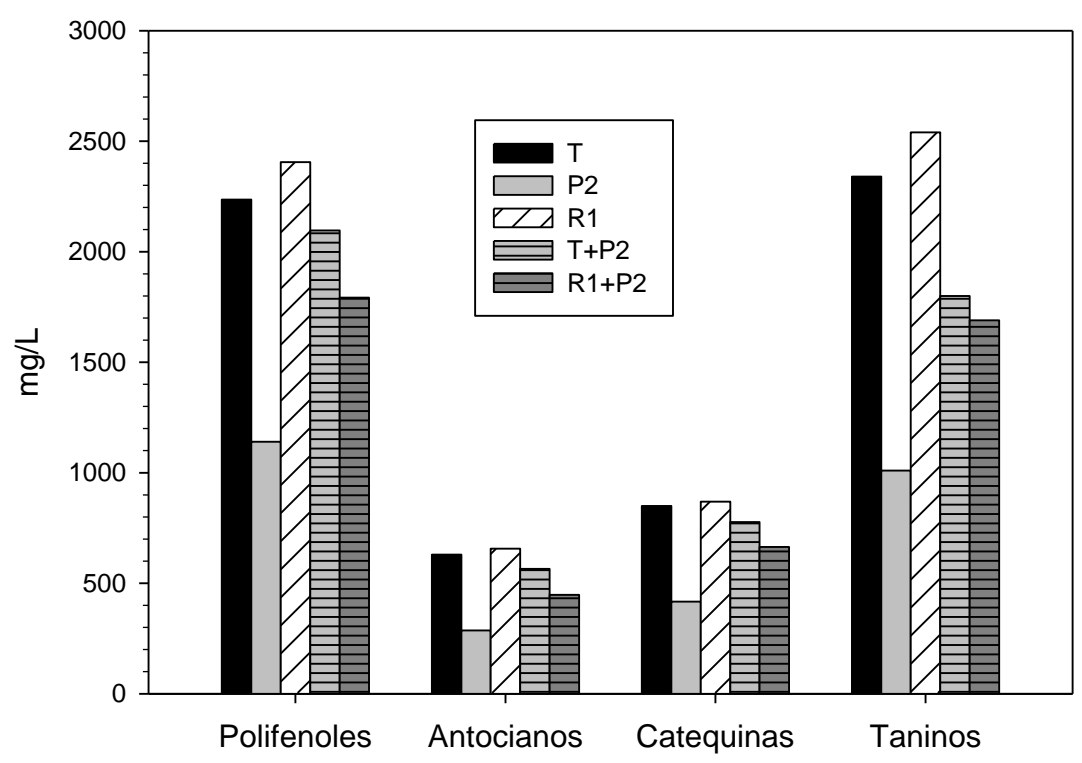

Figura 3.9 Contenido en polifenoles totales, antocianos, catequinas y taninos en las fracciones de filtración y mezclas de los distintos vinos Tinta de Toro, tras el proceso de fermentación alcohólica.

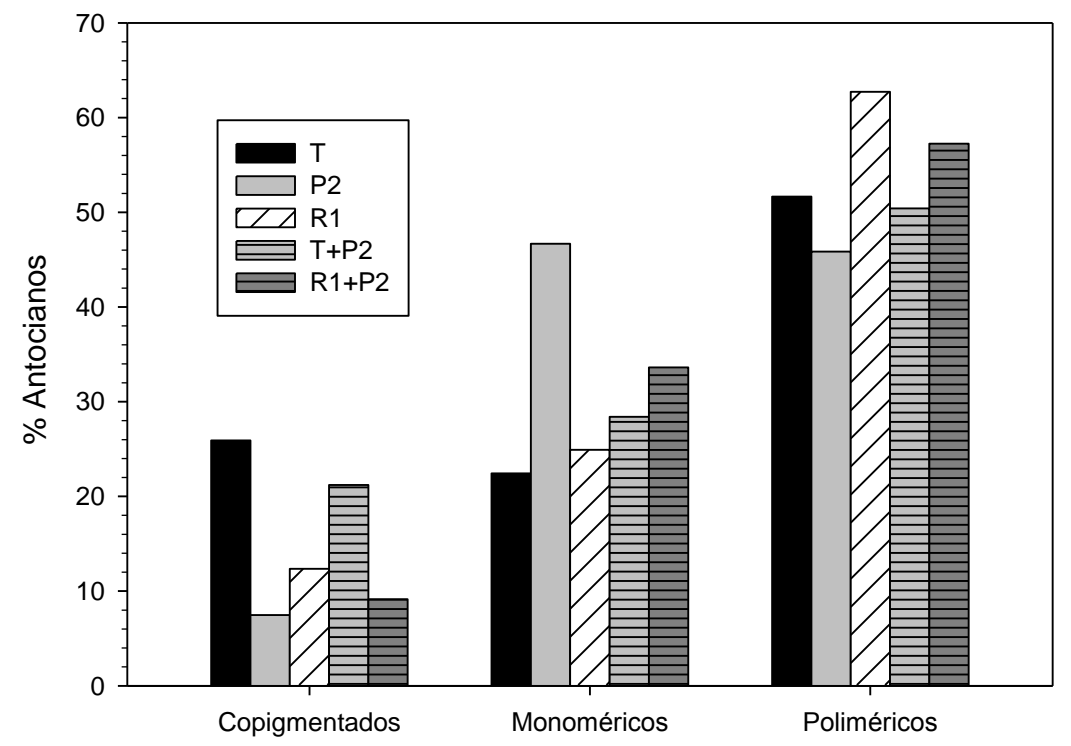

Figura 3.10 Porcentaje de antocianos copigmentados, monoméricos y poliméricos, en las fracciones de filtración y en las mezclas de los distintos vinos Tinta de Toro, tras el proceso de fermentación alcohólica. 
En el caso de los antocianos se ha analizado la composición porcentual de polímeros, monómeros y copigmentados (figura 3.10), como es de esperar, las moléculas grandes están más presentes en los vinos obtenidos con el retenido, y las pequeñas en el vino que participa el permeado. El bajo contenido de antocianos copigmentados en el permeado, y el alto contenido de monómeros, respecto al vino testigo, hace pensar en una rotura de las moléculas copigmentadas en el proceso de nanofiltración.

Después de la fermentación maloláctica, la única diferencia entre los tres vinos, respecto a los parámetros de análisis clásicos, fue su contenido en alcohol, como muestra la tabla 3.14. Como se aprecia, los vinos finales tienen una reducción en el contenido alcohólico muy próximo a $2 \%$.

Los compuestos fenólicos (polifenoles totales, antocianos, catequinas y taninos), ésteres tartáricos, flavonoles y \% de antocianos dependiendo de su polimerización, también fueron analizados después de la fermentación maloláctica. Los datos obtenidos se muestran en las figuras 3.11 y 3.12. Si observamos la primera figura, comprobamos que tenemos una menor concentración de compuestos en los vinos de menor grado alcohólico. Esta pérdida da lugar a una menor intensidad colorante, principalmente en los vinos obtenidos por mezcla del permeado de la segunda filtración (P2) y el retenido de primera filtración (R1). En el caso de la mezcla de P2 con el vino testigo, tenemos unas diferencias menores al $12 \%$ de polifenoles totales, antocianos y catequinas. El porcentaje de antocianos copigmentados es mayor en la mezcla $T+P 2$, que en la mezcla $\mathrm{R} 1+\mathrm{P} 2$; esto refleja el comportamiento inverso en los antocianos poliméricos ya que analizamos una variación porcentual, como explicamos en el caso del vino Verdejo. Esto se debe a que las moléculas grandes están más presentes en las fracciones de los retenidos que de los permeados.

Tabla 3.14 Parámetros enológicos clásicos de los vinos testigo, de las distintas fracciones de filtración y de las mezclas tras el proceso de fermentación maloláctica en mostos de la variedad Tinta de Toro, A. Total: acidez total; A.V: acidez volátil; TH2: ácido tartárico; MH2: ácido málico.

\begin{tabular}{|c|c|c|c|c|c|c|c|c|}
\hline $\begin{array}{c}\text { Vino } \\
\text { Tinta de } \\
\text { Toro }\end{array}$ & $\mathbf{p H}$ & $\mathbf{A}$. Total & A.V. & TH2 & MH2 & Potasio & Azúcar & Grado \\
\cline { 2 - 9 } & & $\mathbf{g} / \mathbf{L}$ & $\mathbf{g} / \mathbf{L}$ & $\mathbf{g} / \mathbf{L}$ & $\mathbf{g} / \mathbf{L}$ & $\mathbf{m g} / \mathbf{L}$ & $\mathbf{g} / \mathbf{l}$ & $\mathbf{v} / \mathbf{v}$ \\
\hline $\mathrm{T}$ & 3.89 & 5.05 & 0.65 & 1.17 & 0.10 & 1555 & 1.30 & 14.28 \\
\hline $\mathrm{T}+\mathrm{P} 2$ & 3.88 & 4.69 & 0.57 & 0.98 & 0.10 & 1435 & 1.30 & 12.49 \\
\hline $\mathrm{R} 1+\mathrm{P} 2$ & 3.87 & 4.16 & 0.52 & 0.94 & 0.10 & 1380 & 1.30 & 12.47 \\
\hline
\end{tabular}




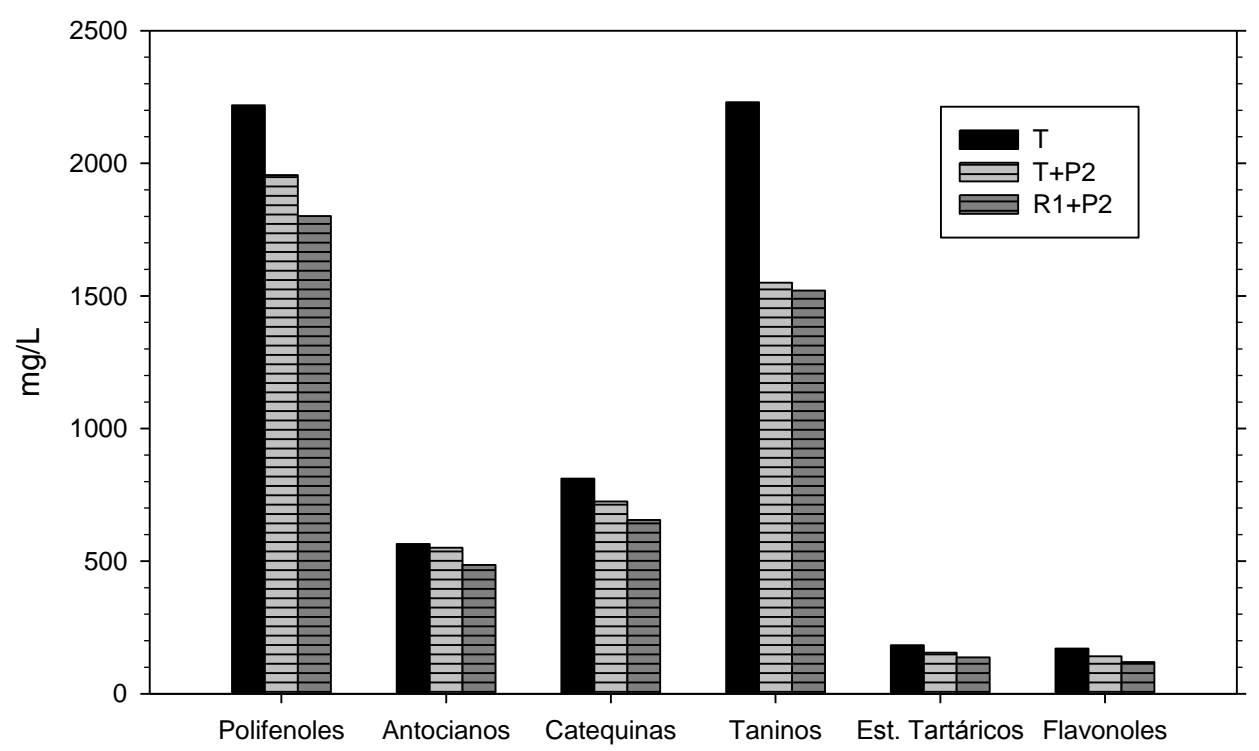

Figura 3.11 Contenido en polifenoles totales, antocianos, catequinas, taninos, ésteres tartáricos y flavonoles, en el vino testigo y en los vinos de menor graduación alcohólica de la variedad Tinta de Toro.

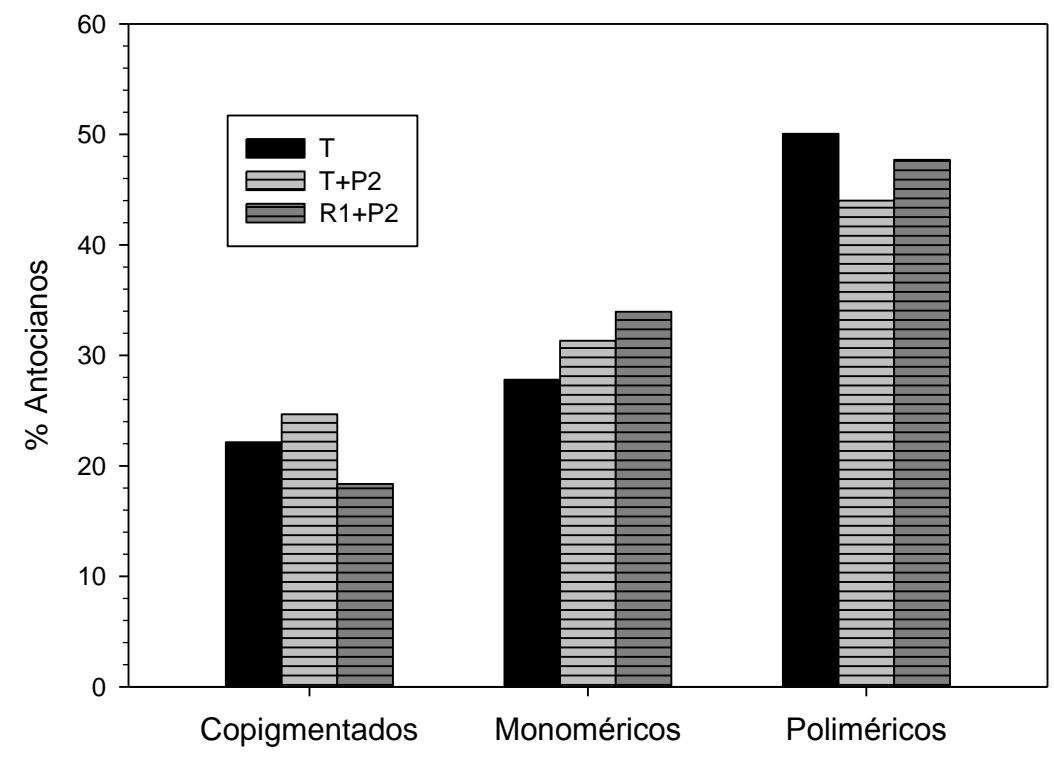

Figura 3.12 Porcentaje de antocianos copigmentados, monoméricos y poliméricos, en el vino testigo y en los vinos de menor graduación alcohólica de la variedad Tinta de Toro. 
Después de analizar los compuestos que afectarán al color del vino, parece que las dos mezclas de vino con menos graduación alcohólica tendrán un color menos intenso que el color del vino testigo, aunque el índice de color, la tonalidad y los porcentajes en azules, amarillos y rojos de los tres vinos elaborados son similares, como se puede observar en la figura 3.13 .

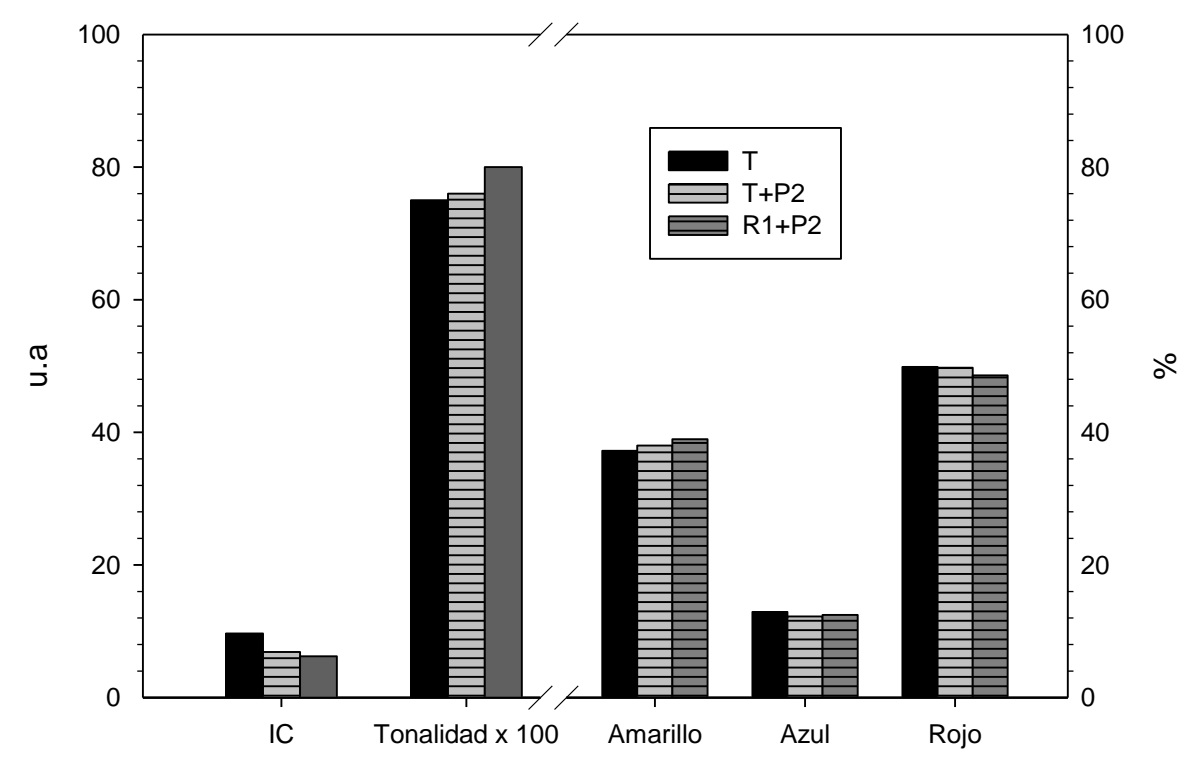

Figura 3.13 Índice de color del vino testigo y de los vinos de menor graduación alcohólica de la variedad Tinta de Toro.

\section{ANÁLISIS AROMÁTICO}

Para completar el estudio sobre las características de los vinos se analizó la fracción volátil de los mismos, la cual tendrá mucha importancia en sus propiedades organolépticas. Se identifican una gran cantidad de compuestos, y se cuantifican, agrupándolos de acuerdo a sus características químicas, de esta forma, se tienen los siguientes grupos:

- Ésteres etílicos: butirato-, isovalerato-, hexanoato-, octanoato-, decanoato- y lactato- de etilo; succinato- y glutarato de dietilo; y 3-hidroxibutirato de etilo.

- Alcoholes superiores y alcoholes bencílicos: butanol, isobutanol, pentanol, isopentanol, heptanol, octanol, 2-feniletanol y alcohol bencílico.

- Acetatos: acetato de isoamilo, acatato de hexilo y acetato feniletílico. 
- Ácidos grasos: ácido succínico, pentanoico, isopentanoico, hexanoico, octanoico, decanoico y dodecanoico.

- Lactonas: $\gamma$-butirolactona y $\gamma$-nanolactona.

- Alcoholes C6 (C6-OH): cis y trans 3-hexenol y hexanol.

- Compuestos Terpénicos: $\alpha$-terpineol, citronelol, geraniol, linalol, nerol y $\beta$ ionona.

Además de estos grupos se han estudiado otros tres compuestos importantes como son: el benzaldehído, el metionol y el ácido geránico.

Todos estos componentes aromáticos se representan en las figuras 3.14 y 3.15 , tanto para vinos Verdejo como Tinta de Toro. El perfil aromático del vino testigo (T) es claramente diferente del perfil de los vinos de baja graduación, obtenidos por reducción de los niveles de azúcar en mosto ( $T+P 2$ y $R 1+P 2)$. Estos vinos de baja graduación tienen un perfil muy similar entre ellos, como podemos ver en las figuras. Las diferencias significativas encontradas entre los vinos de baja graduación alcohólica y el testigo dan lugar a una mayor cantidad de componentes volátiles en el vino sin modificar.

a) Vino Verdejo

Tenemos diferencias cuantitativas importantes en los niveles de: alcoholes superiores, ácidos grasos, ésteres etílicos, lactonas, acetatos y terpenos. Estos resultados los podemos explicar, porque en los mostos en los que se modifica la concentración de azúcar, el proceso de fermentación es menos intenso que en el mosto testigo, y por eso se producen menos aromas secundarios (de fermentación). En el caso del benzaldehído, tenemos mayor cantidad en los vinos de baja graduación alcohólica que en el vino testigo. Esto puede deberse a que un calentamiento de los mostos o vinos eleva la concentración de aldehídos volátiles [28].

Los componentes terpénicos están presentes en la uva, son aromas primarios, pero liberarán sus precursores aromáticos, gracias a enzimas presentes en la fermentación alcohólica. A mayor intensidad de fermentación, se producen más reacciones de hidrólisis y, por lo tanto, se forman más compuestos de este tipo. Pero además de la intensidad de fermentación, tendremos menos precursores terpénicos porque muchos se retienen en los pasos de la nanofiltración, sobretodo en el primer paso de filtración. 


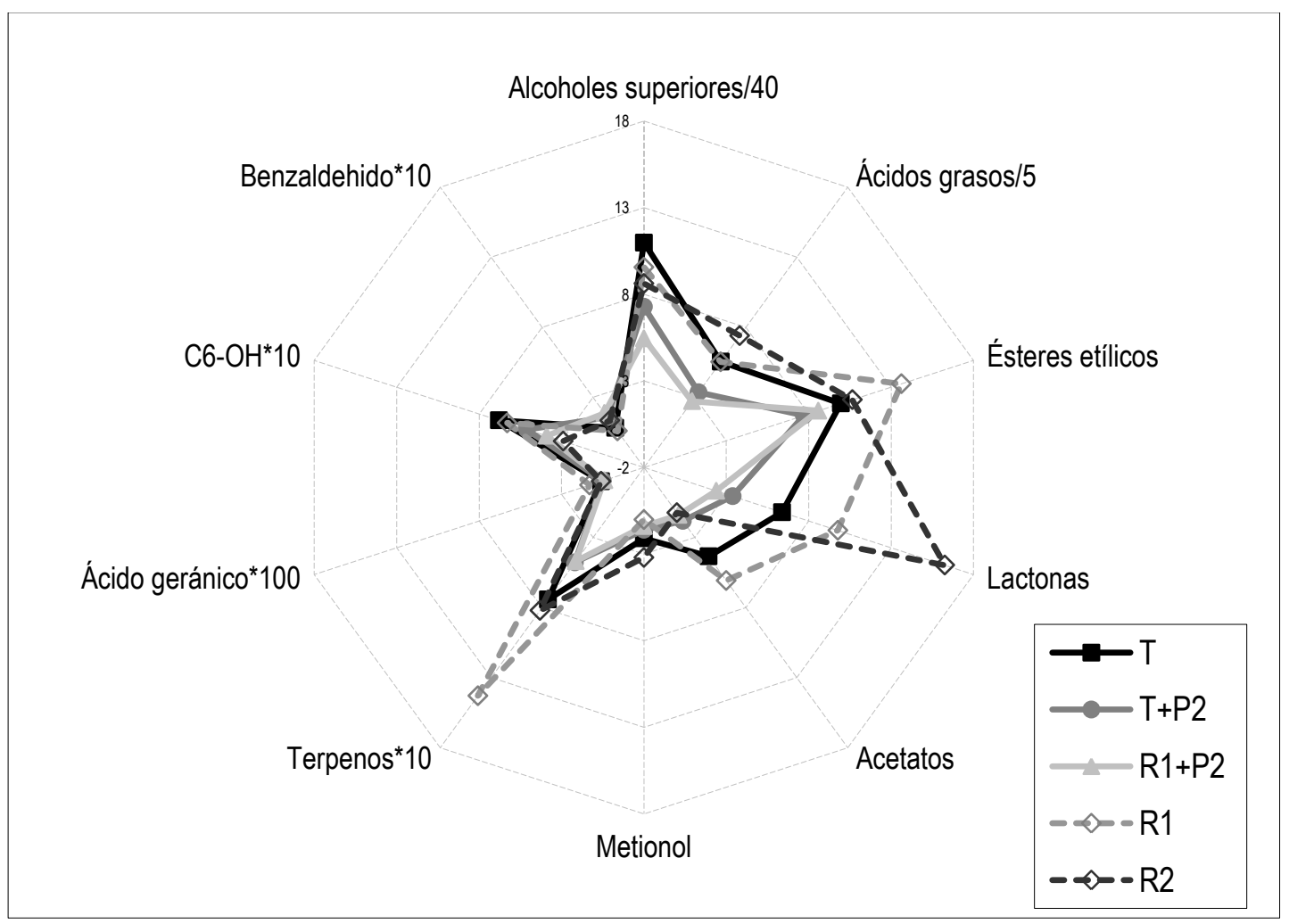

Figura 3.14 Concentración $(\mathrm{mg} / \mathrm{L})$ de los componentes aromáticos para el vino testigo y para los vinos de menor graduación alcohólica de la variedad Verdejo.

Los vinos obtenidos de los retenidos (R1 y R2), muestran un perfil aromático muy diferente respecto al resto de los vinos elaborados, siendo vinos más ricos aromáticamente, pero más desequilibrados en boca como se verá más adelante. EI vino obtenido de la fermentación del retenido de la segunda filtración (R2), presenta altos niveles de lactonas, esto se debe a que por sus tamaños intermedios similares a los azúcares, parte de estos compuestos se retienen en el primer paso de filtración (R1) y otra gran parte pasan al permeado que sufre la segunda filtración. Esto hace que alcancen una concentración alta en R2, además del hecho de que la formación de lactonas aumenta con la temperatura [28]. En cuanto a terpenos, el retenido de segunda filtración (R2) tiene poca concentración, puesto que se quedan retenidos en el primer paso de filtración (R1) o se han podido volatilizar sus precursores.

b) Vino Tinta de Toro

Un comportamiento muy similar se ha obtenido en el caso de los vinos tintos, en este caso las diferencias más importantes se han encontrado en los ácidos grasos y las lactonas, y algo menores en los ésteres etílicos. Igual que en el caso anterior, este comportamiento puede deberse a la combinación de una serie de factores asociados con el bajo nivel de azúcar en los mostos, la retención de sustancias y la evaporación. 


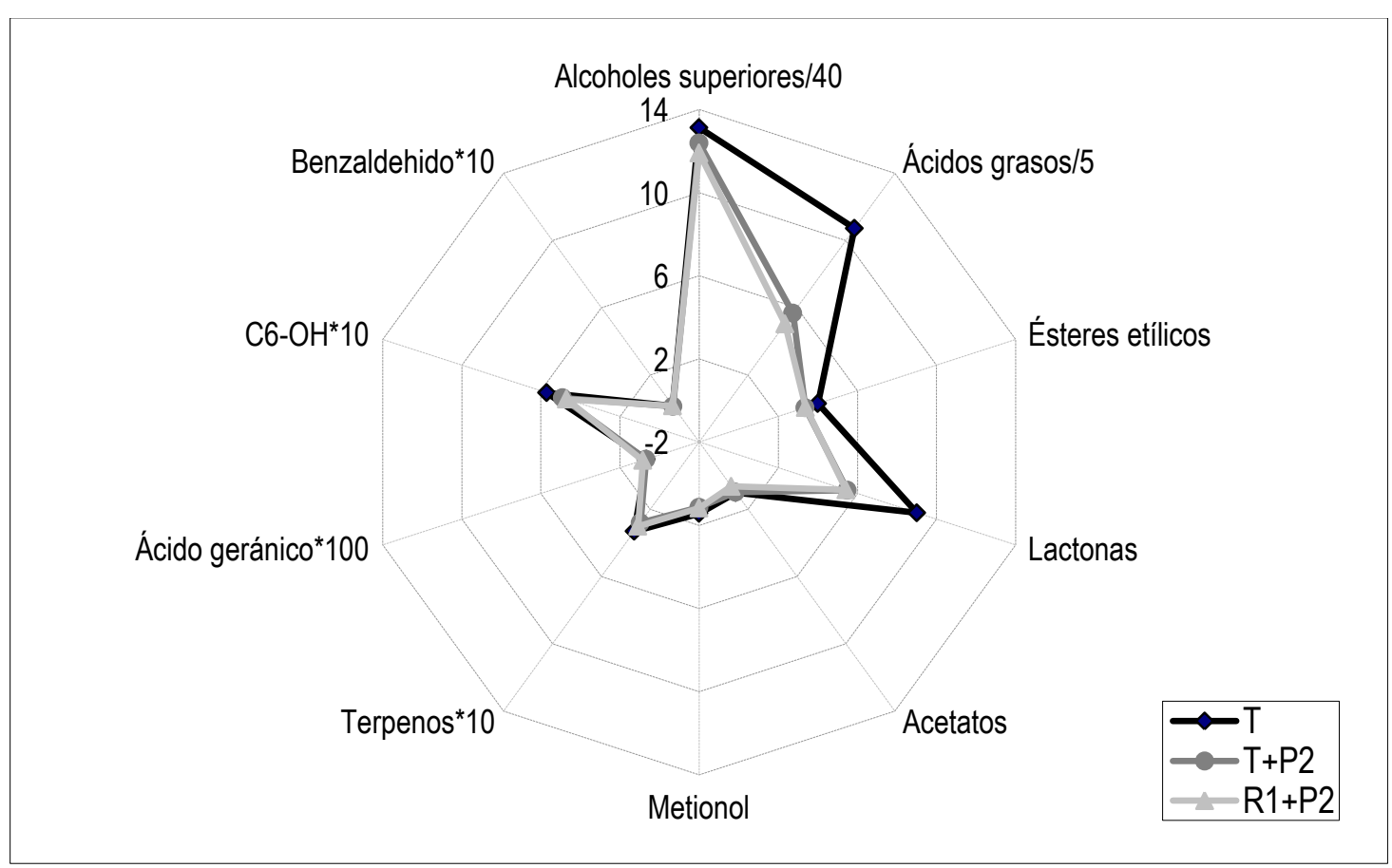

Figura 3.15 Concentración (mg/L) de los componentes aromáticos para el vino testigo y para los vinos de menor graduación alcohólica de la variedad Tinta de Toro.

Como veremos en el siguiente apartado, todos estos resultados, están de acuerdo con los comentarios de cata, que indican, que el vino testigo, tiene un aroma más intenso, con mayores notas florales y frutales, mientras que los vinos de menor graduación alcohólica son menos intensos aromáticamente.

\section{ANÁLISIS SENSORIAL}

Utilizando la metodología de análisis sensorial de alimentos [29], se lleva a cabo el estudio en la Estación Enológica del ITACYL por un panel formado por 12 catadores, técnicos de distintos Consejos Reguladores de Castilla y León, enólogos de diferentes bodegas de la región y personal de la propia Estación Enológica. De la opinión de estos catadores, se deduce lo que comentamos a continuación.

Los análisis sensoriales del vino Verdejo con reducción de alcohol no presentan defectos en términos olfativos ni visuales. No existen diferencias en el color del vino testigo y los de menor graduación alcohólica. Sobre el aroma, el vino testigo tiene mayor intensidad aromática que los vinos con reducción de alcohol. Como era de esperar, las grandes diferencias se encontraron en la fase gustativa, ya que la reducción de alcohol, permite la apreciación de otros componentes presentes en el vino. Los vinos con menos contenido alcohólico son más ácidos que el vino control, especialmente el vino obtenido de la mezcla $\mathrm{R} 1+\mathrm{P} 2$. 
En el vino Tinta de Toro, no se encontraron diferencias en cuanto a color, aunque se observaron diferencias en la fase olfativa. El aroma del vino $\mathrm{T}+\mathrm{P} 2$ era menos intenso que en el vino testigo, mientras que en el vino $\mathrm{R} 1+\mathrm{P} 2$ mostraba aromas artificiales a farmacia [30]. En boca, las únicas diferencias detectadas entre el vino testigo y los vinos de menos graduación alcohólica, se deben a esta característica, siendo los vinos obtenidos menos ardientes que el vino testigo. Algunas de las diferencias mostradas entre el vino obtenido del mosto sin tratar y el mosto nanofiltrado con membranas, puede deberse a la oxidación de compuestos, como consecuencia de la aireación excesiva de los mostos en el proceso de filtración, y el tiempo excesivo de filtración en el que se llevó a cabo la reducción de azúcar del mosto.

\section{CONCLUSIONES}

Como respuesta a las nuevas tendencias hacia estilos de vida saludables y la reducción de ingesta de calorías, se propone un nuevo método para obtener vinos de bajo contenido alcohólico. La ventaja del método propuesto es trabajar con mostos en lugar de manipular vinos terminados, lo que favorece la conservación de las propiedades organolépticas obtenidas en la fermentación.

El estudio realizado en este capítulo nos ha permitido diseñar una serie de modificaciones que nos podría permitir la mejora del método en los capítulos posteriores:

1- Teniendo en cuenta los resultados obtenidos para los vinos tratados, consideramos que el producto $\mathrm{T}+\mathrm{P} 2$ muestra mejores resultados, debido a que es el vino que tiene las características químicas y sensoriales más similares al vino Testigo.

2- Se decide realizar tan sólo un paso de nanofiltración en las campañas posteriores, ya que la doble filtración no reduce la cantidad de azúcar en una proporción adecuada, para compensar el tiempo de operación. Además hemos indicado que se debe reducir el tiempo de filtración para evitar oxidaciones del mosto, por lo que, a partir de este momento se utilizará un sólo paso de filtración por las membranas.

3- Además del módulo espiral de nanofiltración HL, se utilizarán otros módulos de membrana, ya que aunque la membrana $H L$ daba lugar a elevados valores de permeabilidad y retención verdadera, no necesitamos una reducción de azúcar tan drástico y utilizando otras membranas podremos reducir el tiempo de 
filtración y obtener un permeado con la reducción de azúcar adecuada para reducir 2 grados alcohólicos el vino final. Por lo tanto, en el capítulo posterior se desarrollarán las experiencias realizadas con los módulos espirales de las membranas de nanofiltración HL, DL y DK, así como la utilización de la membrana de ultrafiltración GH para el mosto Verdejo y de esa membrana de ultrafiltración GH seguida de la membrana de nanofiltración HL para el mosto tinto (ya que utilizar únicamente la membrana de ultrafiltración, no nos permite reducir la concentración de azúcar en proporciones adecuadas para reducir el grado alcohólico del vino final en los términos descritos).

4- En cuanto a la caída de flujo detectada no se puede evitar, ya que los mostos son líquidos muy complejos con elevada carga coloidal que dará lugar al ensuciamiento de las membranas. Sin embargo, la fase de limpieza permite una estabilidad y recuperación de la membrana de nanofiltración para que siga siendo utilizada.

Para el mosto Verdejo se realizará, en la siguiente campaña, un análisis de aminoácidos de los permeados y retenidos obtenidos en las filtraciones. Con este nuevo análisis, lo que se pretende es comprobar si se pierden aminoácidos en las filtraciones y no se recuperan posteriormente al añadir el mosto sin tratar $(T)$ antes de la fermentación. Esta posible pérdida de aminoácidos, daría lugar a desajustes en términos olfativos del vino final.

Obviamente el éxito del método depende de las características del vino como respuesta al producto demandado, y el coste de producción sería un factor crítico de viabilidad. Este método es económico en términos de costes de producción y aunque da lugar a una pérdida de volumen del mosto, la rentabilidad del proceso se puede aumentar usando la parte del retenido para la producción de vinos dulces, vinos licorosos, aditivos funcionales o puede destinarse a la industria de la mermelada.

\section{REFERENCIAS}

1. García-Martín, N., Palacio, L., Prádanos, P., Hernández, A., Ortega-Heras, M., Pérez-Magariño, S., and González-Huerta, D. C., Evaluation of several ultraand nanofiltration membranes for sugar control in winemaking. Desalination, 2009. 245(1-3): p. 554-558.

2. García-Martín, N., Palacio, L., Prádanos, P., A.Hernández, M.Ortega-Heras, Pérez-Magariño, S., and González-Huerta, D. C., Evaluation of several ultra- 
and nanofiltration membranes for sugar control in winemaking., in Membrane Processes: Development, Monitoring and Modelling. 2008: Vale do Lobo, Algarve, Portugal.

3. Togores, J. H., Tratado de Enología. Mundi-Prensa ed. 2003.

4. García-Martín, N., Perez-Magariño, S., Ortega-Heras, M., González-Huerta, C., Mihnea, M., González-Sanjosé, M. L., Palacio, L., Prádanos, P., and Hernández, A., Sugar reduction in musts with nanofiltration membranes to obtain low alcohol-content wines. Separation and Purification Technology, 2010. 76(2): p. 158-170.

5. García-Martín, N., Perez-Magariño, S., Ortega-Heras, M., González-Huerta, C., Mihnea, M., González-Sanjosé, M. L., Palacio, L., Prádanos, P., and Hernández, A., Sugar reduction in white and red musts with nanofiltration membranes. Desalination and Water Treatment, 2011. 27(1-3): p. 167-174.

6. Pradanos, P., Arribas, J. I., and Hernandez, A., Flux limiting factors in crossflow ultrafiltration of invertase through an asymmetric inorganic membrane. Separation science and technology, 1993. 28(10): p. 1899-1911.

7. El Rayess, Y., Albasi, C., Bacchin, P., Taillandier, P., Raynal, J., MiettonPeuchot, M., and Devatine, A., Cross-flow microfiltration applied to oenology: A review. Journal of Membrane Science, 2011. 382(1-2): p. 1-19.

8. Compendium of international Methods of wine and must Analysis (OIV) 2011. 1.

9. Paronetto, L., Polifenoli e tecnica enologica. Selepress ed. 1977, Milan (Italy).

10. Amerine, M. A. and Ough, C. S., Análisis de vinos y mostos, ed. Acribia. 1976.

11. Cliff, M. A., King, M. C., and Schlosser, J., Anthocyanin, phenolic composition, colour measurement and sensory analysis of BC commercial red wines. Food Research International, 2007. 40(1): p. 92-100.

12. Mihnea, M., González-SanJosé, M. L., Ortega-Heras, M., Pérez-Magariño, S., García-Martin, N., Palacio, L., Prádanos, P., and Hernández, A., Impact of Must Sugar Reduction by Membrane Applications on Volatile Composition of Verdejo Wines. Journal of Agricultural and Food Chemistry, 2012. 60(28): p. 7050-7063.

13. Ortega-Heras, M., González-SanJosé, M. L., and Beltrán, S., Aroma composition of wine studied by different extraction methods. Analytica Chimica Acta, 2002. 458(1): p. 85-93.

14. Al-Amoudi, A., Williams, P., Mandale, S., and Lovitt, R. W., Cleaning results of new and fouled nanofiltration membrane characterized by zeta potential and permeability. Separation and Purification Technology, 2007. 54(2): p. 234-240. 
15. Jonsson, G., Prádanos, P., and Hernández, A., Fouling phenomena in microporous membranes. Flux decline kinetics and structural modifications. Journal of Membrane Science, 1996. 112(2): p. 171-183.

16. Prádanos, P., de Abajo, J., de la Campa, J. G., and Hernández, A., A comparative analysis of flux limit models for ultrafiltration membranes. Journal of Membrane Science, 1995. 108(1-2): p. 129-142.

17. Choi, H., Zhang, K., Dionysiou, D. D., Oerther, D. B., and Sorial, G. A., Influence of cross-flow velocity on membrane performance during filtration of biological suspension. Journal of Membrane Science, 2005. 248(1-2): p. 189199.

18. Tu, S.-C., Ravindran, V., Den, W., and Pirbazari, M., Predictive membrane transport model for nanofiltration processes in water treatment. AIChE Journal, 2001. 47(6): p. 1346-1362.

19. Hoek, E. M. V. and Elimelech, M., Cake-Enhanced Concentration Polarization: A New Fouling Mechanism for Salt-Rejecting Membranes. Environmental Science \& Technology, 2003. 37(24): p. 5581-5588.

20. Jacob, J., Prádanos, P., Calvo, J. I., Hernández, A., and Jonsson, G., Fouling kinetics and associated dynamics of structural modifications. Colloids and Surfaces A: Physicochemical and Engineering Aspects, 1998. 138(2-3): p. 173183.

21. Palacio, L., Ho, C. C., Prádanos, P., Hernández, A., and Zydney, A. L., Fouling with protein mixtures in microfiltration: BSA-lysozyme and BSA-pepsin. Journal of Membrane Science, 2003. 222(1-2): p. 41-51.

22. Barceló, J. G., Técnicas Analíticas para Vinos. GAB ed. 1990.

23. Togores, J. H., La calidad del vino desde el viñedo. Mundi-Prensa ed. 2010.

24. Flanzy, C., Enología: Fundamentos Científicos y Tecnológicos, ed. MundiPrensa. 2000.

25. Montalvillo, M., Silva, V., Palacio, L., Calvo, J. I., Carmona, F. J., Hernández, A., and Prádanos, P., Charge and dielectric characterization of nanofiltration membranes by impedance spectroscopy. Journal of Membrane Science, 2014. 454(0): p. 163-173.

26. Revilla, I. and González-San José, M. L., Addition of pectolytic enzymes: an enological practice which improves the chromaticity and stability of red wines. International Journal of Food Science \& Technology, 2003. 38(1): p. 29-36.

27. K. Bui, R. Dick, G. Moulin, and Galazy, P., A Reverse Osmosis for the Production of Low Ethanol Content Wine. American Journal of Enology and Viticulture, 1986. 37(4): p. 297-300. 
28. Jackson, R. S., Wine Science: Principles, Practice, Perception. Elsevier Science \& Technology ed, ed. 2. 2000.

29. Gonzalez-Sanjose, M. L., Ortega-Heras, M., and Perez-Magarino, S., Microoxygenation Treatment and Sensory Properties of Young Red Wines. Food Science and Technology International, 2008. 14: p. 123-130.

30. Catarino, M. and Mendes, A., Dealcoholizing wine by membrane separation processes. Innovative Food Science \& Emerging Technologies, 2011. 12(3): p. 330-337. 


\section{CAPÍTULO 4 MODIFICACIONES DEL PROCESO DE NANOFILTRACIÓN. INFLUENCIA DEL TIPO DE MEMBRANA EN LOS VINOS OBTENIDOS}

\section{INTRODUCCIÓN}

Después de los resultados obtenidos en la primera campaña, y tratando de disminuir el tiempo de filtración para mejorar los resultados obtenidos en el análisis sensorial de los vinos finales, retomamos todos los módulos de membrana que utilizamos en un principio (en el Capítulo 2) para filtrar la disolución de azúcar y el mosto tinto comercial.

El sistema de filtración diseñado para este propósito se modifica respecto a la campaña anterior, para conseguir una mejora de las características organolépticas del vino. En este caso se realiza un solo paso del mosto por el módulo de filtración, reduciendo, de este modo, el tiempo de filtración a través de la membrana. El cambio respecto al sistema de filtración utilizado en la campaña anterior, donde se realizaban dos filtraciones consecutivas del mosto, tiene su fundamento en la valoración de la disminución de la concentración de azúcar respecto al tiempo de filtración empleado, concluyendo que la disminución de azúcar del segundo paso de filtración no compensa el aumento de tiempo empleado en el proceso. Además, como indicamos en las conclusiones del capítulo anterior, para obtener vinos con una reducción de graduación alcohólica de $2 \%$ vol, se mezclará la fracción de permeado necesaria con el mosto testigo.

\section{MATERIALES USADOS Y DISPOSITIVOS EXPERIMENTALES}

\subsection{MEMBRANAS}

Se utilizan todos los módulos de membrana utilizados en el capítulo 2. Las características de los módulos de membrana empleados se mostraron en la tabla 2.11 de dicho capítulo.

Como explicamos en el Capítulo 2, a los módulos de membrana nuevos se les elimina la solución conservante y se acondicionan según las especificaciones descritas en la tabla 2.12. En este capítulo también se usarán módulos de membrana que han sido utilizados en la filtración de disoluciones de azúcar y mostos comerciales, y que se han conservado en una disolución de fenol. Para eliminar esta disolución de fenol, se lavan 
en el sistema de filtración con agua del grifo durante 1 hora y 1 hora más con agua milli-Q. Esta eliminación de fenol tiene lugar a la presión más elevada que podamos aplicar (distinta para cada módulo), al igual que el proceso de eliminación de la solución bactericida de los módulos nuevos.

\subsection{ELABORACIÓN Y PREPARACIÓN DE MOSTOS}

Al igual que en el capítulo anterior se utiliza uva Verdejo y Tinta de Toro para obtener los mostos, pero en este caso vendimiada en Septiembre de 2008. Estos mostos se elaboran según el método tradicional como ya describimos en el apartado 2.2 del capítulo anterior.

\subsection{DISPOSITIVO EXPERIMENTAL}

El equipo necesario para realizar la filtración es el mismo que el descrito en el capítulo anterior, introduciendo cada módulo espiral de membrana en la carcasa correspondiente dependiendo del tamaño del mismo.

Para todas las pruebas de filtración con el mosto Verdejo y con el mosto Tinta de Toro se utilizan 30 litros de mosto, se introduce el serpentín de refrigeración en el depósito de alimentación y se ajusta la temperatura a $6^{\circ} \mathrm{C}$ tanto para el mosto Verdejo como para el mosto Tinta de Toro, para no tener problemas de fermentación del mismo. En las filtraciones con el mosto Verdejo se utilizaron distintos módulos. En el caso de la membrana GH se hicieron medidas para dos tiempos diferentes de filtración; en el primer tiempo se filtra el $50 \%$ del mosto de partida (UF-GH t1) y en el segundo tiempo el 63\%, (UF-GH t2)). Además de este módulo de filtración para la filtración de mosto Verdejo, se utilizan los módulos de nanofiltración HL, DL y DK. Con el mosto Tinta de Toro se utiliza el módulo de membrana GH seguido del módulo HL, y los módulos HL, DL y DK. Debido a que la utilización del módulo de membrana de ultrafiltración GH con el mosto Verdejo muestra que la reducción de azúcar es muy baja, la elaboración de vinos no sería viable para la obtención de un vino de baja graduación alcohólica y no se realiza esta prueba.

En la tabla 4.1 se muestran las presiones aplicadas para conseguir flujos de recirculación aceptables de 1L/min [1]. 
Tabla 4.1 Presiones de filtración para el mosto Verdejo y mosto Tinta de Toro.

\begin{tabular}{|c|c|c|}
\hline \multirow{2}{*}{ Módulo membrana } & \multicolumn{2}{|c|}{ Presión (10 $\left.{ }^{5} \mathrm{~Pa}\right)$} \\
\cline { 2 - 3 } & Mosto Verdejo & Mosto Tinta de Toro \\
\hline UF-GH(t1) & 23 & --- \\
\hline UF-GH (t2) & 22.5 & --- \\
\hline UF-GH + NF-HL & --- & 22.5 \\
\hline NF-HL & 22.5 & 22.5 \\
\hline NF-DL & 22 & 22.5 \\
\hline NF-DK & 22 & 22 \\
\hline
\end{tabular}

\subsection{MÉTODOS ANALÍTICOS}

En el transcurso de la filtración se miden por polarimetría los valores de concentración de azúcar, permitiendo calcular de este modo la retención de la membrana a lo largo del tiempo. Así, además de hacer un seguimiento de la caída de flujo con el tiempo debido al ensuciamiento de la membrana, podemos ver la evolución de las características de retención de la misma. Es decir, podemos hacer un estudio de la variación de las propiedades permoselectivas de la membrana como consecuencia del ensuciamiento y de la variación de la presión osmótica.

Como en el capítulo anterior, además de medir la concentración de azúcar respecto al tiempo por polarimetría, se analizan las concentraciones de azúcar de la alimentación, del permeado y de los retenidos finales en la Estación Enológica del ITACyL por personal adscrito al centro. Para ello se utilizan los métodos refractométricos y enzimático, utilizando este último más exacto para calcular la retención de la membrana. Todos los métodos de medida de concentración de azúcar, se explicaron en el capítulo 2 (apartados 3.1 .4 y 4.1.4).

El resto de componentes del mosto y el vino se analizan de acuerdo a los métodos indicados en el apartado 2.4 del capítulo anterior. Para estos compuestos no se hace un seguimiento temporal, sino que se analizan en el mosto antes del proceso de filtración y en el permeado y retenido totales después de finalizado el proceso, así como en las mezclas de los mostos y vinos elaborados. Estos análisis se realizan en la Estación Enológica del ITACyL, junto con los análisis de aminoácidos del mosto Verdejo que se realizan mediante cromatografía de líquidos de alta resolución (HPLC). 


\section{RESULTADOS}

\subsection{PERMEABILIDAD HIDRÁULICA}

Una vez que se ha eliminado el fenol, se mide la permeabilidad para analizar su variación por los efectos de ensuciamiento que tiene lugar en la membrana en los procesos anteriores de filtración. Así tenemos una referencia de las condiciones de partida de cada módulo que suelen ser distintas a las de la membrana nueva. Esta determinación se realiza con agua milli-Q, en el intervalo de presiones apropiado (ver tablas 4.2 y 4.3), teniendo en cuenta las características funcionales del módulo utilizado en cada caso.

En las tablas 4.2 y 4.3 , se muestran los valores de permeabilidad de cada membrana espiral antes y después de cada filtración del mosto Verdejo y del mosto Tinta de Toro, al igual que después de la limpieza de dichas membranas. Con todos los módulos de membrana se filtra primero el Verdejo y luego el mosto Tinta de Toro, excepto para el módulo de membrana $\mathrm{DL}$ que se hace al contrario por razones operativas.

Tabla 4.2 Permeabilidad de los módulos de membranas espirales antes y después de la filtración del mosto Verdejo y tras la limpieza de los módulos. En el caso del módulo GH la filtración del mosto Verdejo tiene lugar a dos tiempos diferentes.

\begin{tabular}{|c|c|c|c|c|c|c|}
\hline \multirow{2}{*}{$\begin{array}{c}\text { Módulo } \\
\text { membrana }\end{array}$} & $\begin{array}{c}\text { Rango de } \\
\text { presiones } \\
\text { aplicado } \\
\text { (bar) }\end{array}$ & $\begin{array}{c}\text { Membrana } \\
\text { nueva }\end{array}$ & $\begin{array}{c}\text { Antes de } \\
\text { la } \\
\text { filtración } \\
\text { de } \\
\text { Verdejo }\end{array}$ & $\begin{array}{c}\text { Después filtración } \\
\text { Verdejo }\end{array}$ & $\begin{array}{c}\text { Después de } \\
\text { la limpieza } \\
\text { con } \\
\text { detergente }\end{array}$ \\
\cline { 3 - 7 } & & \multicolumn{5}{|c|}{$L_{p}\left(10^{-11} \mathrm{~m} /(\mathrm{s} \cdot \mathrm{Pa})\right)$} \\
\hline UF-GH & $8-18$ & 0.574 & 0.497 & $0.509(\mathrm{t} 1)$ & $0.362(\mathrm{t} 2)$ & 0.266 \\
\hline NF-HL & $2-10$ & 1.933 & 1.580 & 1.213 & 1.217 \\
\hline NF-DL & $8-16.5$ & 1.649 & --1 & 0.802 & 0.825 \\
\hline NF-DK & $6-15$ & 0.692 & 0.692 & 0.619 & 0.559 \\
\hline
\end{tabular}

${ }^{1}$ Valores no determinados 
Tabla 4.3 Permeabilidad de los módulos de membranas espirales antes y después de la filtración del mosto Tinta de Toro y tras la limpieza de los módulos.

\begin{tabular}{|c|c|c|c|c|c|c|}
\hline \multirow[t]{2}{*}{$\begin{array}{c}\text { Módulo } \\
\text { membrana }\end{array}$} & \multirow[t]{2}{*}{$\begin{array}{l}\text { Rango de } \\
\text { presiones } \\
\text { aplicado } \\
\text { (bar) }\end{array}$} & $\begin{array}{c}\text { Membrana } \\
\text { nueva }\end{array}$ & $\begin{array}{c}\text { Antes de la } \\
\text { filtración de } \\
\text { Tinta de Toro }\end{array}$ & $\begin{array}{l}\text { Después } \\
\text { de la } \\
\text { filtración } \\
\text { de Tinta } \\
\text { de Toro }\end{array}$ & $\begin{array}{c}\text { Después } \\
\text { de la } \\
\text { limpieza } \\
\text { con } \\
\text { detergente }\end{array}$ & $\begin{array}{c}\text { Después } \\
\text { de la } \\
\text { limpieza } \\
\text { con fenol }\end{array}$ \\
\hline & & \multicolumn{5}{|c|}{$L_{p}\left(10^{-11} \mathrm{~m} /(\mathrm{s} \cdot \mathrm{Pa})\right)$} \\
\hline \multirow{2}{*}{$\begin{array}{c}\text { UF-GH + } \\
\text { NF-HL }\end{array}$} & 8-18 & 0.574 & 0.509 & 0.335 & $--^{1}$ & 0.379 \\
\hline & $2-10$ & 1.933 & 1.212 & 1.643 & $--^{1}$ & $--{ }^{1}$ \\
\hline NF-HL & $2-10$ & 1.933 & 1.190 & 1.340 & 1.333 & 0.987 \\
\hline NF-DL & $8-16.5$ & 1.649 & 1.287 & 1.211 & $--^{1}$ & 1.195 \\
\hline NF-DK & $6-15$ & 0.692 & 0.559 & 0.578 & 0.692 & 0.796 \\
\hline
\end{tabular}

${ }^{1}$ Valores no determinados

Como se observa en las tablas, los valores de permeabilidad disminuyen respecto a la membrana nueva, tanto al pasar el mosto Verdejo como el mosto Tinta de Toro. Si comparamos la permeabilidad antes y después de la filtración de mosto Verdejo o Tinta de Toro, en general disminuye debido al fenómeno de "fouling" [2]. Sin embargo, podemos encontrar algunas excepciones, por ejemplo, en el primer dato de permeabilidad del mosto Verdejo con la membrana GH referido a la filtración a tiempos cortos; es decir, reduciendo tan solo el $50 \%$ del volumen, el valor de permeabilidad es mayor probablemente por no disponer de tiempo suficiente para que se deposite una capa significativa de sustancias sobre la membrana. El pequeño aumento puede ser debido al error experimental.

Tiene lugar otra excepción en la filtración del mosto Tinta de Toro con las membranas de nanofiltración HL y DK, ya que la permeabilidad después de la filtración es mayor que antes de la misma, lo que puede deberse a que las sustancias de mayor tamaño del mosto tinto, eliminen sustancias de menor tamaño que se han depositado sobre la membrana en la filtración de mosto blanco, produciendo una limpieza sobre la misma.

Si comparamos la permeabilidad después de filtrar los mostos Verdejo y Tinta de Toro (tablas 4.2 y 4.3), respecto a la permeabilidad de los módulos espirales, una vez filtrada la disolución de azúcar y los mostos comerciales modificados (tablas 2.16 y 2.20 respectivamente) presentes en el capítulo 2. Se puede comprobar que la permeabilidad medida después de la filtración del mosto Verdejo es menor que 
después de la filtración de la disolución de azúcar y el mosto comercial en todas las membranas, excepto en la membrana DK donde se obtiene el mismo valor.

Si tenemos en cuenta la filtración del mosto Tinta de Toro, en todas las membranas la permeabilidad se reduce respecto a la filtración de la disolución de azúcar o el mosto comercial modificado, excepto en la membrana $\mathrm{DL}$, en la que su valor de permeabilidad es mayor si hacemos pasar por ella el mosto elaborado para este trabajo que el mosto comercial modificado. Esto puede ser debido a que la membrana $\mathrm{DL}$ al pH del mosto, (aproximadamente 3.0), está cargada negativamente, al contrario que las membranas de nanofiltración DK y HL que están cargadas positivamente [3]. Por esta razón, al utilizar la membrana DL para filtrar el mosto Tinta de Toro con más sustancias de gran tamaño que un mosto comercial, estos compuestos tendrían un efecto de "limpieza" en los poros de membrana que harían aumentar la permeabilidad como ya explicamos en la comparación de permeabilidad entre la filtración de una disolución de azúcar y un mosto tinto comercial.

Después de la limpieza de la membrana, se obtienen unos valores de permeabilidad próximos a los que teníamos antes de realizar la filtración y del mismo orden que los datos de permeabilidad de los módulos de membrana nuevos. En todos los casos, después del almacenamiento del módulo en fenol, la permeabilidad disminuye, excepto en el módulo DK donde aumenta este valor. Esto puede deberse a que las sustancias químicas del proceso de limpieza o las sustancias conservantes utilizadas ataquen parciamente al material de la membrana aumentando su permeabilidad. En resumen podremos decir que la recuperación de la funcionalidad de la membrana con el tratamiento de limpieza aplicado es adecuada.

\subsection{CURVAS TIEMPO-FLUJO}

Como en capítulos anteriores, con el fin de analizar los efectos del ensuciamiento, del aumento de la viscosidad y de la presión osmótica, en este epígrafe se analiza la caída de flujo en función del tiempo para las distintas membranas usadas y ambos mostos.

En las figuras 4.1 y 4.2 se presentan estas cinéticas de flujo de permeado de mosto Verdejo y Tinta de Toro. Para comparar las distintas membranas estas caídas de flujo se normalizan respecto a su flujo inicial $\left(J_{v} / J_{v, 0}\right)$, como ya hicimos en la filtración del mosto comercial tanto con los módulos de membrana como con las membranas planas. Podemos ver que, de forma general, la caída es mucho más significativa en el caso de los tintos que en los blancos, debido principalmente al efecto de la capa de 
gel, la viscosidad del fluido y el ensuciamiento, ya que la concentración de sustancias presentes es mayor en el tinto. Todos estos efectos se explicaron en el apartado 3.2 del capítulo anterior [4-6].

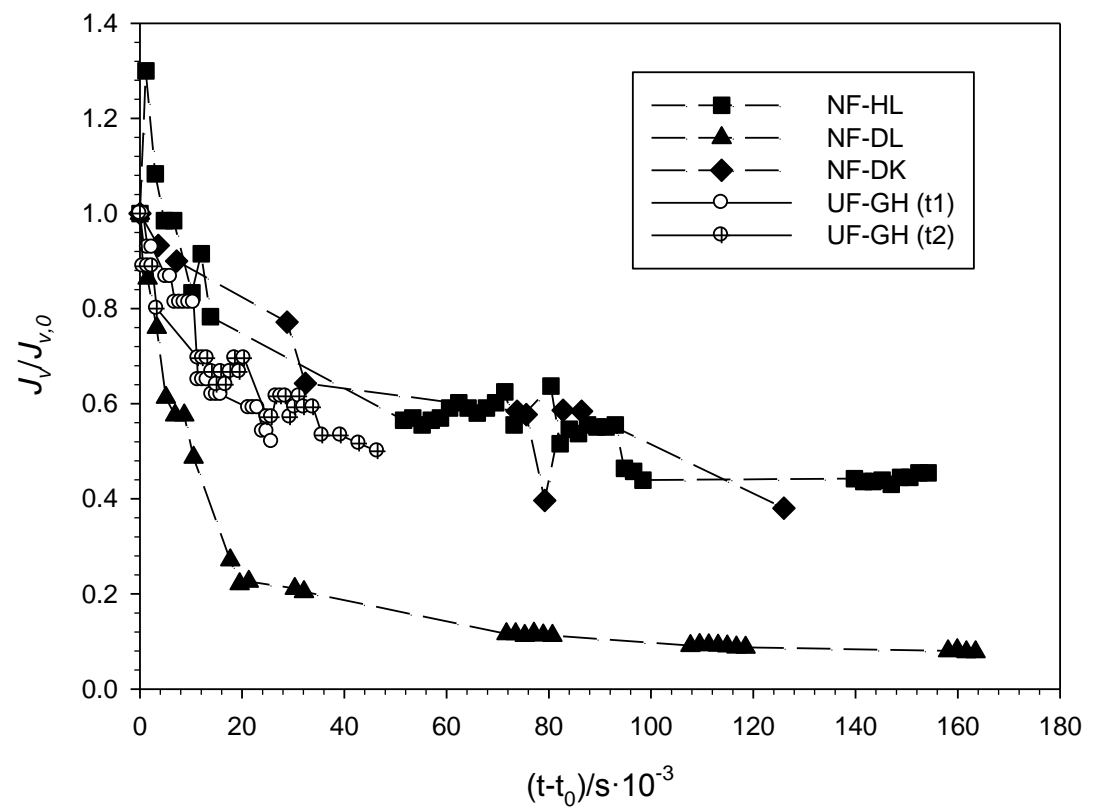

Figura 4.1 Flujo relativo frente al tiempo de filtración, para mosto Verdejo.

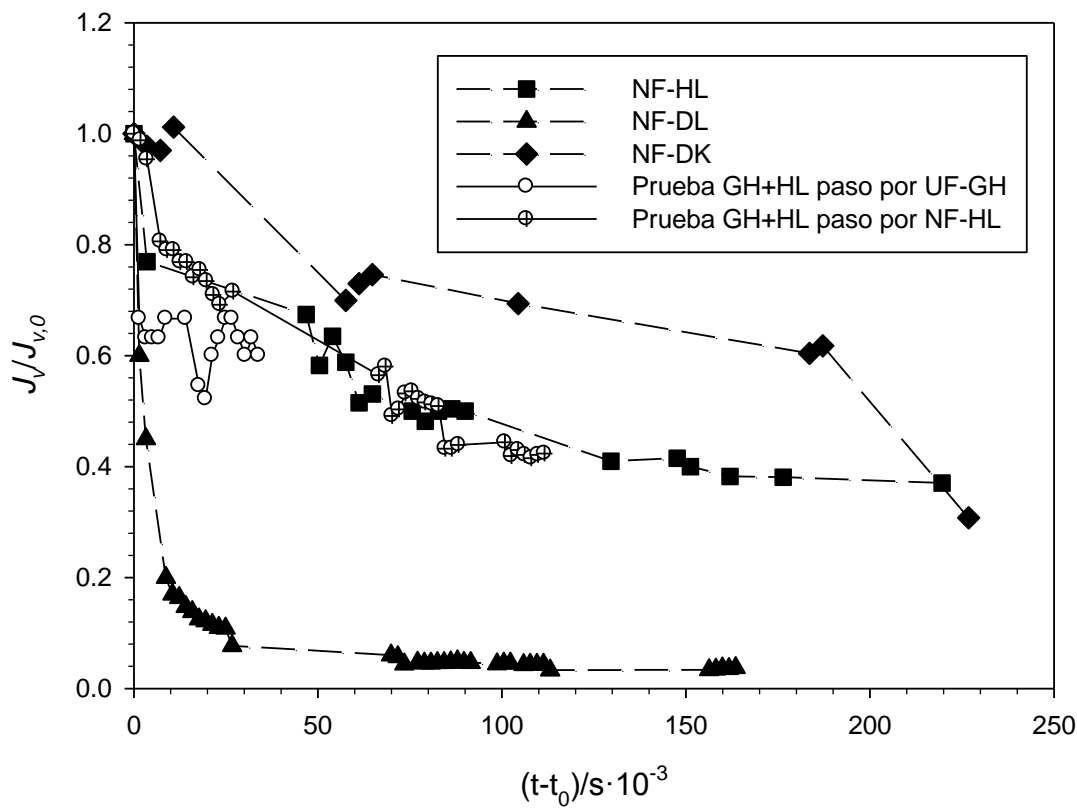

Figura 4.2 Flujo relativo frente al tiempo de filtración, para mosto Tinta de Toro. 
En general, la disminución de flujo respecto al tiempo puede explicarse por el ensuciamiento que sufre la membrana como resultado del paso del mosto, el aumento de la viscosidad y el aumento de la presión osmótica. No obstante con la membrana de ultrafiltración el factor principal debe ser el ensuciamiento y acumulación de sólidos de alto peso molecular en su superficie, ya que el efecto de la presión osmótica y la viscosidad debe ser muy bajo por la baja retención de azúcar que presenta la membrana $\mathrm{GH}$, como veremos en el epígrafe siguiente. Si comparamos las caídas de flujo de los distintos módulos de membrana, podemos comentar lo siguiente:

A excepción de la membrana de nanofiltración DL, los módulos de nanofiltración NFHL y NF-DK tienen un comportamiento muy similar. Este comportamiento es el mismo que en la filtración del mosto tinto comercial con las membranas planas (figura 2.24 del capítulo 2), lo que es esperable porque se trata de membranas de material y tamaños de poro similares. Por el contrario, la caída de flujo de la membrana de ultrafiltración $\mathrm{GH}$, es mayor. Como ya explicamos, en este caso es previsible que el material de la membrana sea diferente y tenga más afinidad a algunos de los compuestos del mosto, además de tener un tamaño de poro mayor de forma que algunos compuestos de alto y medio peso molecular pueden entrar en los poros y producir un bloqueo de estos. Es decir, en el caso de la membrana $\mathrm{GH}$, teniendo en cuenta la baja incidencia que deben tener los efectos osmótico y viscoso comentados anteriormente, el ensuciamiento es mucho más importante.

En las dos filtraciones, la membrana DL cae más rápidamente que la membrana DK. En este caso estamos comparando dos módulos con la misma configuración, tamaño, área de membrana y espaciado. La explicación a este comportamiento puede deberse a los dos factores indicados en la filtración del mosto comercial con los módulos de membrana:

- La menor retención de la membrana DL frente a la DK, tanto en la filtración del mosto Verdejo como en el mosto Tinta de Toro (ver apartado siguiente), haría que sustancias de mayor tamaño pudieran estar en los poros bloqueándolos.

- Su distinta carga eléctrica al $\mathrm{pH}$ del mosto ( $\mathrm{pH} 3$ ), ya que en esas condiciones la membrana DK está cargada positivamente mientras que la DL tiene carga negativa [3]. Por ello, la membrana DL tendrá gran afinidad por moléculas positivas provocando esa caída de flujo más acusada. 
El segundo efecto debe ser el más significativo, ya que aunque una menor retención (mayor tamaño de los poros) incide en un mayor bloqueo, también supone un menor efecto osmótico y viscoso.

\subsection{RETENCIÓN DE AZÚCAR}

Si aplicamos las ecuaciones y modelos de retención mostrados en el capítulo 2 (apartado 2.2), a la filtración del mosto blanco Verdejo y del mosto tinto Tinta de Toro, obtendremos unos valores de retención observada y verdadera de azúcar con los módulos de membrana espirales. Estos resultados se pueden comparar con los obtenidos en el capítulo 2 para la filtración de una disolución de azúcar y de un mosto tinto comercial con los diferentes módulos de membrana espirales.

Los procesos de filtración del mosto Verdejo y Tinta de Toro con los módulos de membranas se realizan a una presión (ver tabla 4.1) y flujo de recirculación constantes. En este proceso se determina la concentración azúcar y el flujo del permeado a intervalos de 15 a 60 minutos dependiendo de la permeabilidad y retención de las membranas. En las figuras 4.3-4.6 puede verse de forma aproximada la frecuencia de medida que se ha tomado en cada experiencia.

Para conocer la retención observada además de la medida de la concentración de permeado, se calcula la concentración del tanque de alimentación en función del tiempo mediante un balance de masas, al igual que en el capítulo anterior.

La retención verdadera se calcula como se explicó en el capítulo 2 cuando se filtró la disolución de azúcar o el mosto comercial modificado con los módulos de membrana (apartados 4.2.1 y 4.2.2). Como ya explicamos, se utilizará la teoría de película para conocer la polarización de la concentración en las capas límite de membrana por medio del coeficiente de transferencia de masa $\left(K_{m}\right)$. Este dato junto con las medidas de concentración de permeado $\left(C_{p}\right)$, concentración de alimentación $\left(C_{0}\right)$ y flujo, todas ellas en función del tiempo, se utilizarán para conocer la concentración en la superficie de la membrana $\left(C_{m}\right)$ y por tanto la retención verdadera en función del tiempo.

Tanto en el mosto Verdejo como en el mosto Tinta de Toro, la concentración de permeado con el tiempo aumenta, ya que el tanque de alimentación cada vez tiene mayor concentración. El flujo por su parte disminuye con el tiempo debido al efecto de polarización y presión osmótica además del ensuciamiento de la membrana en el transcurso de la filtración. Sumando todos estos efectos, para la mayor parte de las membranas la retención sufre un descenso en el transcurso de la filtración como veremos a continuación. 


\subsection{1) Mosto Verdejo}

En las figuras 4.3 y 4.4 podemos comprobar cómo disminuye la retención de los módulos de membrana a lo largo del tiempo de filtración. Este comportamiento lo siguen todas las membranas utilizadas, excepto la membrana DL donde se produce un aumento de la retención debido a que la membrana DL está cargada negativamente al contrario que el resto de las membranas [3]. Esta característica daría lugar a una afinidad de esta membrana hacia las moléculas positivas (que serán muchas ya que el mosto tiene carácter ácido), provocando la acumulación de sustancias en la superficie de la membrana, formando una pseudomembrana que cambia las propiedades iniciales de la membrana.

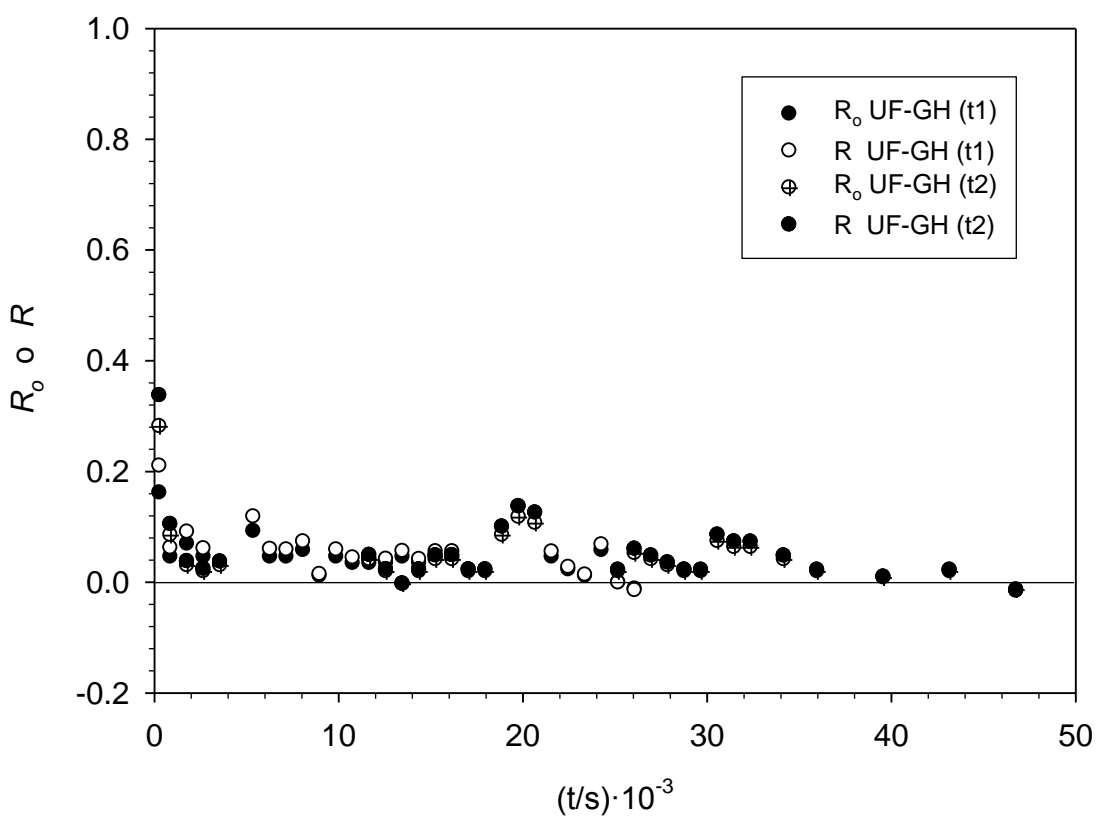

Figura 4.3 Retención observada y retención verdadera del mosto Verdejo con la membrana de ultrafiltración.

Los datos obtenidos de retención observada y verdadera para un mosto blanco son muy próximos, aunque siempre tenemos valores ligeramente mayores de retención verdadera. El orden de retención verdadera de los módulos de membranas espirales, es el siguiente: en primer lugar la membrana que tiene mayor retención, es la DK, seguida por HL y DL y por último, como es lógico, la membrana de ultrafiltración $\mathrm{GH}$, que es la que da lugar a una retención menor. 


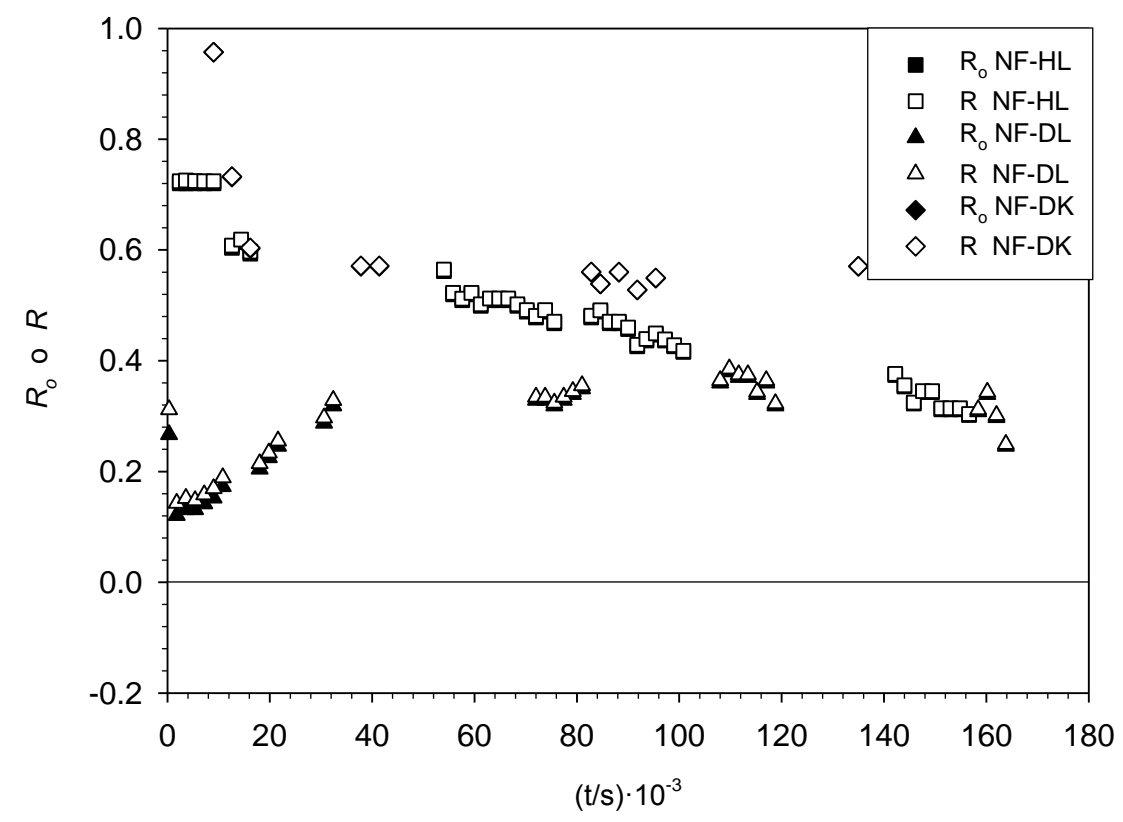

Figura 4.4 Retención observada y retención verdadera del mosto Verdejo con las membranas de nanofiltración.

\subsection{2) Mosto Tinta de Toro}

Teniendo en cuenta las filtraciones realizadas con el mosto tinto y explicadas en el apartado 2.3, representamos la retención observada y verdadera en las figuras 4.5 y 4.6.

El orden de retención de los módulos de membranas tras la filtración del mosto Tinta de Toro es el mismo que tras la filtración del Verdejo, la mayor retención tiene lugar para el módulo de membrana DK, después para el módulo HL, y por último para el módulo DL. La retención de la experiencia $\mathrm{GH}+\mathrm{HL}$ es un poco mayor que la de un solo paso por el módulo de membrana HL; esta experiencia se lleva a cabo para comprobar si hay determinadas sustancias que se eliminan en la etapa de filtración $\mathrm{GH}$ y facilitan el paso por la membrana de nanofiltración. Esta cuestión se valorará más adelante, pero como podemos comprobar, no es un sistema factible en términos de producción respecto a la eliminación de azúcar, ya que no se produce un aumento tan importante en la retención tras esta doble filtración y además se aumenta el coste y tiempo de operación. No obstante, veremos que tiene interés respecto a otras sustancias. 


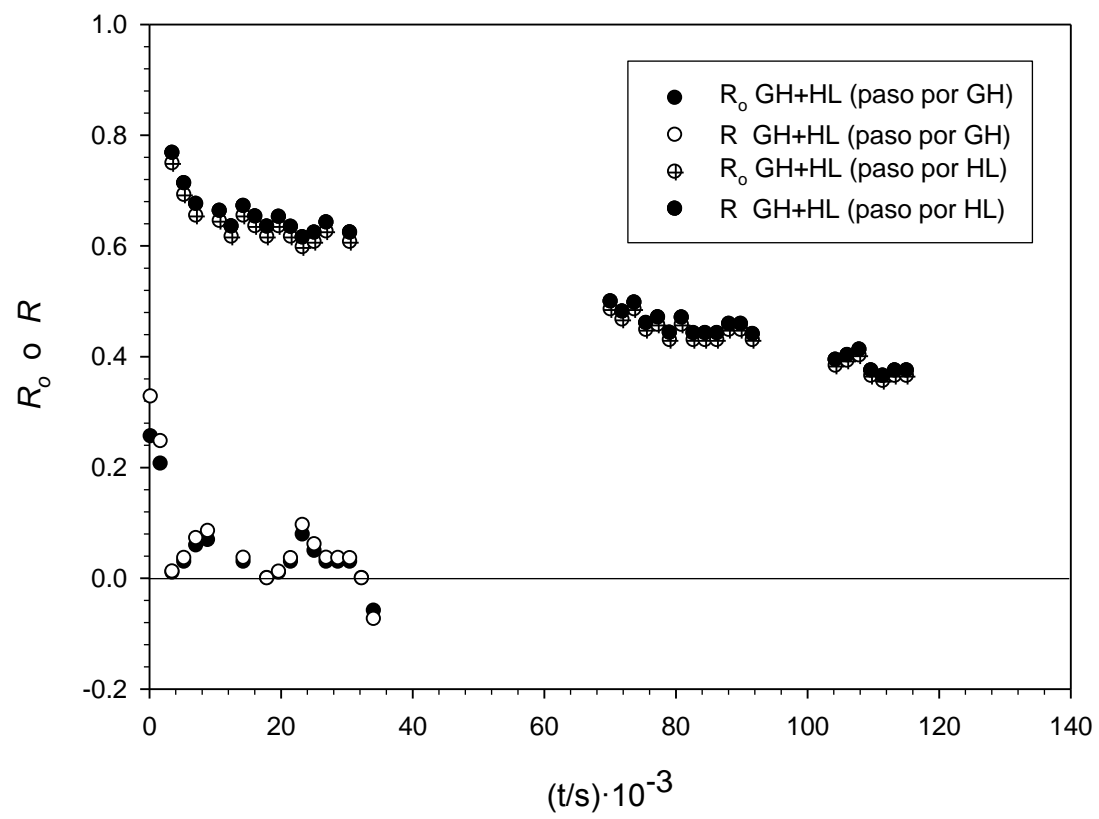

Figura 4.5 Retención observada y retención verdadera del mosto Tinta de Toro en la prueba de filtración $\mathrm{GH}+\mathrm{HL}$.

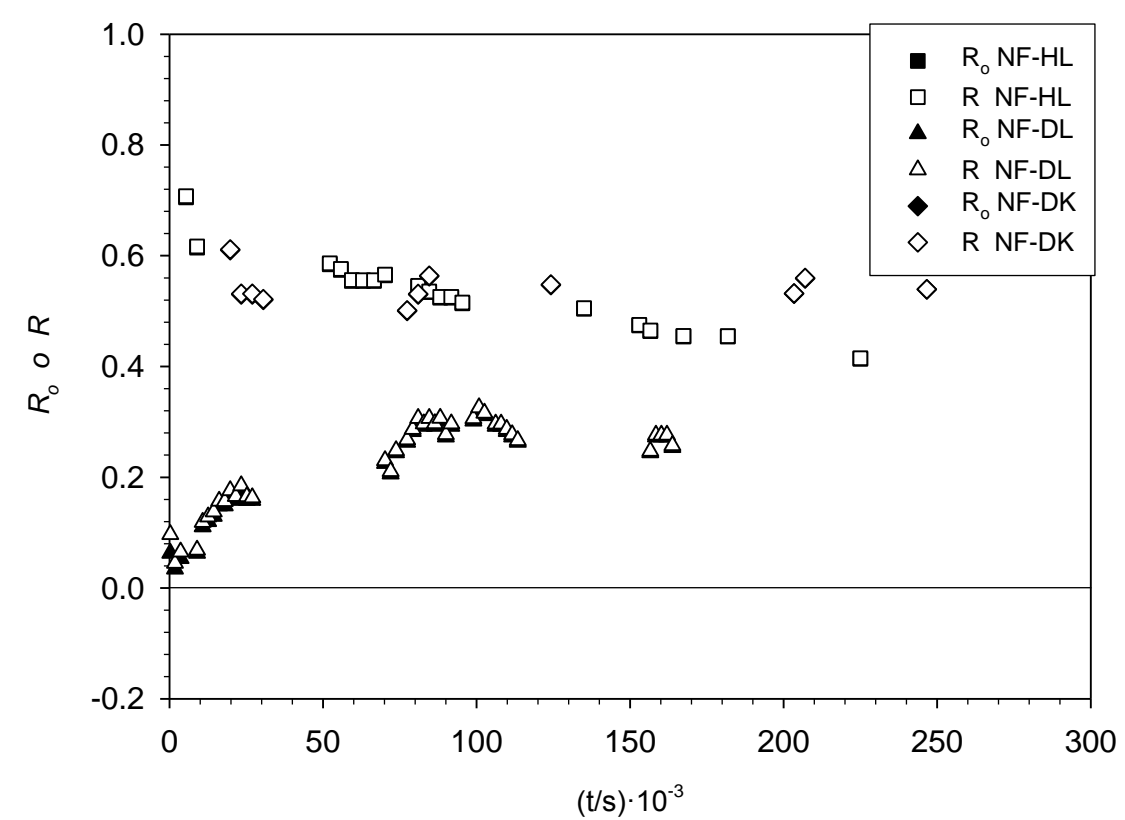

Figura 4.6 Retención observada y retención verdadera del mosto Tinta de Toro con las membranas de nanofiltración.

Si comparamos la retención entre el mosto blanco de la variedad Verdejo y el mosto tinto de la variedad Tinta de Toro al mismo tiempo de filtración, tenemos mayores valores de retención en los mostos tintos que en los blancos. Esto se debe a que el 
ensuciamiento es más acusado en los mostos tintos, como hemos explicado en las curvas de flujo en el apartado 3.2 de este capítulo.

Con todos los resultados obtenidos de las filtraciones de los mostos, tanto blancos como tintos, utilizando los distintos módulos espirales de membrana, parece que el módulo de membrana más apropiado para conseguir una efectiva retención de azúcar sería el módulo de membrana de nanofiltración HL. Para llegar a esta conclusión debemos tener en cuenta que, aunque el módulo de membrana DK tiene una retención de azúcar ligeramente mayor que el módulo HL, la permeabilidad es la mitad siendo la caída de flujo similar entre los dos módulos.

\subsection{RENDIMIENTO DE LA FILTRACIÓN}

Teniendo en cuenta los datos de retención y la caída de flujo en las filtraciones, calculamos el rendimiento tras las filtraciones del mosto Verdejo y el mosto Tinta de Toro. Este rendimiento como ya explicamos en el capítulo anterior, puede indicarse en valores de reducción de concentración de azúcar y en valor de pérdida de volumen al finalizar las filtraciones.

\subsection{1) Concentración de azúcar}

Los valores de concentración utilizados para conocer el rendimiento de la filtración, son los valores del método enzimático que se muestran en las tablas 4.6 y 4.7 y que corresponden a la concentración de los tanques de testigo, permeado y retenido una vez finalizado el proceso. Una vez conocidos los datos de concentración, se calcularán los porcentajes de reducción de azúcar conseguidos tras la filtración de cada mosto.

En la tabla 4.4, se muestran los porcentajes de reducción de azúcar, r, conseguidos tras cada proceso de filtración. Indicamos $\mathrm{C}_{\mathrm{p}}^{\mathrm{t}}$ como la concentración en el tanque de permeado y $\mathrm{C}_{\mathrm{r}}^{\mathrm{t}}$ como la de retenido una vez que se ha finalizado el proceso $\left(\mathrm{C}_{0}^{\mathrm{t}}\right.$ es la concentración de azúcar en el tanque de alimentación antes de iniciar el proceso de filtración).

Como podemos comprobar para una misma prueba de filtración, es decir, utilizando los mismos módulos de membrana, la reducción de azúcar es más significativa en el mosto Verdejo que en el mosto Tinta de Toro, al contrario de lo que ocurría en términos de retención. Esto podría deberse a que en las reducciones de azúcar calculadas en la tabla, se utilizan datos de concentraciones finales obtenidas a distintos tiempos de filtración, ya que estos tiempos de filtración dependen de la permeabilidad y retención de cada membrana a utilizar. 
Tabla 4.4 Reducción de azúcar en los procesos de filtración del mosto Verdejo y mosto Tinta de Toro.

\begin{tabular}{|c|c|c|c|c|c|c|c|c|c|}
\cline { 2 - 9 } \multicolumn{1}{c|}{} & \multicolumn{4}{c|}{ Mosto Blanco (\%) } & \multicolumn{3}{c|}{ Mosto Tinto (\%) } \\
\cline { 2 - 9 } \multicolumn{1}{c|}{} & \multicolumn{2}{c|}{ UF-GH } & NF-HL & NF-DL & NF-DK & $\begin{array}{c}\text { UF-GH } \\
+ \text { NF-HL }\end{array}$ & NF-HL & NF-DL & NF-DK \\
\cline { 2 - 9 } \\
\hline $\begin{array}{c}\text { Proceso de } \\
\text { filtración } \\
\boldsymbol{r}=\mathbf{1}-\frac{\boldsymbol{C}_{\boldsymbol{p}}^{\boldsymbol{t}}}{\boldsymbol{C}_{\boldsymbol{r}}^{\boldsymbol{1}}} \mathbf{1 0 0}\end{array}$ & 9.22 & 17.26 & 59.59 & 30.45 & 48.05 & 50.54 & 47.74 & 5.48 & 35.65 \\
\hline $\begin{array}{c}\text { Mosto Inicial } \\
\boldsymbol{r}=\mathbf{1}-\frac{\boldsymbol{C}_{\boldsymbol{p}}^{\boldsymbol{t}}}{\boldsymbol{C}_{\mathbf{t}} \mathbf{1 0 0}}\end{array}$ & 6.64 & 11.37 & 44.08 & 12.32 & 43.13 & 39.38 & 38.50 & 8.41 & 38.50 \\
\hline
\end{tabular}

\subsection{2) Volumen final}

Como indicamos en el capítulo anterior, para calcular el rendimiento de la filtración en volumen, debemos tener en cuenta la cantidad de litros de vino que podemos elaborar con el volumen de permeado obtenido de cada módulo de membrana. Para ello debemos valorar la concentración de azúcar del permeado y el testigo, así podremos calcular la pérdida de volumen obtenida al elaborar un vino con dos grados de alcohol menos que el vino que se obtendría si utilizáramos el mosto sin tratar. Téngase en cuenta que, como hemos dicho anteriormente, en esta campaña se ha decidido obtener el vino de bajo contenido alcohólico mezclando el mosto permeado con el mosto testigo, y no usar el retenido.

La pérdida de volumen de mosto que tiene lugar en las filtraciones realizadas con los distintos módulos de membrana, se representan en la tabla 4.5.

Como podemos observar, la pérdida de volumen de mosto en la filtración del Verdejo con los módulos de membrana de nanofiltración DL y DK es muy elevada. En el caso de la membrana DK tiene más retención de azúcar y reduce más la concentración de azúcar en la filtración que la membrana DL. Pero esto no indicaría que la pérdida de volumen de mosto en el proceso de filtración que hemos llevado a cabo es menor, como podemos ver en los resultados obtenidos. 
Tabla 4.5 Pérdida de volumen de mosto en los procesos de filtración.

\begin{tabular}{|c|c|c|c|c|}
\hline \multicolumn{2}{|c|}{$\%$ volumen de mosto Verdejo } & \multicolumn{2}{c|}{ \% volumen de mosto Tinta de Toro } \\
\hline \multirow{2}{*}{ UF-GH } & $\mathrm{t} 1$ & $--{ }^{-}$ & \multirow{2}{*}{ UF-GH + NF-HL } & 42.50 \\
\cline { 2 - 3 } & $\mathrm{t} 2$ & $--^{1}$ & NF-HL & 40.00 \\
\hline \multicolumn{2}{|c|}{ NF-HL } & 17.61 & NF-DL & 30.50 \\
\hline NF-DL & 100.15 & NF-DK & - --. $^{2}$ \\
\hline NF-DK & 271.43 &
\end{tabular}

1 Valores no determinados, pruebas de filtración no fermentadas por poca retención de azúcar de la membrana de ultrafiltración GH en blancos.

${ }^{2}$ Valor no determinado, prueba de filtración no fermentada por poca cantidad obtenida de volumen de permeado tras 4 días de filtración.

La pérdida de volumen además de la retención de azúcar, depende de la cantidad de volumen de retenido que se elimina, ya que este volumen no es utilizado en la fermentación. Los tiempos de filtración con las diferentes membranas, lo marca el volumen de permeado obtenido y la concentración de éste, buscando siempre reducir el tiempo que tenemos el mosto pasando por la membrana. De este modo tendremos menos cantidad de permeado DK, pero como tiene menos concentración que el permeado obtenido con el módulo de membrana DL, será suficiente para realizar las mezclas con el mosto Testigo y bajar dos grados de alcohol el vino resultante. Esto daría lugar a un mayor volumen de retenido utilizando la membrana DK que la DL, por lo que la pérdida de volumen sería mayor en este primer caso como se muestra en la tabla anterior.

\section{ANÁLISIS QUÍMICOS}

Como ya explicamos en el capítulo anterior, las sustancias que forman parte del mosto o del vino las podemos dividir en varias familias, la primera de ella serán los azúcares cuyo análisis es el tema principal del trabajo, después se analizarán otras sustancias de pequeño tamaño, y finalmente se realizará el estudio de las moléculas de gran tamaño molecular y polifenoles.

\subsection{ANÁLISIS DE MOSTOS}

En los siguientes apartados se mostrará la composición del mosto testigo y de los permeados y retenidos obtenidos tras utilizar los distintos módulos de membrana en cada filtración. 


\section{Azúcares}

En las tablas 4.6 y 4.7 se muestran los resultados de la concentración de azúcar utilizando varios métodos de análisis. Se representarán los datos para los mostos testigo $(T)$ de Verdejo y Tinta de Toro, y para los volúmenes finales de permeado $(P)$ y retenido $(R)$ después de cada filtración.

Observando los valores obtenidos y teniendo en cuenta los errores propios de los métodos utilizados, comentados anteriormente (refractométrico, polarimétrico y enzimático), podemos decir que los resultados obtenidos son similares para todos ellos.

Tabla 4.6 Concentración de azúcar total determinada por refractometría y polarimetría, glucosa y fructosa determinado por el método enzimático, índice de azúcares y alcohol probable, del mosto Verdejo.

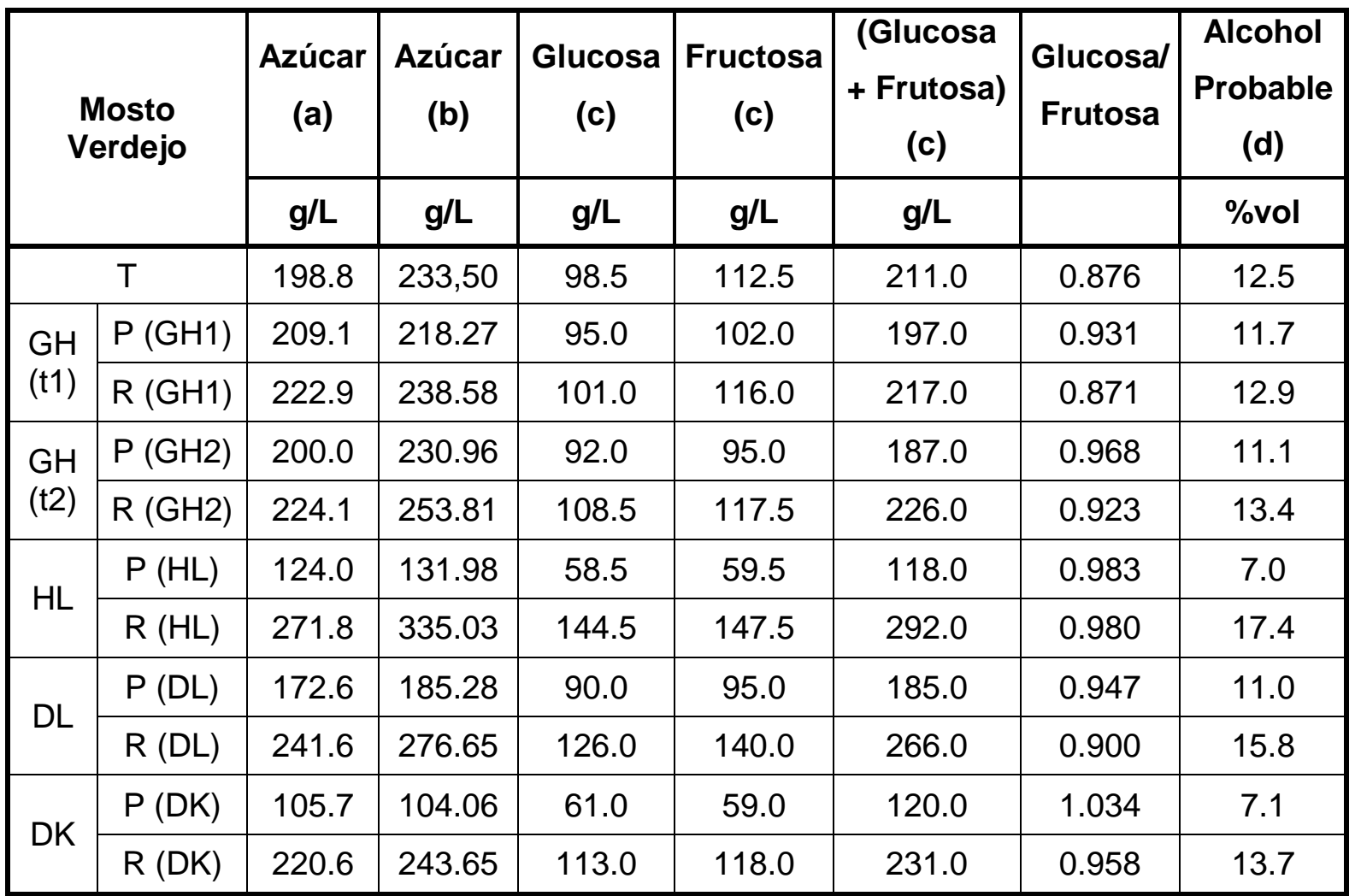

(a) Tablas de equivalencia del refractómetro Brix-molaridad según Reglamento CEE 2676/90

(b) Concentración obtenida mediante método polarimétrico.

(c) Concentración obtenida mediante método enzimático.

(d) \%vol estimado según el Reglamento CEE 2676/90. 
Tabla 4.7 Concentración de azúcar total determinada por refractometría y polarimetría, glucosa y fructosa determinado por el método enzimático, índice de azúcares y alcohol probable, del mosto Tinta de Toro.

\begin{tabular}{|c|c|c|c|c|c|c|c|c|}
\hline \multirow{2}{*}{\multicolumn{2}{|c|}{ Mosto Tinta de Toro }} & $\begin{array}{c}\text { Azúcar } \\
\text { (a) }\end{array}$ & $\begin{array}{c}\text { Azúcar } \\
\text { (b) }\end{array}$ & $\begin{array}{c}\text { Glucosa } \\
\text { (c) }\end{array}$ & $\begin{array}{c}\text { Fructosa } \\
\text { (c) }\end{array}$ & $\begin{array}{c}\text { (Glucosa + } \\
\text { Frutosa) } \\
\text { (c) }\end{array}$ & $\begin{array}{c}\text { Glucosa } \\
\quad / \\
\text { Frutosa }\end{array}$ & $\begin{array}{c}\text { Alcohol } \\
\text { Probable } \\
\text { (d) }\end{array}$ \\
\hline & & g/L & g/L & g/L & g/L & g/L & & \%vol \\
\hline \multicolumn{2}{|c|}{$\mathrm{T}$} & 219.5 & 253.81 & & & 226.0 & & 12.9 \\
\hline \multirow{2}{*}{$\begin{array}{c}\mathrm{GH}+\mathrm{HL} \\
\text { (paso por } \\
\mathrm{GH})\end{array}$} & $\mathrm{P}(\mathrm{GH})$ & 191.9 & 258.88 & 99.0 & 108.0 & 207.0 & 0.917 & 11.9 \\
\hline & $\mathrm{R}(\mathrm{GH})$ & 232.3 & 263.96 & 120.0 & 131.0 & 251.0 & 0.916 & 14.3 \\
\hline \multirow{2}{*}{$\begin{array}{c}\mathrm{GH}+\mathrm{HL} \\
\text { (paso por } \\
\mathrm{HL})\end{array}$} & $\mathrm{P}(\mathrm{GH}+\mathrm{HL})$ & 113.2 & 134.52 & 66.0 & 71.0 & 137.0 & 0.930 & 7.8 \\
\hline & $\mathrm{R}(\mathrm{GH}+\mathrm{HL})$ & 257.8 & 355.33 & 126.0 & 151.0 & 277.0 & 0.834 & 15.8 \\
\hline \multirow{2}{*}{ HL } & $\mathrm{P}(\mathrm{HL})$ & 116.5 & 121.83 & 67.0 & 72.0 & 139.0 & 0.931 & 7.9 \\
\hline & $\mathrm{R}(\mathrm{HL})$ & 250.7 & 312.18 & 126.0 & 140.0 & 266.0 & 0.900 & 15.2 \\
\hline \multirow{2}{*}{ DL } & $P(D L)$ & 187.4 & 220.81 & 99.0 & 108.0 & 207.0 & 0.917 & 11.9 \\
\hline & $\mathrm{R}(\mathrm{DL})$ & 240.3 & 302.03 & 102.0 & 117.0 & 219.0 & 0.872 & 12.5 \\
\hline \multirow{2}{*}{ DK } & $P(D K)$ & 114.3 & 167.51 & & & 139.0 & & 7.9 \\
\hline & $\mathrm{R}(\mathrm{DK})$ & 197.7 & $--^{1}$ & & & 216.0 & & 12.3 \\
\hline
\end{tabular}

(a) Tablas de equivalencia del refractómetro Brix-molaridad según Reglamento CEE 2676/90

(b) Concentración obtenida mediante método polarimétrico.

(c) Concentración obtenida mediante método enzimático.

(d) \%vol estimado según experiencias de la Estación Enológica del ITACyL.

${ }^{1}$ Valor no determinado por excesiva turbidez para medirlo por polarimetría a pesar de la dilución.

Como ya se ha comentado anteriormente y aunque se presentan los resultados por distintos métodos, el enzimático es específico para la glucosa y la fructosa. A partir de la concentración de azúcar obtenida por este método, se pueden obtener los grados probables a los que el mosto puede dar lugar después de su fermentación. Esta relación como indicamos en el capítulo anterior será de 16.83 gramos por litro de azúcar por cada grado alcohólico para vinos blancos, según la normativa de la Comunidad Europea y de acuerdo al Reglamento CEE 2676/90. En el caso de los 
vinos tintos se utilizan las tablas de conversión obtenidas, teniendo en cuenta las experiencias de fermentación de la Estación Enológica del ITACyl en mostos tintos.

Para los dos mostos (Verdejo y Tinta de Toro), la filtración con membranas de nanofiltración modifica la concentración total de azúcar del mosto inicial y por lo tanto el contenido de alcohol probable, pero la relación de glucosa y fructosa en el mosto testigo y en los permeados es similar para los casos analizados. De los resultados de la membrana de ultrafiltración $\mathrm{GH}$, a dos tiempos diferentes en el mosto Verdejo, vemos que no nos aporta ninguna reducción sustancial de azúcar.

En el caso del mosto Verdejo pasaríamos de vinos de 12.5 grados a vinos de entre 7.0 y 11.0 grados y en el caso del mosto Tinta de Toro, pasaríamos de 12.9 a vinos entre 7.8 y 11.9 grados dependiendo del tipo de módulo. Para bajar 2 grados alcohólicos que es nuestro objetivo, se mezclará el permeado con el mosto testigo inicial, lo que además permite recuperar sustancias importantes para la elaboración del vino que no estarían en el permeado.

\subsection{1) Sustancias de bajo peso molecular}

En las tablas 4.8 y 4.9 , se presentan los resultados de los análisis de otras sustancias de bajo peso molecular importantes en la composición de mostos.

Tabla 4.8 $\quad p H$, acidez total (AT), ácido tartárico (TH2), ácido málico (MH2) y potasio en el mosto Verdejo.

\begin{tabular}{|c|c|c|c|c|c|c|}
\hline \multicolumn{2}{|c|}{ Mosto Verdejo } & $\mathbf{p H}$ & $\mathbf{A T}$ & $\mathbf{T H 2}$ & $\mathbf{M H} 2$ & Potasio \\
\cline { 3 - 7 } & & $\mathbf{g} / \mathbf{L}$ & $\mathbf{g} / \mathbf{L}$ & $\mathbf{g} / \mathbf{L}$ & $\mathbf{~} \mathbf{g} / \mathbf{L}$ \\
\hline \multicolumn{2}{|c|}{$\mathrm{T}$} & 3.08 & 6.76 & 5.5 & 3.3 & 870 \\
\hline \multirow{2}{*}{$\mathrm{GH}(\mathrm{t} 1)$} & $\mathrm{P}(\mathrm{GH} 1)$ & 3.09 & 5.78 & 4.8 & 3.1 & 750 \\
\cline { 2 - 7 } & $\mathrm{R}(\mathrm{GH} 1)$ & 3.02 & 6.32 & 5.6 & 3.1 & 870 \\
\hline \multirow{2}{*}{$\mathrm{GH}(\mathrm{t} 2)$} & $\mathrm{P}(\mathrm{GH} 2)$ & 3.08 & 6.63 & 4.8 & 2.8 & 800 \\
\cline { 2 - 7 } & $\mathrm{R}(\mathrm{GH} 2)$ & 3.07 & 7.68 & 6.7 & 3.0 & 1080 \\
\hline \multirow{2}{*}{$\mathrm{HL}$} & $\mathrm{P}(\mathrm{HL})$ & 3.12 & 7.22 & 5.4 & 3.2 & 1040 \\
\cline { 2 - 7 } & $\mathrm{R}(\mathrm{HL})$ & 3.13 & 7.05 & 6.3 & 2.7 & 980 \\
\hline \multirow{2}{*}{$\mathrm{DL}$} & $\mathrm{P}(\mathrm{DL})$ & 2.99 & 6.33 & 5.6 & 3.0 & 910 \\
\cline { 2 - 7 } & $\mathrm{R}(\mathrm{DL})$ & 2.95 & 6.54 & 5.9 & 2.8 & 870 \\
\hline \multirow{2}{*}{$\mathrm{DK}$} & $\mathrm{P}(\mathrm{DK})$ & 3.00 & 6.05 & 5.1 & 3.1 & 960 \\
\cline { 2 - 7 } & $\mathrm{R}(\mathrm{DK})$ & 3.14 & 6.02 & 5.4 & 2.9 & 880 \\
\hline
\end{tabular}


Tabla 4.9 $\quad$ pH, acidez total (AT), ácido tartárico (TH2), ácido málico (MH2) y potasio en el mosto Tinta de Toro.

\begin{tabular}{|c|c|c|c|c|c|c|}
\hline \multirow{2}{*}{ Mosto Tinta de Toro } & $\mathbf{p H}$ & $\mathbf{A T}$ & $\mathbf{T H 2}$ & $\mathbf{M H 2}$ & Potasio \\
\cline { 3 - 7 } & & $\mathbf{g} / \mathbf{L}$ & $\mathbf{g} / \mathbf{L}$ & $\mathbf{g} / \mathbf{L}$ & $\mathbf{~} \mathbf{g} / \mathbf{L}$ \\
\hline \multicolumn{2}{|c|}{$\mathrm{T}$} & 3.50 & 6.78 & 4.0 & 4.2 & 1360 \\
\hline \multirow{2}{*}{$\begin{array}{c}\mathrm{GH}+\mathrm{HL} \text { (paso } \\
\text { por GH) }\end{array}$} & $\mathrm{P}(\mathrm{GH})$ & 3.32 & 5.85 & 3.5 & 4.3 & 1040 \\
\cline { 2 - 7 } & $\mathrm{R}(\mathrm{GH})$ & 3.08 & 7.48 & 4.3 & 4.7 & 1280 \\
\hline \multirow{2}{*}{$\begin{array}{c}\mathrm{GH}+\mathrm{HL} \text { (paso } \\
\text { por HL) }\end{array}$} & $\mathrm{P}(\mathrm{GH}+\mathrm{HL})$ & 3.20 & 6.28 & 3.5 & 4.3 & 1040 \\
\cline { 2 - 7 } & $\mathrm{R}(\mathrm{GH}+\mathrm{HL})$ & 3.18 & 5.87 & 3.6 & 4.1 & 1000 \\
\hline \multirow{2}{*}{$\mathrm{HL}$} & $\mathrm{P}(\mathrm{HL})$ & 3.30 & 7.50 & 3.9 & 4.7 & 1220 \\
\cline { 2 - 7 } & $\mathrm{R}(\mathrm{HL})$ & 3.12 & 6.77 & 4.0 & 4.1 & 1170 \\
\hline \multirow{2}{*}{$\mathrm{DL}$} & $\mathrm{P}(\mathrm{DL})$ & 3.13 & 7.27 & 4.1 & 4.3 & 1240 \\
\cline { 2 - 7 } & $\mathrm{R}(\mathrm{DL})$ & 3.15 & 7.10 & 4.2 & 4.3 & 1240 \\
\hline \multirow{2}{*}{$\mathrm{DK}$} & $\mathrm{P}(\mathrm{DK})$ & 3.14 & 7.01 & 3.6 & 5.1 & 1220 \\
\cline { 2 - 7 } & $\mathrm{R}(\mathrm{DK})$ & 3.25 & 7.49 & 3.7 & 4.7 & 1210 \\
\hline
\end{tabular}

Como tendencia general, en ambos mostos, podemos decir que todos los componentes de bajo peso molecular analizados tras las filtraciones los resultados son similares a los valores obtenidos para el mosto testigo. Como explicamos en el capítulo anterior, la retención de estas sustancias de bajo peso molecular, está relacionada con su peso molecular y con su carga (por ejemplo, para el pH del mosto, hay que tener en cuenta que las membranas HL y DK están cargadas positivamente y la DL está cargada negativamente) [3]. Además, muchas de estas pequeñas sustancias se encuentran asociadas a otras de alto peso molecular por lo que serán retenidas por la membrana.

En el caso del ácido málico $\left(\mathrm{M}_{\mathrm{w}}=134.09 \mathrm{~g} / \mathrm{mol}, \mathrm{pK}=3.40\right)$, tenemos una ligera variación entre el permeado y el retenido de cada módulo de membrana, siendo ligeramente mayor la concentración de estas sustancias en la fracción de los permeados. Estas variaciones pueden deberse más al error del método de determinación que al proceso de filtración. Como explicamos en el capítulo anterior, pese a su bajo peso molecular $\left(\mathrm{M}_{\mathrm{W}}=39.1 \mathrm{~g} / \mathrm{mol}\right)$, el efecto de la carga junto con los efectos dieléctricos explican la retención de iones como el potasio [7-8].

Para el ácido tartárico la variación de concentración respecto al testigo es muy pequeña, y en los dos tipos de mostos es mayor en la fracción de los retenidos que de los permeados. Con peso molecular algo mayor y un pK menor $\left(M_{W}=150 \mathrm{~g} / \mathrm{mol}\right.$, $\mathrm{pK}=3.03$ ) sufre mayor retención que el málico. 
Si observamos la acidez total, para el mosto Verdejo tenemos un aumento de concentración en el caso de la membrana $\mathrm{HL}$ al contrario que lo obtenido con el resto de las membranas, pero en todos los casos las variaciones son muy pequeñas. Para el mosto Tinta de Toro, la acidez total aumenta con todas las membranas de nanofiltración. En este caso, es posible que las sustancias responsables del color, influyan en la retención de los distintos ácidos que aumentan el valor de la acidez total en el mosto.

\subsection{2) Familias fenólicas y color}

El siguiente grupo de sustancias que estudiaremos será el de las familias fenólicas que además están relacionadas con el color. En las gráficas que se muestran a continuación, se representarán distintos componentes fenólicos e índices de color de las distintas fracciones de motos filtrados y testigo. Todas las medidas de los componentes se realizan por duplicado, y lo que se representa en estas gráficas es la media de los valores obtenidos.

Los resultados obtenidos para los dos mostos filtrados se presentan en las figuras 4.74.10:

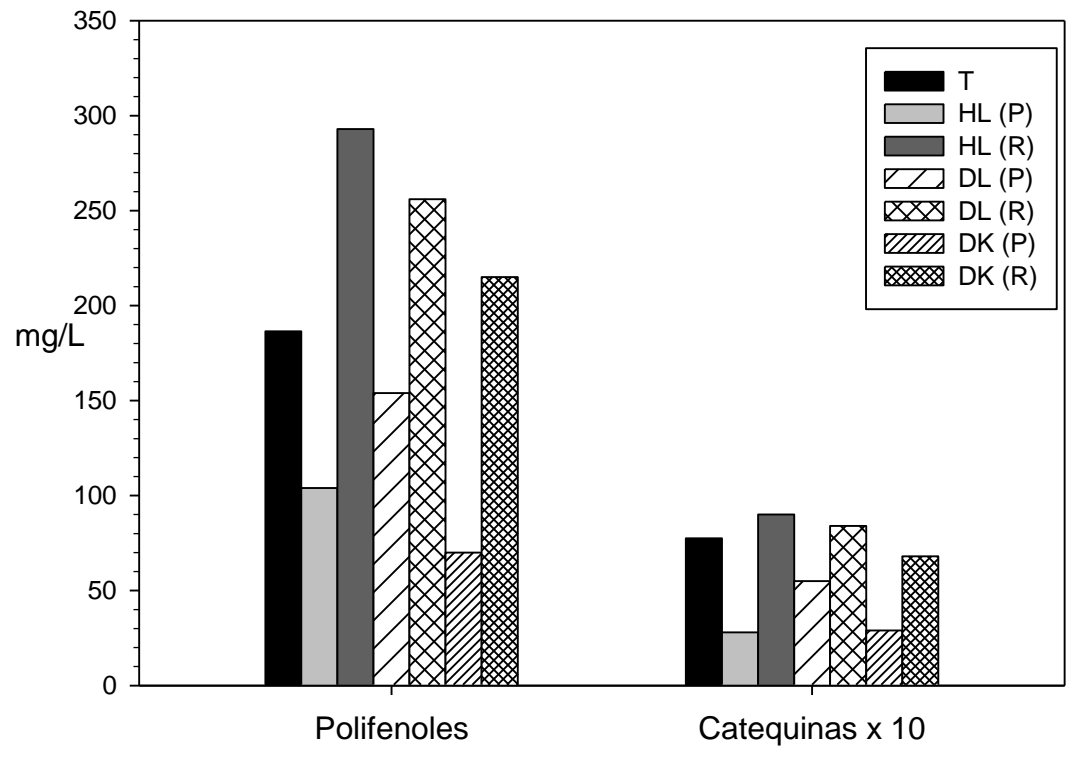

Figura 4.7 Concentración de los polifenoles y catequinas de todos los permeados y retenidos de las pruebas de filtración del mosto Verdejo. 


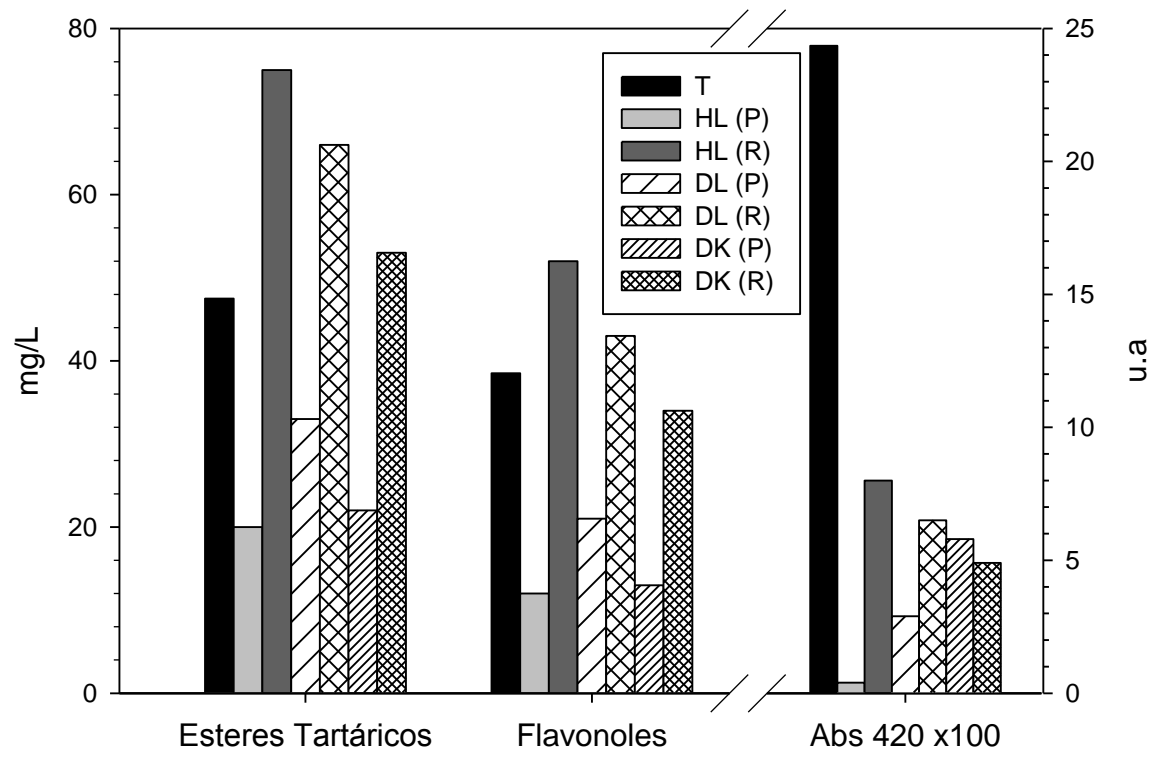

Figura 4.8 Concentración de los esteres tartáricos, flavonoles y absorbancia a 420 $\mathrm{nm}$ de todos los permeados y retenidos de las pruebas de filtración del mosto Verdejo.

En el caso del mosto Verdejo, todos los retenidos tienen más concentración de compuestos fenólicos (polifenoles, catequinas, esteres tartáricos y flavonoles) que los permeados, esto es lógico ya que su peso molecular es elevado y son componentes muy retenidos por las membranas. Si comparamos entre todas las membranas utilizadas, el orden de retención es similar al encontrado para los azúcares: la membrana DL sería la que menos componentes de este tipo perdería en su permeado. En este caso tenemos una relación de R/P de 1.5-2 respecto a otras membranas en las que esta relación es de incluso el doble. No obstante, para la elección de la utilización de una u otra membrana, se deben tener en cuenta más aspectos (permeabilidad de la membrana, retención al azúcar, retención de sustancias de bajo peso molecular...etc.) ya que la mayoría de los componentes fenólicos se pueden recuperar en el vino final por su mezcla con el vino testigo.

Si comparamos la absorbancia a $420 \mathrm{~nm}$, que es como se mide el color en los mostos y vinos blancos, podemos decir que es mucho mayor para el testigo que para los permeados y retenidos obtenidos tras la filtración, llegando incluso a 60 veces mayor para el permeado de la membrana HL. Esto tendría la misma explicación que hemos indicado para los compuestos fenólicos, la única diferencia es que parece que la membrana que menos retención provoca para esta medida es la DK, aunque aún así los resultados son muy diferentes respecto al testigo, la absorbancia del permeado es 4 veces menos que la del testigo. No obstante, el hecho de que para todas las 
membranas se reduzca el índice de color tanto para el permeado, como para el retenido, parece indicar que algunos de los compuestos responsables del color se pierden por alguna transformación química durante el proceso de filtración (oxidaciones, polimerizaciones, etc.)

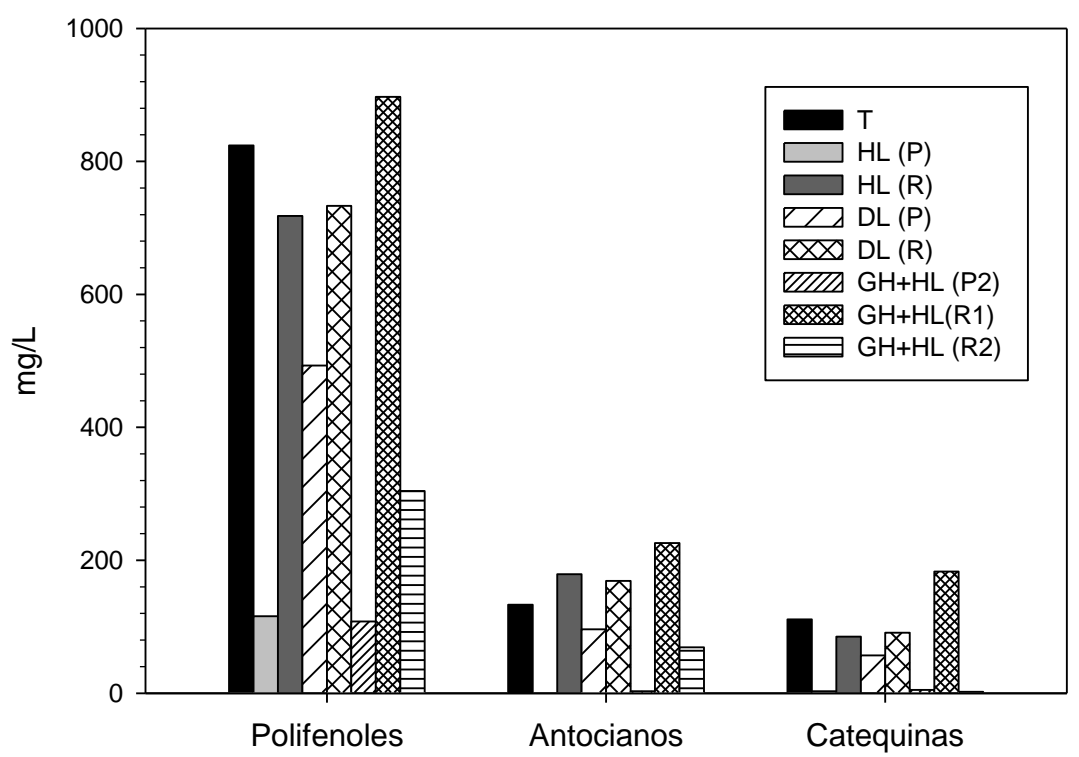

Figura 4.9 Concentración de los polifenoles, antocianos y catequinas de todos los permeados y retenidos de las pruebas de filtración del mosto Tinta de Toro.

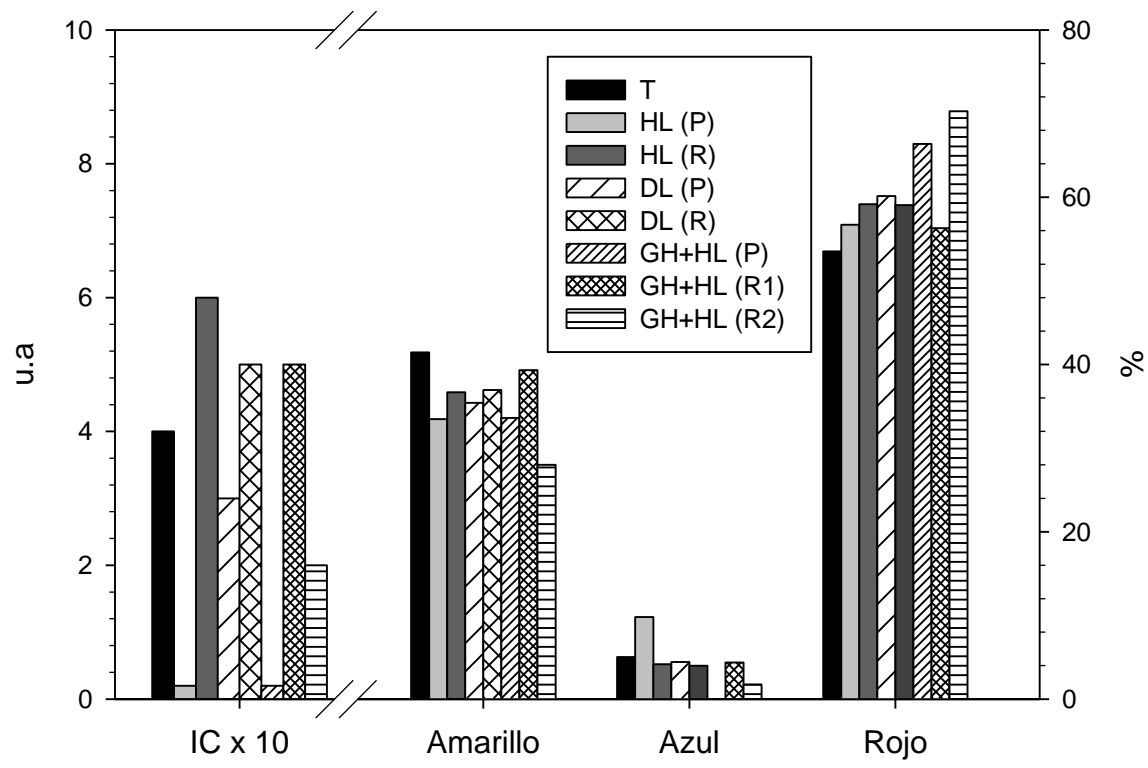

Figura 4.10 Índice de color y porcentaje de colores (amarillo, azul y rojo), de todos los permeados y retenidos de las pruebas de filtración del mosto Tinta de Toro. 
Para el mosto Tinta de Toro, la concentración en los retenidos de polifenoles, antocianos, catequinas e índice de color es mayor que para los permeados en todas las membranas. En el caso de los retenidos de la prueba de filtración $\mathrm{GH}+\mathrm{HL}$, tenemos un primer retenido (R1) que es el que se obtiene al pasar el mosto por la membrana GH donde se quedan la mayoría de estos componentes fenólicos. En el segundo retenido (R2), conseguido tras filtrar el permeado de la membrana de ultrafiltración GH por la membrana de nanofiltración HL tenemos menos de estos compuestos porque ya el permeado de partida tiene menos compuestos de alto peso molecular. Como ocurre con el mosto Verdejo la membrana que menos pérdida de componentes fenólicos da lugar en su permeado, es la membrana DL con relaciones $\mathrm{R} / \mathrm{P}$ de 1.5 respecto a otras membranas como la membrana $\mathrm{HL}$ en las que este valor llega a 30 para catequinas o índice de color.

Si analizamos el porcentaje de cada color por separado, vemos que las menores variaciones de concentración de permeados y retenidos respecto al testigo, se encuentran en el porcentaje de amarillos y azules. Como lo que representamos en el gráfico son valores de porcentaje, tendremos el efecto inverso para el color rojo, pero comparando con el mosto blanco, en el mosto Tinto los permeados respetan bastante bien el color del mosto sin tratar.

Lo que vamos a comprobar en este capítulo es $\mathrm{si}$, al realizar las mezclas de los permeados con el mosto testigo, seguirían todavía estas diferencias de componentes fenólicos. En las tablas 4.10 y 4.11 se muestran las cantidades de permeado y testigo que fueron mezcladas para cada prueba:

Tabla 4.10 Volúmenes de testigo y permeado utilizados en la fermentación del mosto Verdejo.

\begin{tabular}{|c|c|c|}
\hline $\begin{array}{c}\text { Pruebas de } \\
\text { mosto Verdejo }\end{array}$ & Testigo (L) & Permeado (L) \\
\hline T & 14.0 & \\
\hline NF-HL & 11.6 & 2.4 \\
\hline NF-DL & 7.3 & 6.7 \\
\hline NF-DK & 6.0 & 1.0 \\
\hline
\end{tabular}

${ }^{1}$ Con la membrana DK se fermenta menos volumen y no se realiza por duplicado, porque después de 37.5 horas de filtración no se obtuvo más volumen de permeado. 
En el caso de la elaboración del vino tinto, se debe tener en cuenta la adicción de la proporción adecuada de pasta, además de la fracción del testigo y del permeado. Para este mosto, no se realiza la prueba con la membrana NF-DK porque después de 4 días de filtración no tenemos volumen suficiente para realizar la fermentación.

Tabla 4.11 Cantidades de pasta, testigo y permeado utilizadas en la fermentación del mosto Tinta de Toro.

\begin{tabular}{|c|c|c|c|}
\hline $\begin{array}{c}\text { Pruebas de } \\
\text { mosto Tinta de } \\
\text { Toro }\end{array}$ & Pasta (Kg) & Testigo (L) & Permeado (L) \\
\hline T & 6 & 15 & \\
\hline NF-HL & 6 & 12 & 3 \\
\hline NF-DL & 5 & 5 & 7 \\
\hline UF-GH + NF-HL & 6 & 12 & 3 \\
\hline
\end{tabular}

A continuación, en las figuras 4.11 y 4.12 , se representarán la concentración de los compuestos fenólicos para el mosto testigo y para las mezclas que van a dar lugar al vino de baja graduación alcohólica.
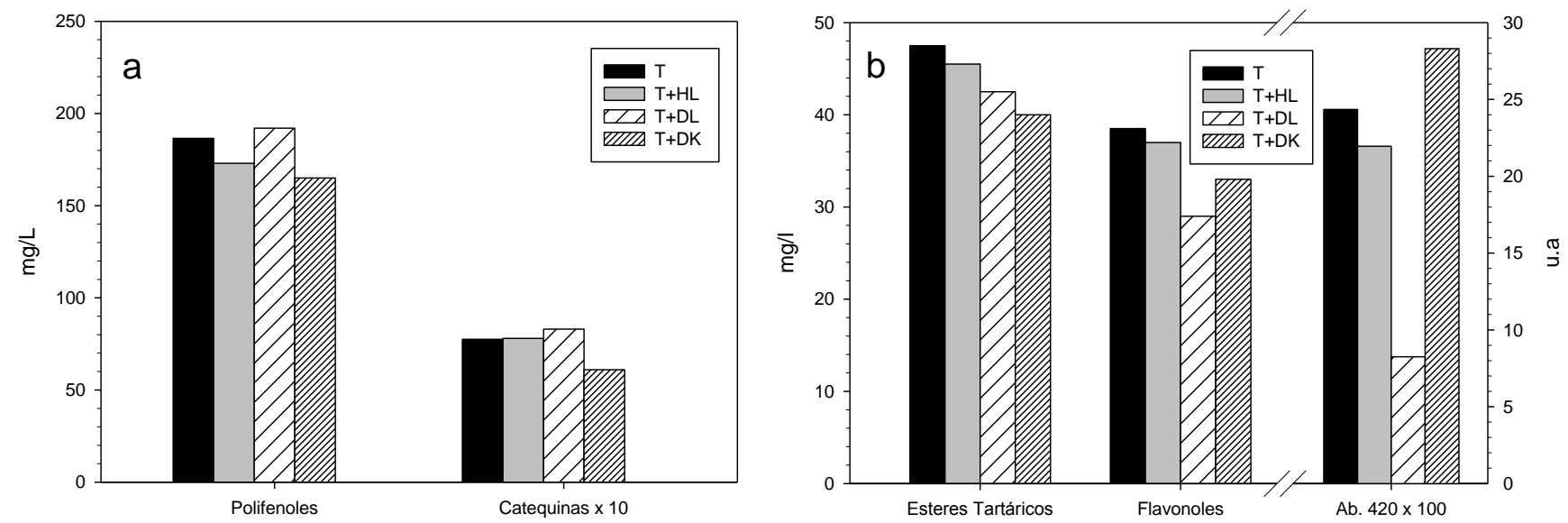

Figura 4.11 Concentración de los compuestos relacionados con el color y absorbancia a $420 \mathrm{~nm}$ del mosto testigo (T), y las mezclas realizadas para obtener el vino de bajo grado alcohólico del mosto Verdejo. (a) polifenoles totales y catequinas (b) ésteres tartáricos, flavonoles y Absorbancia a $420 \mathrm{~nm}$. 

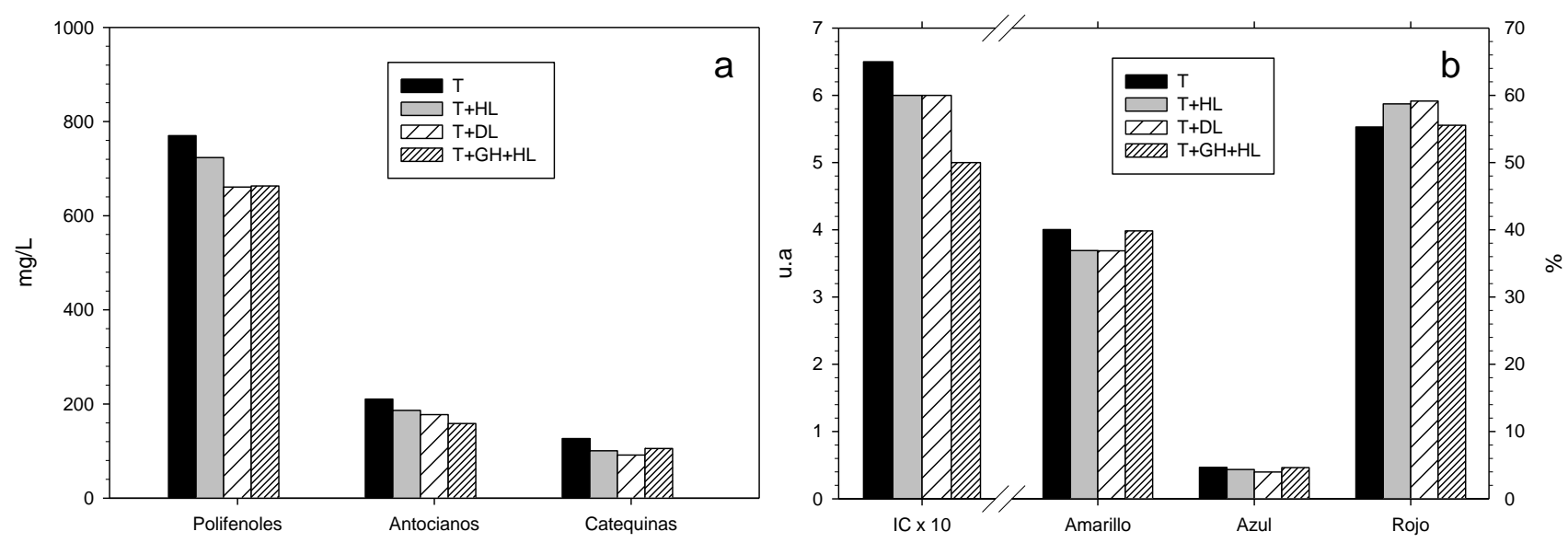

Figura 4.12 Concentración de los compuestos relacionados con el color del mosto testigo $(T)$, y las mezclas realizadas para obtener el vino de bajo grado alcohólico del mosto Tinta de Toro. (a) polifenoles totales, antocianos y catequinas (b) intensidad colorante (IC) y porcentajes de rojo, azul y amarillos.

Como podemos ver en las distintas gráficas que comparan la composición fenólica del mosto sin tratar, con las mezclas, las diferencias de concentración son mínimas. No obstante hay que tener en cuenta que estas concentraciones estarán también condicionadas por las proporciones de mezcla dadas en las tablas 4.10 y 4.11 .

En el mosto Verdejo en cuanto a polifenoles, catequinas, esteres tartáricos, flavonoles y absorbancia a $420 \mathrm{~nm}$, la mezcla que más se asemeja al mosto testigo será la T+HL. Para el mosto Tinto, en cuanto a polifenoles, antocianos y catequinas ocurre lo mismo que en el mosto Verdejo y la mezcla que más se aproxima a la composición del mosto testigo sin modificar, es la obtenida por la mezcla del permeado de la membrana HL con el mosto sin tratar.

Para el análisis del índice de color en las mezclas de mostos tintos según la figura 4.12.b, vemos que hay pocas diferencias entre la mezcla del permeado de la membrana HL o DL con el testigo. Teniendo prácticamente los mismos resultados, si comparamos con el mosto testigo cualquiera de estas dos mezclas, tendrán un índice de color próximo a la muestra sin tratar. Si bien, cuando analizamos el porcentaje de colores por separado, vemos que la mezcla resultante del permeado obtenido tras la filtración en dos etapas (usando primero el módulo GH y luego el HL) con el testigo, es la que más se aproxima a los porcentajes de color del mosto sin tratar. Como podemos ver en la figura 4.9 el permeado de la filtración de ultrafiltración seguida de la 
membrana de nanofiltración (P2), tiene muy poca concentración de antocianos, pero la estabilidad del color depende de la relación de concentración antociano-tanino, si esta relación es similar a 1 se evita la formación de ácidos fenólicos por oxidación de los antocianos restantes, ya que estos componentes que se formarían serían incoloros [9].

\subsection{3) Aminoácidos}

Como se indicó en las conclusiones del capítulo anterior, para el mosto Verdejo se realiza un análisis de aminoácidos de los permeados, de los retenidos y de la mezclas. Con este nuevo análisis, lo que se pretende es comprobar si se pierden aminoácidos en las filtraciones y no se recuperan posteriormente al añadir el mosto sin tratar (T) antes de la fermentación. Esta posible pérdida de aminoácidos, daría lugar a desajustes en términos olfativos del vino final, como los encontrados en el vino Verdejo en el capítulo 3.

Para descartar esta pérdida de aminoácidos, en las tablas 4.12 y 4.13 se muestra la concentración de aminoácidos después de las nanofiltraciones y después de las mezclas llevadas a cabo para las fermentaciones.

Como podemos comprobar en la tabla 4.12, prácticamente en todos los compuestos la concentración de aminoácidos en los retenidos de cada prueba, es mayor que en los permeados respectivos. Hay alguna excepción en la prolina y el cloruro de amonio en los que la concentración en el permeado es mayor que en el retenido y en la cadaverina y la feniletilamina en la que los valores en los permeados y retenidos son similares. Comparando las distintas membranas de nanofiltración utilizadas, vemos que la membrana DK es la que da lugar a mayor retención, esto puede ser debido a efectos de tamaño, de carga o ambos. 
Tabla 4.12 Concentración de aminoácidos ( $\mathrm{mg} / \mathrm{L}$ ) de testigo, permeados y retenidos tras las pruebas de nanofiltración del mosto Verdejo, punto isoeléctrico $(P I)$ y masa molecular $\left(M_{W}\right)$.

\begin{tabular}{|c|c|c|c|c|c|c|c|c|c|}
\hline & Testigo & $\begin{array}{c}\text { Permeado } \\
\text { HL }\end{array}$ & $\begin{array}{c}\text { Permeado } \\
\text { DL }\end{array}$ & $\begin{array}{c}\text { Permeado } \\
\text { DK }\end{array}$ & $\begin{array}{c}\text { Retenido } \\
\text { HL }\end{array}$ & $\begin{array}{c}\text { Retenido } \\
\text { DL }\end{array}$ & $\begin{array}{c}\text { Retenido } \\
\text { DK }\end{array}$ & PI [10] & $\mathbf{M}_{\mathrm{W}}[10]$ \\
\hline Ácido Aspártico & 35.26 & 33.01 & 40.55 & 9.79 & 49.31 & 44.55 & 44.91 & 2,77 & 133,10 \\
\hline Ácido Glutámico & 94.79 & 61.25 & 87.91 & 18.03 & 118.99 & 100.52 & 101.17 & 3,22 & 147,13 \\
\hline Asparagina & 5.25 & 2.28 & 3.40 & 0.83 & 5.54 & 4.44 & 4.01 & 5,41 & 132,12 \\
\hline Serina & 45.29 & 53.37 & 60.54 & 12.83 & 71.69 & 64.37 & 63.91 & 5,68 & 105,09 \\
\hline Histidina & 10.23 & nd & 9.58 & $\mathrm{nd}$ & 21.29 & 19.52 & 13.45 & 7,59 & 155,16 \\
\hline Glutamina & 101.56 & 44.23 & 84.46 & 18.33 & 163.04 & 122.20 & 112.88 & 5,65 & 146,15 \\
\hline Glicina & 4.98 & 3.32 & 3.98 & 2.66 & 5.03 & 4.53 & 4.40 & 5,97 & 75,07 \\
\hline Treonina & 66.88 & 57.28 & 84.77 & 14.15 & 128.69 & 105.67 & 101.59 & 5,60 & 119,12 \\
\hline Arginina & 474.43 & 56.10 & 301.21 & 4.87 & 823.37 & 626.69 & 540.74 & 10,76 & 174,20 \\
\hline Alanina & 70.95 & 64.06 & 69.11 & 45.94 & 71.50 & 66.91 & 69.05 & 6,00 & 165,00 \\
\hline Ácido Y-aminobutírico (GABA) & 56.87 & 53.18 & 61.26 & 45.62 & 49.66 & 49.16 & 56.63 & 7,29 & 103,12 \\
\hline Prolina & 32.08 & 57.68 & 35.80 & 60.48 & 6.23 & 10.60 & 17.03 & 6,30 & 115,13 \\
\hline Tirosina & 8.64 & 5.70 & 8.67 & 3.90 & 13.03 & 10.73 & 10.60 & 5,66 & 181,19 \\
\hline Cloruro de Amonio & 57.16 & 84.46 & 76.43 & 70.67 & 51.99 & 61.47 & 69.19 & 9,25 & 53,49 \\
\hline Valina & 20.74 & 11.04 & 21.36 & 5.36 & 37.67 & 29.26 & 27.96 & 5,96 & 117,15 \\
\hline Metionina+Cisteina & 1.65 & 2.54 & 3.19 & 0.83 & 4.14 & 3.28 & 3.53 & $5,74+5,07$ & $149,21+121,16$ \\
\hline Isoleucina & 11.51 & 5.54 & 13.82 & 1.34 & 27.74 & 21.07 & 19.57 & 6,02 & 131,16 \\
\hline Ácido Triptofano & 4.22 & 5.74 & 7.90 & 1.66 & 13.94 & 9.52 & 8.96 & 5,89 & 204,23 \\
\hline Leucina & 9.56 & 8.55 & 17.04 & 1.32 & 30.38 & 23.74 & 22.36 & 5,98 & 131,17 \\
\hline Fenilalanina & 17.07 & 13.38 & 20.39 & 6.17 & 30.59 & 24.83 & 24.29 & 5,48 & 165,19 \\
\hline Ornitina monohidrocloruro & 3.94 & 0.60 & 2.15 & 0.60 & 5.54 & 4.53 & 3.83 & 7,08 & 168,62 \\
\hline Lisina & 1.96 & 0.42 & 2.24 & 0.12 & 6.21 & 5.08 & 4.30 & 9,74 & 146,19 \\
\hline Espermidina & 6.09 & 1.81 & 3.13 & 1.32 & 11.58 & 6.52 & 2.97 & $9,38[11]$ & 145,25 \\
\hline Putrescina & 2.06 & 0.55 & 1.47 & 0.47 & 3.32 & 2.62 & 2.36 & 10,22 & 88,15 \\
\hline Cadaverina & 0.35 & 0.38 & 0.35 & 0.35 & 0.34 & 0.35 & 0.35 & 10,49 & 102,18 \\
\hline Feniletilamina & 0.33 & 0.35 & 0.34 & 0.47 & 0.31 & 0.33 & 0.34 & 9,83 & 121,18 \\
\hline
\end{tabular}

nd $=$ no detectable

* La Hidroxiprolina y la Histamina dihidrocloruro incluidas en el protocolo del método de análisis, no fueron detectadas en ninguna muestra. 
Los aminoácidos son moléculas muy apropiadas para el análisis de membranas de nanofiltración, ya que se encuentran en tamaños de pesos moleculares en los que este tipo de membranas presentan retención parcial, y además poseen carga. Esto significa que su retención estará condicionada no sólo por su tamaño, sino por su punto isoeléctrico y por el $\mathrm{pH}$ del mosto. En la tabla 4.12 se recogen los valores de peso molecular y del punto isoeléctrico de cada aminoácido. Aunque lo normal es que para cada aminoácido, la concentración de permeado sea menor que el testigo y el retenido mayor, hay algunos caso en que esto no se cumple. Con el fin de analizar esto, se puede representar la diferencia entre la concentración del testigo $C_{0}$ y la del permeado, $C_{p}$, dividido por la diferencia entre la concentración del retenido, $C_{r}$ y la del testigo, $C_{0}$.

En las figuras 4.13 y 4.14 se muestran estas relaciones para la membrana $H L$ frente al punto isoeléctrico y el peso molecular de los aminoácidos. El comportamiento es similar para todas las membranas. En todos los casos se observa que dado que los mostos de Verdejo se encuentran a un pH próximo a 3, en esas condiciones la mayor parte de los aminoácidos con punto isoeléctrico próximo a 6 , están cargados positivamente y son los que presentan mayor desviación. Los de punto isoeléctrico alrededor de 3 tienen dos grupos ácido (ácido aspártico y ácido glutámico) y los que tienen punto isoeléctrico mayor que 7 son aminas o aminoácidos con grupos aminos adicionales.

La influencia del peso molecular también es importante. Se observa que a partir de $100 \mathrm{~g} / \mathrm{mol}$ el cociente de concentraciones aumenta en valor absoluto, dando cuenta de los efectos de tamaño en el proceso de permeación de los aminoácidos.

Como parte de los aminoácidos son retenidos por la membrana, lo que debemos comprobar ahora, es si al mezclar los permeados con el mosto testigo, esta concentración se recupera y se ajusta a la cantidad de aminoácidos del mosto sin filtrar. 


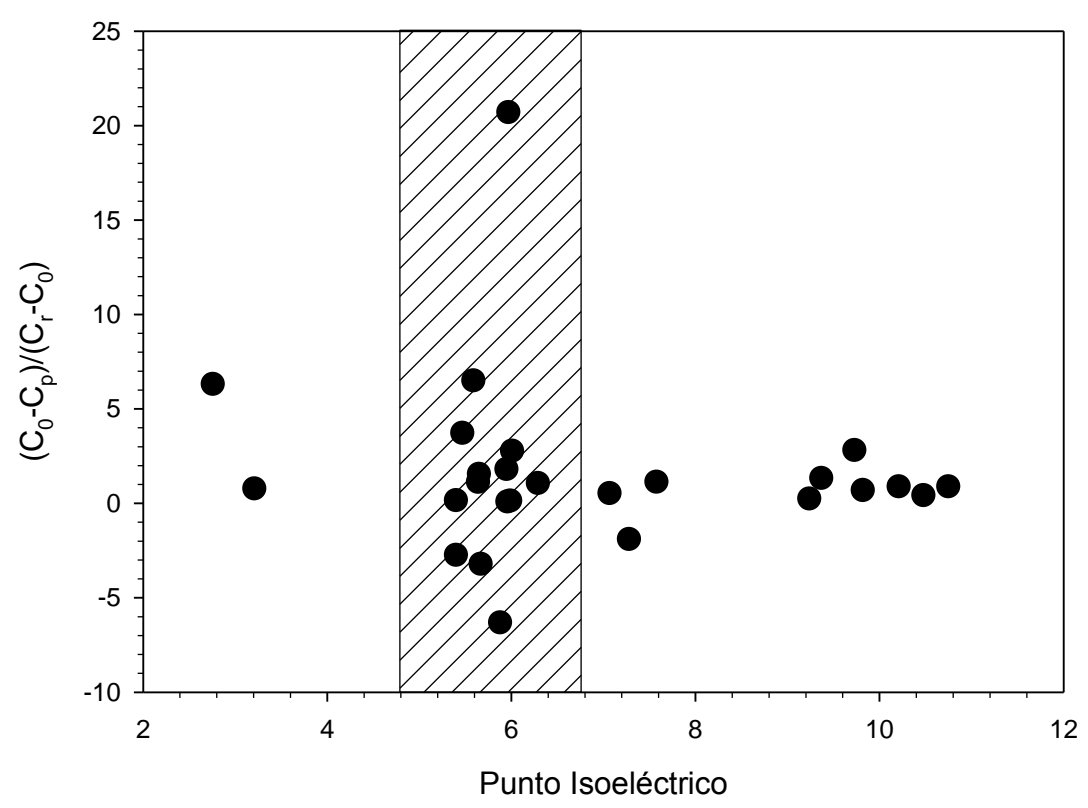

Figura 4.13 Relación de diferencia de concentraciones respecto al punto isoeléctrico para el módulo de membrana HL.

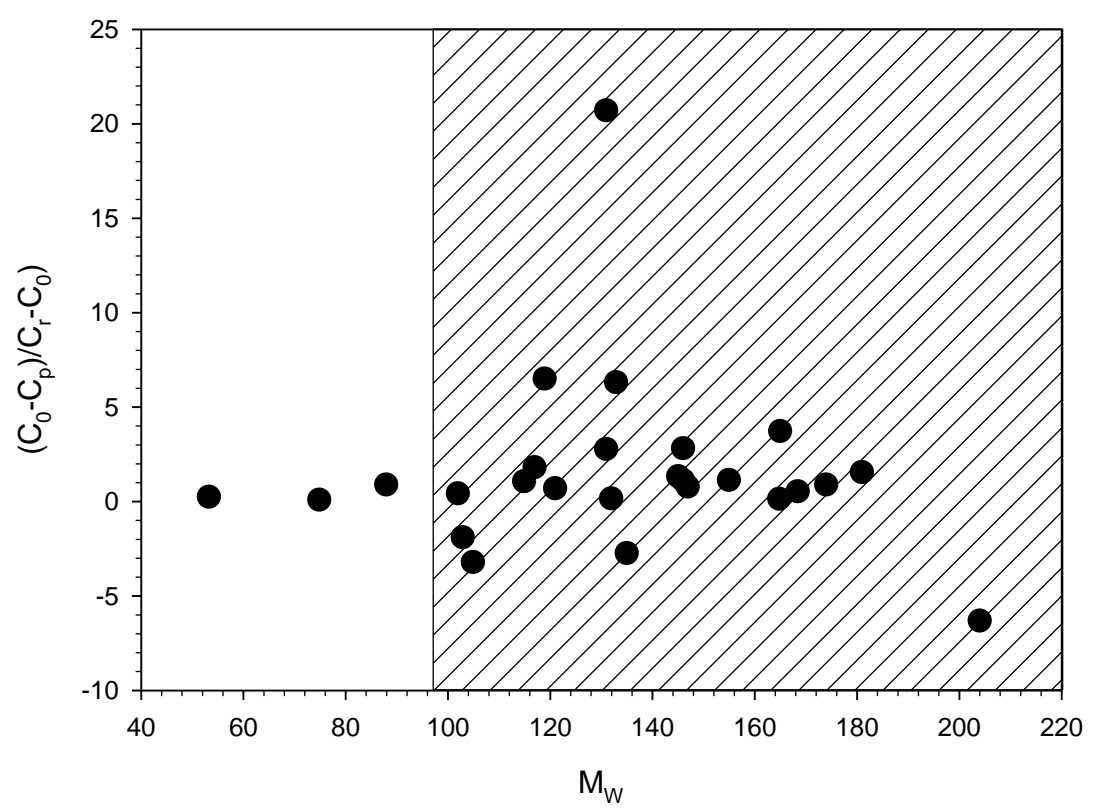

Figura 4.14 Relación de diferencia de concentraciones respecto al peso molecular para el módulo de membrana HL. 
Tabla 4.13 Concentración de aminoácidos ( $\mathrm{mg} / \mathrm{L})$ de testigo, y mezclas de testigo con los permeados de nanofiltración del mosto Verdejo.

\begin{tabular}{|c|c|c|c|c|}
\hline & Testigo & T+ HL & T+DL & T+ DK \\
\hline Ácido Aspártico & 35,261 & 34,192 & 37,643 & 31,704 \\
\hline Ácido Glutámico & 94,792 & 87,855 & 91,017 & 83,736 \\
\hline Asparagina & 5,254 & 4,631 & 4,320 & 4,533 \\
\hline Serina & 45,286 & 45,652 & 52,212 & 40,637 \\
\hline Histidina & 10,235 & 7,734 & 9,929 & 8,758 \\
\hline Glutamina & 101,563 & 91,097 & 92,419 & 87,856 \\
\hline Glicina & 4,977 & 4,642 & 4,374 & 4,554 \\
\hline Treonina & 66,880 & 63,994 & 74,599 & 58,842 \\
\hline Arginina & 474,435 & 397,294 & 387,882 & 401,828 \\
\hline Alanina & 70,948 & 68,488 & 69,700 & 67,460 \\
\hline Ácido y-aminobutírico (GABA) & 56,872 & 54,663 & 58,431 & 55,001 \\
\hline Prolina & 32,080 & 31,496 & 37,913 & 37,623 \\
\hline Tirosina & 8,641 & 8,244 & 8,754 & 7,921 \\
\hline Cloruro de Amonio & 57,163 & 60,846 & 67,080 & 59,074 \\
\hline Valina & 20,737 & 18,736 & 21,000 & 18,255 \\
\hline Metionina + Cisteina & 1,649 & 1,625 & 3,475 & 1,470 \\
\hline Isoleucina & 11,513 & 10,291 & 12,532 & 9,759 \\
\hline Ácido Triptofano & 4,219 & 4,178 & 6,647 & 3,817 \\
\hline Leucina & 9,562 & 9,155 & 13,053 & 7,971 \\
\hline Fenilalanina & 17,069 & 16,052 & 18,581 & 15,246 \\
\hline Ornitinamonohidrocloruro & 3,938 & 3,289 & 3,015 & 3,427 \\
\hline Lisina & 1,962 & 1,666 & 2,030 & 1,291 \\
\hline Espermidina & 6,092 & 5,253 & 4,635 & 5,199 \\
\hline Putrescina & 2,065 & 1,770 & 1,764 & 1,802 \\
\hline Cadaverina & 0,350 & 0,332 & 0,371 & 0,354 \\
\hline Feniletilamina & 0,327 & 0,330 & 0,357 & 0,326 \\
\hline & & & & \\
\hline
\end{tabular}

* La Hidroxiprolina y la Histamina dihidrocloruro incluidas en el protocolo del método de análisis, no fueron detectadas en ninguna muestra.

Como vemos, en las mezclas de los permeados con el mosto sin tratar, tenemos unos valores de aminoácidos similares a los obtenidos en el mosto sin tratar. Incluso en la membrana DK, que daba lugar a mayor retención de aminoácidos, la concentración es similar ya que utilizamos menos volumen de permeado en la mezcla con el testigo, porque este permeado tiene una concentración de azúcar menor.

Al tener concentraciones de aminoácidos similares tanto en las mezclas como en el mosto testigo solo, estos compuestos no serán los responsables de los posibles cambios organolépticos que se produzcan entre dichas mezclas. Los aminoácidos son capaces de sintetizar alcoholes superiores que influyen en las características organolépticas de los vinos finales como tal o formando esteres [12], pero en nuestras mezclas estas concentraciones se mantienen respecto al vino testigo. En el caso del 
mosto tinto se renuncia a la realización de este análisis de aminoácidos, ya que la pérdida de alcoholes superiores entre el testigo y las mezclas en la campaña anterior es prácticamente inapreciable (ver figura 3.15).

\subsection{ELABORACIÓN Y ANÁLISIS DE VINOS}

Una vez realizadas todas las mezclas de los permeados y el mosto testigo, se realiza la elaboración de los vinos en la bodega experimental de la Estación Enológica del ITACyL por personal adscrito al centro.

\subsection{1) Vino Verdejo}

Se realiza la fermentación alcohólica de todas las pruebas por duplicado en tanques de 16 litros (excepto con el módulo de membrana DK en la que no se realiza por duplicado por la falta de volumen de permeado, como explicamos anteriormente). Se inoculan levaduras comerciales para llevar a cabo la fermentación y se controla la temperatura en el proceso, de forma similar a la descrita en el capítulo anterior. Una vez terminada la fermentación, los vinos fueron embotellados y almacenados para su posterior análisis. Los análisis realizados por duplicado después de la fermentación alcohólica, se mostrarán en la tabla siguiente.

Tabla 4.14 Parámetros enológicos clásicos del vino Verdejo tras la fermentación alcohólica, A. Total: acidez total; A.V: acidez volátil; TH2: ácido tartárico; MH2: ácido málico.

\begin{tabular}{|c|c|c|c|c|c|c|c|c|}
\hline \multirow{2}{*}{$\begin{array}{c}\text { Vino } \\
\text { Verdejo }\end{array}$} & $\mathbf{p H}$ & A.Total & $\mathbf{A . V}$. & $\mathbf{T H 2}$ & $\mathbf{M H 2}$ & Potasio & Azúcar & Grado \\
\cline { 2 - 8 } & & $\mathbf{g} / \mathbf{L}$ & $\mathbf{g} / \mathbf{L}$ & $\mathbf{g} / \mathbf{L}$ & $\mathbf{g} / \mathbf{L}$ & $\mathbf{m g} / \mathbf{L}$ & $\mathbf{g} / \mathbf{l}$ & $\mathbf{v / v}$ \\
\hline $\mathrm{T}$ & 3.13 & 7.38 & 0.24 & 5.25 & 2.34 & 795 & 2.07 & 13.3 \\
\hline $\mathrm{T}+\mathrm{HL}$ & 3.06 & 7.16 & 0.18 & 5.04 & 2.40 & 815 & 2.21 & 12.4 \\
\hline $\mathrm{T}+\mathrm{DL}$ & 3.03 & 7.43 & 0.17 & 5.05 & 2.43 & 845 & 1.87 & 12.0 \\
\hline $\mathrm{T}+\mathrm{DK}$ & 2.98 & 7.49 & 0.17 & 4.68 & 1.98 & 770 & 3.16 & 12.0 \\
\hline
\end{tabular}

Las mezclas realizadas dan lugar a vinos de aproximadamente $1 \%$ vol menos que el vino testigo. En todos los casos la reducción de alcohol lograda fue menor que la que nos propusimos al realizar las mezclas, (al contrario que en la campaña anterior en la que obtuvimos vinos con una reducción mayor que los $2 \%$ vol). Esto se produce porque es difícil calcular las proporciones exactas, basándonos en la cantidad de azúcar de los mostos. Cada año la actuación de las levaduras en los procesos de 
fermentación depende de factores que cambian con cada campaña, como la maduración de la cosecha que influye en los nutrientes que se aportan a las levaduras para realizar la fermentación alcohólica, las plagas y en definitiva todas las prácticas vitícolas realizadas; además también se deben tener en cuenta otros factores incontrolables como las condiciones climáticas [13].

En la tabla 4.14, se observa que para la mezcla $T+D K$, los parámetros estudiados son los que menos se aproximan a los correspondientes del mosto sin tratar. En las pruebas de las otras dos membranas, podemos comprobar que no tenemos diferencias significativas entre los vinos elaborados y el vino testigo. A continuación, en las figuras 4.15 y 4.16 se muestra la concentración de los polifenoles y otros compuestos relacionados con el color, para cada uno de los vinos obtenidos.

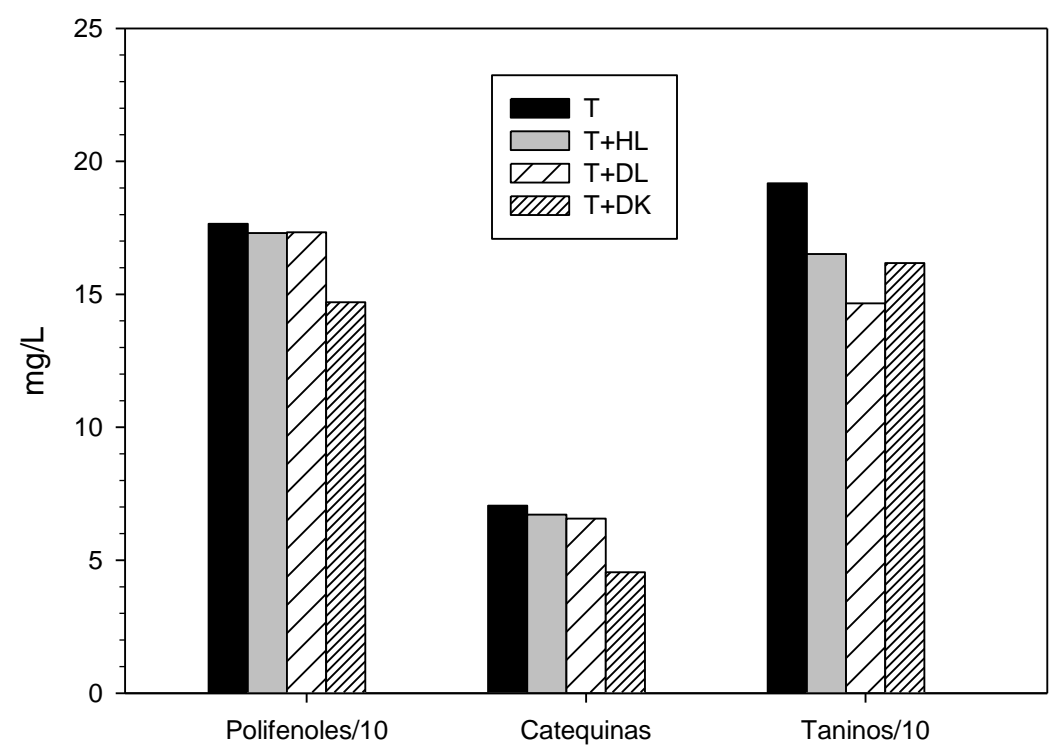

Figura 4.15 Contenido en polifenoles totales, catequinas y taninos de los distintos vinos Verdejo elaborados.

Como podemos comprobar, la concentración de la mayoría de los componentes relacionados con el color (polifenoles, catequinas, esteres tartáricos y flavonoles) en los vinos elaborados con el permeado de filtración del módulo de membrana HL y DL, son similares a las del vino elaborado con mosto sin tratar. En el caso del vino elaborado con el permeado del módulo de membrana DK, estas concentraciones se reducen en aproximadamente un $20 \%$, excepto para el caso de la absorbancia a 420 $\mathrm{nm}$ indicadora del índice de color, donde aumenta en ese porcentaje la absorbancia a esa longitud de onda, seguramente debido a una oxidación del vino [14] por su menor permeabilidad. 


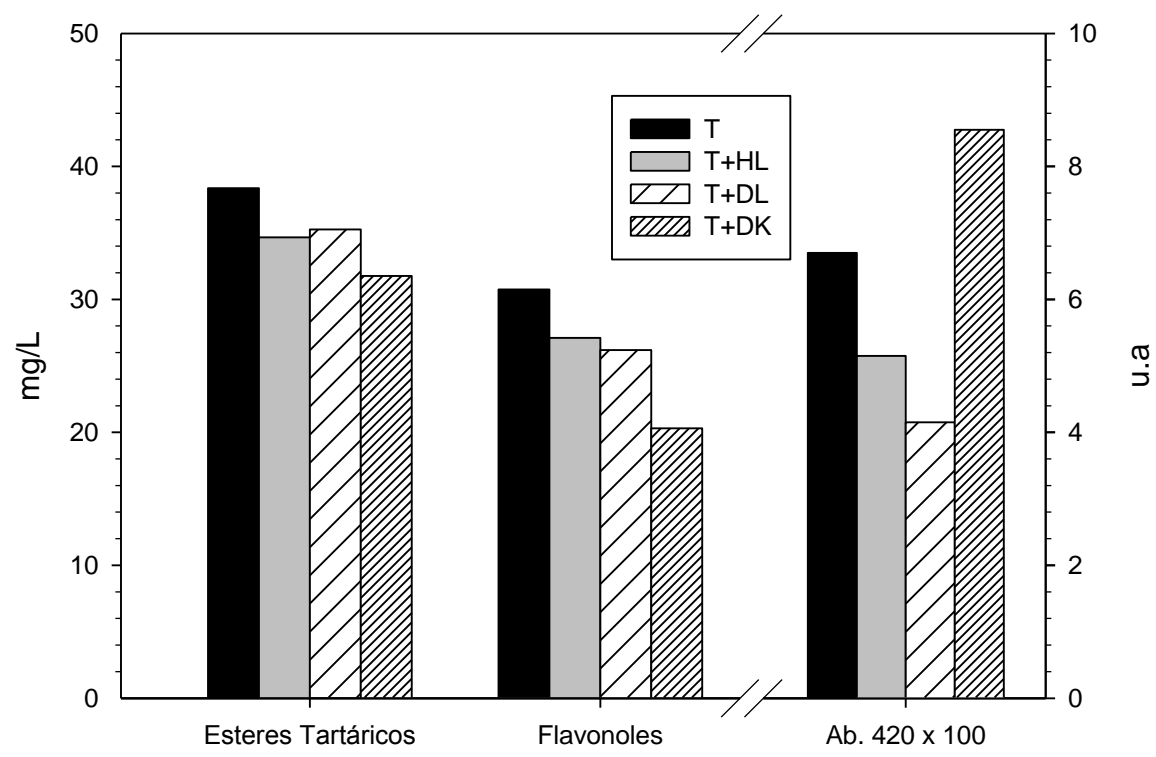

Figura 4.16 Contenido en ésteres tartáricos, flavonoles y color (Absorbancia a 420 $n m)$ de los distintos vinos Verdejo elaborados.

La concentración de taninos en vinos blancos tiene un orden de magnitud mayor que la campaña pasada. Esto se debe a que la composición fenólica de la uva varía mucho de una campaña a otra y también de una parcela a otra (se utilizaron parcelas diferentes respecto a las de la campaña anterior).

\subsection{2) Vino Tinta de Toro}

En la elaboración del vino tinto como hemos indicado en la tabla 4.11, hay que añadir la cantidad indicada de la pasta que fue retirada antes de la filtración y que ha permanecido a una temperatura de $4^{\circ} \mathrm{C}$ durante la filtración. Los pasos que sigue el mosto después de la mezcla serían:

- Fermentaciones alcohólicas llevadas a cabo por duplicado en tanques de 35 litros e inoculando levaduras comerciales. Una vez que la fermentación alcohólica se ha completado, se retira la pasta y se trasiega el vino a depósitos siempre llenos.

- Fermentación maloláctica realizadas en tanques de 16 litros por duplicado, se siembra el mosto con bacterias para no tener problemas en la finalización de la fermentación maloláctica.

Después de las fermentaciones los depósitos han sido analizados, y los datos obtenidos (media de las dos réplicas) se muestran a continuación: 
Tabla 4.15 Parámetros enológicos clásicos del vino Tinta de Toro tras la fermentación alcohólica, A.Total: acidez total; A.V: acidez volátil; TH2: ácido tartárico; MH2: ácido málico.

\begin{tabular}{|c|c|c|c|c|c|c|c|c|}
\hline $\begin{array}{c}\text { Vino } \\
\text { Tinta de } \\
\text { Toro }\end{array}$ & $\mathbf{p H}$ & A. Total & A.V. & TH2 & MH2 & Potasio & Azúcar & Grado \\
\cline { 2 - 8 } & & $\mathbf{g} / \mathbf{L}$ & $\mathbf{g} / \mathbf{L}$ & $\mathbf{g} / \mathbf{L}$ & $\mathbf{g} / \mathbf{L}$ & $\mathbf{m g} / \mathbf{L}$ & $\mathbf{g} / \mathbf{L}$ & $\mathbf{v} / \mathbf{v}$ \\
\hline $\mathrm{T}$ & 3.41 & 6.81 & 0.26 & 1.35 & 4.05 & 1180 & 1.30 & 13.6 \\
\hline $\mathrm{T}+\mathrm{HL}$ & 3.39 & 6.65 & 0.23 & 1.32 & 4.12 & 1225 & 1.30 & 12.7 \\
\hline $\mathrm{T}+\mathrm{DL}$ & 3.40 & 6.84 & 0.23 & 1.40 & 4.17 & 1235 & 1.30 & 12.7 \\
\hline $\mathrm{T}+\mathrm{GH}+\mathrm{HL}$ & 3.41 & 6.87 & 0.23 & 1.37 & 4.12 & 1200 & 1.30 & 12.7 \\
\hline
\end{tabular}

Tabla 4.16 Parámetros enológicos clásicos del vino Tinta de Toro tras la fermentación maloláctica, A.Total: acidez total; A.V: acidez volátil; TH2: ácido tartárico; MH2: ácido málico.

\begin{tabular}{|c|c|c|c|c|c|c|c|c|}
\hline $\begin{array}{c}\text { Vino } \\
\text { Tinta de } \\
\text { Toro }\end{array}$ & $\mathbf{p H}$ & A. Total & A.V. & TH2 & MH2 & Potasio & Azúcar & Grado \\
\cline { 2 - 8 } & & $\mathbf{g} / \mathbf{L}$ & $\mathbf{g} / \mathbf{L}$ & $\mathbf{g} / \mathbf{L}$ & $\mathbf{g} / \mathbf{L}$ & $\mathbf{m g} / \mathbf{L}$ & $\mathbf{g} / \mathbf{L}$ & $\mathbf{v} / \mathbf{v}$ \\
\hline $\mathrm{T}$ & 3.61 & 4.81 & 0.43 & 0.96 & 0.11 & 1226.5 & 1.33 & 13.2 \\
\hline $\mathrm{T}+\mathrm{HL}$ & 3.61 & 5.44 & 0.44 & 1.13 & 0.10 & 1455.0 & 1.30 & 10.3 \\
\hline $\mathrm{T}+\mathrm{DL}$ & 3.52 & 5.07 & 0.41 & 1.09 & 0.10 & 1249.0 & 1.31 & 12.1 \\
\hline $\mathrm{T}+\mathrm{GH}+\mathrm{HL}$ & 3.61 & 4.97 & 0.47 & 1.12 & 0.10 & 1216.5 & 1.34 & 10.2 \\
\hline
\end{tabular}

En ambas tablas se puede comprobar que los vinos elaborados a partir de las mezclas, dan resultados similares de todos los componentes analizados a excepción del grado alcohólico final. También podemos observar que, tras la fermentación maloláctica, se producen cambios en la concentración de varios componentes como el ácido málico, la acidez volátil y la acidez total, debido al metabolismo de las bacterias. El ácido tartárico también disminuye en una pequeña proporción para formar ácido láctico por la acción de estas bacterias [9].

En las tres figuras siguientes (figuras 4.17-4.19), se muestran las concentraciones de los compuestos polifenólicos y el color para los vinos de baja graduación y el vino testigo. 


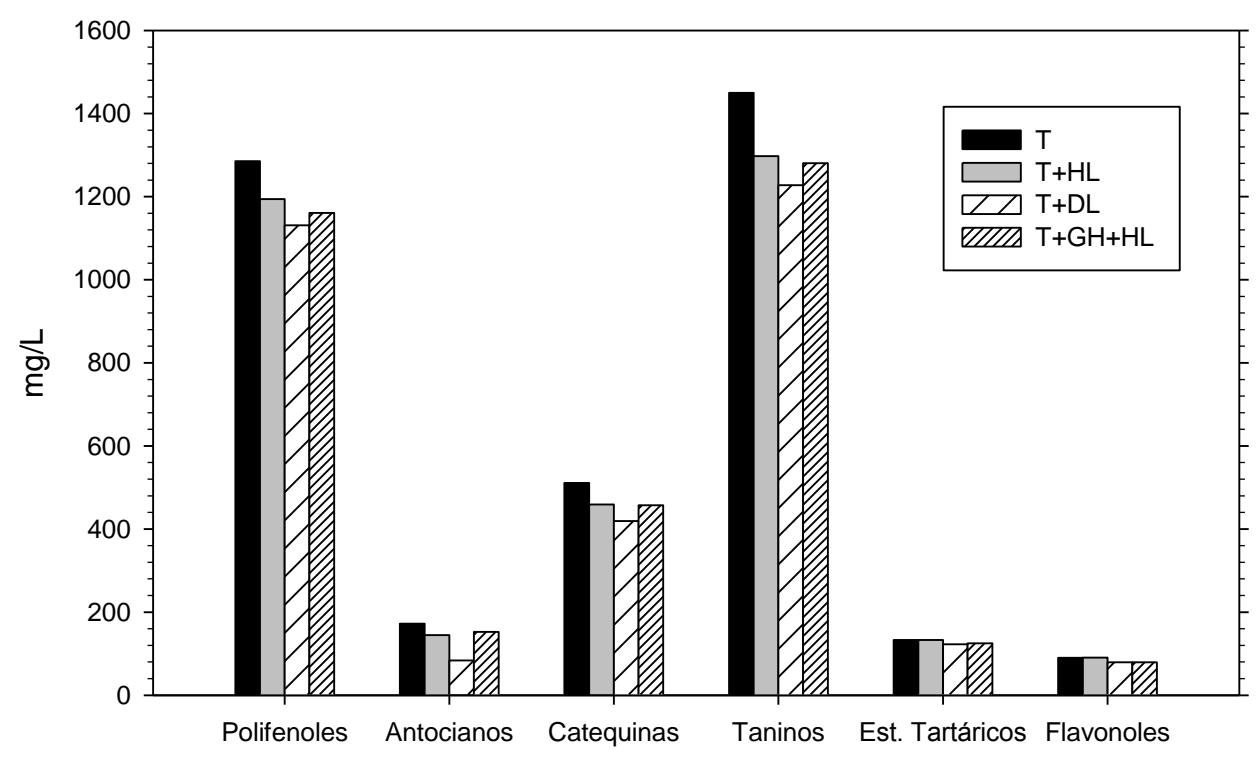

Figura 4.17 Contenido en polifenoles totales, antocianos, catequinas, taninos, ésteres tartáricos y flavonoles, de los distintos vinos elaborados de la variedad Tinta de Toro.

Como podemos comprobar, tenemos una concentración similar de todos los compuestos analizados en los vinos de baja graduación elaborados, respecto al vino testigo. El módulo de membrana DL es el que más diferencia de concentración de polifenoles, antocianos, catequinas y taninos tiene respecto a las otras dos membranas y el vino testigo. Al igual que en el análisis de color en las mezclas antes de realizar las fermentaciones (figura 4.12.a), la concentración de polifenoles y catequinas es menor para esta membrana. En el caso de los antocianos debería tener una concentración similar al resto de vinos elaborados, pero hay que tener en cuenta que en el transcurso de las fermentaciones tenemos factores (temperatura, dióxido de azufre, días de maceración, precipitación de materia colorante,...etc.) que influyen en estas concentraciones. Además, la menor concentración de compuestos de alto peso molecular para los vinos elaborados con los mostos filtrados con la membrana DL debe ser también consecuencia de la menor proporción de pasta utilizada frente a las otras membranas (ver tabla 4.11). 


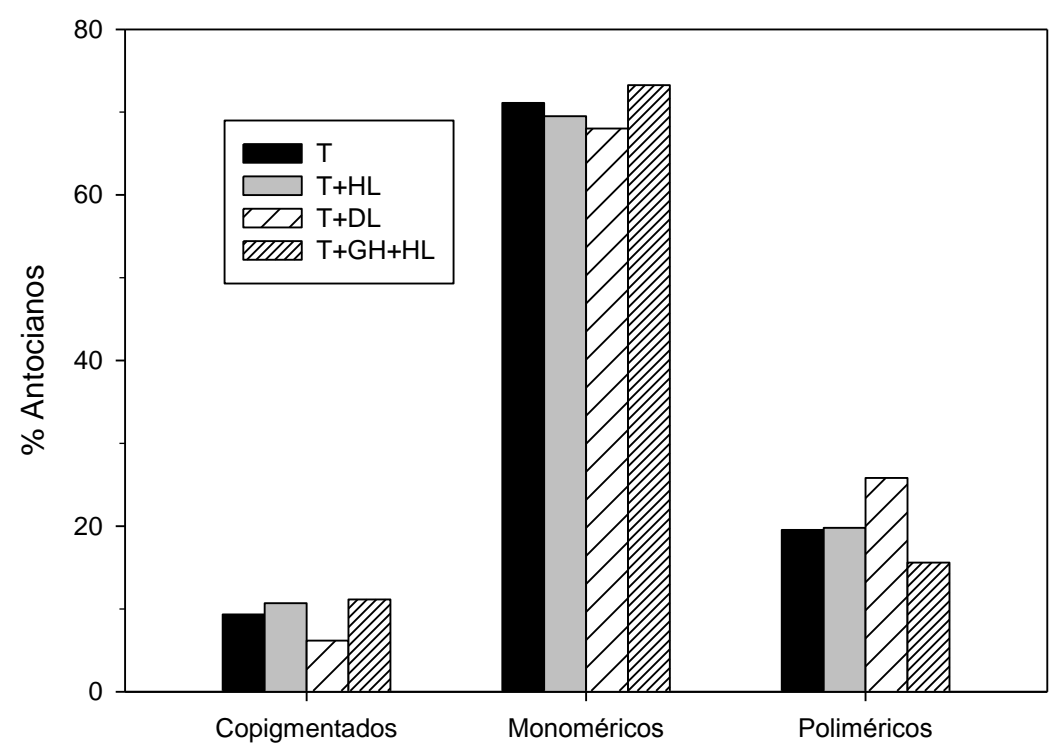

Figura $4.18 \%$ de antocianos copigmentados, monoméricos y poliméricos, de los distintos vinos elaborados de la variedad Tinta de Toro.

Observando la figura 4.18, podemos comprobar cómo el vino obtenido de la mezcla del testigo con el permeado de la membrana $\mathrm{GH}+\mathrm{HL}$ tiene una menor concentración de antocianos poliméricos, porque han sido retenidos en los dos pasos de filtración con los módulos de membrana. En el caso del vino elaborado como mezcla del vino testigo y el permeado del módulo de membrana DL ocurre lo contrario, tiene más concentración de antocianos poliméricos porque han sido menos retenidos, y por el contrario tiene menos concentración de antocianos copigmentados dado que lo que se muestra en la figura es un análisis porcentual. El vino de baja graduación que tiene un porcentaje de antocianos más parecido al vino sin filtrar, sería el elaborado de la mezcla con el permeado del módulo de membrana HL.

Finalmente, comparando el índice de color, la tonalidad y los \% de color de los vinos tintos de baja graduación y el vino testigo, según la figura 4.19, vemos que obtenemos un perfil muy similar entre todos los vinos elaborados.

Podríamos decir que el vino de baja graduación que más se ajusta al vino sin tratar, es el obtenido de la mezcla del testigo con el permeado del módulo de membrana HL, pero como hemos dicho anteriormente, los resultados obtenidos son muy parecidos para todas las membranas, teniendo variaciones menores al $4 \%$ para los datos de color en todas las pruebas. 


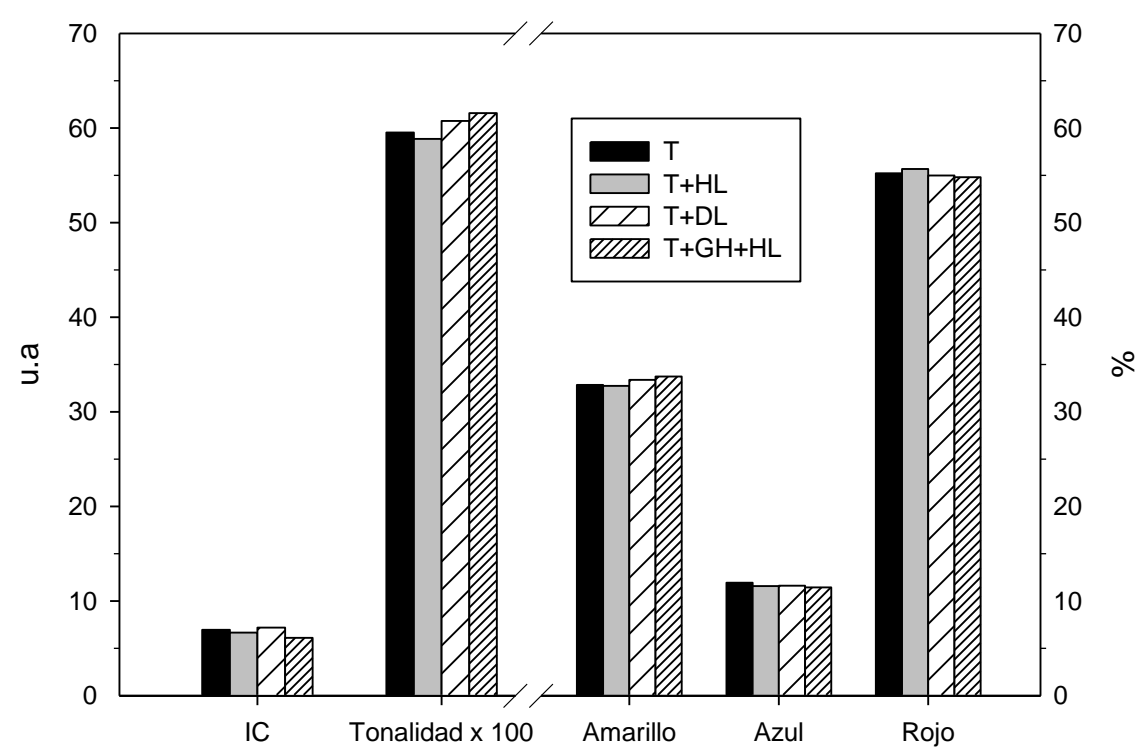

Figura 4.19 Índice de color los vinos elaborados de la variedad Tinta de Toro.

\section{ANÁLISIS AROMÁTICO}

Como último análisis de los vinos elaborados, se muestra a continuación su composición aromática. Para ello, se identifican los mismos compuestos que en el capítulo anterior y se cuantifican agrupándolos por sus características químicas (ésteres etílicos, alcoholes superiores y bencílicos, acetatos, ácidos grasos, lactonas, alcoholes C6 y compuestos terpénicos), además de compuestos como el benzaldehído, metionol y el ácido geránico.

En las figuras 4.20 y 4.21, se representan estos grupos para los vinos Verdejo y Tinta de Toro respectivamente. El perfil aromático del vino testigo en el caso del vino Verdejo, es más parecido al de los vinos de baja graduación alcohólica que en el caso de los vinos Tinta de Toro.

Los perfiles aromáticos del vino testigo y de los vinos de baja graduación alcohólica no muestran diferencias cuantitativas importantes. Por lo general, los vinos de baja graduación alcohólica tienen menos aromas secundarios (alcoholes superiores, ácidos grasos, ésteres etílicos, lactonas, acetatos y terpenos), porque el proceso de fermentación será menos intenso que en el vino testigo. 
a) Vino Verdejo

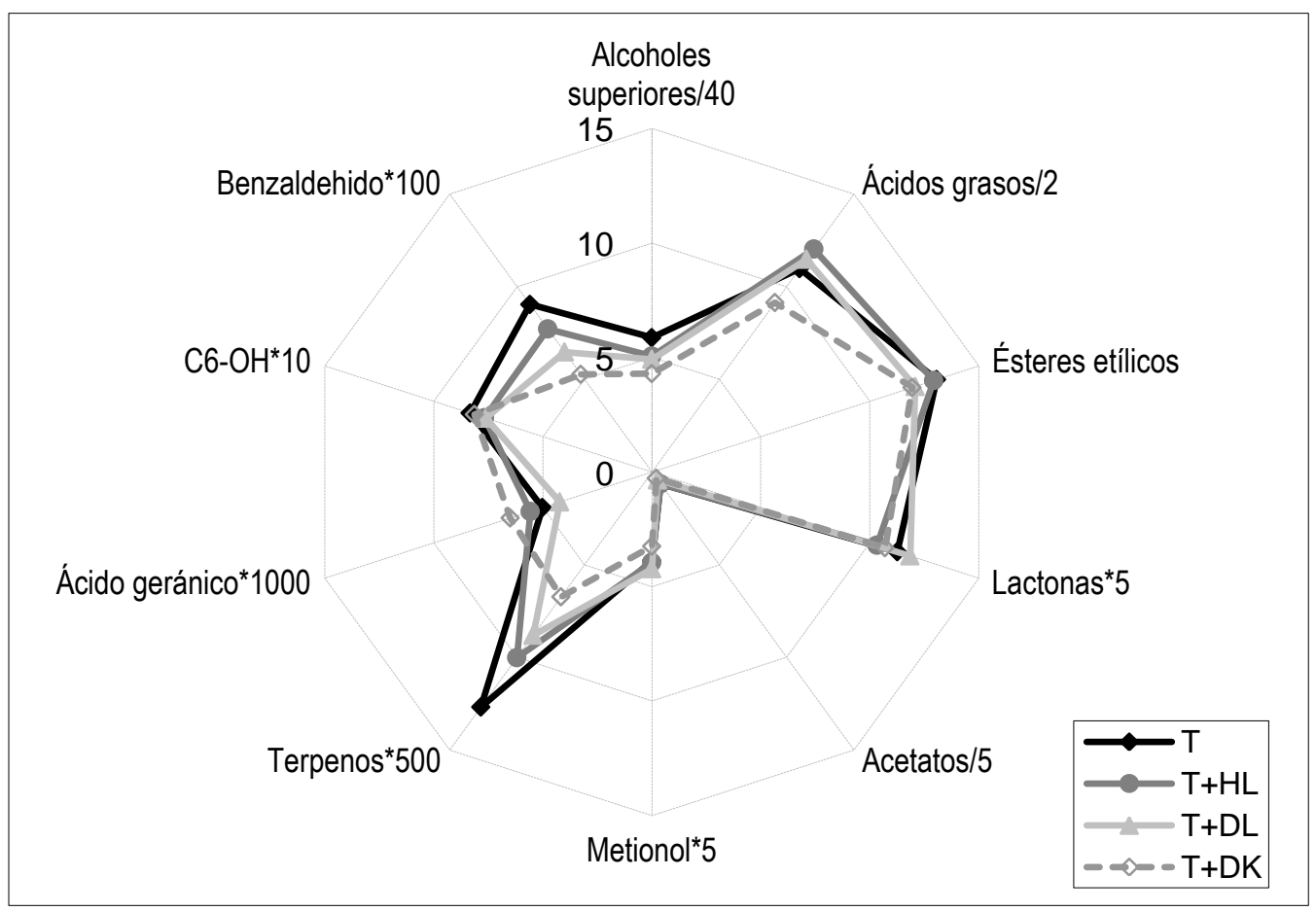

Figura 4.20 Concentración $(\mathrm{mg} / \mathrm{L})$ de los componentes aromáticos para el vino testigo y para los vinos de menor graduación alcohólica de la variedad Verdejo.

Lo que sí podemos deducir a simple vista, es que el perfil que más se ajusta al vino sin tratar es el obtenido de la mezcla del mosto testigo y del permeado del módulo de membrana HL. Las mayores diferencias en estos dos perfiles las encontramos en el benzaldehído y en los terpenos, por la menor intensidad de la fermentación como dijimos anteriormente. No obstante, hay que destacar que en este caso las diferencias en el perfil aromático entre el vino testigo y los de baja graduación son mucho menores que las encontradas en la campaña anterior.

b) Vino Tinta de Toro

Como dijimos anteriormente, en el caso de los vinos tintos los perfiles aromáticos de los vinos de baja graduación alcohólica, respecto al vino testigo, son menos parecidos que en el caso del vino Verdejo. Tenemos diferencias en los alcoholes superiores, ésteres etílicos, lactonas, acetatos y terpenos, que como en el caso anterior pueden deberse a la menor intensidad de fermentación de estos vinos. La única excepción sería el aumento de acetato en el vino $T+H L$, pero además de que los compuestos aromáticos son susceptibles a la variación de nutrientes y las condiciones de fermentación (concentración de azúcar y turbidez del mosto, oxígeno, 
temperatura...etc.), la producción de los ésteres está ligada a la pérdida por evaporación [13], y este efecto puede ser más intenso en esta membrana porque es en la que más tiempo se emplea para obtener el volumen de permeado deseado (ver figura 4.6).

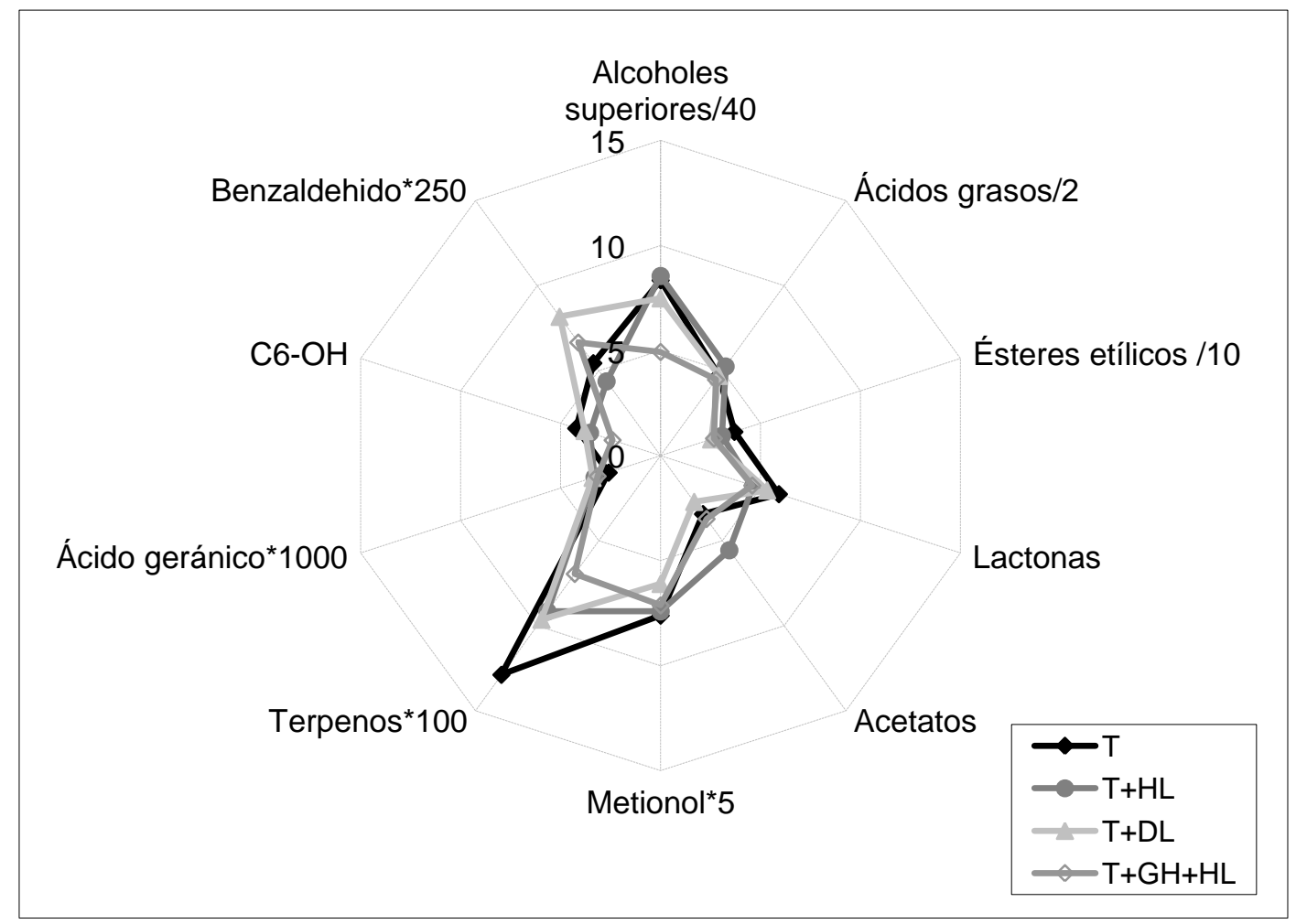

Figura 4.21 Concentración $(\mathrm{mg} / \mathrm{L})$ de los componentes aromáticos para el vino testigo y para los vinos de menor graduación alcohólica de la variedad Tinta de Toro.

Respecto al benzaldehído, el vino resultante de la mezcla $\mathrm{T}+\mathrm{HL}$ tiene menos concentración que el vino testigo y las otras dos mezclas tienen una concentración mayor que el testigo. Puesto que un aumento de la temperatura de los mostos en la filtración, puede elevar la concentración de los aldehídos fenólicos volátiles [9], puede ser que en el caso de los mostos $\mathrm{GH}+\mathrm{HL}$ y $\mathrm{DL}$ haya ocurrido este aumento de temperatura.

\section{ANÁLISIS SENSORIAL}

Utilizando la misma metodología de análisis sensorial de alimentos que en el capítulo anterior [15], se lleva a cabo el análisis descriptivo de los vinos blancos y tintos que se han elaborado en la Estación Enológica del ITACyL. 
En cuanto al análisis sensorial de los vinos Verdejo, el vino de menor graduación alcohólica T+DK fue el que presentó la intensidad de color más alta, hecho que concuerda con los resultados obtenidos en el análisis instrumental. En la fase olfativa, en todos los vinos de menor graduación alcohólica elaborados se detectó la presencia de un olor artificial desagradable con notas a farmacia, olor que no debe estar presente en el aroma de un vino. La presencia de este olor fue muy acusado en el vino $\mathrm{T}+\mathrm{DL}$, mientras que en el vino $\mathrm{T}+\mathrm{HL}$ su presencia fue más sutil. En la fase gustativa los tres vinos de menor graduación alcohólica fueron más ligeros en boca que el vino testigo, hecho que provocó que destacase más su acidez.

En el análisis sensorial de los vinos Tinta de Toro, no se encontraron diferencias entre los tres vinos de menor graduación alcohólica y el vino testigo en el color. En la fase olfativa, también se detectó la presencia de olores artificiales o farmacéuticos en los vinos de menor graduación alcohólica. La presencia de este olor fue muy alta en los vinos $\mathrm{DL}$, moderada en los $\mathrm{HL}$ y ligera en los $\mathrm{GH}+\mathrm{HL}$. En boca fueron estos últimos vinos los más equilibrados y en los que la acidez era menos marcada. En los vinos DL en la fase gustativa se detectó un sabor artificial desagradable similar al que se detectaba en la fase olfativa.

\section{CONCLUSIONES}

Tras esta campaña, parece claro que todas las pruebas de nanofiltración realizadas, han conseguido disminuir la cantidad de azúcar en sus permeados, sin embargo, la utilización de la membrana de ultrafiltración $\mathrm{GH}$ a dos tiempos diferentes en el mosto Verdejo nos indica que la concentración de azúcar no disminuye. Por ello debemos descartar el uso de esta membrana en un solo paso para elaborar vinos de baja graduación, pero no hay que descartar su uso previo a una etapa posterior de nanofiltración.

Los resultados obtenidos tanto con el mosto Verdejo como con el mosto Tinta de Toro, nos indican que los permeados de las nanofiltraciones llevadas a cabo, tienen concentraciones similares de sustancias de bajo peso molecular e incluso de componentes fenólicos, siendo el permeado del módulo de membrana DL el que menos componentes fenólicos pierde respecto al testigo. Si comparamos las mezclas de los mostos realizadas antes de fermentar, tenemos que tanto para el mosto Verdejo como para el mosto Tinta de Toro, la mezcla que más se parece al mosto sin modificar, es la obtenida del testigo con el permeado obtenido de la filtración del módulo HL $(T+H L)$, tanto en componentes polifenólicos como en color. 
Observando los resultados obtenidos para los vinos de baja graduación alcohólica elaborados, tanto para el vino Verdejo como para el vino Tinta de Toro, la mezcla $\mathrm{T}+\mathrm{HL}$, es la que más se parece al vino testigo, tanto en componentes polifenólicos como en perfil aromático, aunque los parámetros enológicos son similares para todos los vinos elaborados.

Parece que con todos los resultados analíticos obtenidos, la membrana que mejor se adapta a la elaboración de vinos de baja graduación alcohólica es la membrana de nanofiltración HL, además esta decisión estaría apoyada por los datos de permeabilidad y retención de dicha membrana, ya que tiene unos valores elevados de ambas propiedades.

Hasta ahora, el problema de los vinos de baja graduación es que la calidad sensorial no era satisfactoria, teniendo en cuenta los resultados obtenidos en aroma y sabor. Del análisis de aminoácidos, podemos deducir que estos compuestos no son los responsables de los cambios organolépticos producidos en el mosto Verdejo, ya que las mezclas de los mostos tienen una concentración similar al mosto testigo.

Lo que intentaremos en el siguiente capítulo será ajustar las condiciones de filtración, para que el rendimiento del proceso sea adecuado, aumentando la superficie de filtración de la membrana para reducir el tiempo de filtración. Esto será más beneficioso que aumentar la presión aplicada, ya que un aumento de la velocidad tangencial podría aumentar la oxidación de los mostos. Este aumento de superficie activa de filtración, evitará la oxidación de compuestos como consecuencia del elevado tiempo de filtración en el que se lleva a cabo la reducción de azúcar del mosto, lo que se apoyará con el doble control de la temperatura de la filtración, enfriando tanto el tanque de alimentación como el tanque de permeado.

En cuanto a las membranas utilizadas en la próxima campaña (capitulo 5), además de usar módulos de membrana $\mathrm{HL}$, se realiza la experiencia $\mathrm{GH}+\mathrm{HL}$ (con un módulo de HL para Verdejo y dos módulos para Tinta de Toro). Aunque indicamos anteriormente que productivamente no se obtienen ventajas con esta filtración en la reducción de azúcar, si se obtienen mejoras en el análisis de color (los porcentajes de amarillos, azules y rojos en el mosto $\mathrm{T}+\mathrm{GH}+\mathrm{HL}$, eran más parecidos al mosto sin filtrar que si realizamos la mezcla $T+H L)$. Además en el análisis sensorial del vino Tinta de Toro la presencia de olores artificiales o farmacéuticos es menor para la prueba $\mathrm{GH}+\mathrm{HL}$, ya que la membrana de ultrafiltración ha podido retener precursores aromáticos de olor a farmacia que permanecerán en el retenido de la primera membrana y por tanto, no pasarán al vino final. 


\section{REFERENCIAS}

1. Pradanos, P., Arribas, J. I., and Hernandez, A., Flux limiting factors in crossflow ultrafiltration of invertase through an asymmetric inorganic membrane. Separation science and technology, 1993. 28(10): p. 1899-1911.

2. García-Martín, N., Perez-Magariño, S., Ortega-Heras, M., González-Huerta, C., Mihnea, M., González-Sanjosé, M. L., Palacio, L., Prádanos, P., and Hernández, A., Sugar reduction in musts with nanofiltration membranes to obtain low alcohol-content wines. Separation and Purification Technology, 2010. 76(2): p. 158-170.

3. Al-Amoudi, A., Williams, P., Mandale, S., and Lovitt, R. W., Cleaning results of new and fouled nanofiltration membrane characterized by zeta potential and permeability. Separation and Purification Technology, 2007. 54(2): p. 234-240.

4. Jonsson, G., Prádanos, P., and Hernández, A., Fouling phenomena in microporous membranes. Flux decline kinetics and structural modifications. Journal of Membrane Science, 1996. 112(2): p. 171-183.

5. Prádanos, P., de Abajo, J., de la Campa, J. G., and Hernández, A., A comparative analysis of flux limit models for ultrafiltration membranes.Journal of Membrane Science, 1995. 108(1-2): p. 129-142.

6. El Rayess, Y., Albasi, C., Bacchin, P., Taillandier, P., Raynal, J., MiettonPeuchot, M., and Devatine, A., Cross-flow microfiltration applied to oenology: $A$ review. Journal of Membrane Science, 2011. 382(1-2): p. 1-19.

7. Montalvillo, M., Silva, V., Palacio, L., Calvo, J. I., Carmona, F. J., Hernández, A., and Prádanos, P., Charge and dielectric characterization of nanofiltration membranes by impedance spectroscopy. Journal of Membrane Science, 2014. 454(0): p. 163-173.

8. Versari, A., Ferrarini, R., Parpinello, G. P., and Galassi, S., Concentration of Grape Must by Nanofiltration Membranes. Food and Bioproducts Processing, 2003. 81(3): p. 275-278.

9. Jackson, R. S., Wine Science: Principles, Practice, Perception. Elsevier Science \& Technology ed, ed. 2. 2000.

10. Lide, D. R., CRC Handbook of Chemistry and Physics, 85th Edition. 2004: Taylor \& Francis. 
11. Conca, R., Bruzzoniti, M. C., Mentasti, E., Sarzanini, C., and Hajos, P., Ion chromatographic separation of polyamines: putrescine, spermidine and spermine. Analytica Chimica Acta, 2001. 439(1): p. 107-114.

12. Rapp, A. and Versini, G., Influence of nitrogen compounds in grapes on aroma compounds of wines, in Developments in Food Science, Charalambous George, Editor. 1995, Elsevier. p. 1659-1694.

13. Moreno-Arribas, M. V. and Polo, M. C., Wine Chemistry and Biochemistry. Springer ed. 2009.

14. Togores, J. H., Tratado de Enología. Mundi-Prensa ed. 2003.

15. Gonzalez-Sanjose, M. L., Ortega-Heras, M., and Perez-Magarino, S., Microoxygenation Treatment and Sensory Properties of Young Red Wines. Food Science and Technology International, 2008. 14: p. 123-130. 



\section{CAPÍTULO 5 INFLUENCIA DEL DOBLE PROCESO ULTRAFILTRACIÓN-NANOFILTRACIÓN EN LOS VINOS DE BAJA GRADUACIÓN}

\section{INTRODUCCIÓN}

De los resultados obtenidos en la campaña anterior, deducimos que el módulo de membrana que debemos utilizar es el HL, tanto para el mosto Verdejo como para el mosto Tinta de Toro. Esta conclusión estaría apoyada por los valores elevados de permeabilidad y retención de esta membrana, además de la similitud de los datos analíticos con los mostos sin tratar. También se utilizan en este capítulo la filtración en dos etapas, pasando primero por el módulo de ultrafiltración $\mathrm{GH}$, y el permeado obtenido por el módulo de membrana HL, ya que el color y la presencia de olores artificiales o farmacéuticos es menor con este doble proceso que al usar sólo el modulo HL. Esto parece indicar que se retienen precursores aromáticos en la etapa de ultrafiltración y que su eliminación reduciría los defectos en el vino final. Es de suponer que estos precursores son grandes macromoléculas o sustancias asociadas a estas macromoléculas.

Como en el capítulo anterior, las fracciones mezcladas para obtener el vino de baja graduación será el mosto testigo con el permeado de la filtración ya que, como vimos en el capítulo 3, de esta forma se obtienen vinos con mejores características organolépticas que usando el retenido de la primera etapa de nanofiltración. La novedad de las condiciones de filtración en este capítulo, se basa en el aumento de la superficie activa de filtración para reducir el tiempo de filtración en el mosto Tinta de Toro. De esta forma se impedirá la oxidación de compuestos del mosto por el elevado tiempo de filtración en el que transcurre la reducción de azúcar del mosto, y mejorará la calidad sensorial de los vinos finales. Además, en esta campaña se utilizará una bomba que permite aumentar la presión aplicada y se controlará la temperatura tanto del tanque de alimentación como del permeado. 


\section{MATERIALES USADOS Y DISPOSITIVOS EXPERIMENTALES}

\subsection{MEMBRANAS Y MOSTOS}

Las características de los módulos de membrana que emplearemos (GH y HL) se mostraron en el capítulo 2 en la tabla 2.11. En el mosto Verdejo se realizan dos pruebas: una utilizando dos módulos de filtración (módulo de membrana de ultrafiltración GH seguida del módulo de membrana de nanofiltración HL) y otra simplemente utilizando el módulo de nanofiltración HL. En las dos filtraciones el módulo de membrana de nanofiltración (HL) es nuevo (no el utilizado en las campañas anteriores) y el de ultrafiltración (GH) se ha empleado en las otras campañas.

Al módulo nuevo se le tiene que eliminar la solución conservante, como ya hemos explicamos en el capítulo 2 (apartado 4.1.1), aunque las condiciones son diferentes puesto que con la nueva bomba se pueden alcanzar presiones mayores. En este caso, el proceso de eliminación de conservante tiene lugar durante una hora a $25 \cdot 10^{-5} \mathrm{~Pa}$ de presión y un flujo de recirculación de $9.5 \mathrm{~L} / \mathrm{min}$.

Para la etapa de acondicionamiento del módulo, sucede lo mismo que en la etapa anterior y las condiciones son diferentes a las que se emplearon anteriormente. En este caso se pasa agua milli-Q durante una hora en las mismas condiciones que las usadas para la eliminación del conservante, consiguiendo así un valor de flujo constante.

El módulo de nanofiltración $\mathrm{HL}$ y el de ultrafiltración $\mathrm{GH}$ utilizados en campañas anteriores, se han mantenido en una disolución de fenol para su conservación. Para eliminar esta disolución, se realiza el mismo tratamiento que en el capítulo anterior (apartado 2.1).

En el caso del mosto Tinta de Toro las pruebas realizadas son las mismas que en el mosto blanco, pero en lugar de utilizar sólo un módulo de nanofiltración HL, se utilizan dos módulos idénticos en serie cuando aplicamos la etapa de nanofiltración (uno nuevo y otro utilizado en campañas anteriores). El retenido del primer módulo de nanofiltración pasará al segundo módulo y las dos fracciones de permeado se mezclan.

En la figura 5.1 se muestra esquemáticamente las pruebas realizadas para el mosto Verdejo. En el caso del mosto tinto la única diferencia sería que en lugar de utilizar un módulo de membrana HL, utilizaríamos dos módulos colocados en serie. 


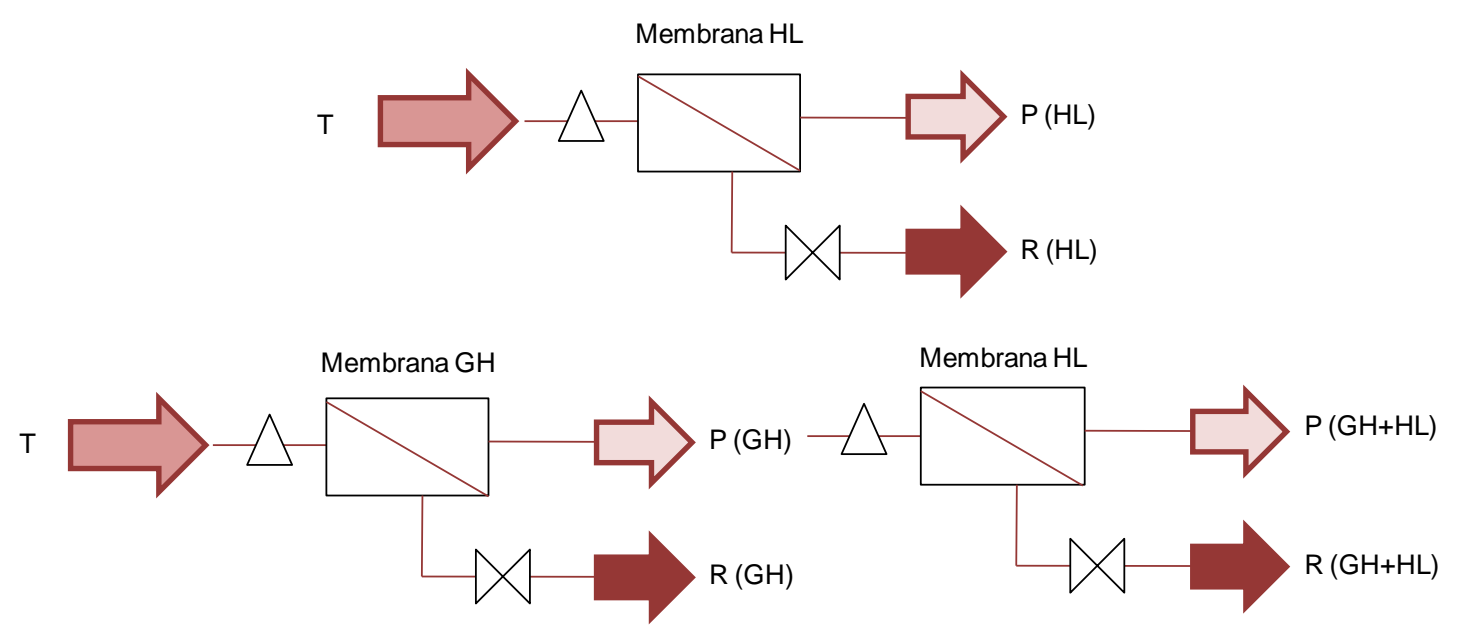

Figura 5.1 Pruebas de filtración realizadas con el mosto Verdejo.

\subsection{ELABORACIÓN Y PREPARACIÓN DE MOSTOS}

Se utilizará uva vendimiada en Septiembre de 2009, para obtener ambos mostos, los cuales se elaborarán según el método tradicional como ya describimos en el apartado 2.2 del capítulo 3 .

\subsection{DISPOSITIVO EXPERIMENTAL}

El equipo utilizado ya se ha descrito en el apartado 4.1.3 del capítulo 2. En este caso se utilizan dos unidades de refrigeración, una para el tanque de alimentación y otra para el tanque de permeado. En las campañas anteriores, el equipo de frío utilizado (descrito en el apartado 2.3 del capítulo 3 ) controlaba la temperatura del tanque de alimentación. En esta campaña, esta unidad se utiliza para el tanque de permeado y la nueva Unidad Refrigeradora (TUR-2 Digital Cooler Inmersion Thermostat), para el tanque de alimentación.

Con estas dos unidades de refrigeración, se controla la temperatura digitalmente, manteniendo constante dicha temperatura en $6^{\circ} \mathrm{C}$, lo que evitará la volatilización de compuestos importantes cuya falta se detectaría en el análisis organoléptico del vino final.

Para todas las pruebas de filtración se utilizan 30 litros. Se introduce el serpentín en el depósito de alimentación y de permeado, y se ajusta la temperatura a $6^{\circ} \mathrm{C}$ en ambos casos, para no tener problemas de fermentación del mosto.

En la tabla 5.1 se muestran las presiones aplicadas para conseguir flujos de recirculación aceptables en la filtración con cada módulo de membrana. Con la bomba usada en esta campaña, una bomba de pistón regulable Wanner Hydra-cell G-03- 
XInox/Viton, se alcanzan flujos $6 \mathrm{~L} /$ min para ambos mostos (frente a 1L/min alcanzado con la bomba de campañas anteriores [1]). Esta bomba ya fue utilizada para la filtración de la disolución de azúcar con el módulo espiral DL1812C, como indicamos en el apartado 4.1.3 del capítulo 2. La capacidad de la misma para alcanzar hasta 69 bar, permitirá conseguir flujos de recirculación más elevados, sin que afecte a las características organolépticas por el aumento de temperatura en la filtración (lo que ocurrirá según Rayess et al., con vinos a flujos de recirculación mayores de 101.64 L/min y $224.4 \mathrm{~L} / \mathrm{min}$, para los módulos GH y HL respectivamente) [2]. Además se reducirán los tiempos de filtración considerablemente, sobre todo en tintos donde se reduce el tiempo de filtración en un $80 \%$ con el doble módulo de membrana HL y un $50 \%$ con el módulo de membrana $\mathrm{GH}$.

Tabla 5.1 Condiciones de filtración para los mostos Verdejo y Tinta de Toro.

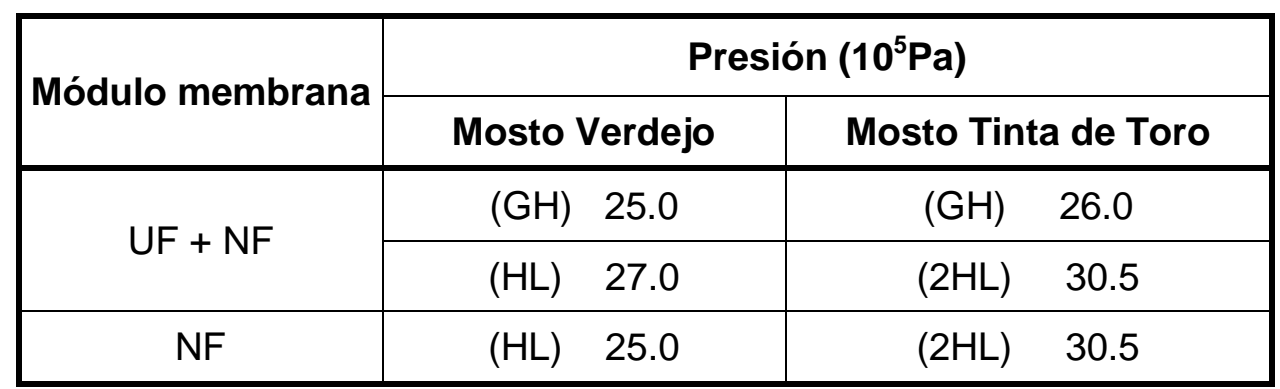

\subsection{MÉTODOS ANALÍTICOS}

Durante la filtración se miden por polarimetría los valores de concentración de azúcar. Como en capítulos anteriores, las concentraciones de azúcar de alimentación, de permeado y los retenidos finales se analizan en la Estación Enológica del ITACyL por personal adscrito al centro mediante método refractométrico y método enzimático. Utilizando estos últimos datos calcularemos la retención de la membrana. La explicación de todos los métodos de medida de concentración de azúcar, se muestra en el capítulo 2 (apartados 3.1 .4 y 4.1.4). También durante la filtración se comprueba la caída de flujo, lo que nos permitirá conocer el ensuciamiento de las mismas.

Para el análisis del resto de componentes del mosto y el vino y de los compuestos aromáticos, se utilizan los métodos indicados en el apartado 2.4 del capítulo 3 , y se realizan por la Estación Enológica del ITACyL. 


\section{RESULTADOS}

\subsection{PERMEABILIDAD HIDRÁULICA}

La permeabilidad se medirá una vez que se ha acondicionado el módulo nuevo de nanofiltración HL o se ha eliminado la disolución de fenol para el resto. El motivo de medir la permeabilidad de los módulos de membrana utilizados en filtraciones anteriores, es para comprobar el efecto de ensuciamiento que tiene lugar en la misma. Esta medida se llevará a cabo con agua milli-Q en un intervalo de presiones apropiado (ver tablas 5.2 y 5.3), teniendo en cuenta las características funcionales del módulo utilizado en cada caso.

En las tablas 5.2 y 5.3 , se muestran los valores de permeabilidad antes y después de cada filtración del mosto Verdejo y del mosto Tinta de Toro, respectivamente, al igual que después de la limpieza de dichas membranas. Se debe tener en cuenta que, en todos los casos, las presiones de medida son las máximas que podemos aplicar en cada módulo, y que ha realizado primero la filtración del mosto tinto y luego la del blanco.

Tabla 5.2 Permeabilidad de los módulos de membranas espirales antes y después de la filtración del mosto Verdejo y tras la limpieza de los módulos.

\begin{tabular}{|c|c|c|c|c|c|}
\hline \multicolumn{2}{|c|}{} & Membrana & $\begin{array}{c}\text { Antes de } \\
\text { la } \\
\text { ládulo membrana } \\
\text { filtración } \\
\text { nueva }{ }^{1}\end{array}$ & $\begin{array}{c}\text { Después de } \\
\text { la filtración } \\
\text { de Verdejo }\end{array}$ & $\begin{array}{c}\text { Después de } \\
\text { la limpieza } \\
\text { con } \\
\text { detergente }\end{array}$ \\
\cline { 3 - 6 } & \multicolumn{4}{|c|}{$L_{p}\left(10^{-11} \mathrm{~m} /(\mathrm{s} \cdot \mathrm{Pa})\right)$} \\
\hline $\begin{array}{c}\text { Prueba } \\
\text { UF-GH + NF-HL }\end{array}$ & UF-GH & 0.574 & 0.396 & 0.270 & 0.270 \\
\cline { 2 - 6 } & NF-HL & 2.594 & 1.649 & 1.579 & 1.649 \\
\hline \multicolumn{2}{|c|}{ NF-HL } & 2.594 & 1.649 & 1.579 & $-^{2}$ \\
\hline
\end{tabular}

${ }^{1}$ El rango de presiones para las membranas nuevas es: 8-18 bar para GH (según se indicó en el epígrafe 4.2.1 del capítulo 2) y de 6-25 bar para HL.

${ }^{2}$ Valor no determinado.

Los valores de permeabilidad de la membrana nueva son lógicamente los más elevados. En el caso de utilizar dos módulos de nanofiltración HL dispuestos en serie, tenemos que tener en cuenta que la permeabilidad de los dos módulos nuevos es diferente porque se acondicionaron a diferentes presiones. 
Tabla 5.3 Permeabilidad de los módulos de membranas espirales antes y después de la filtración del mosto Tinta de Toro y tras la limpieza de los módulos.

\begin{tabular}{|c|c|c|c|c|c|}
\hline \multicolumn{2}{|c|}{} & Membrana & $\begin{array}{c}\text { Antes de la } \\
\text { filtración de } \\
\text { nueva }\end{array}$ & $\begin{array}{c}\text { Después de } \\
\text { la filtración } \\
\text { Tinta de Toro } \\
\text { de Tinta de } \\
\text { Toro }\end{array}$ & $\begin{array}{c}\text { Después de } \\
\text { la limpieza } \\
\text { con } \\
\text { detergente }\end{array}$ \\
\cline { 2 - 6 } & \multicolumn{5}{|c|}{$L_{p}\left(10^{-11} \mathrm{~m} /(\mathrm{s} \cdot \mathrm{Pa})\right)$} \\
\hline $\begin{array}{c}\text { Prueba } \\
\text { UF-GH + 2 NF-HL }\end{array}$ & UF-GH & 0.574 & 0.379 & 0.432 & 0.396 \\
\cline { 2 - 6 } & $2 \mathrm{NF}-\mathrm{HL}$ & $\begin{array}{c}2.594 \mathrm{y} \\
1.933^{1}\end{array}$ & 3.246 & 3.053 & 3.074 \\
\hline \multicolumn{2}{|c|}{$2 \mathrm{NF}-\mathrm{HL}$} & $\begin{array}{c}2.594 \mathrm{y} \\
1.933^{1}\end{array}$ & 3.200 & 3.158 & 3.246 \\
\hline
\end{tabular}

${ }^{1}$ El valor de $2,594 \cdot 10^{-11} \mathrm{~m} /(\mathrm{s} \cdot \mathrm{Pa})$ corresponde al módulo nuevo estabilizado a 25 bar y medido entre 6 y 25 bar, y el valor de $1.933 \cdot 10^{-11} \mathrm{~m} /(\mathrm{s} \cdot \mathrm{Pa})$ corresponde al módulo antiguo estabilizado a 10 bar y medido como se indicó en el epígrafe 4.2.1 del capítulo 2.

Comparando las permeabilidades antes y después de las filtraciones de los mostos, comprobamos que disminuye después de la filtración debido al fenómeno de ensuciamiento de la membrana [3]. La única excepción se presenta en la filtración del mosto tinta de Toro con el módulo de membrana de ultrafiltración $\mathrm{GH}$, ya que tenemos mayor permeabilidad tras la filtración. Esto puede producirse porque las sustancias de gran tamaño dan lugar a un ensuciamiento reversible y pueden eliminar sustancias depositadas en la membrana [2]. También pude ocurrir que alguno de los componentes del mosto tinto tenga una alta afinidad por el polímero de esta membrana, se introduzca en la matriz polimérica y abre su estructura porosa.

Después de la etapa de limpieza de los módulos, se obtienen valores de permeabilidad iguales o muy próximos a los que se presentan antes de la filtración. Esto confirma que la etapa de limpieza nos permitirá la recuperación de funcionalidad de las membranas utilizadas.

\subsection{CURVAS TIEMPO-FLUJO}

Como sucede en el resto de capítulos en el que se utilizan estos módulos de membrana, el flujo disminuye respecto al tiempo de filtración. Para estudiar esta caída de flujo, normalizamos el flujo y el tiempo respecto a los valores iniciales de flujo y tiempo respectivamente. 
En las figuras 5.2 y 5.3 se muestra la cinética del flujo de permeado del mosto Verdejo y Tinta de Toro, respectivamente. Las condiciones de filtración se indicaron en la tabla 5.1 para los dos mostos.

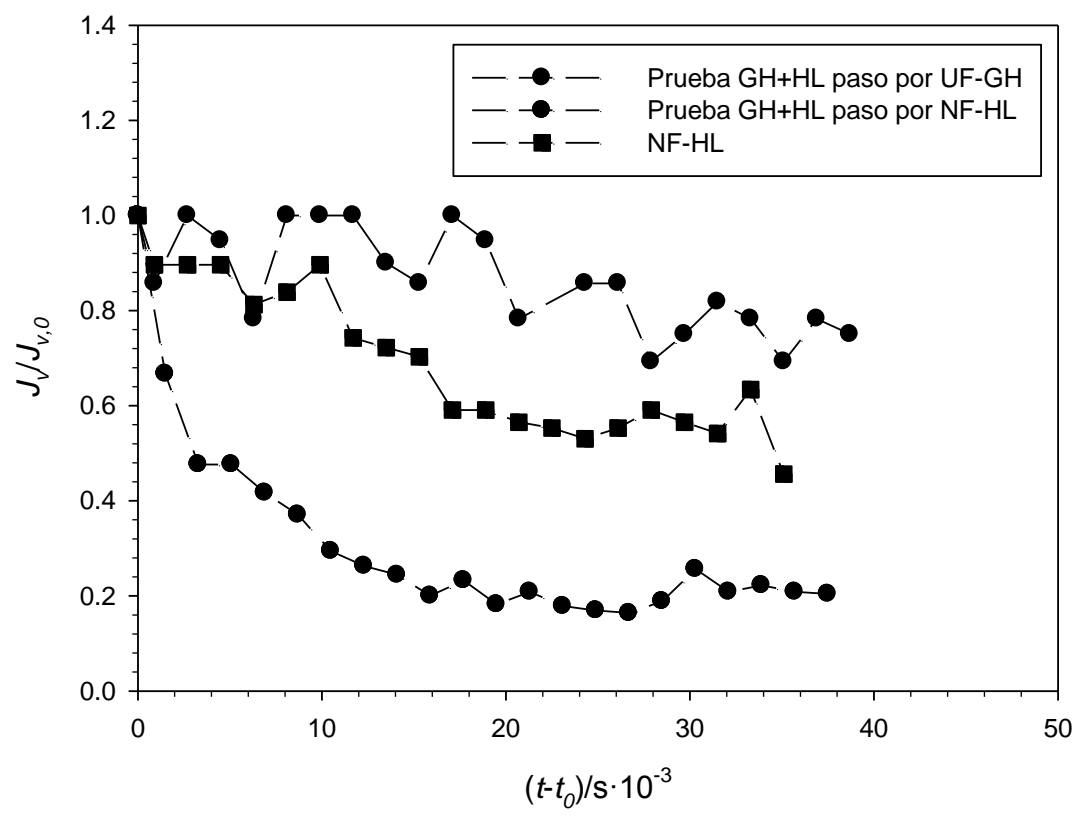

Figura 5.2 Flujo relativo frente al tiempo de filtración, para mosto Verdejo.

Podemos comprobar cómo el flujo de mosto en términos del flujo inicial $\left(J_{v} / J_{v, 0}\right)$ frente al tiempo, cae en los dos tipos de mosto filtrados de forma similar. La caída es más importante en el caso de la membrana de nanofiltración HL que en el caso de la membrana de ultrafiltración $\mathrm{GH}$, lo que puede explicarse por la mayor retención de sustancias que conducen a una mayor acumulación (capa de gel y deposición) y por tanto un mayor ensuciamiento con al paso del mosto [4]. Además, con los dos tipos de mosto, la caída de flujo relativo con $\mathrm{HL}$ es mayor en la prueba en la que se pasa previamente por el módulo de ultrafiltración $\mathrm{GH}$, que cuando se utiliza en solitario. Este efecto ya lo hemos visto en el capítulo anterior, aunque de forma menos acusada. Posiblemente, los grandes coloides presentes en el mosto protegen la membrana de nanofiltración de otras moléculas de menor tamaño, que reducen el flujo cuando se enfrentan directamente a la superficie de la membrana de nanofiltración. 


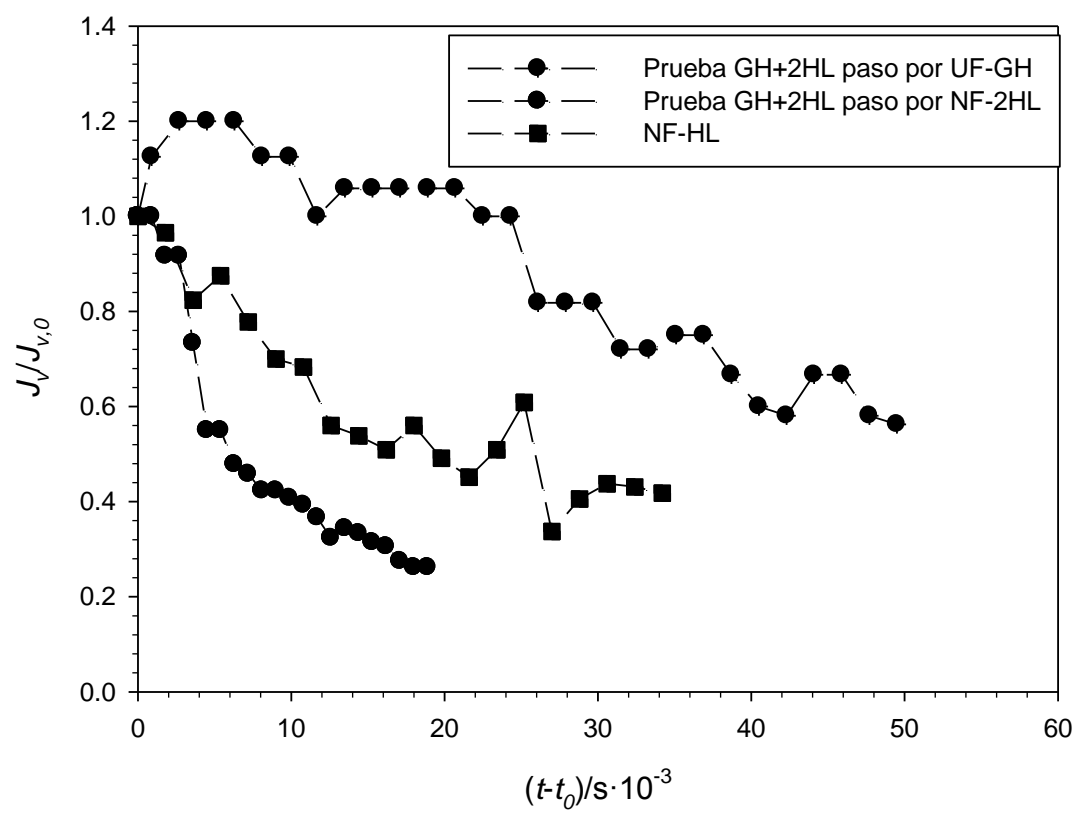

Figura 5.3 Flujo relativo frente al tiempo de filtración, para mosto Tinta de Toro.

\subsection{RETENCIÓN DE AZÚCAR}

Aplicando las ecuaciones de los modelos de retención indicados en el capítulo 2 (apartado 2.2), se obtienen los datos de retención observada y verdadera de los módulos utilizados.

Durante este proceso de filtración, representado en las figuras 5.2 y 5.3 , se realizan medidas de concentración con periodicidad de 30 minutos en todas las pruebas, excepto en la filtración $\mathrm{GH}+2 \mathrm{HL}$ del mosto Tinta de Toro. En este caso, el paso por los dos módulos de nanofiltración HL se mide tanto la concentración como el flujo de permeado cada 15 minutos. Este menor tiempo de medida, se debe al aumento de la velocidad de filtración que tiene lugar por el menor ensuciamiento inicial de los módulos de nanofiltración HL, como consecuencia del paso previo del mosto por la membrana de ultrafiltración $\mathrm{GH}$.

El comportamiento de la concentración y el flujo respecto al tiempo es opuesto. En el caso de la concentración aumenta respecto al tiempo al aumentar la concentración de alimentación en el tanque de alimentación; por el contrario, el flujo disminuye respecto al tiempo como consecuencia del ensuciamiento, el efecto de la presión osmótica y la polarización en la superficie de la membrana. Por todo ello, la retención tanto para el mosto Verdejo como para el mosto Tinta de Toro disminuye en el proceso de filtración. 


\subsection{1) Mosto Verdejo}

En la figura 5.4 se puede comprobar cómo disminuye la retención de los módulos de membrana a lo largo del tiempo de filtración.

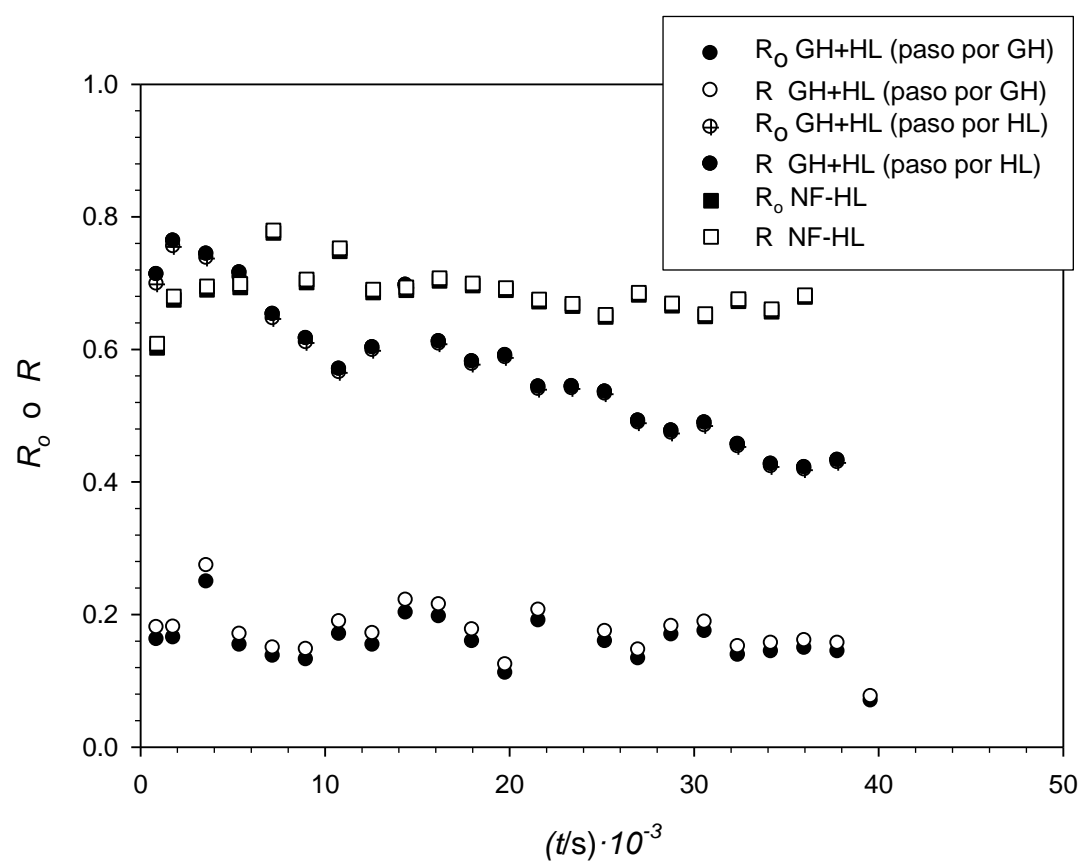

Figura 5.4 Retención observada y retención verdadera del mosto Verdejo.

En todas las pruebas realizadas con el mosto Verdejo, podemos ver como los valores de retención verdadera son ligeramente mayores que los de retención observada como sucedía en las campañas anteriores. La retención de la membrana de nanofiltración $\mathrm{HL}$ (en las dos pruebas realizadas) es lógicamente mayor que la de la membrana de ultrafiltración $\mathrm{GH}$.

Para la prueba $\mathrm{GH}+\mathrm{HL}$ se tendrían que sumar los porcentajes de retención de las dos membranas, por lo que obtendríamos con esta prueba una retención similar a la del módulo de nanofiltración HL en solitario. En cualquier caso, si comparamos la retención de azúcar con la membrana $\mathrm{HL}$ cuando el mosto ha pasado previamente por la $\mathrm{GH}$ y cuando no, vemos que la retención de azúcar es mayor en el segundo caso. Este hecho corrobora la presencia de una pseudomembrana formada por sustancias de alto peso molecular (partículas, coloides, etc.) que son eliminadas por la membrana $\mathrm{GH}$.

Más adelante se valorará si el sistema de eliminación de azúcar $\mathrm{GH}+\mathrm{HL}$ es viable, teniendo en cuenta la retención que presenta frente a otros compuestos, en comparación con el sistema de nanofiltración HL por sí solo. 


\subsection{2) Mosto Tinta de Toro}

Si representamos la retención observada y verdadera del mosto Tinta de Toro (figura 5.5), podemos comprobar cómo el comportamiento es prácticamente el mismo que el que obteníamos en la filtración del mosto Verdejo. En todas las pruebas tenemos valores ligeramente mayores de la retención verdadera respecto a la retención observada. La única diferencia respecto a la filtración del mosto blanco, es que en la prueba $\mathrm{GH}+2 \mathrm{HL}$ tendríamos una retención mayor al sumar los dos porcentajes de retención, que la de los módulos de nanofiltración $\mathrm{HL}$ en solitario. Sin embargo, el aumento de coste y tiempo de esta doble filtración también se tendría que tener en cuenta si finalmente se elige este sistema de filtración.

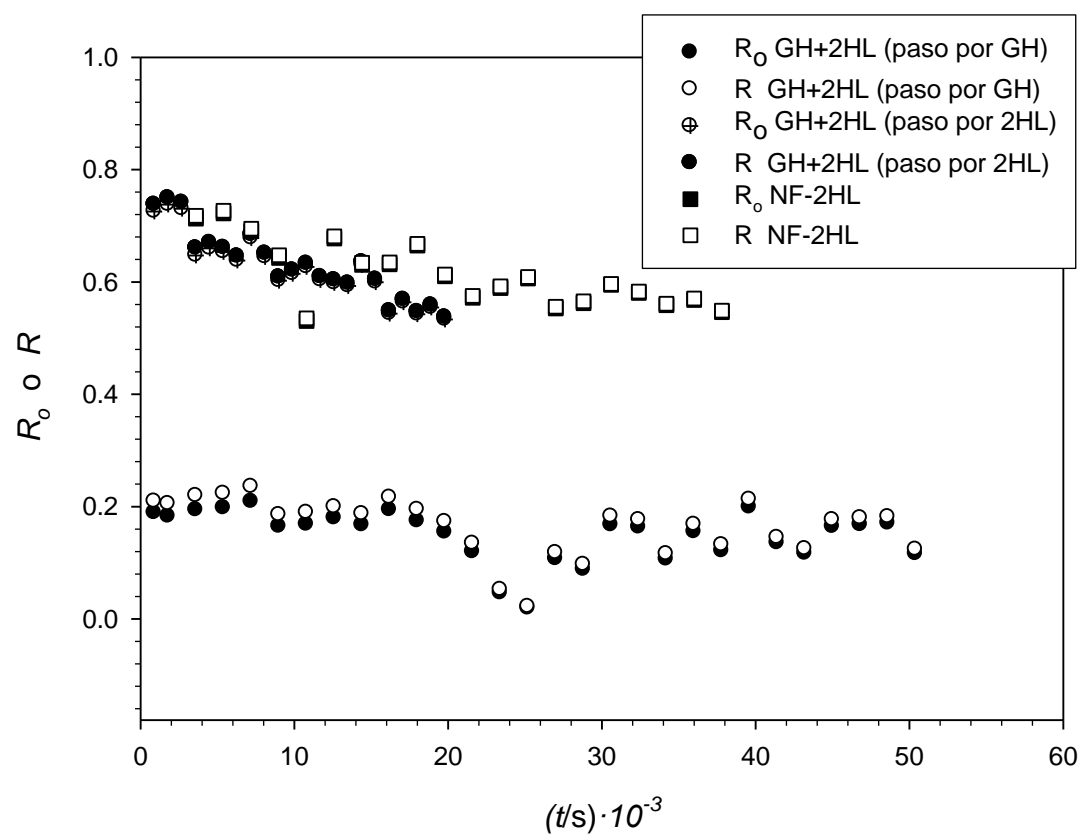

Figura 5.5 Retención observada y retención verdadera del mosto Tinta de Toro.

Comparando las retenciones entre el mosto blanco y tinto, tenemos retenciones ligeramente más elevadas con el mosto blanco, lo que puede deberse a las condiciones de filtración de cada mosto. Se utilizan presiones más elevadas para la filtración de mosto tinto (ver tabla 5.1).

La cuestión de si la doble filtración en Verdejo $(\mathrm{GH}+\mathrm{HL})$ o en Tinta de Toro $(\mathrm{GH}+2 \mathrm{HL})$ es factible la valoraremos más adelante, pero como podemos comprobar, en términos de retención no se produce un aumento tras esa doble filtración. Además la caída de flujo es mayor para la membrana de nanofiltración $\mathrm{HL}$ después de utilizar la de ultrafiltración $\mathrm{GH}$ que si se utiliza por separado. Sin embargo, se deben tener en 
cuenta otros factores como la retención de otros compuestos o precursores que pueden mejorar el perfil sensorial del vino.

\subsection{RENDIMIENTO DE LA FILTRACIÓN}

Utilizando los datos de concentración y caída de flujo en las filtraciones de los mostos Verdejo y Tinta de Toro, podremos calcular el rendimiento de filtración, tanto en términos de reducción de concentración de azúcar como de pérdida de volumen, cuando el proceso de filtración ha finalizado.

\subsection{1) Concentración de azúcar}

Para conocer el rendimiento de las filtraciones en términos de concentración, se utilizan los datos de azúcar del método enzimático, que se presentarán en las tablas 5.5 y 5.6. Conocidas las concentraciones de azúcar en los tanques de permeado y retenido al finalizar la filtración ( $c_{p}^{t}$ y $c_{r}^{t}$ respectivamente) y la concentración de alimentación antes del comienzo de la misma $\left(c_{0}^{t}\right)$ se podrán calcular los porcentajes de reducción de azúcar, $r$, conseguidos tras cada proceso de filtración y que se muestran en la tabla 5.4 .

Tabla 5.4 Reducción de azúcar en los procesos de filtración del mosto Verdejo y mosto Tinta de Toro.

\begin{tabular}{|c|c|c|c|c|}
\cline { 2 - 5 } \multicolumn{1}{c|}{} & \multicolumn{2}{|c|}{ Mosto Blanco (\%) } & \multicolumn{2}{c|}{ Mosto Tinto (\%) } \\
\cline { 2 - 5 } & UF-GH + NF-HL & NF-HL & UF-GH + 2 NF-HL & 2 NF-HL \\
\hline $\begin{array}{c}\text { Proceso de } \\
\text { filtración } \\
\boldsymbol{r}=\mathbf{1}-\frac{\boldsymbol{c}_{\boldsymbol{t}}^{\boldsymbol{t}}}{\boldsymbol{c}_{\boldsymbol{r}}^{\boldsymbol{t}}} \mathbf{1 0 0}\end{array}$ & 69.76 & 66.15 & 62.30 & 51.24 \\
\hline $\begin{array}{c}\text { Mosto Inicial } \\
\boldsymbol{r}=\mathbf{1}-\frac{\boldsymbol{c}_{\boldsymbol{p}}^{\boldsymbol{t}}}{\boldsymbol{c}_{\mathbf{0}}^{\mathbf{t}}} \mathbf{1 0 0}\end{array}$ & 57.89 & 57.89 & 58.18 & 42.91 \\
\end{tabular}

Para una misma prueba de filtración (utilizando los mismos módulos de membrana), tenemos una reducción de azúcar ligeramente mayor para el mosto blanco que para el tinto, lo que se corresponde con las retenciones ligeramente mayores para el mosto Verdejo encontradas en las figuras 5.4 y 5.5 . 


\subsection{2) Volumen final para el mosto Verdejo}

Conociendo el volumen de vino que podemos elaborar con el permeado obtenido de las distintas pruebas de filtración, podremos calcular el rendimiento en términos de volumen de cada proceso de filtración. Si tenemos en cuenta la concentración de azúcar del permeado y el testigo, podremos calcular la pérdida de volumen en el proceso de reducción alcohólica.

Debido a la forma de elaboración de los vinos, en esta campaña sólo podemos calcular el rendimiento en volumen del mosto Verdejo. Para el mosto Tinta de Toro en lugar de separar la pasta del mosto antes de producirse la filtración, lo que se ha realizado es procesar la uva necesaria para obtener el volumen que se va a filtrar y la pasta se desecha. Una vez que tenemos los permeados de las pruebas de filtración se procesa el resto de la uva que ha permanecido en una cámara de frio y se intercambia el volumen de permeado necesario para disminuir $2 \%$ vol el vino final por el mosto testigo que se acaba de obtener. De esta forma intentamos evitar la degradación de la pasta, al mantenerla por separado en la cámara de frío desde que se procesa la uva hasta que se realizan las mezclas con los permeados como en las campañas anteriores. Esto se ha hecho así porque se trata de una prueba experimental. En un proceso real en bodega, con los sistemas de filtración en funcionamiento, el almacenamiento de la pasta no sería necesario porque se realizaría la filtración de forma inmediata en el momento en que se dispone del mosto.

La pérdida de volumen de mosto Verdejo que tiene lugar con la prueba $\mathrm{GH}+\mathrm{HL}$ es de $26.25 \%$ y con la prueba HL es de $37.19 \%$. Utilizando únicamente el módulo de membrana $\mathrm{HL}$ tenemos más pérdida de volumen ya que la reducción de azúcar es menor. Pero además de la retención de azúcar, la pérdida de volumen depende del volumen de retenido que se elimina por no ser utilizado en la filtración, que en nuestro caso también es mayor para la prueba en la que se utiliza la membrana HL en solitario.

\section{ANÁLISIS QUÍMICOS}

Dada la gran cantidad de compuestos que tienen los mostos y vinos agrupamos los análisis químicos en tres familias: azúcares, sustancias de pequeño tamaño y sustancias de gran tamaño. 


\subsection{ANÁLISIS DE MOSTOS}

Se analizarán tanto el mosto testigo, como los permeados y retenidos.

\section{$\underline{\text { Azúcares }}$}

La concentración de azúcar se ha analizado con diferentes métodos como indicamos en el apartado 2.4. En las tablas 5.5 y 5.6, se recogen los valores para el mosto Testigo $(T)$ y para el permeado $(P)$ y el retenido $(R)$, en las diferentes pruebas.

En ambos mostos tenemos resultados similares para la concentración final de azúcar, si tenemos en cuenta los errores de los propios métodos utilizados (refractométrico, polarimétrico y enzimático).

Tabla 5.5 Concentración de azúcar total determinada por refractometría y polarimetría, glucosa y fructosa determinado por el método enzimático, índice de azúcares y alcohol probable, del mosto Verdejo.

\begin{tabular}{|c|c|c|c|c|c|c|c|c|}
\hline \multicolumn{2}{|c|}{ Mosto Verdejo } & $\begin{array}{c}\text { Azúcar } \\
\text { (a) }\end{array}$ & $\begin{array}{l}\text { Azúcar } \\
\text { (b) }\end{array}$ & $\begin{array}{c}\text { Glucosa } \\
\text { (c) }\end{array}$ & $\begin{array}{c}\text { Fructosa } \\
\text { (c) }\end{array}$ & $\begin{array}{c}\text { (Glucosa } \\
+ \text { Frutosa) } \\
\text { (c) }\end{array}$ & $\begin{array}{c}\text { Glucosa } \\
/ \\
\text { Frutosa }\end{array}$ & $\begin{array}{c}\text { Alcohol } \\
\text { Probable } \\
\text { (d) }\end{array}$ \\
\hline & & g/L & g/L & g/L & g/L & g/L & & \%vol \\
\hline \multicolumn{2}{|r|}{$\mathrm{T}$} & 206.8 & 215.74 & 89.5 & 119.5 & 209.0 & 0.749 & 12.4 \\
\hline \multirow{2}{*}{$\begin{array}{c}\mathrm{GH}+\mathrm{HL} \\
\text { (paso por } \\
\mathrm{GH} \text { ) }\end{array}$} & $\mathrm{P}(\mathrm{GH})$ & 164.8 & 190.35 & 83.0 & 92.0 & 175.0 & 0.902 & 10.4 \\
\hline & $\mathrm{R}(\mathrm{GH})$ & 263.6 & 256.35 & 136.0 & 119.0 & 255.0 & 1.143 & 15.2 \\
\hline \multirow{2}{*}{$\begin{array}{c}\mathrm{GH}+\mathrm{HL} \\
\text { (paso por } \\
\mathrm{HL} \text { ) }\end{array}$} & $\mathrm{P}(\mathrm{GH}+\mathrm{HL})$ & 85.6 & 88.83 & 48.0 & 40.0 & 88.0 & 1.200 & 5.2 \\
\hline & $\mathrm{R}(\mathrm{GH}+\mathrm{HL})$ & 304.1 & $--{ }^{1}$ & 142.0 & 149.0 & 291.0 & 0.953 & 17.3 \\
\hline \multirow{2}{*}{$\mathrm{HL}$} & $\mathrm{P}(\mathrm{HL})$ & 84.5 & 68.53 & 50.0 & 38.0 & 88.0 & 1.316 & 5.2 \\
\hline & $\mathrm{R}(\mathrm{HL})$ & 249.7 & 269.04 & 216.0 & 44.0 & 260.0 & 4.909 & 15.4 \\
\hline
\end{tabular}

(a) Tablas de equivalencia del refractómetro Brix-molaridad según Reglamento CEE 2676/90.

(b) Concentración obtenida mediante método polarimétrico.

(c) Concentración obtenida mediante método enzimático.

(d) \%vol estimado según el Reglamento CEE 2676/90.

${ }^{1}$ Valor no determinado, excesiva turbidez para medirlo por polarimetría a pesar de la dilución. 
Tabla 5.6 Concentración de azúcar total determinada por refractometría y polarimetría, glucosa y fructosa determinado por el método enzimático, índice de azúcares y alcohol probable, del mosto Tinta de Toro.

\begin{tabular}{|c|c|c|c|c|c|c|c|c|}
\hline Mosto T & nta de Toro & $\begin{array}{c}\text { Azúcar } \\
\text { (a) }\end{array}$ & $\begin{array}{c}\text { Azúcar } \\
\text { (b) }\end{array}$ & $\begin{array}{c}\text { Glucosa } \\
\text { (c) }\end{array}$ & $\begin{array}{c}\text { Fructosa } \\
\text { (c) }\end{array}$ & $\begin{array}{c}\text { (Glucosa } \\
+ \text { Frutosa) } \\
\text { (c) }\end{array}$ & $\begin{array}{c}\text { Glucosa } \\
/ \\
\text { Frutosa }\end{array}$ & $\begin{array}{l}\text { Alcohol } \\
\text { Probable } \\
\text { (d) }\end{array}$ \\
\hline & & g/L & g/L & g/L & g/L & $g / L$ & & $\%$ vol \\
\hline & $\mathrm{T}$ & 255.0 & 307.11 & 128.0 & 147.0 & 275.0 & 0.87 & 15.7 \\
\hline $\mathrm{GH}+2 \mathrm{HL}$ & $\mathrm{P}(\mathrm{GH})$ & 228.7 & 256.35 & 115.5 & 135.5 & 251.0 & 0.85 & 14.3 \\
\hline $\mathrm{GH})$ & $\mathrm{R}(\mathrm{GH})$ & 335.7 & 350.25 & 173.0 & 174.0 & 347.0 & 0.99 & 19.8 \\
\hline $\mathrm{GH}+2 \mathrm{HL}$ & $P(G H+2 H L)$ & 96.1 & $--{ }^{1}$ & 56.0 & 59.0 & 115.0 & 0.95 & 6.6 \\
\hline $\mathrm{HL})$ & $\mathrm{R}(\mathrm{GH}+2 \mathrm{HL})$ & 287.3 & $--{ }^{1}$ & 142.0 & 163.0 & 305.0 & 0.87 & 17.4 \\
\hline & $\mathrm{P}(\mathrm{HL})$ & 121.8 & 124.37 & 84.5 & 72.5 & 157.0 & 1.17 & 9.0 \\
\hline & $\mathrm{R}(\mathrm{HL})$ & 299.3 & 329.95 & 144.0 & 178.0 & 322.0 & 0.81 & 18.4 \\
\hline
\end{tabular}

(a) Tablas de equivalencia del refractómetro Brix-molaridad según Reglamento CEE $2676 / 90$

(b) Concentración obtenida mediante método polarimétrico.

(c) Concentración obtenida mediante método enzimático.

(d) \%vol estimado según experiencias de la Estación Enológica del ITACyL.

${ }^{1}$ Valor no determinado, excesiva turbidez para medirlo por polarimetría a pesar de la dilución.

Para los dos mostos, las filtraciones realizadas reducen la concentración de azúcar total en los permeados y por ello el grado alcohólico probable calculado. La relación de glucosa y fructosa no sufre mucha variación en ninguno de los dos mostos, excepto para la prueba de nanofiltración HL con el mosto Verdejo. En este caso, podemos ver que esta relación en la fracción del retenido aumenta mucho (4.909), por la concentración elevada de glucosa. Esto puede deberse a un error experimental, ya que en el resto de casos y en el resto de campañas la concentración de glucosa y fructosa siempre ha sido similar.

El hecho de utilizar la membrana de ultrafiltración GH con el mosto de Verdejo antes del paso por la membrana de nanofiltración HL, no aporta ninguna reducción de 
azúcar adicional al proceso global, como podemos comprobar en la tabla 5.5. La concentración de azúcar en los permeados después de la membrana de HL es la misma en ambos casos. Si bien, en el mosto Tinta de Toro tenemos una concentración de azúcar menor cuando se utiliza la el doble paso $\mathrm{GH}+\mathrm{HL}$ que si utilizamos sólo la membrana HL.

El grado alcohólico del vino Verdejo pasaría de 12.4 grados a vinos de 5.2 grados después de la filtración. El vino Tinta de Toro pasaría de 15.7 grados a vinos entre 6.6 y 9.0 grados, dependiendo de si tenemos una etapa previa de ultrafiltración o no. Con estos datos, calcularíamos el volumen de permeado que se debe mezclar con el mosto testigo para bajar 2 grados alcohólicos en el vino final.

\subsection{1) Sustancias de bajo peso molecular}

Las principales sustancias de bajo peso molecular se presentan en las tablas 5.7 y 5.8 .

Tabla 5.7 $\quad p H$, acidez total (AT), ácido tartárico (TH2), ácido málico (MH2) y potasio en el mosto Verdejo.

\begin{tabular}{|c|c|c|c|c|c|c|}
\hline \multirow{2}{*}{ Mosto Verdejo } & pH & AT & TH2 & MH2 & Potasio \\
\cline { 2 - 7 } & & $\mathbf{g} / \mathbf{L}$ & $\mathbf{g} / \mathbf{L}$ & $\mathbf{g} / \mathbf{L}$ & $\mathbf{~} \mathbf{g} / \mathbf{L}$ \\
\hline \multicolumn{2}{|c|}{$\mathrm{T}$} & 3.78 & 3.57 & 5.2 & 2.0 & 1470 \\
\hline \multirow{2}{*}{$\begin{array}{c}\mathrm{GH}+\mathrm{HL} \text { (paso } \\
\text { por GH) }\end{array}$} & $\mathrm{P}(\mathrm{GH})$ & 4.39 & 2.43 & 2.5 & 2.0 & 1130 \\
\cline { 2 - 7 } & $\mathrm{R}(\mathrm{GH})$ & 3.72 & 4.13 & 5.1 & 2.6 & 1680 \\
\hline \multirow{2}{*}{$\begin{array}{c}\mathrm{GH}+\mathrm{HL}(\text { paso } \\
\text { por HL) }\end{array}$} & $\mathrm{P}(\mathrm{GH}+\mathrm{HL})$ & 4.68 & 2.16 & 1.9 & 2.0 & 1070 \\
\cline { 2 - 7 } & $\mathrm{R}(\mathrm{GH}+\mathrm{HL})$ & 3.96 & 3.11 & 4.1 & 1.8 & 1220 \\
\hline \multirow{2}{*}{$\mathrm{HL}$} & $\mathrm{P}(\mathrm{HL})$ & 3.81 & 2.91 & 2.9 & 2.3 & 1500 \\
\cline { 2 - 7 } & $\mathrm{R}(\mathrm{HL})$ & 3.78 & 3.58 & 4.6 & 2.1 & 1610 \\
\hline
\end{tabular}

En mosto Verdejo podemos comprobar cómo los valores de acidez total, ácido málico y potasio de los permeados y retenidos son similares al mosto testigo que no ha sido filtrado, teniendo en cuenta los errores experimentales. En el caso del pH y el ácido tartárico las diferencias entre las fracciones de permeado y el testigo son mayores, sobretodo en el caso de los permeados, en los que disminuye el ácido tartárico y por consiguiente aumenta el $\mathrm{pH}$ del mismo. Esto puede deberse a que, como ya hemos indicado, la retención de las sustancias de bajo peso molecular está asociada a su peso molecular y carga.

Para el pH del mosto tanto la membrana de ultrafiltración GH como la membrana de nanofiltración HL están cargadas positivamente [5], además, debemos tener en cuenta 
que muchas de estas sustancias de bajo peso molecular pueden estar asociadas a moléculas de mayor peso molecular, favoreciendo la retención por la membrana. Esto es lo que sucedería con el potasio ya que, a pesar de su bajo peso molecular $\left(M_{w}=39.1 \mathrm{~g} / \mathrm{mol}\right)$, el efecto de la carga junto con los efectos dieléctricos explicados en el capítulo 3 darían lugar a la retención de este ion.

Para el ácido tartárico $\left(\mathrm{M}_{\mathrm{W}}=150 \mathrm{~g} / \mathrm{mol}\right.$, $\left.\mathrm{pK}=3.03\right)$ en el que la concentración de los permeados es menor que la del mosto testigo y los retenidos, podemos indicar que debido al mayor peso molecular y pK menor que el ácido málico $\left(M_{W}=134.09 \mathrm{~g} / \mathrm{mol}\right.$, $\mathrm{pK}=3.40$ ), la retención es mayor. Esto explicaría también el pH más elevado de los permeados que de los retenidos, teniendo más diferencias respecto al mosto testigo en la prueba $\mathrm{GH}_{+} \mathrm{HL}$, que en la prueba en la que sólo se usa la membrana de nanofiltración HL.

Tabla $5.8 \quad p H$, acidez total (AT), ácido tartárico (TH2), ácido málico (MH2) y potasio en el mosto Tinta de Toro.

\begin{tabular}{|c|c|c|c|c|c|c|}
\hline \multirow{2}{*}{ Mosto Tinta de Toro } & pH & AT & TH2 & MH2 & Potasio \\
\cline { 2 - 7 } & & $\mathbf{g} / \mathbf{L}$ & $\mathbf{g} / \mathbf{L}$ & $\mathbf{g} / \mathbf{L}$ & $\mathbf{~} \mathbf{g} / \mathbf{L}$ \\
\hline \multicolumn{2}{|c|}{$\mathrm{T}$} & 3.58 & 3.73 & 4.6 & 1.8 & 1460 \\
\hline \multirow{2}{*}{$\begin{array}{c}\mathrm{GH}+2 \mathrm{HL} \\
\text { paso por GH) }\end{array}$} & $\mathrm{P}(\mathrm{GH})$ & 3.63 & 2.60 & 2.3 & 1.7 & 940 \\
\cline { 2 - 7 } & $\mathrm{R}(\mathrm{GH})$ & 3.45 & 4.28 & 3.4 & 2.2 & 1210 \\
\hline $\begin{array}{c}\mathrm{GH}+2 \mathrm{HL} \\
(\text { paso por HL) }\end{array}$ & $\mathrm{P}(\mathrm{GH}+\mathrm{HL})$ & 3.62 & 2.29 & 1.9 & 1.6 & 850 \\
\cline { 2 - 7 } & $\mathrm{R}(\mathrm{GH}+\mathrm{HL})$ & 3.64 & 2.60 & 2.5 & 1.5 & 840 \\
\hline \multirow{2}{*}{$2 \mathrm{HL}$} & $\mathrm{P}(\mathrm{HL})$ & 3.60 & 2.90 & 2.7 & 1.8 & 1100 \\
\cline { 2 - 7 } & $\mathrm{R}(\mathrm{HL})$ & 3.64 & 2.94 & 3.2 & 1.6 & 1050 \\
\hline
\end{tabular}

El comportamiento para el mosto Tinto es similar al mosto Verdejo; los valores de acidez total y ácido málico de las muestras filtradas son similares a las del mosto testigo. Las variaciones de ácido tartárico son parecidas a las que se obtienen para el mosto blanco, pero en el caso del potasio tenemos variaciones respecto al mosto blanco, debido a que los polifenoles favorecen la retención del potasio por asociación [6-7], lo que además influirá en la menor variación de $\mathrm{pH}$ de los permeados respecto al mosto testigo.

\subsection{2) Familias fenólicas y color}

En los capítulos anteriores hemos estudiado la concentración de los componentes fenólicos de todas las fracciones de filtración. Pero como indicamos en el capítulo 4, lo 
verdaderamente importante es que, al realizar la mezcla de los permeados con el mosto testigo para elaborar los vinos de menor contenido alcohólico, las diferencias de estos componentes respecto al mosto testigo sean mínimas.

Como en la campaña anterior, tenemos pequeñas diferencias de concentración en Verdejo, en esta campaña se realiza el estudio únicamente de los polifenoles totales y color. Para el mosto Tinta de Toro no hemos realizado este estudio ya que la mayor parte de estos compuestos proviene de la pasta, con lo que la influencia del permeado de filtración utilizado para la mezcla es menor.

En la tabla 5.9 podemos ver las cantidades de permeado y testigo que fueron mezcladas, y en la figura 5.6 se representa la concentración de los polifenoles y la absorbancia para las mezclas y para el mosto testigo.

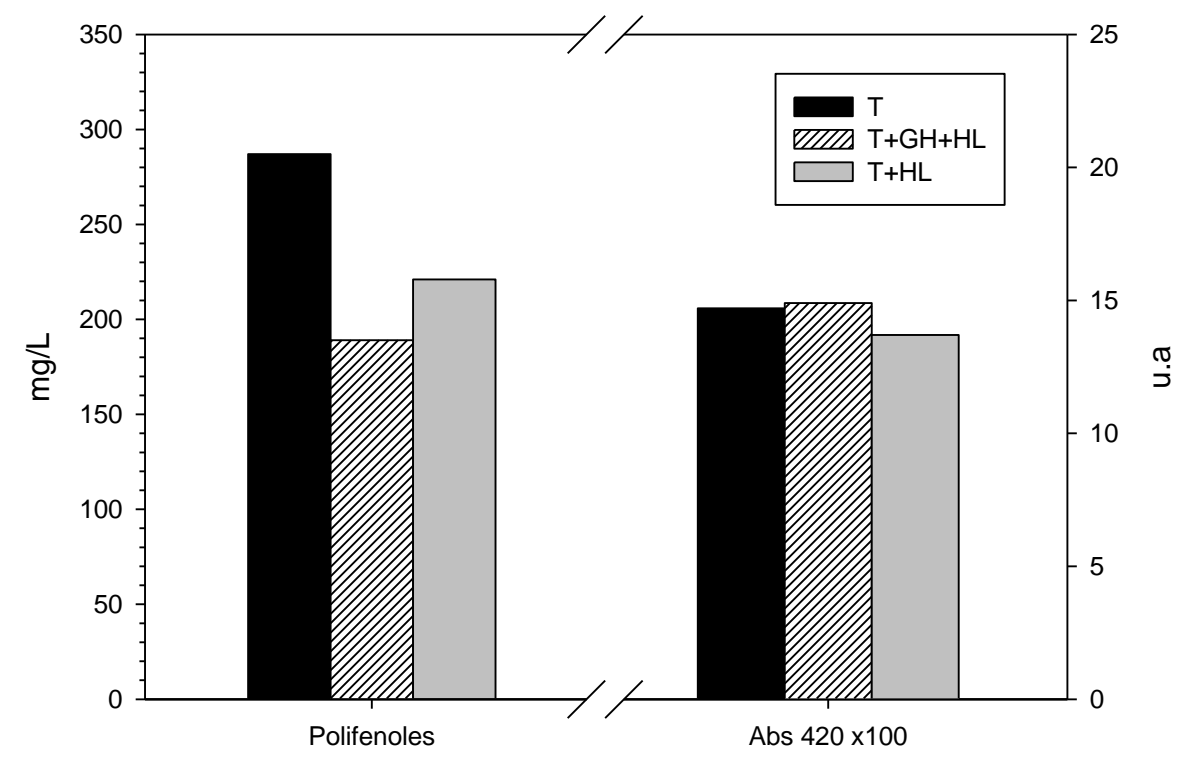

Figura 5.6 Concentración de polifenoles y absorbancia a $420 \mathrm{~nm}$ del mosto testigo (T), y las mezclas realizadas para obtener el vino de bajo grado alcohólico del mosto Verdejo.

En esta campaña tenemos más variación de polifenoles de las mezclas respecto al vino testigo que en la campaña anterior, lo que puede deberse a la mayor presión de filtración aplicada. En cuanto al color de las mezclas realizadas es prácticamente el mismo que el del vino testigo. 


\subsection{ELABORACIÓN Y ANÁLISIS DE VINOS}

Después de analizar las fracciones de filtración de los mostos, se realiza la mezcla del permeado con el testigo ( $y$ pasta en el caso del vino tinto), para que el vino final tenga dos grados alcohólicos menos. Estas mezclas se realizan en la bodega experimental de la Estación Enológica del ITACyL por personal adscrito al centro. En las tablas 5.9 y 5.10 se muestran las cantidades de permeado y testigo que fueron mezcladas para cada prueba:

Tabla 5.9 Volumen de testigo y permeado utilizadas en la fermentación del mosto Verdejo.

\begin{tabular}{|c|c|c|}
\hline $\begin{array}{c}\text { Pruebas de } \\
\text { mosto Verdejo }\end{array}$ & $\begin{array}{c}\text { Testigo } \\
\text { (L) }\end{array}$ & $\begin{array}{c}\text { Permeado } \\
\text { (L) }\end{array}$ \\
\hline $\mathrm{T}$ & 16 & \\
\hline $\mathrm{UF}-\mathrm{GH}+\mathrm{NF}-\mathrm{HL}$ & 13.2 & 2.8 \\
\hline $\mathrm{NF}-\mathrm{HL}$ & 13.2 & 2.8 \\
\hline
\end{tabular}

Tabla 5.10 Cantidad de pasta, testigo y permeado utilizadas en la fermentación del mosto Tinta de Toro.

\begin{tabular}{|c|c|c|}
\hline $\begin{array}{c}\text { Pruebas de } \\
\text { mosto Tinta de } \\
\text { Toro }\end{array}$ & $\begin{array}{c}\text { Pasta + Testigo } \\
\mathbf{( K g )}\end{array}$ & $\begin{array}{c}\text { Permeado } \\
\mathbf{( L )}\end{array}$ \\
\hline $\mathrm{T}$ & 16 & \\
\hline UF-GH + 2 NF-HL & 13.2 & 2.7 \\
\hline $2 \mathrm{NF}-\mathrm{HL}$ & 12.8 & 3 \\
\hline
\end{tabular}

\subsection{1) Vino Verdejo}

Se realiza la fermentación alcohólica de las mezclas del mosto Verdejo por duplicado en tanques de 16 litros. Como en las campañas anteriores, se inoculan levaduras comerciales y se controla la temperatura de fermentación. Cuando la fermentación alcohólica ha finalizado, los vinos se embotellan y se almacenan para su análisis. Los análisis se realizaron por duplicado, la media de estos valores se muestran en las tablas y figuras siguientes. 
Tabla 5.11 Parámetros enológicos clásicos del vino Verdejo tras la fermentación alcohólica, A. Total: acidez total; A.V: acidez volátil; TH2: ácido tartárico; MH2: ácido málico.

\begin{tabular}{|c|c|c|c|c|c|c|c|c|}
\hline $\begin{array}{c}\text { Vino } \\
\text { Verdejo }\end{array}$ & $\mathbf{p H}$ & A.Total & $\mathbf{A . V}$. & $\mathbf{T H 2}$ & $\mathbf{M H 2}$ & Potasio & Azúcar & Grado \\
\cline { 2 - 8 } & & $\mathbf{g} / \mathbf{L}$ & $\mathbf{g} / \mathbf{L}$ & $\mathbf{g} / \mathbf{L}$ & $\mathbf{g} / \mathbf{L}$ & $\mathbf{m g} / \mathbf{L}$ & $\mathbf{g} / \mathbf{L}$ & $\mathbf{v} / \mathbf{v}$ \\
\hline $\mathrm{T}$ & 3.39 & 4.7 & 0.23 & 2.2 & 1.6 & 770 & 0.17 & 12.93 \\
\hline $\mathrm{T}+\mathrm{GH}+\mathrm{HL}$ & 3.34 & 4.5 & 0.12 & 2.3 & 1.6 & 755 & 0.10 & 11.67 \\
\hline $\mathrm{T}+\mathrm{HL}$ & 3.29 & 4.7 & 0.23 & 2.2 & 1.7 & 755 & 0.10 & 11.61 \\
\hline
\end{tabular}

Los vinos elaborados con las mezclas del permeado de las filtraciones y el mosto testigo tienen $1.3 \%$ vol menos que el testigo. En los dos vinos, la reducción de alcohol lograda ha sido menor que los $2 \%$ vol propuestos ya que es muy difícil calcular las proporciones exactas de mosto a mezclar basándonos en la cantidad de azúcar de los mismos. Además como ya explicamos en campañas anteriores, los procesos de fermentación dependen de muchos factores además de esta concentración de azúcar, como puede ser la cantidad de nutrientes presentes y necesarios para las levaduras, las plagas, las prácticas vitícolas realizadas en las parcelas, etc. [7].

En la tabla 5.11 podemos comprobar que los parámetros enológicos estudiados para las dos pruebas nanofiltradas y el testigo son similares a excepción del grado alcohólico. Del resto de parámetros, la mayor diferencia se encuentra en la acidez volátil de la prueba $\mathrm{GH}+\mathrm{HL}$ en la que el valor es la mitad que en el mosto testigo y en la prueba de filtración en la que sólo se utiliza el módulo de membrana de nanofiltración. Sin embargo, estos niveles obtenidos de acidez volátil no son perjudiciales para las características organolépticas del vino [7].

El estudio de los polifenoles y los compuestos relacionados con el color para el vino testigo y los de baja graduación se muestran en las figuras 5.7 y 5.8 .

Tanto en la prueba en la que se utiliza previamente el módulo de ultrafiltración GH seguido del módulo de nanofiltración $\mathrm{HL}(\mathrm{T}+\mathrm{GH}+\mathrm{HL})$, como en la que se utiliza únicamente el módulo de nanofiltración $\mathrm{HL}(\mathrm{T}+\mathrm{HL})$, tenemos resultados similares de los componentes relacionados con el color (polifenoles, catequinas, taninos, ésteres tartáricos, flavonoles y absorbancia a $420 \mathrm{~nm}$ ). Ante las pequeñas diferencias, la 
prueba $(T+G H+H L)$ suele tener valores más elevados de estos compuestos que la $(\mathrm{T}+\mathrm{HL})$.

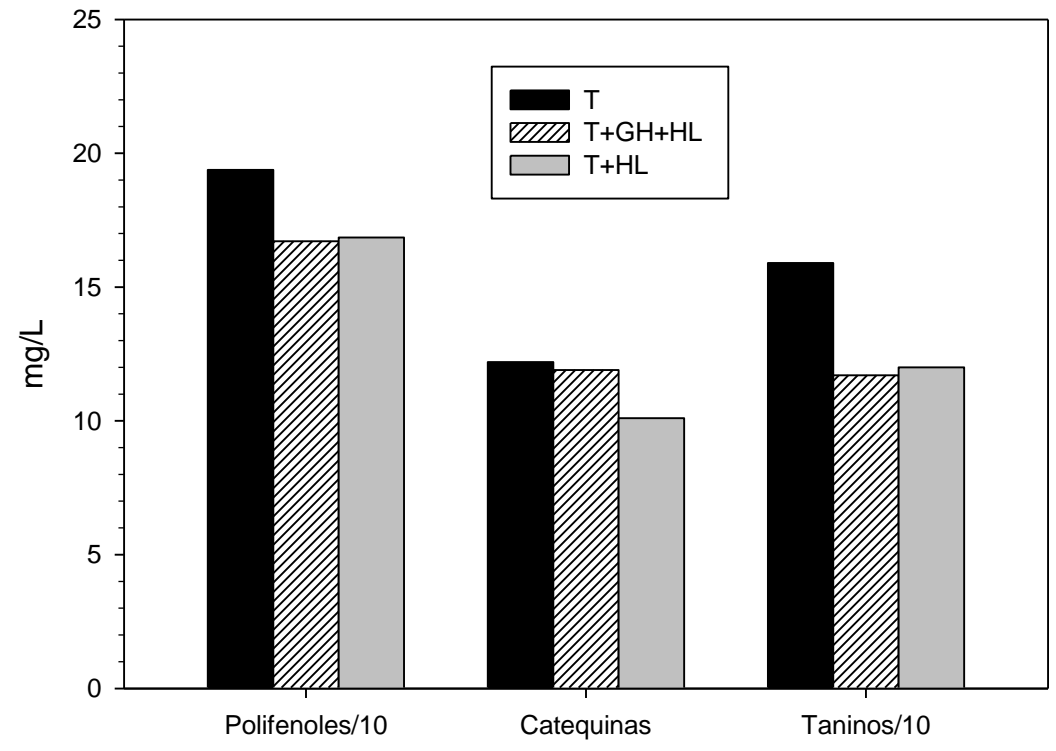

Figura 5.7 Contenido en polifenoles totales, catequinas y taninos de los distintos vinos Verdejo elaborados.

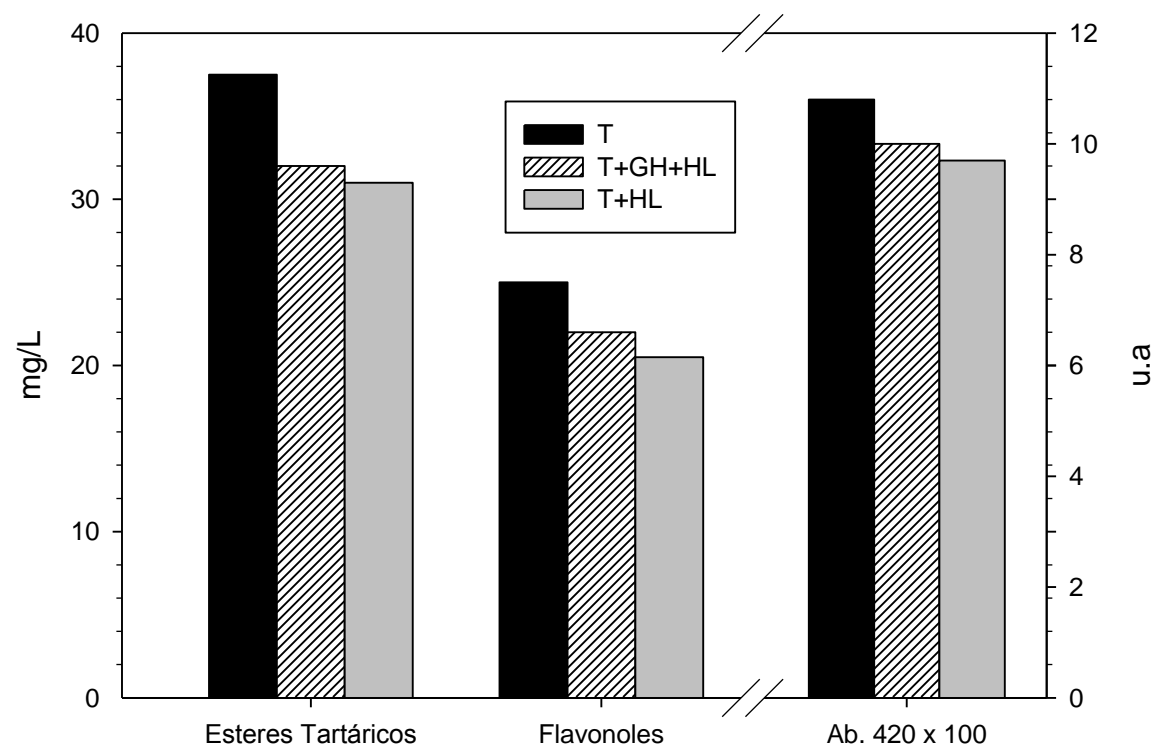

Figura 5.8 Contenido en ésteres tartáricos, flavonoles y color (Absorbancia a 420 $n m)$ de los distintos vinos Verdejo elaborados. 
Respecto al mosto sin tratar, las pruebas realizadas presentan variaciones superiores al $20 \%$, únicamente en los taninos, debido a su gran tamaño y a su capacidad de polimerización con proteínas y polisacáridos [8].

\subsection{2) Vino Tinta de Toro}

Como indicamos en el apartado 3.4.2 para el mosto Tinta de Toro se procesa la uva necesaria para obtener el volumen que se va a filtrar y la pasta se desecha. Una vez que tenemos los permeados de las pruebas de filtración, se procesa el resto de la uva que ha permanecido en una cámara de frio y se intercambia el volumen de permeado necesario para disminuir $2 \%$ vol el vino final, por el mosto testigo que se acaba de obtener (ver tabla 5.10). Las fermentaciones se realizaron con las siguientes características:

- Fermentaciones alcohólicas llevadas a cabo por duplicado en tanques de 35 litros e inoculando levaduras comerciales. Después de tener lugar la fermentación alcohólica, se retira la pasta y se trasiega el vino a depósitos siempre llenos.

- Fermentación maloláctica realizadas en tanques de 16 litros por duplicado, se siembra el mosto con bacterias para no tener problemas en la finalización de la fermentación maloláctica.

Al finalizar cada una de las dos fermentaciones se analizan los parámetros enológicos de todos los depósitos, mostrando en las tablas 5.12 y 5.13 las medias de las dos réplicas.

Tabla 5.12 Parámetros enológicos clásicos del vino Tinta de Toro tras la fermentación alcohólica, A.Total: acidez total; A. V: acidez volátil; TH2: ácido tartárico; MH2: ácido málico.

\begin{tabular}{|c|c|c|c|c|c|c|c|c|}
\hline $\begin{array}{c}\text { Vino Tinta } \\
\text { de Toro }\end{array}$ & $\mathbf{p H}$ & A. Total & A.V. & TH2 & MH2 & Potasio & Azúcar & Grado \\
\cline { 2 - 9 } & & $\mathbf{g} / \mathbf{L}$ & $\mathbf{g} / \mathbf{L}$ & $\mathbf{g} / \mathbf{L}$ & $\mathbf{g} / \mathbf{L}$ & $\mathbf{m g} / \mathbf{L}$ & $\mathbf{g} / \mathbf{L}$ & $\mathbf{v} / \mathbf{v}$ \\
\hline $\mathrm{T}$ & 3.54 & 6.79 & 0.61 & 0.92 & 1.73 & 1250 & 1.46 & 15.3 \\
\hline $\mathrm{T}+\mathrm{GH}+2 \mathrm{HL}$ & 3.54 & 6.29 & 0.34 & 1.14 & 2.60 & 1285 & 1.30 & 13.6 \\
\hline $\mathrm{T}+2 \mathrm{HL}$ & 3.62 & 6.13 & 0.28 & 0.91 & 2.80 & 1375 & 1.30 & 14.0 \\
\hline
\end{tabular}


Tabla 5.13 Parámetros enológicos clásicos del vino Tinta de Toro tras la fermentación maloláctica, A.Total: acidez total; A.V: acidez volátil; TH2: ácido tartárico; MH2: ácido málico.

\begin{tabular}{|c|c|c|c|c|c|c|c|c|}
\hline $\begin{array}{c}\text { Vino Tinta } \\
\text { de Toro }\end{array}$ & $\mathbf{p H}$ & A. Total & A.V. & TH2 & MH2 & Potasio & Azúcar & Grado \\
\cline { 2 - 9 } & & $\mathbf{g} / \mathbf{L}$ & $\mathbf{g} / \mathbf{L}$ & $\mathbf{g} / \mathbf{L}$ & $\mathbf{g} / \mathbf{L}$ & $\mathbf{m g} / \mathbf{L}$ & $\mathbf{g} / \mathbf{L}$ & $\mathbf{v} / \mathbf{v}$ \\
\hline $\mathrm{T}$ & 3.63 & 5.88 & 0.71 & 0.66 & 0.10 & 1030 & 1.50 & 15.1 \\
\hline $\mathrm{T}+\mathrm{GH}+2 \mathrm{HL}$ & 3.63 & 5.52 & 0.46 & 0.75 & 0.10 & 1140 & 1.40 & 13.3 \\
\hline $\mathrm{T}+2 \mathrm{HL}$ & 3.78 & 5.15 & 0.47 & 0.67 & 0.10 & 1325 & 1.30 & 13.5 \\
\hline
\end{tabular}

Tanto después de la fermentación alcohólica como después de la fermentación maloláctica las diferencias entre los parámetros enológicos de las pruebas realizadas respecto al vino sin filtrar son mínimas. Sólo son significativas en el grado alcohólico, que es lo que pretendíamos modificar en nuestro trabajo.

Como ya indicamos en el capítulo anterior, al realizar la fermentación maloláctica hay varios parámetros que se modifican por actuación de las bacterias, como son principalmente el ácido málico, la acidez volátil y la acidez total. El ácido tartárico también disminuye en una pequeña proporción para formar ácido láctico por la acción de estas bacterias [9].

En las figuras 5.9 y 5.10 , se muestran las concentraciones de los compuestos polifenólicos y el color para los vinos de baja graduación y el vino testigo. En esta campaña no realizamos análisis de los ésteres tartáricos y flavonoles en tintos ya que en la campaña anterior ya se comprobó que no se obtenían diferencias respecto al vino testigo. Tampoco se realizan los análisis de grado de polimerización de los antocianos porque ya explicamos en la campaña anterior que los pequeños cambios producidos son consecuencia del proceso de filtración (ver figura 4.18).

En todos los compuestos analizados de los vinos tratados tenemos una concentración similar al vino testigo. Si comparamos las dos pruebas de filtración realizadas, la concentración de antocianos y catequinas es prácticamente la misma. En el caso de polifenoles hay más diferencia puesto que la filtración por una membrana de ultrafiltración seguida de una membrana de nanofiltración retendrá más estos compuestos de alto peso molecular que el paso por una única membrana. En cuanto a los taninos, que tengamos más concentración en los vinos de baja graduación que en el propio testigo puede deberse a fenómenos de oxidación en la que se formarán polímeros y pigmentos insolubles [10]. 


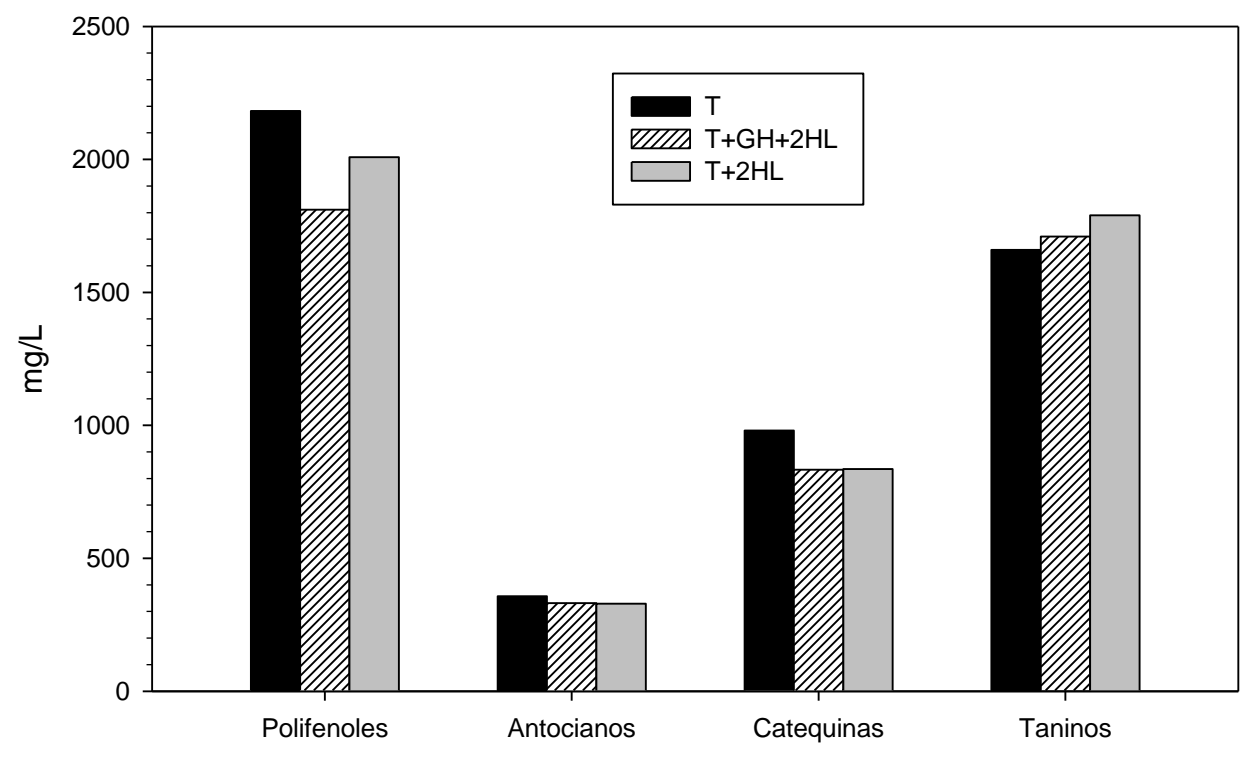

Figura 5.9 Contenido en polifenoles totales, antocianos, catequinas y taninos, de los distintos vinos elaborados de la variedad Tinta de Toro.

Si comparamos el índice de color, la tonalidad y los porcentajes de color de los vinos de baja graduación respecto al vino testigo, podemos comprobar que tenemos un perfil similar entre los tres vinos (el testigo y las dos pruebas realizadas). Al igual que en la campaña anterior, las variaciones en los porcentajes de color son menores al 4\%, por lo que podríamos indicar que analíticamente, el color del vino no se ve modificado tras los tratamientos de ultra- y nano-filtración utilizados.

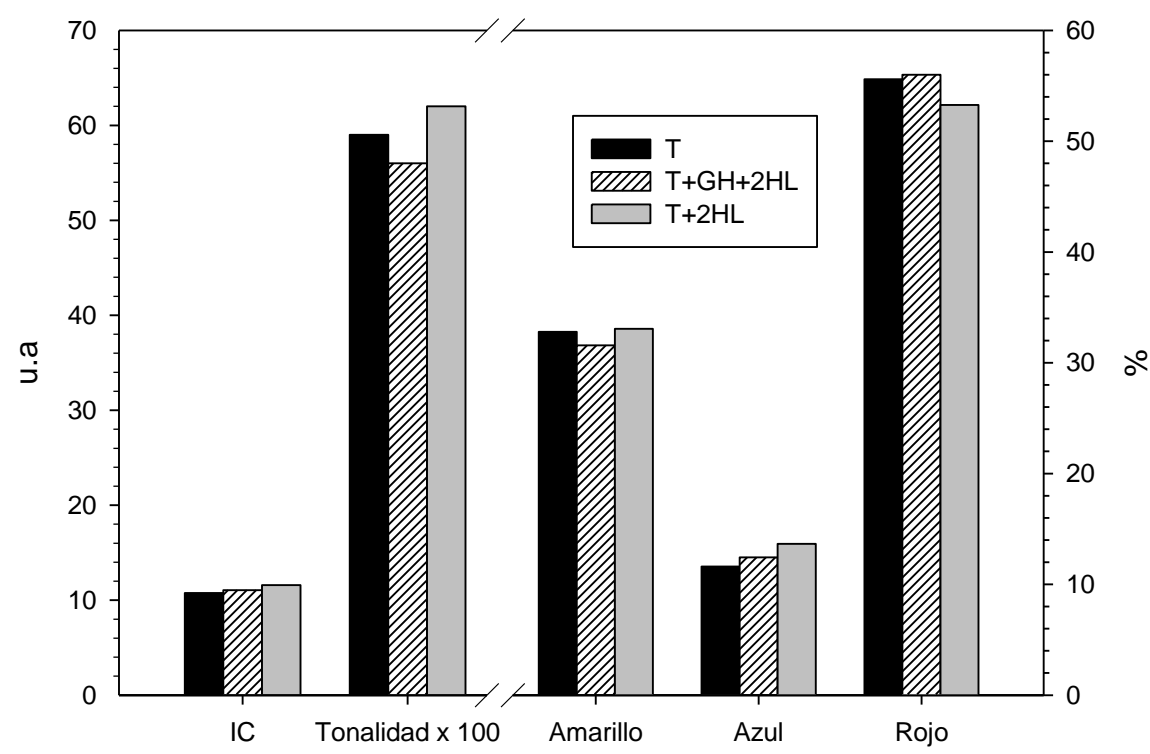

Figura 5.10 Índice de color de los vinos elaborados de la variedad Tinta de Toro. 


\section{ANÁLISIS AROMÁTICO}

Para completar los análisis químicos realizados, mostraremos el análisis aromático de los vinos elaborados. La identificación de compuestos se agrupará por características químicas de la misma forma que hemos realizado en los capítulos anteriores.

A continuación se presentan en las figuras 5.11 y 5.12 los perfiles aromáticos de los vinos blancos y tintos respectivamente. Al igual que en la campaña anterior, los perfiles aromáticos de las pruebas realizadas en el vino Verdejo, son más parecidos al testigo que en el caso de los vinos Tinta de Toro.

a) Vino Verdejo

Como podemos ver en la figura 5.11, en esta campaña se ha conseguido obtener un perfil aromático de los vinos de baja graduación muy similares al vino testigo. Entre todas las familias analizadas el compuesto con mayor diferencia de concentración es el benzaldehído. Tenemos también una ligera diferencia en los terpenos, en los ácidos grasos y en los ésteres etílicos pero sólo en el caso del vino de baja graduación que se obtiene de la prueba T+HL. Estas diferencias de los vinos de baja graduación con el vino testigo puede deberse a la mayor intensidad de fermentación de estos últimos.

Entre los dos vinos de baja graduación elaborados, los perfiles son prácticamente iguales, excepto en la concentración de ácidos grasos, ésteres etílicos y benzaldehído. En el caso de algunos aromas secundarios (ácidos grasos y ésteres etílicos), el vino elaborado con las dos membranas de filtración $(T+G H+H L)$ tienen la misma concentración que el vino testigo, sin embargo, en el vino en el que sólo se utiliza la membrana de nanofiltración ( $\mathrm{T}+\mathrm{HL}$ ) la concentración de estos compuestos es menor. Este hecho puede deberse a que el paso del mosto por la membrana de ultrafiltración, impide el paso de grandes coloides al permeado, lo que favorecerá el paso de los precursores aromáticos por la membrana de nanofiltración. Sin embargo, cuando se realiza directamente la nanofiltración se retienen los precursores aromáticos por la actuación de estos grandes coloides. Otros aromas secundarios de los vinos de baja graduación por el contrario, tienen la misma concentración que el vino testigo, como son los alcoholes superiores y las lactonas. En el caso del benzaldehído como hemos indicado en otros capítulos, es un compuesto muy susceptible a un aumento de temperatura de los mostos o vinos [9], por lo que cualquier diferencia de temperatura en el proceso puede originar estas diferencias. 


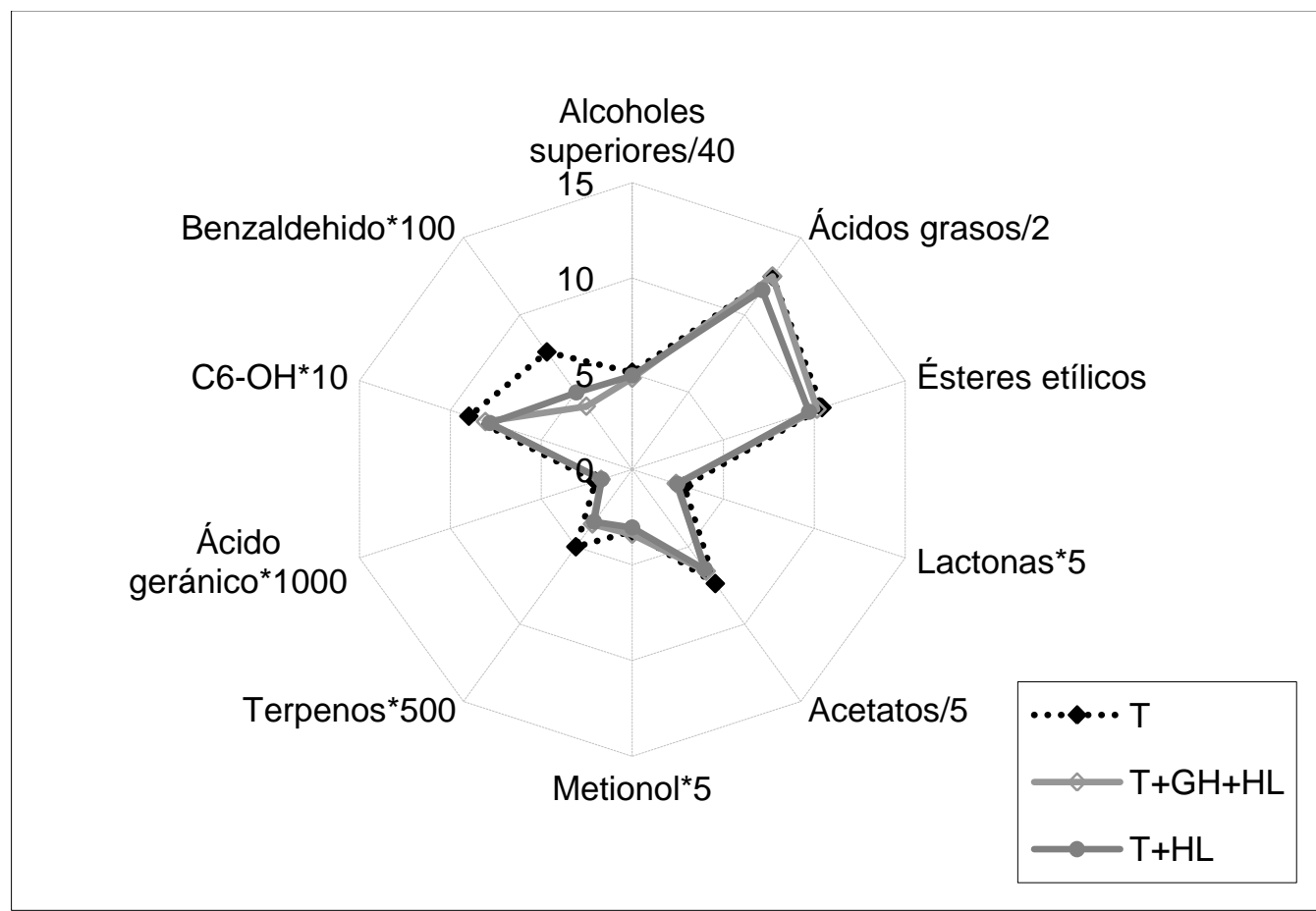

Figura 5.11 Concentración ( $\mathrm{mg} / \mathrm{L}$ ) de los componentes aromáticos para el vino testigo y para los vinos de menor graduación alcohólica de la variedad Verdejo.

b) Vino Tinta de Toro

En el caso de los vinos tintos, los perfiles aromáticos de los vinos de baja graduación tienen más diferencias respecto al testigo que los vinos blancos, éstas se encuentran principalmente en el ácido geránico y el metionol. En el caso del ácido geránico, la mezcla $\mathrm{T}+\mathrm{GH}+\mathrm{HL}$ tiene menos concentración que la mezcla $\mathrm{T}+\mathrm{HL}$, al contrario de lo ocurrido con el metionol. El ácido geránico es un terpeno que liberará su precursor aromático gracias a los enzimas presentes en la fermentación alcohólica. Sin embargo, el metionol se forma debido al metabolismo de la levadura, pero en los dos casos, cualquier variación en las condiciones de fermentación, puede dar lugar a las diferencias de concentración encontradas.

En cuanto a los aromas secundarios, solo encontramos diferencias en los terpenos y los acetatos. En el caso de los terpenos los vinos de baja graduación alcohólica tienen menos concentración que el testigo por la menor intensidad de fermentación de los primeros, al igual que ocurría en los vinos blancos. Los acetatos por su parte, sólo se ven modificados en la prueba de nanofiltración $\mathrm{T}+2 \mathrm{HL}$, en la que tenemos una concentración mayor que el vino testigo, debido a que su producción se ve modificada por el aumento de temperatura durante la fermentación [7]. El resto de aromas 
secundarios (alcoholes superiores, ácidos grasos, ésteres etílicos y lactonas) tienen una concentración similar a la del vino testigo.

Respecto al benzaldehído, el vino resultante de la mezcla $\mathrm{T}+\mathrm{GH}+2 \mathrm{HL}$ tiene menor concentración que el vino testigo y el vino obtenido de la mezcla $T+2 \mathrm{HL}$, lo que está relacionado con lo que indicamos para el mosto Verdejo: una mayor temperatura de los mostos o vinos, eleva la concentración de los aldehídos fenólicos volátiles [9].

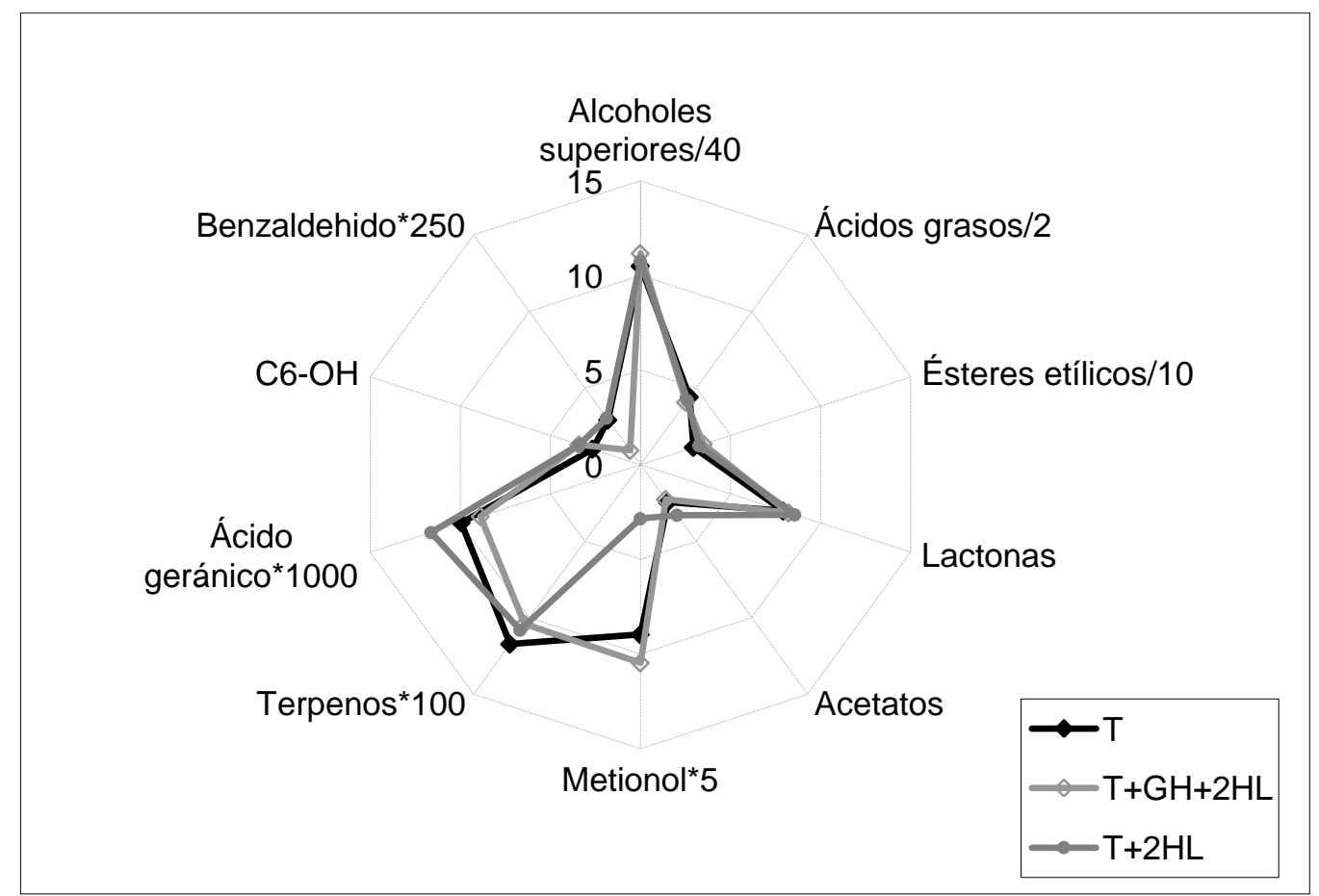

Figura 5.12 Concentración $(\mathrm{mg} / \mathrm{L})$ de los componentes aromáticos para el vino testigo y para los vinos de menor graduación alcohólica de la variedad Tinta de Toro.

Además de las diferencias indicadas, debemos destacar que en esta campaña los perfiles aromáticos de los vinos de baja graduación elaborados, tanto de la variedad Verdejo como Tinta de Toro, son muy similares respecto al vino testigo y han mejorado considerablemente los datos obtenidos en las campañas anteriores. Comparando ambos vinos de baja graduación, podríamos decir que el que usa la doble etapa UF+NF tiene un perfil aromático algo más parecido al testigo. 


\section{ANÁLISIS SENSORIAL}

Finalmente se realiza el análisis sensorial de los vinos elaborados para completar nuestro estudio en la Estación Enológica del ITACyL. La metodología a seguir es la que se indicó en el apartado 6 del capítulo 3 [11].

En esta campaña, se utiliza una ficha de cata para el análisis descriptivo de los vinos blancos y tintos, en la que la escala consta de 7 puntos: 1 corresponde a la ausencia del atributo y 7 a la intensidad máxima del mismo, se obtienen las figuras 5.13 y 5.14 por representación de esos datos.

a) Vino Verdejo

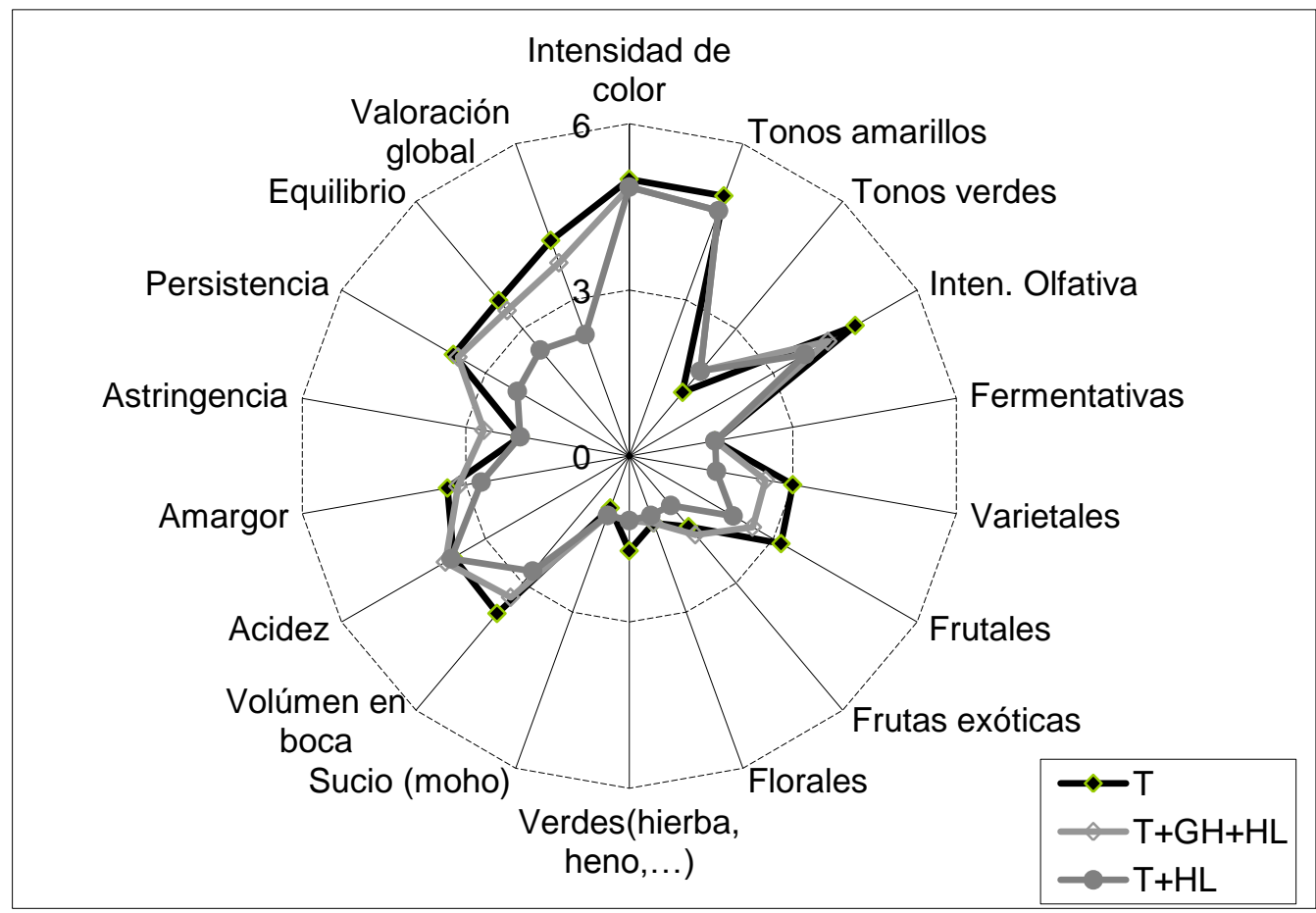

Figura 5.13 Análisis sensorial para el vino testigo y para los vinos de menor graduación alcohólica de la variedad Verdejo.

Como vemos en el análisis sensorial de los vinos Verdejo, el vino de baja graduación alcohólica que más se parece al vino testigo es el vino que proviene de la mezcla $\mathrm{T}+\mathrm{GH}+\mathrm{HL}$.

La intensidad de color de los dos vinos de baja graduación alcohólica elaborados es similar a la del vino testigo, lo que concuerda con los resultados obtenidos en el análisis químico. En la fase olfativa, el vino $\mathrm{T}+\mathrm{HL}$ tiene una puntuación menor que el que proviene de la mezcla $\mathrm{T}+\mathrm{GH}+\mathrm{HL}$, lo que también está de acuerdo con lo comentado en el apartado anterior. Aromas como los varietales y frutales están más 
presentes en los vinos en los que utilizamos la membrana de ultrafiltración previamente a la membrana de nanofiltración. En esta campaña no se encuentran aromas artificiales, posiblemente por el control de temperatura del permeado en la etapa de filtración.

En la fase gustativa el vino $\mathrm{T}+\mathrm{GH}+\mathrm{HL}$ tiene la misma persistencia y amargor que el vino testigo, aunque tiene menos volumen en boca, lo que destaca más su astringencia. Finalmente este vino es algo menos equilibrado que el vino testigo, pero la valoración global respecto a éste es muy similar a diferencia del vino procedente de la mezcla $\mathrm{T}+\mathrm{HL}$ que principalmente en boca está mucho más desestructurado.

b) Vino Tinta de Toro

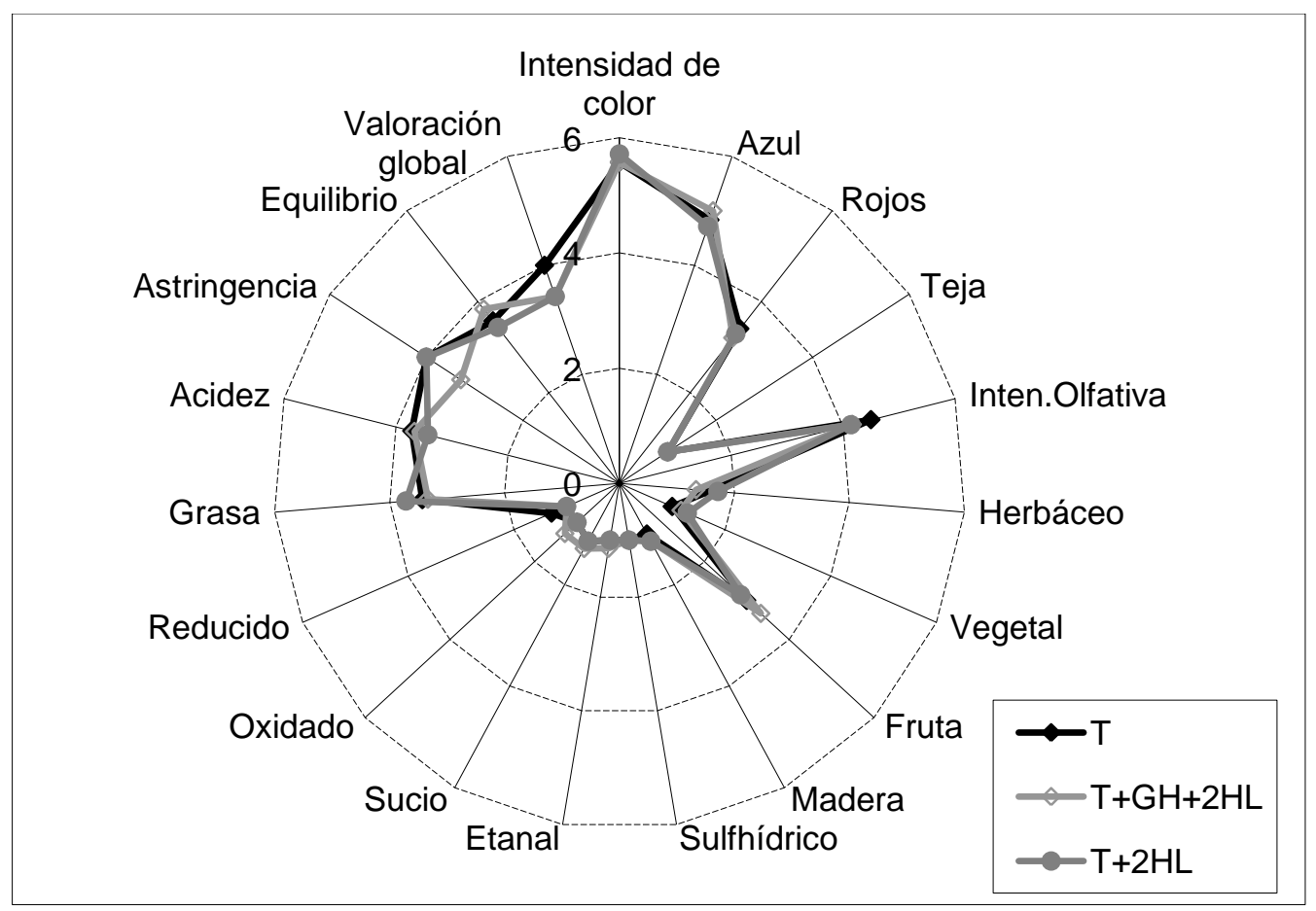

Figura 5.14 Análisis sensorial para el vino testigo y para los vinos de menor graduación alcohólica de la variedad Tinta de Toro.

Como podemos comprobar, el perfil sensorial de los vinos tintos de baja graduación se ajusta más al vino testigo que en el caso de los vinos blancos. Tanto en la fase visual como en la fase olfativa, no se encontraron prácticamente diferencias entre los tres vinos. Los olores desagradables (reducción, oxidación, suciedad y sulfhídrico) no tienen más presencia que las del vino testigo, por lo que en estas dos fases de cata no podríamos seleccionar ninguna de las dos pruebas de filtración realizadas. 
Las diferencias se encuentran en la fase gustativa, en las que el vino que proviene de la mezcla $\mathrm{T}+\mathrm{GH}+2 \mathrm{HL}$ tiene menos astringencia y más equilibrio en boca que el vino testigo, precisamente lo contrario que el vino que proviene de la mezcla $T+2 H L$, por lo que la valoración global de los dos vinos de baja graduación alcohólica tendrían la misma puntuación y sería menor que la del vino testigo.

\section{CONCLUSIONES}

Después de esta campaña está claro que las pruebas de ultrafiltración y nanofiltración realizadas han permitido obtener vinos con una reducción de alcohol aproximadamente de $2 \%$ vol. Las dos pruebas de nanofiltración realizadas, utilizando una membrana de ultrafiltración anterior $(T+G H+H L)$ o sin utilizarla $(T+H L)$, han dado lugar a unas concentraciones similares de compuestos de bajo peso molecular e incluso de componentes fenólicos tanto en el vino Verdejo como en el vino Tinta de Toro.

Viendo los perfiles aromáticos y sensoriales de los vinos Verdejo y Tinta de Toro, podemos indicar que en el primer caso el vino de baja graduación que más se parece al vino testigo es el resultante de la prueba $\mathrm{T}+\mathrm{GH}+\mathrm{HL}$ (especialmente si tenemos en cuenta la fase gustativa del análisis sensorial). Sin embargo, en el caso del vino Tinta de Toro, teniendo en cuenta las pequeñas diferencias presentes, no parece que podamos indicar si la etapa previa de ultrafiltración es necesaria para obtener vinos de calidad o no.

Los datos de permeabilidad y caída de flujo son similares en las dos pruebas de filtración, aunque la caída de flujo es ligeramente más pronunciada para la prueba de filtración $\mathrm{GH}+\mathrm{HL}$. Los datos de retención de azúcar son similares para las dos membranas, tanto en mosto Verdejo como en mosto Tinto, por lo que cualquiera de las dos pruebas podría utilizarse para reducir el grado alcohólico de los vinos.

Las mejoras realizadas en esta campaña como el aumento del área de membrana en la filtración de mosto tinto, y la utilización del control de temperatura en el tanque de permeado además de en el tanque de alimentación como se realizó en la campaña pasada ha permitido que la calidad aromática y sensorial de los vinos mejore considerablemente.

Como hemos visto, la pérdida de aromas influye mucho en la valoración final de los vinos, para evitarlo, un método de mejora sería realizar las filtraciones en atmósfera inerte para evitar en mayor medida la oxidación de los mostos. 


\section{REFERENCIAS}

1. Pradanos, P., Arribas, J. I., and Hernandez, A., Flux limiting factors in crossflow ultrafiltration of invertase through an asymmetric inorganic membrane. Separation science and technology, 1993. 28(10): p. 1899-1911.

2. El Rayess, Y., Albasi, C., Bacchin, P., Taillandier, P., Raynal, J., MiettonPeuchot, M., and Devatine, A., Cross-flow microfiltration applied to oenology: A review. Journal of Membrane Science, 2011. 382(1-2): p. 1-19.

3. García-Martín, N., Perez-Magariño, S., Ortega-Heras, M., González-Huerta, C., Mihnea, M., González-Sanjosé, M. L., Palacio, L., Prádanos, P., and Hernández, A., Sugar reduction in musts with nanofiltration membranes to obtain low alcohol-content wines. Separation and Purification Technology, 2010. 76(2): p. 158-170.

4. Jonsson, G., Prádanos, P., and Hernández, A., Fouling phenomena in microporous membranes. Flux decline kinetics and structural modifications. Journal of Membrane Science, 1996. 112(2): p. 171-183.

5. Al-Amoudi, A., Williams, P., Mandale, S., and Lovitt, R. W., Cleaning results of new and fouled nanofiltration membrane characterized by zeta potential and permeability. Separation and Purification Technology, 2007. 54(2): p. 234-240.

6. Massot, A., Noilet, P., Milisic, V., and Mietton-Peuchot, M., Nanofiltration et osmose inverse en oenologie. Bulletin de l'OIV, 2008. 81(932-934): p. 531-540.

7. Moreno-Arribas, M. V. and Polo, M. C., Wine Chemistry and Biochemistry. Springer ed. 2009.

8. Ribéreau-Gayon, P., Glories, Y., Maujean, A., and Dubourdieu, D., Tratado de Enología: Química del Vino. Estabilización y Tratamientos, ed. Mundi-Prensa. Vol. 2. 2003.

9. Jackson, R. S., Wine Science: Principles, Practice, Perception.Elsevier Science \& Technology ed, ed. 2. 2000.

10. Ribéreau-Gayon, P., Glories, Y., Maujean, A., and Dubourdieu, D., Handbook of Enology: The Chemistry of Wine Stabilization and Treatments. 2 ed, ed. Ltd John Wiley \& Sons. Vol. 2. 2006.

11. Gonzalez-Sanjose, M. L., Ortega-Heras, M., and Perez-Magarino, S., Microoxygenation Treatment and Sensory Properties of Young Red Wines. Food Science and Technology International, 2008. 14: p. 123-130. 


\section{CONCLUSIONES FINALES}

Debido al cambio climático, a la demanda de vinos de baja graduación y a la mayor preocupación por seguir estilos de vida saludables, se procede al estudio de reducción del grado alcohólico de un vino en $2 \%$ vol.

$>$ Del análisis de las técnicas de reducción de alcohol en vinos, concluimos que la nanofiltración de mosto puede ser un método apropiado para conseguir los objetivos planteados. Realizando una reducción de concentración de azúcar antes de la fermentación, conseguimos preservar las características organolépticas del vino final y obtener un vino de calidad.

$>$ Del estudio de las membranas planas con azúcar, se comprueba la idoneidad para la separación de las membranas de nanofiltración empleadas. Teniendo en cuenta los valores más elevados de permeabilidad y retención verdadera, la membrana más apropiada es la membrana de nanofiltración HL.

$>$ Del estudio de las membranas planas con mostos comerciales, se comprueba la idoneidad del proceso de separación. Analizando la retención de azúcar y de otros componentes importantes del mosto (polifenoles totales, antocianos, ácido tartárico y potasio), y las caídas de flujo que tienen lugar en cada proceso de filtración, la membrana más apropiada también sería la membrana de nanofiltración HL.

$>$ Del estudio de los módulos de membrana espirales con disoluciones de azúcar y mostos comerciales, se confirma el efecto de las propiedades de membrana a mayor área de filtración. A escala de planta piloto, el sistema espiral más apropiado es el módulo HL.

> Primera campaña: Aplicación del proceso de doble filtración a mostos reales y realización de dos mezclas diferentes de mostos para elaborar los vinos finales. Se obtienen mejores resultados químicos y organolépticos en la mezcla de testigo y permeado de segunda filtración $(T+P 2)$, que en la mezcla de permeado de segunda filtración y el retenido de la primera filtración (P2+R1) por lo que será el modo de obtener los vinos con menos alcohol en el resto de campañas. En esta campaña también se comprueba que el doble paso de 
filtración no reduce la cantidad de azúcar lo suficiente para compensar el tiempo de filtración de la segunda etapa, por lo que se utilizará únicamente un paso de filtración en las siguientes campañas.

Del análisis de los mostos y vinos, se determina que los parámetros enológicos clásicos son similares para las mezclas realizadas con el testigo y los permeados de todas las membranas utilizadas, respecto al vino testigo. La diferencia más significativa de estos parámetros, es la concentración de azúcar o el grado alcohólico en mostos y vinos respectivamente. Ya que la retención de azúcar de la membrana HL es elevada y nuestro objetivo es únicamente reducir le grado alcohólico en $2 \%$ vol, se decidió incorporar el uso del resto de membranas estudiadas en la siguiente campaña. Estas membranas que tienen una retención de azúcar aceptable, podrían ofrecer mejores resultados que la membrana HL respecto a otros componentes importantes en el vino.

Las mayores diferencias entre las pruebas realizadas y el testigo, se encuentran en la calidad organoléptica, tanto en blancos como en tintos. Los desajustes principales se presentan en la fase olfativa y gustativa.

Segunda campaña: Optimización del proceso. Al utilizar todos los módulos de membrana (el módulo de ultrafiltración GH y las de nanofiltración HL, DL y DK), podemos concluir que la membrana de ultrafiltración GH no debe utilizarse en solitario ya que no nos permite reducir el grado alcohólico final que perseguimos.

Al realizar las mezclas de testigo y permeado de cada membrana utilizada, obtenemos concentraciones similares de sustancias de bajo peso molecular y compuestos fenólicos. La mezcla que más se parece al mosto sin modificar, tanto en blancos como en tintos, es la mezcla de testigo con el permeado de la membrana $\mathrm{HL}(\mathrm{T}+\mathrm{HL})$. Lo que también se corresponde con los vinos elaborados, siendo esta mezcla la que da lugar a un vino con componentes polifenólicos y perfil aromático similar al vino sin tratar. Tanto el vino blanco como el tinto, presentaban diferencias respecto al vino testigo en la fase olfativa y gustativa, que disminuyen su calidad organoléptica. Aunque la prueba en la que se utiliza la membrana de ultrafiltración como etapa anterior a la nanofiltración $(\mathrm{T}+\mathrm{GH}+\mathrm{HL})$ en vinos tintos, es la que tiene menos presencia de olores artificiales. 
Teniendo en cuenta todos estos resultados, se seleccionan las membranas más apropiadas para la siguiente campaña. En dicha campaña se comparará la filtración en la que se utiliza una etapa de ultrafiltración anterior $(T+G H+H L)$, con la que sólo utiliza nanofiltración $(T+H L)$, para poder decidir cuál de las dos pruebas da lugar a vinos finales de mayor calidad. El esquema de filtración también variará en la siguiente campaña, aumentando la superficie de filtración de la membrana para reducir el tiempo de filtración. También se controla la temperatura del permeado obtenido en el proceso, además de la temperatura de alimentación que se ha controlado hasta el momento, para evitar fenómenos de oxidación.

Tercera campaña: Definición del proceso definitivo. Los resultados de la tercera campaña muestran que los datos de permeabilidad, caída de flujo y retención de azúcar son similares, por lo que cualquiera de las dos pruebas podría utilizarse para reducir el grado alcohólico de los vinos. Sin embargo, en el vino Verdejo, la mezcla $\mathrm{T}+\mathrm{GH}+\mathrm{HL}$ tiene mejores características gustativas. Para el vino Tinta de Toro, no podemos indicar si la etapa previa de ultrafiltración es necesaria para obtener vinos de calidad o no, porque tanto la fase visual como la olfativa y la gustativa son similares.

También podemos concluir que todas las mejoras aplicadas en el proceso de filtración en esta campaña (aumento de superficie activa de filtración y control de temperatura tanto del depósito de alimentación como del de permeado), evitan oxidaciones de compuestos relacionados con la calidad sensorial y organoléptica del vino final. Por ello, la reducción del tiempo de filtración y el control de temperatura del proceso, serán dos parámetros muy importantes a tener en cuenta.

Los parámetros que definen el proceso serán, valores elevados de permeabilidad, retención verdadera y flujos de recirculación. La presión debería ser la más alta posible hasta alcanzar el flujo límite. También se debe tener en cuenta que el ensuciamiento de la membrana sea el mínimo para que el tiempo de filtración sea menor. Aunque la caída de flujo no se puede evitar porque los mostos tienen elevada carga coloidal, la fase de limpieza descrita permite una estabilidad y recuperación de la membrana de nanofiltración para que siga siendo utilizada. 
La aplicación de las membranas de nanofiltración para la elaboración de una gama de productos de contenido alcohólico reducido, supone una innovación importante, ya que hasta el momento los procesos de membrana utilizados en el sector vitivinícola, son básicamente la ultrafiltración y la ósmosis inversa, y sólo se utilizaban en algunos casos membranas de nanofiltración con el fin de concentración de mostos. De esta forma, el sector se prepara para las nuevas demandas, lo que permitirá el asentamiento de los vinos desalcoholizados en el mercado y la aceptación de estos productos por enólogos y profesionales además de los consumidores.

El proceso descrito depende, además de las características del vino como respuesta al producto demandado, del coste de producción. Este método es económico en términos de costes de producción y aunque da lugar a una pérdida de volumen del mosto, la rentabilidad del proceso se puede aumentar usando la parte del retenido para la producción de vinos dulces, vinos licorosos, aditivos funcionales o puede destinarse a la industria de la mermelada. 